\title{
Corporate Social Responsibility in Multinational Companies Based in Lebanon: Exploring the Role of Managers' Individual and Situational Factors in Institutionalizing CSR
}

\author{
Marguerite Eid
}

A thesis submitted to The University of Gloucestershire in accordance with the requirements of the degree of Doctor of Philosophy in the School of Business and Technology

August 2020

Word Count: 75,978 words 


\begin{abstract}
In a world that is becoming more unstable the implementation of CSR activities is changing. CSR started at the corporate level in a context that firm behaviour should move away from a concentration on profit seeking. Multinational companies (MNCs) must take responsibility for contributing (or not) to the progress of society, environment, and economy in developing countries as some large MNCs can have more economic and social power than governments (Garriga \& Mele, 2004). Understanding how MNCs execute corporate social responsibility (CSR) in diverse and developing countries worldwide is still at an early stage, (Hah \& Freeman, 2014). Microfoundational studies are vital because the understanding of how communication, cognition, and behaviour at micro-levels influence and are influenced by higher-level structures then permits researchers to develop a better understanding of diversity in institutional results. This study explores the practice of CSR through exploratory qualitative interviews using Lebanon as a case study. A major contribution is that the levels of CSR engagement are impacted by institutional theory. The microfoundations are thus institutional work, becoming institutional entrepreneurship at the meso level using that as a way to legitimize their operations in Lebanon. Macro and meso level aspects are developed from these CSR microdynamics. It also discusses how people who work in Lebanon make sense of CSR using an identified centrifugal approach and tailoring processes to suit the religious and social context.
\end{abstract}




\section{Author's Declaration}

I declare that the work in this thesis was carried out in accordance with the regulations of the University of Gloucestershire and is original except where indicated by specific reference in the text. No part of the thesis has been submitted as part of any other academic award. The thesis has not been presented to any other education institution in the United Kingdom or overseas.

Any views expressed in the thesis are those of the author and in no way represent those of the University.

Signed:

Date: $18 / 08 / 2020$

doi:10.46289/BUSI4759 


\section{Acknowledgment}

First and foremost, I would like to acknowledge my first supervisor Dr. Mark Loon whose professional guidance, support, and experience allowed me to stay on track and complete my dissertation. He was always ready to assist me, explain to me, and answer all my questions despite his busy schedule. I would not have enhanced my writing skills and completed this thesis without his assistance. Moreover, I would like to thank my second supervisor Dr. Robin Bown who was always present to assist me and provide me with answers and information needed for the facilitation of the $\mathrm{PhD}$ process. I would also like to acknowledge Dr. Maria Galindo and Dr. William Sun who accepted to be my examiners and Dr. Keith Donne who facilitated the process and administrative procedures for my $\mathrm{PhD}$ completion. Last but not least, I am grateful to Mr. George Ghaleb because he was the one who referred me to the University of Gloucestershire and encouraged me to pursue a PhD in the United Kingdom which turned out to be an excellent choice. 


\section{Dedication}

I dedicate my $\mathrm{PhD}$ to my family and my husband who supported me throughout this journey. Their patience, prayers, motivation, love, and kindness gave me the strength and will to persevere and complete this dissertation. I would also like to dedicate this dissertation to my

professor, Mr. Hrair Hovivian, who passed away last year and who was my role model and the person behind my career choice as a university professor. 


\section{Table of Contents}

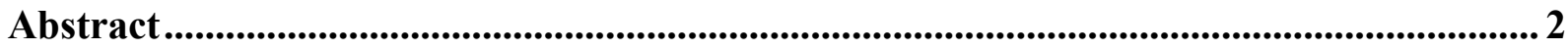

Author's Declaration ...................................................................................................................... 3

Acknowledgment .................................................................................................................................. 4

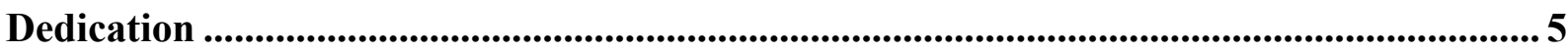

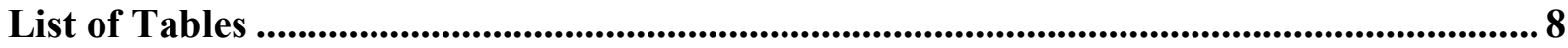

List of Figures .................................................................................................................................9 9

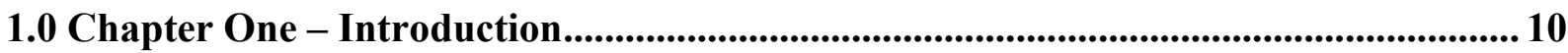

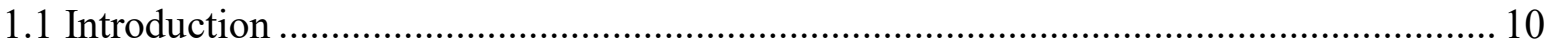

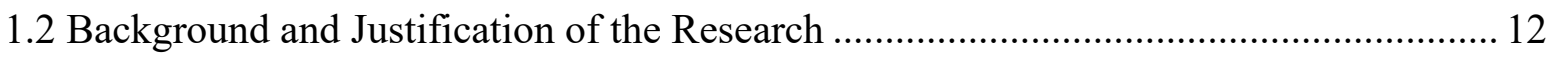

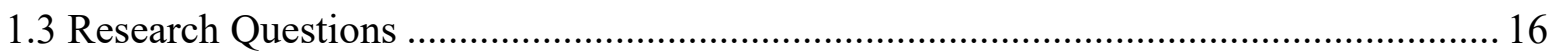

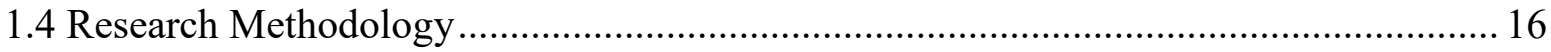

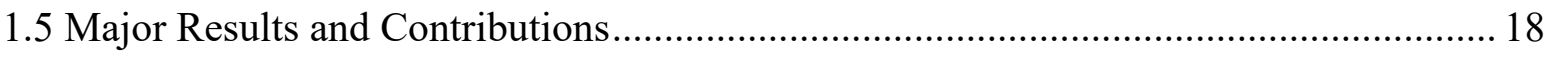

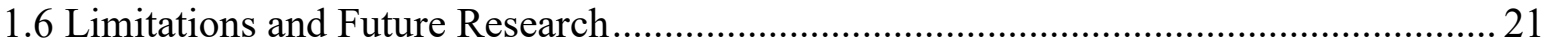

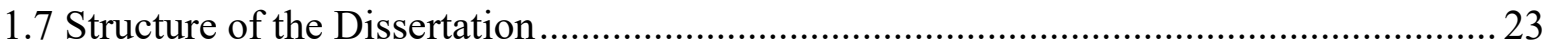

2.0 Chapter Two - Literature Review ........................................................................................ 24

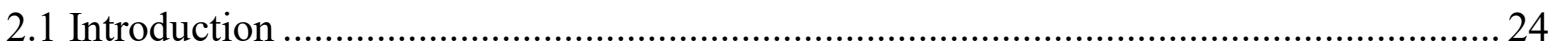

2.2 CSR Practice at Different Levels ...................................................................... 26

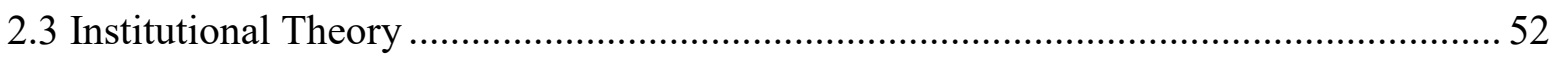

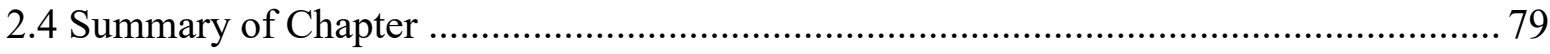

3.0 Chapter Three - Lebanon as a Case Study ...................................................................... 82

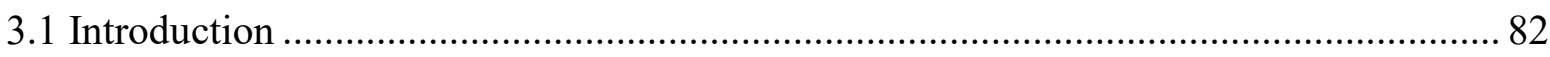

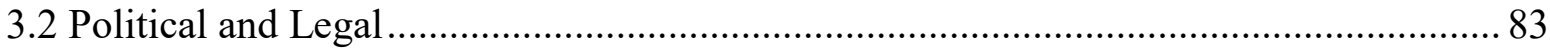

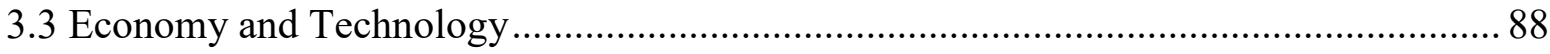

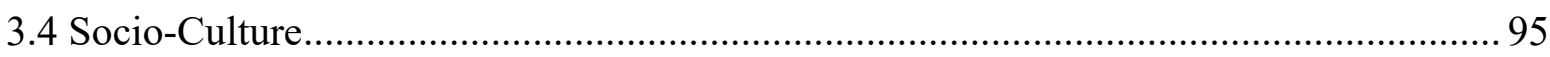

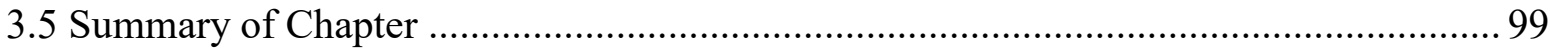

4.0 Chapter Four - Methodology .......................................................................................... 101

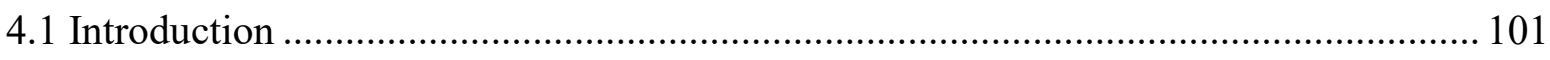



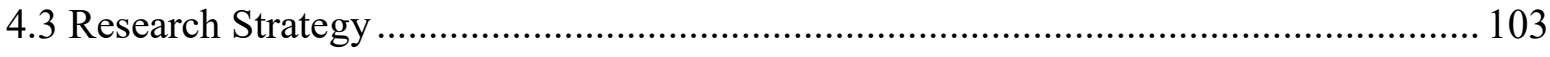

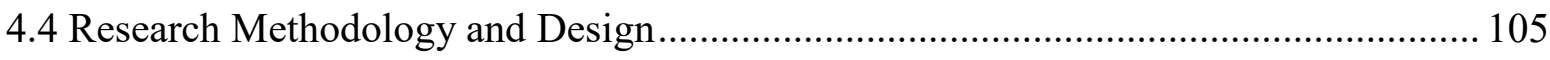


4.5 Data Analysis

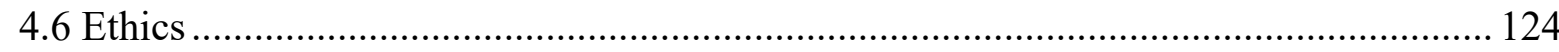

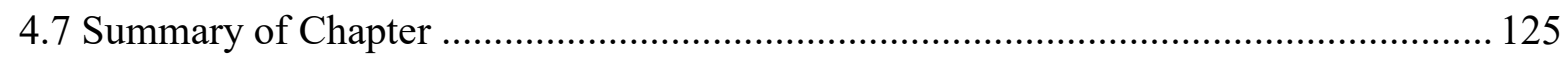

5.0 Chapter Five - Results............................................................................................................ 126

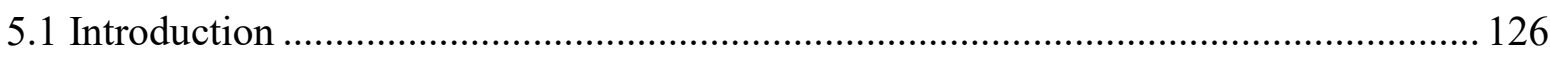

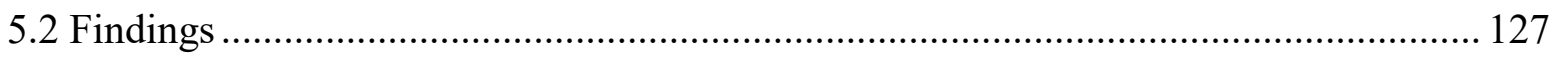

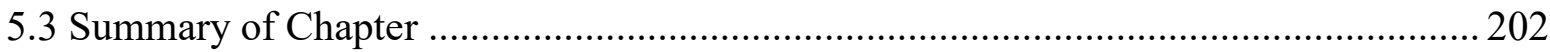

6.0 Chapter Six - Discussion and Conclusion ................................................................... 203

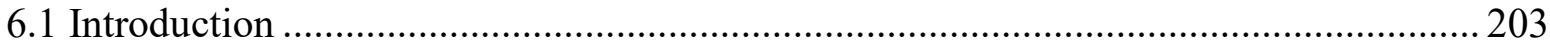

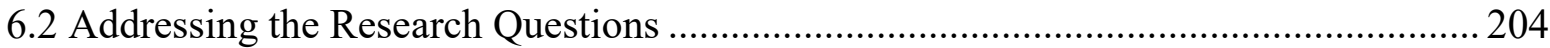

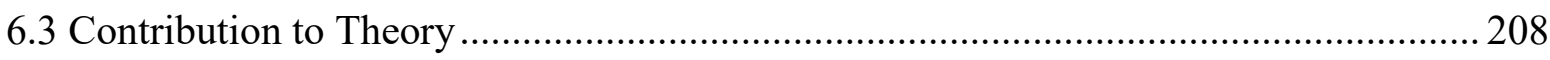

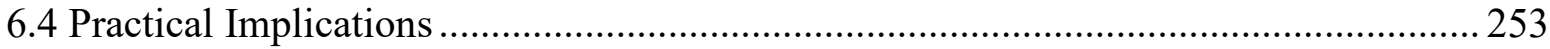

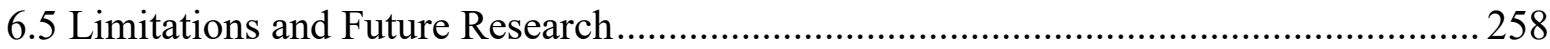

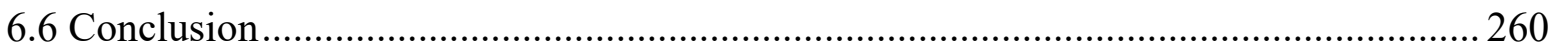

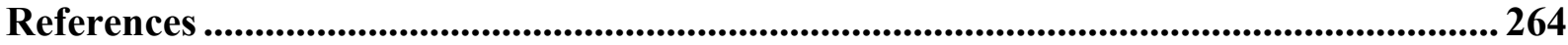

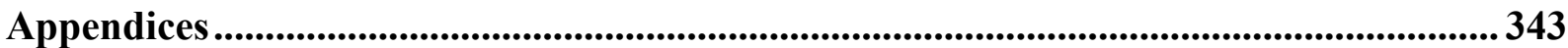

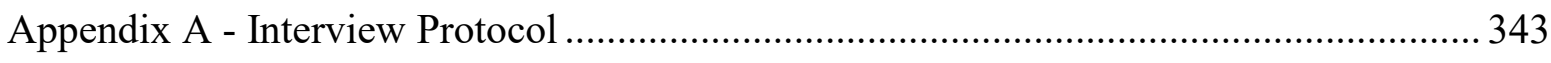

Appendix B - Participant Information Letter....................................................................... 348

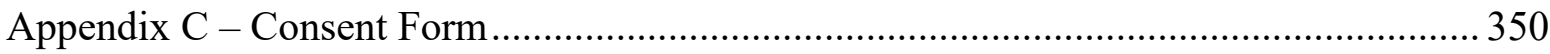

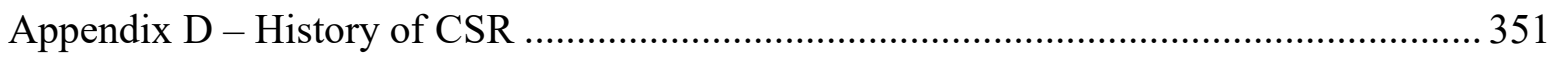

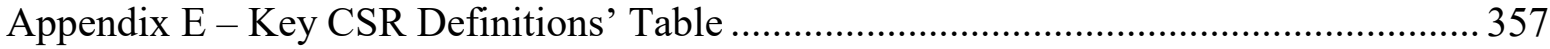

Appendix F - Frederick's Phases of CSR ........................................................................ 359

Appendix G - Lebanon's History, Geography, and Competitiveness ................................. 361 


\section{List of Tables}

Table 3.1: Lebanon's major export partners in 2018 (Source:

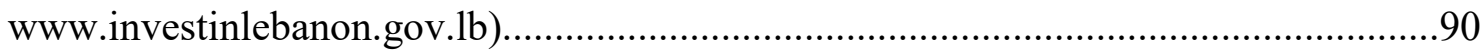

Table 3.2: Lebanon's major import partners in 2018 (Source:

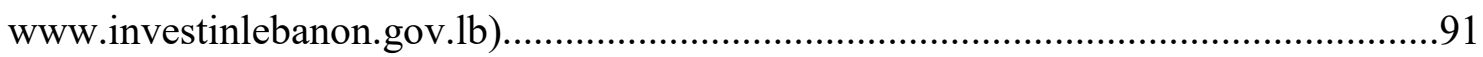

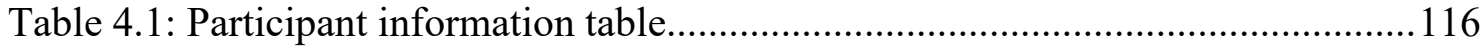

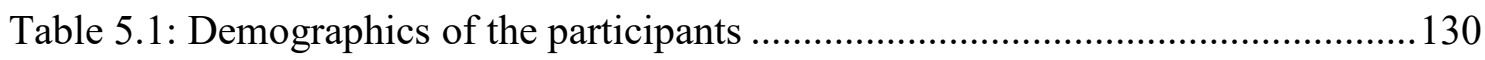

Table 5.2: Coding of the first theme .......................................................................... 131

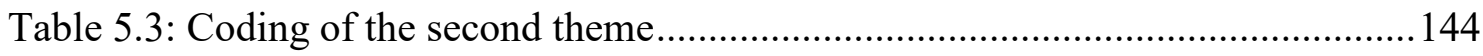

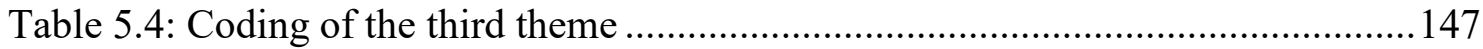

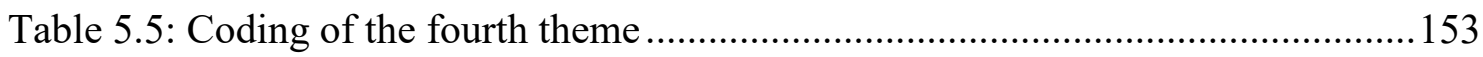

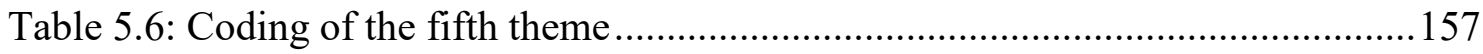

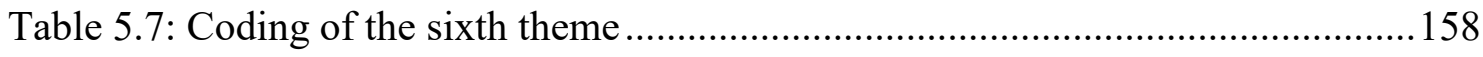

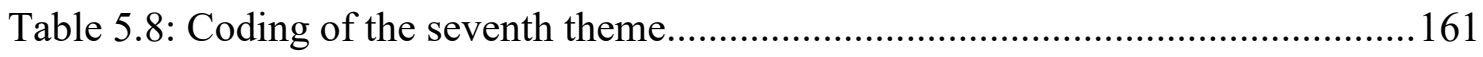

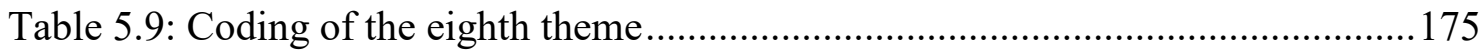






\section{List of Figures}

Figure 3.1: Lebanon's import composition in percentage in 2018 (Source:

www.investinlebanon.gov.lb)

Figure 3.2: Lebanon's export composition in percentage in 2018 (Source:

www.investinlebanon.gov.lb) 


\subsection{Chapter One - Introduction}

\subsection{Introduction}

Corporate social responsibility (CSR) is defined as corporate activities and rules that take into consideration the expectations of stakeholders and the triple bottom line i.e. the environment, the economy, and society (Aguinis, 2011; Rupp, 2011; Rupp, Williams, \& Aguilera, 2010). Even though CSR's definition refers to rules and activities done by corporations, such rules and activities are affected and executed by actors at all levels of analysis i.e. organizational, individual, and institutional (Aguinis \& Glavas, 2012). The World Business Council for Sustainable Development (WBCSD) (2000, as cited in Shah \& Ramamoorthy, 2014) advances a comprehensive scope for CSR as the continuous obligation of companies to act ethically and to support economic growth while enhancing the quality of life of the workforce, its families, local communities, and society as a whole. CSR became common in international companies across various industries (Forney, 2018). The CSR concept has been debated for a long period of time and it has gained importance in the previous decade because of the growing competencies in reporting, international governance, sustainability associations, print and social media, nongovernmental organizations (NGOs), and the hard work of important businesses (Husted, 2015).

Corporate profits and concrete CSR initiatives that positively influence societies such as financial donations are significant indicators for business performance and when these elements are not measurable, criticism emerges (Mishra \& Modi, 2016). Similarly significant to a firm's survival is the need for stakeholders to understand the reasons underpinning their firm's CSR activities and the influence of instigating such activities (Forney, 2018). Numerous companies are continuously refining their CSR initiatives and CSR-leading businesses have 
those main beliefs vigorously rooted in their fundamental business models (Ayadi, Kusy, Minyoung, \& Trabelsi, 2015).

CSR has gained an increasing attention in recent years both in the academic literature (e.g. Gond, Akremi, Sawen, \& Babu, 2017; Ng, Yam, \& Aguinis, 2019; Wang, Tong, Takeuchi, \& George, 2016) and the corporate world. For instance, in the 2013 United Nations Global Compact Accenture (UNGCA) Chief Executive Officer (CEO) study, ninety-three percent of the one thousand CEOs surveyed stated that sustainability is a very significant factor for the long-term success of their companies (Lacy \& Hayward, 2013). Furthermore, in the 2010 UNGCA CEO study, eighty-one percent of the seven hundred and sixty-six CEOs surveyed declared that sustainability matters are completely included in their companies' strategy and operations (Lacy, Cooper, Hayward, \& Neuberger, 2010). The importance that companies have set on their CSR actions has, in many ways, profoundly shifted people's thoughts and understandings of the relations between companies, the institutional environment where they conduct business, and their different stakeholders, comprising local societies, suppliers, personnel, governments, and civil society (Ioannou \& Serafeim, 2012).

The growth of CSR had many implications, therefore, research has been conducted into this field to further gain insight into the phenomenon (Aguinis \& Glavas, 2012). For instance, Peloza (2009) concentrated on how to quantify the effect of CSR on financial performance, Waddock (2004) examined CSR operationalization and dissimilarities and at times unclear commonalities between CSR and comparable concepts, Wood (2010) appraised the literature regarding how to measure CSR, and Peloza and Shang (2011) reviewed how CSR can produce value to stakeholders. Thus, this research was conducted because there is paucity in literature regarding the role of the personal and decisional factors and actions that shape CSR. The sections below provide an overview and a summary of this study. 


\subsection{Background and Justification of the Research}

Literature on CSR is still fragmented despite the reviews issued till now for many reasons (Aguinis \& Glavas, 2012). One reason is that researchers explore CSR through dissimilar theoretical and disciplinary lenses (Garriga \& Mele, 2004; Waddock, 2004). Furthermore, the CSR literature is split concerning frames of analysis (Aguinis \& Glavas, 2012). First, for a certain study researchers frequently use only one frame of analysis to examine CSR (Aguinis \& Glavas, 2012). Second, CSR is mainly explored at the corporate i.e. institutional or firm level as opposed to the micro-level i.e. individual level (Aguinis \& Glavas, 2012). Consequently, Aguinis and Glavas (2012) emphasized the need to conduct a multi-frame review where researchers can incorporate and combine the immense and varied existing literature in a coherent and complete way. Hence, this study will fill this gap in literature as it provides a comprehensive multi-frame analysis of CSR in a developing country context.

This study uses two frames of analysis; intrapersonal and strategic. Each frame relates to different findings; microfoundations and institutional. The intrapersonal frame is used when the managers interviewed talk about themselves as individuals and the corresponding findings relate to the microfoundations of CSR. The intrapersonal frame relates to micro-level or individual-level factors and explains for example how the managers interviewed were brought up and the values that underpin their CSR decisions and actions. The strategic frame is used when the sampled managers talk about the macro-level factors i.e. the country where they operate and the meso-level factors i.e. their organization, and their effects on CSR. The strategic frame was also adopted when the researcher reviewed the corporate documents of the selected multinational companies (MNCs). The corresponding findings relate to the institutional context as it explains the influence of the situational factors on the adoption and implementation of CSR and how CSR was institutionalized in Lebanon by these companies. 
The strategic frame simultaneously looks at the organizations and the context where they operate because these two are tightly intertwined and affect one another. For example, the performance and the work of these organizations were at times negatively affected by the prevalent corruption in Lebanon as it will be explained in the upcoming chapters.

This section provides an explanation of the contextual background and justification of this study. The sub-sections below start by justifying why this research was conducted from a micro-level perspective and provides an interpretation towards a national/macro-level and company/meso-level perspectives respectively. The first section 1.2.1 explains why and how this study answers the first research question by starting from the role of managers' individuallevel factors in the adoption of CSR. The next section 1.2.2 explicates why and how this research adopted the second research question and looked at the situational-level factors that influenced the adoption and implementation of CSR. Finally, section 1.2.3 justifies why and how this study answers the third research question and selected multinational companies (MNCs) to explore how CSR is institutionalized in these companies and what type of work relating to CSR managers do in a developing country context.

\subsubsection{CSR at Different Levels of Analysis}

CSR gained an important and increasing attention among researchers (Aguinis \& Glavas, 2012, 2013; Gond et al., 2017) which is not shocking because many companies integrate it as a central strategic constituent (Bansal, 2005; Wang \& Bansal, 2012). The bigger number of business scandals and social distress over companies' activities has also ignited research and management interest in CSR ( $\mathrm{Ng}$ et al., 2019). Its prominence is also apparent in results that CSR positively affects many corporate outcomes counting financial performance (Orlitzky, Schmidt, \& Rynes, 2003), reputation (Bansal \& Clelland, 2004; Brammer \& Pavelin, 2006), and customer loyalty (Deng \& Xu, 2017; Park, Kim, \& Kwon, 2017). 
Notwithstanding the rising number of studies on CSR, most studies have mainly concentrated on the macro-level of analysis (Aguinis \& Glavas, 2012; Bansal \& Roth, 2000; McWilliams \& Siegel, 2000). However, as in other fields regarding individual conduct in companies (Foss \& Pedersen, 2016), there is a strong need to comprehend the microfoundations of CSR to develop theory ( $\mathrm{Ng}$ et al., 2019).

In their study of research published in the Academy of Management Journal, Wang, Tong, Takeuchi, and George (2016) suggested that future researchers can try to answer the following question: with a progressively more interrelated global economy and a globalization of social actions, would observations of CSR in diverse institutional contexts finally unite, or resolve in dissimilar equilibriums? Developing and underdeveloped countries probably have a dissimilar underlying social contract and expectancy of the role of companies. Additionally, according to Pisani, Kourula, Kolk, and Meijer (2017) there is paucity in literature on CSR in developing countries particularly in the Middle East. In their study of research published in the Academy of Management Journal, Wang, Tong, Takeuchi, and George (2016) suggested that future research should try to answer the following question: would the development process of CSR in developing countries follow the same track as that in developed countries, or is considerably different because of its distinctive institutional context? For instance, companies in developed nations may be subject to robust expectancies on environmental obligation and protection of natural resources, while companies may direct their actions toward social improvement objectives like health and education (George, Schillebeeckx, \& Liak, 2015). In nations hit by poverty, the social compact possibly amends the tools and procedures of social commitment activities (Wang et al., 2016). These dissimilarities in the underlying suppositions in arrears of CSR and the institutional contexts in which companies conduct business offer a lavish context of academic exploration (Wang et al., 2016). 
According to McKinsey Global Institute (2013), by 2025, forty-six percent of the Fortune Global 500 companies will emerge from developing and emerging countries, compared with five percent only in 2000. Given the growing prominence of these companies in the international economy, they have lately gained an increasing attention among international business researchers (Cuervo-Cazurra, 2012; Luo \& Wang, 2012; Ramamurti \& Singh, 2009; Williamson, Ramamurti, Fleury, \& Fleury, 2013). Moreover, Empson, Cleaver, and Allen (2013) argued that there is paucity in literature regarding the notion of institutional work and that it should be systematically applied to several experimental contexts. Hence, the institutional work and practice theory are used in this study to conduct a firm-level analysis of CSR institution and contribute to knowledge.

Based on the previous explanations and existing literature, this study simultaneously examined CSR from a threefold frame of analysis. Individual-level, firm-level, and macrolevel factors were adopted in this research to explain the factors that may impinge of managers' CSR related decisions and actions. This was done in MNCs operating in Lebanon because as previously explained, it is a unique developing country and there is a gap in literature regarding CSR in developing countries and the Middle East in general and in Lebanon in particular.

On a final note, one last motivation for this study is that I am a native Lebanese who speaks fluent English, I teach in an English-speaking university in Lebanon, and I graduated from an English-speaking university. As a native Lebanese I speak French and Arabic as well. I am also very interested in CSR as a research topic. Therefore, I was interested to explore CSR in my home country and the study was efficiently and effectively conducted and written in English without any difficulty regarding the language. 


\subsection{Research Questions}

This research aims to explore how CSR decision-making is done by managers of MNCs operating in Lebanon and attain deeper knowledge of the role of the personal and decisional factors and actions that shape CSR in Lebanon. This will be done by answering the following three research questions;

i) How and why do individual level factors play a role in the adoption of CSR in companies operating in Lebanon?

ii) How and why do situational factors influence the adoption and implementation of CSR?

iii) How is CSR institutionalized in Lebanon if at all?

\subsection{Research Methodology}

According to Saunders, Lewis, and Thornhill (2003) the researcher's philosophical stance takes the research in a certain direction and sheds light on the rationale adopted in choosing the research strategy, methodology, design, and methods. Thus, in this study, the researcher adopted an interpretivist epistemological worldview and held a constructionist ontological stance. The researcher aims to understand social phenomena by exploring the subjective experiences, values, beliefs, ethics, and culture of the participants. Besides, this study aims to explore how managers of MNCs operating in Lebanon make decisions relating to CSR. As explained earlier, CSR is a complex and context bound phenomenon. Hence, a qualitative research methodology would be suitable for the strategic direction of this research for it assists the researcher in interpreting complex and subjective phenomena and analyze human sentiments, values, and principles (Falk \& Blumenreich, 2005). 
Wang et al. (2016) posited that CSR development in some developing countries is much less comprehended and is worthy to be academically considered. Therefore, this study focused on CSR in Lebanon which is an emerging economy where CSR is till today not researched enough. For that reason, an exploratory investigation will be proper for this research because exploratory studies offer an in-depth understanding of the phenomenon at hand and advance knowledge through theory building (Sekaran, 2003).

The researcher will consider the unit of analysis in the first stage the organizations, i.e. ten MNCs operating in Lebanon, when it is explored as a case study. The companies' documents and second-hand data were explored to give the researcher insights into the mesolevel factors that influence CSR in Lebanon. Whilst in the second stage, the unit of analysis is the individual i.e. the managers in MNCs operating in Lebanon when the semi-structured interviews were conducted. The researcher has spoken to these individuals to get two perspectives; one is the firm perspective and the other one is their personal perspective. They are senior enough to give the researcher a general view of the firm. This gives the researcher a rational because she wants to know two things; one how CSR is in Lebanon and what companies do, so it develops a meso-level perspective; two, at the same time talking about microfoundations and even to some extent practice theory, it is all about the individual: the individual's perspective.

This study adopted an exploratory cross-sectional research design because it examined a certain phenomenon i.e. CSR at a specific point in time (Bryman \& Bell, 2007). Besides, this research has no to minimal researcher interference and used a natural study setting because the researcher conducted face-to-face interviews with managers in their regular work environment at their relevant MNCs. There was no attempt to manipulate variables because this is a qualitative research and the researcher is not trying to find a relationship between variables. 
The researcher started off by using CSR Lebanon as a sampling frame to get all the potential businesses that practice CSR in Lebanon. However, only seven firms were found and because that was not enough as a sample, Corporate Knights was used as a second sampling frame. The researcher selected ten MNCs operating in Lebanon and conducted an initial review of their corporate documents and second-hand data. Documents generally tended to be from the foreign MNCs. Using this background material, she also conducted fourteen semistructured face-to-face interviews with managers selected from these ten different MNCs. This study adopted a nonprobability sampling design with a purposive sampling strategy to select the participants. Nonprobability sampling was used because the researcher did not randomly choose participants for her research, so the participants did not have an equal opportunity for being picked (Endacott \& Botti, 2005). The researcher used purposive sampling because she wanted to get information from a specific target population (Sekaran, 2003).

\subsection{Major Results and Contributions}

The results explained in chapter five can be grouped into three major categories; each category providing a contribution to knowledge. The first category of findings contributes to microfoundations of CSR and relates to the participants' personal-level circumstances that underpin their decisions and actions. The results show that managers hold individual-level factors that play a role in their CSR adoption. The most prominent factors were religion, ethics, family values, and their personal belief systems that highly affected their inclinations towards CSR. The interviewees posited that the Lebanese are very religious and therefore CSR practices are generally prompted by religious values like servant leadership in Christianity and zakat as one of the five pillars of Islam. Moreover, the results verify that ethics was seen as a driver for CSR. 
Moreover, the interviewees' professional circumstances including management and corporate values along with their hierarchical level in the MNC played an important role in their CSR adoption. In fact, the results demonstrate that top managers are the ones who set the ethical tone in the firm and henceforth institute CSR practices. In addition, the interviewees explicated that they encountered several ethical dilemmas at work. Consequently, their MNCs had to suffer from poor performance because they were being steadfast and did not modify their convictions and values in the face of all the pressures. These stories of ethical dilemmas were imprinted in the respondents' minds and shaped their future decisions and behaviours.

The second group of findings contribute to the contingency theory in CSR wherein CSR is context bound. These results were related to the interviewees' situational factors that affected their CSR adoption and implementation. These situational factors include the unique Lebanese culture and values which is known for treating individuals like family members. This characteristic had an influence on how the practitioners of CSR view it as a vocation. Similarly, important is how they perceive CSR as internally taking care of the company. So, it is almost like charity starts at home. This perhaps differentiates this study from how CSR is viewed or makes sense in another research in other countries around the world. This also influenced how these managers conduct business predominantly how and why they make their CSR related decisions. Another situational factor was the fact that Lebanon is a developing country where rampant bribery and corruption also had an impact on the participants and their MNCs.

The third group of results contributes to institutional work and practice theory and relates to how CSR was institutionalized in Lebanon. The sampled MNCs conducted various types of work to disrupt, tailor, and maintain CSR in Lebanon. In fact, the MNCs selected practiced various types of CSR activities such as recycling, reducing pollution, enhancing the 
country's infrastructure, and providing scholarships to students. These activities appear to fill the gap in Lebanon that the government is unwilling and unable to fill. Furthermore, the CSR practices of the sampled MNCs seem to disrupt sectarianism in Lebanon because they show the personnel and other stakeholders how to respect diversity in all its forms and treat everyone equally through these activities. In addition, these MNCs are conveying best practices and showing the local Lebanese public and private sectors how things should be done. For instance, their CSR policies, reports, and practices provide an example and demonstration to the Lebanese government regarding what type of laws to endorse to make CSR compulsory. These MNCs' anti-corruption and anti-bribery policies, respect of basic human rights, and a proper whistle-blowing mechanism also had a major influence on society.

Moreover, this research shows that CSR was a top-down approach in foreign MNCs because their headquarters introduced CSR decisions. Nevertheless, the managers of their local subsidiaries were given a degree of freedom to tailor those decisions to suit the needs of the Lebanese society but under the stated guidelines. In contrast, in Lebanese MNCs CSR was bottom up because although the founders of these MNCs incorporated the spirit of giving back in their firms, CSR managers were the ones who officially began CSR in those organizations. Another difference between local and foreign MNCs is that local MNCs practiced CSR of their own free will because the Lebanese government and community do not put any pressure on them. Quite the opposite, foreign governments and communities put a pressure on foreign MNCs to engage in CSR. These results were also part of the contribution to institutional work and practice theory because they revealed how CSR was institutionalized in foreign versus local MNCs.

Additionally, the selected CSR managers are broadening the range of CSR by for instance planning to introduce CSR in employees' objectives, job descriptions, and evaluation 
process. The MNCs selected also have employee volunteering programs and involved numerous stakeholders in their CSR decisions and actions. Taking and considering the feedback of several stakeholders was also important to the interviewees for them to improve their CSR practices. Besides, this study demonstrated that CSR Lebanon is an established organization in Lebanon whose purpose is to spread awareness on CSR in the country and the region. This also assisted MNCs in inaugurating CSR in the Lebanese community. In addition, the findings reveal that the MNCs selected acquired certificates, of which International Organization for Standardization (ISO) certificates, that offered them support in establishing CSR in their companies but the methods they have adopted were diverse and dependent on their appropriateness for their CSR applications.

\subsection{Limitations and Future Research}

In spite of this study's contributions, its limitations have to be noted. The first limitation is that this research used a cross-sectional exploratory research design because it examined CSR as a particular phenomenon in Lebanon at a precise moment (Bryman \& Bell, 2007). Therefore, future studies can address this limitation by adopting a longitudinal research design. In fact, Gilmore and Carson (1996) explained that a longitudinal feature of several qualitative studies helps researchers collect data over a time period and therefore gives them time to understand the phenomenon in development. Consequently, the researcher will be given an opportunity to comprehensively describe the behaviours, phenomena, and practices within a complete context (Gilmore \& Carson, 1996). Thus, future research can examine how CSR advanced in Lebanon throughout time and during diverse stages.

The second limitation of this study is that the sample selected could have been of a bigger size, included companies that are more geographically dispersed, and comprised other types of firms such as small and medium-sized enterprises (SMEs). Accordingly, future 
research may tackle this limitation by selecting a larger sample and comparing MNCs and SMEs in different regions of the Lebanese market. Besides, future studies can increase the size of the sample and select participants from both genders. For instance, I noticed from my observation that all CSR managers interviewed were females and there was only one male. It happened that the majority of CSR managers interviewed were females. Thus, future research may explore if and how the personal dimensions of individuals such as gender play a role in CSR. Future studies can examine how CSR is applied from a gender-based perspective by selecting a bigger sample size.

The third limitation of this research is that this study is qualitative and hence not confirmatory because the results did not demonstrate any correlation between events. Onwuegbuzie and Leech (2005) posited that exploratory studies in general attempt to create theories concerning how and why a phenomenon functions in a certain way, whereas, confirmatory research comprises testing hypotheses that transpire from new or present theories. Consequently, future studies could be confirmatory and concentrate on correlations. For instance, future studies can assess the relationship between microfoundational factors and the success of CSR actions. It can also assess the situational factors.

The sampling is queued or purposeful because the core objective of this study is to comprehend the decision-making process that is related to CSR activities rather than the absence of CSR activities. Therefore, what is left may be the objective of future studies. Future research may examine similar phenomena, which is the decision-making process, in businesses that have not carried out CSR initiatives or those who have only undertaken partial CSR actions. As with all things concerning CSR, even though all interviewees say that they practice CSR for its principles, there is utility for CSR and all firms know it. In addition, it is difficult to evaluate whether or not they are benefiting from their CSR reputation and they are 
using it for marketing purposes. That in itself is another study, so future studies can further examine it. Besides, as will be explained in chapter three, the Lebanese culture is a tight culture where individuals are obliged to follow certain standards of behaviour (Jamali, Abdallah, \& Hmaidan, 2010). Therefore, future studies may do a comparative research of how CSR decision-making and execution is done in tight versus loose cultures.

\subsection{Structure of the Dissertation}

Chapter one outlined the contextual background and the gap in literature that led to the need for this study. Chapter two will comprise a literature review of CSR regarding its impacts and antecedents, a comparison of CSR in developed and developing economies, and a description of the institutional theory. Chapter three will offer a general review about Lebanon and include a description of its history and a detailed explanation of its political, legal, economic, technological, and socio-cultural environments. Chapter four will provide an explanation of the researcher's philosophical stance and research strategy that underpinned this study, a detailed explanation of the research methodology and design, data sampling and collection, data analysis, and the ethical considerations of this research. Chapter five will portray the results of the study that were directed by the research questions. Finally, chapter six will present a discussion of the results by depicting the themes that contribute to knowledge, an overview of the practical implications of this study, and a depiction of the limitations of this research and recommendations for future research. 


\subsection{Chapter Two - Literature Review}

\subsection{Introduction}

The damaging costs of globalization such as increasing social disparities, spiraling income discrepancies, the appearance of universal environmental problems, and the subcontracting of progressively expert procedures to developing countries have resulted in pressures to protect against the chaos of free market forces (Levy \& Kaplan, 2007) and for businesses to be responsible for their effect on society (Moon \& Vogel, 2008). These requests for responsible corporate behaviours and business donations are usually outlined in terms of CSR as in principle, CSR tackles the role and responsibilities of businesses in society (Muthuri \& Gilbert, 2011). Muthuri and Gilbert (2011) define CSR as the responsibility of the businesses towards developing their stakeholders, and towards avoiding and correcting any harmful consequences initiated by corporate actions. The concept that corporations have responsibilities towards society is not modern; it gets back to the seventeenth century, though the way in which individuals perceive and describe the connection of companies to society has progressed and changed over time (Muthuri \& Gilbert, 2011).

There is little reservation that CSR today is a noticeable aspect of the global business agenda (Moon, 2007), and that the meaning of CSR, its directions, relevancy, and appropriateness differ across dissimilar country contexts (Matten \& Moon, 2008). Businesses around the world display a range of CSR ideologies, rules, and practices (Baughn, Bodie, \& McIntosh, 2007; Kusku \& Zarkada-Fraser, 2004) with different intensities (Maignan \& Ralston, 2002; Welford, 2005). Nevertheless, questions still continue as to what explicates the resemblances or dissimilarities in CSR actions across countries, why CSR activities vary over time and what explicates these variations (Muthuri \& Gilbert, 2011). Although there is approval that CSR is unique to a certain context (Matten \& Moon, 2008), there is a prodigious 
domination of western-centric studies mostly concentrating on developed countries such as Europe and North America and progressively more transitional countries such as Brazil and China (e.g. Visser, 2008).

This research will therefore examine the drivers of CSR and explore the institutional environment of a developing country i.e. Lebanon in order to fill this gap in literature and also contribute to institutional theory. This study was conducted through a systematic literature review. The researcher first used the four key words; CSR, Lebanon, MNCs, and institutional theory to find basic articles relating to CSR. Then, a combination of the four key words was used to find articles that are relevant to this study. The researcher referred to the Chartered Association of Business schools (CABS) to make sure that the best articles are read and used in this study. The researcher registered in CABS in order to check what the top ranked journals are. She did her best to select journals ranked four or three such as academy of management journal (4), academy of management review (4), journal of management (4), and journal of business ethics (3). For business related concepts like CSR, management decisionmaking, and business ethics, the researcher has looked at different databases like ProQuest Central, Emerald eJournals Premier, EBSCO ebooks, Sage Publications, Business source complete, regional business news, SpringerLink, and WILEY Online Library. A total of one thousand two hundred and five articles and one hundred and fifty-two books were found and the researcher read all of them and selected the ones used here because many concepts overlap and many things are not necessary to be included. So, many articles and books were disregarded.

This chapter provides a literature review on the most important constructs of CSR engagement at different levels. Firstly, this explicates the needs of the organization itself to practice CSR. Organizations need to look legitimate in the eyes of stakeholders and need to keep corporate government requirements. One of the evolutionary catalysts of CSR is the need 
to legitimize the organization. Frederick (1998, as cited in Kraus \& Brtitzelmaier, 2012)

posited that CSR evolved through four phases and created the terms CSR1, CSR2, CSR3 and CSR4 to describe this evolution. The four terms are shown in a table included in Appendix F. This table can also be linked to the CSR definitions table in Appendix E because it shows the definitions of CSR throughout time. Appendix D offers a detailed history of CSR.

The development of CSR then moved to its operation in a wider contest. Therefore, the examination of CSR in a national and cultural context is given in section 2.2.2. Focusing on the individuals within organizations that drive CSR is then discussed in section 2.2.3. These include personal values, family, ethics, religion, and national culture that underpin a manager's CSR perspectives and practices. The next sections then review the development of Institutional Theory. These are 2.3.1, 2.3.2, and 2.3.3. Finally, section 2.4 offers a summary of the chapter.

\subsection{CSR Practice at Different Levels}

CSR is not new, it's an ever-changing concept and at its foundation is the continuous effort to comprehend what is meant by understanding business as part of society (Idowu, 2011). CSR is about responsibility and whilst an organization can be legally responsible its actions are determined by people: so, this is why this section starts with people. Therefore, this section explains what shapes people's CSR practices. Whilst CSR is a human practice it is also practiced within organizations. Individual and organizational boundaries are not hard. Lantos (2002) identified three terms of CSR; altruistic CSR when actions are done for the interest of others, ethical CSR when one avoids harming and injuring others, and strategic CSR when a company acts in a way to benefit itself and some of its stakeholders. 
There is also the national or cultural context. These often play a large part in the development of CSR. Discussion of the current literature of the three levels is given in the next three sections.

\subsubsection{Organizational Needs - CSR at the Meso Level}

Traditionally, CSR emerged as a concept at the organizational level, hence this review starts at this level - the meso level. Garriga and Mele (2004) classified CSR theories into four categories as follows: instrumental theories assuming that companies are a tool for creating wealth and the only social actions accepted are the ones that create wealth (Garriga \& Domenec, 2004). Political theories underline the social power of companies especially in their interactions with society and their obligation in the political field linked to this power (Kraus

\& Brtitzelmaier, 2012). Therefore, businesses agree to take social responsibilities and rights or take part in some social collaboration (Kraus \& Brtitzelmaier, 2012). Integrative theories assume that firms depend on society for their continuousness, evolution, and survival, thus companies take into account social demands (Kraisornsuthasinee, 2012). Finally, ethical theories argue that ethical values underlie the relation of companies and society (Kraus \& Brtitzelmaier, 2012). Corporations are supposed to accept social duties as an ethical responsibility beyond any other concern (Kraisornsuthasinee, 2012).

Today, society is more alerted to whether companies have been working ethically and social responsibly because of several scandals that took place in the business world, the financial crisis that affected most countries, and the dangers threatening the environment (Kraus \& Brtitzelmaier, 2012). Furthermore, Liao and Teng (2010) posited that due to the ethical and illegal scandals of Enron and WorldCom, the general public was increasingly more concerned with the notion of ethical decision-making in corporations and pushing organizations to be socially responsible when making decisions. Research also suggests that 
when businesses answer stakeholders' demands, their long-term survival will be enhanced (Stanaland, Lwin, \& Murphy, 2011). Hence, many organizations are engaging in CSR as they need to legitimize their operations in the eyes of diverse stakeholders such as customers, NGOs, and local governments.

People cannot really comprehend CSR without understanding business ethics as the two ideas are interrelated (Kilcullen \& Judith, 1999). The Ethics Resource Center (2003, as cited in Joseph, 2003) defines business ethics as simple principles and rules that assist workforces in differentiating correct from incorrect conduct at work. Desjardins (2003) explained that generally business ethics is not a section different from ethics, but a subdivision of the study of ethics which is an expansive range of study. The subcategory of business ethics is about examining and applying ethical principles within the framework of finance, trade, manufacturing, supplying, and selling products and services, and other business practices (Sauser, 2005).

Crane and Matten (2004) defined business ethics as the study of corporate circumstances, actions, and decisions where questions of right and wrong are tackled. Boatright (2000) defined business ethics as a manager behaving ethically by taking the right course of action. Kilcullen and Judith (1999) defined business ethics as a group of values that directs the practices of companies to reveal an overall concern for society while pursuing profits. Ferrell, Hirt, and Ferrell (2014) defined business ethics as the values and standards that define conventional corporate behaviour. Grewal and Levy (2016) defined business ethics as the moral conflicts that might emerge in a corporate context. Ebert and Griffin (2015) defined business ethics as moral or immoral actions of managers and employees in the framework of their work. Carroll (2002) argued that managers promote moral values in the company through their chief position of power and beliefs of exemplarity. Moreover, the corporation enforces 
more expectations on managers to be role models as their position in the organizational hierarchy increases (Rozuel \& Kakabadse, 2011). Literature suggests that business ethics is ethics governing the conduct of organizational behaviour but it is an individual-level construct as it comes from the managers governing organizations.

Corporate actors bring their personal ethics and values into the company and these may go beyond self-actualization or economic interests (Aguilera, Rupp, Williams, \& Ganapathi, 2007). Thus, it appears that managers' values and ethics shape the organizational culture and climate in a way to adopt CSR. Ethical motivations to pressure firms to induce social change through their CSR practices may therefore come from these organizational actors whose deontic drives are predominantly prominent (Aguilera et al., 2007). In a similar vein, Logsdon and Wood (2002) argued that corporate actors working in an international business context may have ethical drivers and responsibilities to engage in minor trials to try to create a just society and to right the inequalities such as fortune, gender, ethnicity, and religion. When managers behave depending on their interest in stewardship by initiating social and ethical actions towards a healthier society, they are expected to introduce CSR practices in their corporate strategies and cause social change (Logsdon \& Wood, 2002).

Expectations like companies should be ethical and socially responsible are not new even though the general public has been recently talking a lot about these issues (Idowu, 2011). Moral misconduct is still taking place in corporations and business scandals seem to replicate despite the various discussions about business ethics and its importance in increasing sustainable development and despite ample vigorous lobbying to include stakeholders' issues into strategic management and to give more importance to good management conduct than profitable conduct (Rozuel \& Kakabadse, 2011). 
Rozuel and Kakabadse (2011) proposed that today corporations need to shift from the goal of maximizing shareholder value towards the goal of producing goods and services that increase value to society. This is because the corporate goal of maximizing shareholder value leads to stockholder value, exploitation in realizing stockholder value, progressively diverged society of very wealthy and very poor, and market constraints (Kakabadse \& Kakabadse, 2010). Whereas the corporate goal of producing goods and services that increase value to society leads to offering goods/services which are important, essential, and affordable to consumers, maximizing stockholder value, reducing exploitation whereby managers are not encouraged to act illegitimately and/or immorally only to maximize stockholder value, having less diverged society, and reaching equilibrium between market and non-market forces (Rozuel \& Kakabadse, 2011).

Schermerhorn (2005) made use of Carroll's (1979) intellectual work and mentioned four responsibilities of companies; a company is economically responsible when it makes profits by selling products and services that consumers desire, a firm is legally responsible when it conducts business within the laws and requests of several external rules, a business is ethically responsible when it voluntarily acts in ways that meet the values and ethical expectations of society, and a corporation's highest level of social responsibility is whenever it voluntarily leads the way to improve society's welfare and go beyond legal, economic, and ethical obligations.

Some businesses view CSR as their legal responsibility while others view it as their social responsibility and define it as ethical activities accepted by society (Hack et al., 2014). Companies that only view CSR as a legal responsibility do not go beyond what the law states and do not engage in any additional CSR practices (Ebert \& Griffin, 2015). For example, these companies comply with legal obligations comprising environmental standards, safety of 
employees, and tax laws (Ramasamy \& Yeung, 2009). Whereas businesses that view CSR as their actual social responsibility go beyond legal compliance and proactively engage in CSR to assist and benefit the societies in which they operate (Ebert \& Griffin, 2015). For example, these companies do what is right and fair, avoid harming the environment and individuals, and enhance the standard of living (Ramasamy \& Yeung, 2009).

Rollinson (2002) explained that it is often hard to know if treating external stakeholders ethically is driven by philanthropy or self-protection. Ashman (2005) posited that nowadays it is evil when people frequently refer to corporate creatures and has the possibility to divert consideration from the actual decision-makers, maybe allowing them to avoid accountability of their activities. Berthouzoz (2000) explained that the potential obligation of the company does not lessen the responsibility and ethical obligation of the members of the company. Certainly, the law is one significant and genuine foundation of moral guidance (Sauser, 2005). Fieser (1996, as cited in Sauser, 2005) explained that state, local, and federal laws create the bounds within which business is conducted. Hosmer (2011) defines the law as a constant set of generally accepted rules that are broadly published and ordinarily compulsory. These rules designate the obligatory behaviour of individuals in their relationships with other individuals within a society (Hosmer, 2011). They are obligations to behave in a certain manner, not just anticipations, recommendations, or requests to behave in that manner (Hosmer, 2011). There is an impression of persistency about the law; it delineates what you should do (Hosmer, 2011). Law violation is practically all the time deemed as immoral conduct (Sauser, 2005).

First, managers were identified as those responsible for CSR, but this idea changed towards a complete corporate approach calling for team ethics and a common understanding of individual firms' influence on society and the environment (Hack et al., 2014). Morrell and 
Anderson (2006) argued that even though everybody should be morally considerate, managers are usually expected to be exemplars and set the attitude in the corporation. Wood (1991, cited in Rozuel \& Kakabadse, 2011) argued that even though CSR studies usually prioritize corporate or international issues and dynamic forces, the importance that corporations place on single performers, comprising managers, is essential in encouraging sustainable corporate actions. Managers have an obligation to be humanitarian due to one's reciprocal esteem for people (Rozuel \& Kakabadse, 2011).

Literature also suggests that consumers play an important role in influencing organizations to practice CSR (e.g. Aguilera et al., 2007; Cowan \& Guzman, 2018; Ramasamy \& Yeung, 2009; Stanaland et al., 2011). For example, customers boycotted Nike's products when the company was accused of ostensibly using sweatshops in its foreign subsidiaries pushing Nike to amend its international labor practices (Knight \& Greenberg, 2002). Studies related to brand image show that when given the choice, some clients are willing to pay more for products offered by a responsible firm (Sen, Gurhan-Canli, \& Morwitz, 2001) as was the case of Ben \& Jerry's ice cream, with differences in customers' perceptions regarding the significance of CSR across various countries (Maignan, 2001; Maignan \& Ferrell, 2003). For example, Maignan and Ferrell (2003) found that American consumers give more importance to a company's economic responsibilities than French and German consumers. This is due to the fact that the United States of America (USA) is characterized by an individualistic culture, so Americans believe that both they and other social agents should mainly aim to fulfill their own short-term self-interests, well-being, and survival (Ebert \& Griffin, 2015). Consequently, American customers may assume that companies' main responsibility is economic because they need to maintain their profitability and productivity for their own survival and prosperity (Maignan \& Ferrell, 2003). On the other hand, Germany and France are characterized by a 
communitarian culture, so French and German customers believe that companies should adapt to the social standards that define proper conduct (Maignan, 2001). Therefore, French and German clients may assume that companies' main responsibilities are ethical and legal expecting firms to be actively involved in society (Ramasamy \& Yeung, 2009).

Maignan and Ferrell (2004) explained that companies need to communicate their CSR practices to their stakeholders not only to spread awareness on their CSR activities but also to show that CSR is a link between the company and its stakeholders. One way to communicate an organization's commitment to CSR is through a values statement and a code of ethics (Stanaland et al., 2011). In a related study on large American-based firms and MNCs, Murphy (2005) found that the majority of corporations have an ethics statement and promote it in a certain way. Stanaland et al. (2011) found that business ethics in the form of code of ethics is one of the most fundamental antecedents of customers' perceptions regarding a company's extent of CSR engagement. Codes of ethics are one of the official structures that firms use to institutionalize ethics (Valentine \& Barnett, 2002) and are known to positively affect a company's ethical context (Stevens, 2008; Valentine \& Barnett, 2002).

Although consumer pressures represent an example of reactive social change, there are also a growing number of examples for proactive social change (Aguilera et al., 2007). For example, companies adopting a triple bottom line philosophy, which proposes that a company's success pivots around economic lucrativeness, social performance, and environmental sustainability (Hart, Milstein, \& Caggiano, 2003). Horrigan (2010) explained that because today's world is globalized and highly interdependent and because trade is borderless this makes companies more visible in terms of CSR rankings such as the 100 Best Corporate Citizens. It also allows managers to incorporate evolving international standards of anticipated responsible behaviour like the UN's Global Compact into their management 
systems, and introduce accountability practices into their manufacturing procedures and international supply chains (Waddock, Bodwell, \& Graves, 2002). In addition, more than half of the Fortune Global 500 MNCs publish an annual distinct CSR report (Williams, 2004), and the top managers of most of them have a responsibility for CSR practices (Crook, 2005). In both cases, reactive or proactive CSR practices, external and internal actors are pressuring companies to practice CSR to respond to the varying expectations regarding companies and their social responsibilities (Clark \& Hebb, 2005; Crook, 2005; De La Cuesta Gonzalez \& Valor Martinez, 2004).

Aguilera et al. (2007) further argued that corporate practices like CSR are a subject of the decoupling effect so that some firms present CSR initiatives at a shallow level for marketing purposes, while other firms incorporate CSR into their main corporate strategy. In studies related to organizations, and mostly new institutional theory, decoupling is the formation and conservation of gaps between official policies and concrete corporate practices (Alexius \& Grossi, 2018). A business' response to varying social expectations, more specifically its thoughtful execution of CSR practices into its strategic objectives, has the possibility not only to modify its corporate culture but also to inform real social change (Aguilera et al., 2007). For example, Chiquita is a company that seriously pursued CSR practices causing positive social change as it applied the standard of living salary for all of its farm labor force in all countries where it crops fruit, and it incorporated advanced environmental practices in its supply chain (Taylor \& Scharlin, 2004). The efforts of Chiquita are being adopted by other international firms in every industry such as the pharmaceutical and apparel sectors and can positively impact the lives of employees in Chiquita, the societies in which this company conducts business, and the ecosystems on which it is dependent (Aguilera et al., 2007). 
Munro (2013) found substantial differences in how people understand CSR across different national cultures in the Middle East and Africa region. Hence, Munro (2013) suggested a need to include cultural differences and the views of dissimilar nationality groups in CSR planning. In a similar vein, Yelkikalan and Kose (2012) explained that businesses prioritize and change their CSR initiatives depending on the needs and primacies of the country in which they operate. Literature also suggests that governments of developing countries play a limited role in the social sector and that CSR is frequently considered as a tactic to answer society's needs as governments prove inadequate (Amaeshi et al., 2006; Frynas, 2005). The power of businesses in developing countries appears to vary as the power of governments changes indicating a remarkable opportunity for operation in the CSR field (Jamali \& Neville, 2011). Consequently, managers need to adopt a view of the institutional landscape and its effect on individual organization before taking any CSR initiative (Muthuri \& Gilbert, 2011).

\subsubsection{CSR in Developed versus Developing Economies: The Macro Level}

CSR is context bound and is far from global, so the national context is significant. Studies concentrating on developing countries are still rare with a small number of exceptions (Amaeshi, Ogbechie, Adi, \& Amao, 2006; Hamann \& Sprague, 2008; Jamali \& Mirshak, 2007; Lindgreen, Swaen, \& Campbell, 2010; Muthuri, Chapple, \& Moon, 2009). There is an increasing need for research focusing on CSR in developing countries and it is very critical with the main concern that present approaches to CSR originated in developed countries and may not adequately respond or link to the context and conditions faced in developing countries (Hamann, 2006). It is known that developing countries do not have similar social and cultural values, customs, and primacies that reinforce CSR in western countries (Blowfield \& Frynas, 2005; Jamali \& Mirshak, 2007). There is some concern that CSR carries on legitimizing and 
reproducing values and perceptions that are not for the benefit of developing countries or the underprivileged and marginalized (Blowfield \& Frynas, 2005). In a real-world setting, businesses are also challenged by the need to balance their desire for international incorporation with the necessity for local sensitivity (Gugler \& Shi, 2009).

Matten and Moon (2008) have depicted cross-country differences in companies' CSR practices. A business' national institutional context, which comprises professional, regulatory, and legal organizations, impacts the business' reaction to CSR, more significantly crosscountry differences in CSR rising from cross-national disparities in stakeholders pressures may lie in the nature of relevant countries' institutional background (Thorne, Mahoney, Gregory, \& Convery, 2017). For example, although the USA and Canada are both part of North America, previous research showed that stakeholder pressure on companies to be socially responsible has conventionally been more robust in Canada than in the USA (Sorenson, 2011). In fact, the regulations of the Canadian government comprise free health care, progressive taxes, banning of capital sentence, alleviating poverty, and valuing cultural mixture, all aspects that reveal important cultural values that impact stakeholders' expectations for CSR (Thorne et al., 2017). Canada is categorized as a liberal, varied, and multicultural country inspiring collectivist leaning customs (Mooney Cotter, 2011) while the USA values the free enterprise system and individual rights and stresses on maximizing short-run profits (Sorenson, 2011). Therefore, it is not surprising if some have categorized Canada's institutional background to be a nationwide system that has traditionally stimulated tougher components of CSR in comparison with the USA (Freeman \& Hasnaoui, 2011).

Moreover, previous studies showed that traditionally, Canadian companies have revealed a higher degree of social and environmental initiatives than American companies (Thorne, Mahoney, \& Bobek, 2010). For instance, Freeman and Hasnaoui (2011) described a 2008 study of two hundred and fifty American companies directed by IBM that revealed that 
American companies lacked responsiveness to CSR. Similarly, Thorne et al. (2017)

highlighted a study by CorporateRegister.com showing that in 2010 the USA tarried behind other countries, comprising Canada, in motivating companies to practice CSR.

Ramasamy and Yeung (2009) argued that people understand social problems more in developed countries. Similarly, Shah and Ramamoorthy (2014) highlighted a latest study of McKinsey \& Company that generally focused on developed countries and found that institutional investors are ready to pay a price of more than twenty percent for stocks of corporations that reveal good governance management systems. Moreover, the growth of the population in developed countries has a lower rate than that in developing countries, but the profit-making energy consumption per person in developed economies is way more than that of developing economies, and as a result, they cause way more pollution and affect global warming (Shah \& Ramamoorthy, 2014). From here, the UN's General Assembly declared the UN's Decade of Education for Sustainable Development and the actions of the UN Educational, Scientific, and Cultural Organization (UNESCO) endeavored to endorse and motivate people to consume energy and products sustainably (Shah \& Ramamoorthy, 2014). Literature suggests that CSR in developed countries is very much and is really developed externally because of societal consumer awareness and government legislation that has forced CSR.

Government practices both passing laws and imposing them is an imperative factor inducing companies to initiate CSR activities and hence become agents of social change (Aguilera et al., 2007). For example, the governments of France, Germany, and the United Kingdom (UK) have respectively enacted laws calling for managers of pension funds to reveal the degree to which they take into consideration the social and environmental histories of the firms in which they invest (Aaronson \& Reeves, 2002). 
In developed countries, government initiatives can be categorized into those trying to promote CSR in matters not presented in the regulatory framework, and those trying to inspire CSR in general (De La Cuesta Gonzalez \& Valor Martinez, 2004). Besides, in greatly developed countries there are possibly fewer expectations on MNCs to solve social problems through their CSR initiatives because this is the governments' responsibility and larger MNCs may have more control over their behaviour (Crilly, 2011). In addition, the main function of governments' economic rules in developed countries is to create local competition among companies and encourage international economic development in countries where MNCs from developed countries operate (Aguilera et al., 2007). Therefore, governments have instrumental motives to endorse CSR rules to the degree those rules are assumed to encourage international competitiveness (Aguilera et al., 2007).

The European Union (EU) is pressuring member countries to adopt uniform standards of CSR by motivating businesses to voluntarily undertake responsibilities beyond their legal requirements and by demanding domestic governments to impose the usage of universally agreed upon practices (European Commission, 2002; Habisch, Wegner, R., \& Jonker, 2005). Inside the European region, the integration of institutional and economic systems substantially pressures countries to converge in adopting a high level of corporate citizenship (Albareda, Lozano, \& Ysa, 2007; De Schutter, 2008). It appears that in developed countries companies are not only pressured by the government but also by other types of organizations like the EU. There is also a pressure on companies to adopt uniform standards of CSR practices. This does not seem to be the case in developing countries where there is dearth in the role of local governments in instituting CSR laws and standard practices (Mijatovic \& Stokic, 2010).

Despite the fact that creating jobs is essential all over the world, in developed economies creating and protecting jobs are less important than encouraging social fairness and international trade on the CSR agenda (Husted \& Allen, 2006). Companies in developed 
countries focus more on environmental protection through their CSR initiatives (Gruber \& Schlegelmilch, 2015). However, in developing economies job creation is more significant than in developed economies where many MNCs are headquartered (Reed, 2002). This may be due to the fact that developing countries are less developed economically, have a lower institutional quality, have a reduced living standard than developed countries, and face important market and institutional changes (Hoskisson, Eden, Lau, \& Wright, 2000; Khanna \& Palepu, 2010; Sullivan \& Sheffrin, 2003). Moreover, MNCs from developed countries have always been behind publishing CSR reports internationally because this practice is very important in their home countries (Li, Fetscherin, Alon, Lattemann, \& Yeh, 2010). CSR reporting is important as it helps those firms gain legitimacy for their actions and social approval (Marano et al., 2017). Besides, MNCs in developed countries are more than ever inspected not only for their own conduct but for the conduct of companies in their international supplier networks (Browne \& Nuttall, 2013; Chouinard \& Stanley, 2012).

Research on developing countries demonstrates that CSR is usually presented by MNCs, and transferred through their branches in the area (Mijatovic \& Stokic, 2010). Gugler and Shi (2009) argued that the formulation of CSR and its rising practices are being undertaken in developed countries, while CSR commitment in developing countries is negligent (Mijatovic \& Stokic, 2010). Mijatovic and Stokic (2010) argued that CSR studies conventionally were done on developed countries' MNCs, their practices in developing countries have to be reexamined. Besides, Jamali, Sidani, and El-Asmar (2009) found that there is a growing awareness of CSR and its possible paybacks or added value amongst managers in developing countries and the contemporary understanding of CSR is becoming progressively widespread among managers in diverse Middle Eastern contexts. It appears that there is paucity in literature regarding developing economies especially in the Middle East. Most Middle Eastern countries are considered emerging economies (Pisani et al., 2017). But 
because there so many emerging economies, a case study approach to each country needs to be taken to explain the CSR phenomenon and therefore this study is looking at Lebanon and fills this gap in literature.

Chapple and Moon (2005) found that MNCs are more expected to engage in CSR than firms only conducting business in their home country, but their CSR's profile is likely to replicate the country of operations' profile rather than the country of origin. Developing economies offer a cultural, social, and economic context for CSR, which is in various ways not the same as the one in developed economies (Mijatovic \& Stokic, 2010). As a predominantly western construct, CSR initiatives vary in diverse cultural, socio-economic, and even among western societies (Mijatovic \& Stokic, 2010). CSR in developing economies is still more about donations and philanthropy and is mainly perceived as external to a company and not as an internal procedure that is incorporated into main tasks, strategies, and long-run plans (Visser, 2008).

Bylaws in developed economies are likely to be more constricted than in developing countries (Crilly, 2011). Nevertheless, Crilly (2011) found that managers in developing countries directly encounter social needs, recognize more prospective for social involvement, and are pressured to observe international standards. Literature suggests that CSR in developing countries is a bit of mix because depending on how rigid the laws are, organizations in the emerging economies may not be compelled to make any changes. Therefore, there is reliance on individual managers to make it happen. So, it can be deduced that emerging economies is a bit mixed.

As explained, CSR is practiced differently in various countries. For example, Kumar (2017) found that CSR in MNCs operating in Bangladesh was represented by an independent department. Codruta and Driga (2017) conducted a study on MNCs operating in Romania and found that they allocate a budget for CSR. A study conducted by Papasolomou-Doukakis, 
Krambia-Kapardis, and Katsioloudes (2005) on the CSR methodology of Cypriot firms proposes the significance of managerial initiative and financial profits as a main motivation for adopting CSR by the corporate sector in Cyprus to reduce its taxes. Another example is a study done by Juholin (2004) that similarly highlights the significance of top management initiative, the restricted attention given to philanthropy, and long-run profits as an important motivation to practice CSR in Finland. When it comes to examples related to government interference, the Spanish government established policies to promote CSR (Fassin et al., 2015) whereas the Lebanese government does not have any CSR related laws or incentives to encourage corporations to practice CSR (Jamali \& Neville, 2011).

Most studies on CSR have concentrated on the strategies of businesses in developed countries (Quazi \& O'Brien, 2000). Research on CSR and MNCs is still primary (Rodriguex, Siegel, Hillman, \& Eden, 2006). Nevertheless, MNCs are more and more introducing operations in developing economies (Tihanyi, Griffith, \& Russell, 2005). With the rising economic prominence of developing economies, like Russia, India, Brazil, and China (Hitt, Franklin, \& Zhu, 2006), it is expected that an MNC's subsidiaries from a developed country like the USA or Germany will be in a state where their CSR initiatives are contradicting to the dominant CSR initiatives in a developing country like China (Yang \& Rivers, 2009). As CSR becomes progressively more essential to MNCs (Fulop, Hisrich, \& Szegedi, 2000; Joyner \& Payne, 2002), it is important to understand how MNCs practice CSR in developing countries to better comprehend how they align their CSR practices with local practices (Yang \& Rivers, 2009). Research on how MNCs practice CSR in developing countries and how they customize their initiatives to local CSR activities is still under-explored (Yang \& Rivers, 2009). Therefore, this research will contribute to literature as it fills the gap in literature by explaining 
how MNCs of local and foreign origins institutionalize CSR in a developing country context i.e. Lebanon.

\subsubsection{The Individual - CSR at the Micro Level}

Often CSR occurs through managerial choice. Armstrong (2011) defined management as the practice when managers choose what goals to reach and then achieving them through other people. Hannagan (2005) explained that managers' experience does not consist of a professional or technical understanding, but in the capacity to manage operations, organize individuals, and produce an overall plan for growth. People prolong the structure of their behaviours to the company they choose to construct and within which they are actors in making decisions (Rozuel \& Kakabadse, 2011). Managers as directors, controllers, and organizers play an important role in the activities of the company for which they are at least partially responsible (Rozuel \& Kakabadse, 2011).

Maclagan (1998, as cited in Hemingway \& Maclagan, 2004) explained that CSR may be considered as a process wherein managers are responsible for detecting and satisfying the interests of those influenced by the company's activities. This focus on managers highlights the idea that important individuals will be influential in expressing and applying corporations' CSR policies (Hemingway \& Maclagan, 2004). When CSR is understood this way, the significance of personal drives and values is raised, and particularly the business status is contested and not the individual status of the resultant initiative (Hemingway \& Maclagan, 2004).

In recent years, research and literature concerning the impact of individual values and belief systems on managers' views and orientations of CSR strongly increased (Jamali \& Sdiani, 2013). Rokeach (1973, as cited in Lee \& Carter, 2005) described values as permanent beliefs that underlie actions, attitudes, and judgments in particular situations. Grebitus, Steiner, 
and Veeman (2013) posited that values provide standards that individuals use to determine which end-state of existence is preferable over another. Human beings from various countries, religions, and cultures hold different values and beliefs about what is right and wrong and will thus make ethical decisions differently (Crane \& Matten, 2004). Robbins and Coulter (2016) defined ethics as the values, standards, and beliefs that determine what is correct and incorrect comportment. Life is a show, individuals are players, and ethics pertains to beliefs controlled by relations with others (Rozuel \& Kakabadse, 2011). For individuals to enhance their ethical conduct, they have to understand what makes them behave that way (Rozuel \& Kakabadse, 2011).

The key to comprehend why individuals act the way they do, correctly or incorrectly, lies in their internal considerations which reveal the views they have of the circumstance (Rozuel \& Kakabadse, 2011). This corresponds to what Trevino and Brown (2004) point out as a deficiency of ethical attentiveness, moral acknowledgment, or moral compassion. Victor and Cullen (1988, as cited in Hemingway \& Maclagan, 2004) argued that nowadays in the writings on individual ethical development, there is acknowledgment that personal characteristics only are not enough to describe ethical conduct. People are actively or passively performers and this is generally enough for the law and for social tradition to hold everyone accountable for their actions or non-actions (Rozuel \& Kakabadse, 2011).

Ethics has to do with conduct, specially a person's ethical conduct with regards to society (Sauser, 2005). Solomon (2002) explained that ethics is about creating a moral personality which refers to a normal character to properly exercise the virtues and to accept that this contributes to accomplishing one's purpose and a profound feeling of selfactualization. In the business context, ethics has to do with the degree to which an individual's conduct satisfies standards like the law, the rules of the company, business association and 
professional standards, prevalent expectations of justice and what is correct, in addition to an individual's personally adopted ethical values (Sauser, 2005).

Parke (2004) explained that family is known to form a person's values. In a similar vein, Noorderhaven and Harzing (2003, p. 54) found that people become "mentally programmed" through the way their family raises them and through organizations, precisely educational organizations, in the country where they grew up. This will form their values and preferences for certain corporate actions (Noorderhaven \& Harzing, 2003). Shah and Ramamoorthy (2014) found that fifty-seven percent of the respondents said that their family values were a motivation for their charitable contributions. Similarly, in their study on CSR in China, Hofman, Moon, and Wu (2015) highlighted the significance of CSR within family values that in turn triggered CSR in companies. It appears that family values underpin an individual's behaviour more particularly his/her CSR inclinations and actions.

Values that people learn early in life and that are strengthened by experiences in life, are adopted values which are usually based on an individual's religious and/or philosophical understandings of ethics (Sauser, 2005). Zinbarg (2001) posited that one should consider religion to better understand business ethics because ethical understandings result from religion and from worldly education. Religion significantly impacts the orientations of business and society because it underpins managers' decisions and behaviours (Brammer, Williams, \& Zinkin, 2007). Research on the rapport of Islam and CSR found that the Islamic perception encourages CSR (Ullah \& Jamali, 2010). Weir (2012) explained that in the ethics of Islam, the idea of Ummah involves removing harm from the wider community which is one of the main ideas involving CSR. A wide stakeholder view and an ample view of the role of companies in society are also well-founded in the Christian faith (Jamali \& Sdiani, 2013).

Longenecker et al. (2004) conducted a study on managers and professionals in the USA regarding their religious memberships, degree of religiosity, and ethical decisions. They 
found a slight relationship between their religious affiliation and ethical business decisionmaking comprising situations linked to areas of CSR (Longenecker et al., 2004). Angelidis and Ibrahim (2004) surveyed Christian business students in the Midwest USA to explore the relationship between their level of religiousness and their CSR orientation. The results showed a positive relationship between the level of religiosity and views of CSR particularly ethical responsibility (Angelidis \& Ibrahim, 2004). Ethical responsibilities are more ambiguous than legal responsibilities because they are not written; they represent the ethical norms and values of a society (Griseri \& Seppala, 2010). The results also showed a positive correlation between the level of religiosity and the tendency to sacrifice profits in quest of the social good (Angelidis \& Ibrahim, 2004). Agle and Van Buren (1999, as cited in Jamali \& Sdiani, 2013) conducted a survey on Master of Business Administration (MBA) and executive MBA students to examine if religious practices would have a positive correlation with their wider perception of CSR. The results did not show a correlation between the two (Jamali \& Sdiani, 2013). They found that only participants who use religion for social commitments would have a wider understanding of CSR (Jamali \& Sdiani, 2013).

Philanthropy is not only limited to Christianity (Hemingway \& Maclagan, 2004). Both the Islam and Christian religions expect the rich to help the poor (Jamali \& Sdiani, 2013). Similarly, religious individuals from both religions expect companies, which are a wealthy social sector, to engage in different kinds of good actions which are beneficial to society (Jamali \& Sdiani, 2013). The significance of aiding others can be seen in Islam, Buddhism, and Judaism (Hemingway \& Maclagan, 2004).

Religious principles can be considered as a stimulus of philanthropy or CSR, even though the religious drive in itself can be considered to be elicited by causes of self-interest (Hemingway \& Maclagan, 2004). For instance, for Christians to guarantee a place in heaven, 
or for Jains, Hindus, and Buddhists to exercise Karma (Hemingway \& Maclagan, 2004).

Although ethical education is obvious in several main religions, ethical values are not essentially the same as religious values (Hemingway \& Maclagan, 2004). Rescher (1969, as cited in Hemingway \& Maclagan, 2004) distinguishes ethical values from other types of values: "social values, political values, religious/spiritual values, and sentimental values" (p. 37). Any of these classifications of values could correspondingly be deemed as motivators of CSR (Hemingway \& Maclagan, 2004).

Stackhouse (1995b, as cited in Sauser, 2005) argued that religion affects business ethics especially with regards to issues of aptitude, ethical law, freedom, sin, convention, and conception. Zinbarg (2001) summarizes the ethical standards of the Christian, Islamic, Jewish, Buddhist, Hindu, and Confucian traditions and describe how they come together to guide actions in the economic sector; economic efficiency would not be at the expense of selfesteem, economic agents would demonstrate reciprocal sympathy, and individual success would not sacrifice collective team spirit. Balanced economic and ethical development would be achieved with modesty and serenity (Zinbarg, 2001).

Stackhouse summarizes the Christian religion's guidance for moral corporate behaviour and many of these standards are exhibited worldwide across the prominent religious customs:

Do not lie, cheat, steal, or covet; deal as equitably with the foreigner and the stranger as with the family member and the beloved neighbor; if authority is given to someone, it must not be used to extort or gain advantage; all bounty is to be treated as a trusted and trustworthy steward treats that which is the Lord's. Honor is not to go to the rich and the powerful because they are rich and powerful but accordingly as they love mercy, do justice, and walk humbly with God. Further, the greedy accumulation of wealth which removes some from accountability to all others is contrary to God's justice but damaging to 
the community...Forced poverty is equally contrary to God's justice and destructive of viable economic development. Thus, efforts to call the greedy to account, to relieve the needs of the distressed, and to convert both to a disciplined life, are always necessary (1995c, as cited in Sauser, 2005, p. 349).

When a person quickly embraces such religious principles, then he/she strives for behaving and working on a daily basis in ways which complies to them (Sauser, 2005).

Furthermore, Desai and Rittenberg (1997, as cited in Hemingway \& Maclagan, 2004) posited that individual managers frequently form the ethical setting in which they operate. Rozuel and Kakabadse (2011) added that one cannot deny that managers' and leaders' culture and personal characters establish a particular character or mood within the corporation, and they should practice their moral obligations if they want them to be meaningful. There is a diversity of standards for social conduct, so moral conduct is usually characterized with regards to certain contexts (Sauser, 2005). With regards to ethics, individuals can similarly be moral and immoral depending on their environment (Rozuel \& Kakabadse, 2011). Even if an action strictly abides by the law, corporate rules, and professional principles it may still be considered as unjust and incorrect by society (Sauser, 2005).

The significance, meaning, and attention of ethics can differ based on a person's perspective (Rozuel \& Kakabadse, 2011). It can be impartially claimed that a moral individual behaves properly in all social contexts (Sauser, 2005). Cohen, Pant, and Sharp (1995, as cited in Beekun, Hamdy, Westerman, \& HassabElnaby, 2008) studied decision makers who have different national cultures and who work for the same MNC but in various countries. The results revealed that the participants hold diverse ethical values and hence understand the ethical consequences of a certain decision differently (Beekun et al., 2008). Robbins and Coulter (2005) defined national culture as "the values and attitudes shared by individuals from a specific country that shape their behaviour and beliefs about what is important" (p. 89). 
Hofstede (1980, as cited in Muller, Spang, \& Ozcan, 2009) defined culture as "the collective programming of the mind which distinguishes the member of one human group from another" (p. 72). Hofstede (2001) advanced that values are a main constituent of culture and developed a framework to understand how value differences between national cultures underlie organizational behaviour. When conducting business, there is a diversity of problems and expectations which may vary from culture to culture (Sauser, 2005).

Trompenaars (as cited in Bickerstaffe, 2002) described culture as a set of rules and procedures that a society develops in coping with life challenges. The social values grounded in shared principles about "what is right and what is wrong" and "what is fair and what is unfair" can be important determining factors of a person's social reputation (Sauser, 2005, p. 346). Prasnikar, Pahor, and Vidmar Svetlik (2008) conducted a study on Russian, Serbian, and Slovenian managers and business students. The results revealed that the participants have different values and their national cultures strongly influence their attitudes, expectations, and behaviours in the workplace (Prasnikar et al., 2008). The degree to which a person's actions satisfy the social standards is normally used as a measure of that person's morality (Sauser, 2005). Society's perception of ethics is another type of standard which is usually understood and generally accepted (Sauser, 2005).

Even though the number of studies about CSR is increasing, most studies have mainly concentrated on a macro-level analysis (Aguinis \& Glavas, 2012; Bansal \& Roth, 2000; McWilliams \& Siegel, 2000). Nevertheless, as in other areas concerning the conduct of individuals in companies (Foss \& Pedersen, 2016), there is a strong need to comprehend the microfoundations of CSR to develop theory (Ng et al., 2019). In summary, microfoundations are explored in studies intended to unpack the "black box" or mediational procedures in strategic management studies by integrating understandings from organizational behaviour, applied psychology, human resource management (HRM), and applied psychology (Bridoux 
\& Stoelhorst, 2014; Helfat \& Peteraf, 2015). Thus, this study will contribute to knowledge and fill this gap in literature as it explores the microfoundations of CSR in Lebanon. When people talk about microfoundations they either talk about microfoundations of capabilities or routines. Here, this study focuses on routines and not capabilities.

Research on microfoundations is defined as studies concentrated on clarifying the relations between forms of behaviour in a collectivity and individual-level perceptions and behaviours that create and amend those collective forms (Tolbert \& Zucker, 2020). This situates microfoundations as an appropriate lens to explore the role of family, religion, and ethics with institutional theory. The word institution is frequently used to designate both broad patterns of behaviour that distinguish a collectivity and perceptions and values common to the individual members of the collectivity that most probably create the patterns (Haack, Sieweke, \& Wessel, 2020). Institutional microfoundations particularly concentrate on the latter (Tolbert \& Zucker, 2020). Examining this, entails responding to a set of questions, comprising: (1) what settings stimulate individuals' normative and cognitive approval of and compliance with present institutions; and (2) what individual cognitive practices and social relations take part in creating changes in common cognitions and consequently patterns of behaviour? The latter series of processes may generate new and altered institutions over time based on new or combined sets of cognitions (Haack et al., 2020).

The first question is regularly the one tackled by studies taking cognitive and behavioural perspectives (Tolbert \& Zucker, 2020). More explicitly, it is focused on comprehending what settings make individuals more obedient to or unaffected by institutional pressures and in the latter case, capable of convincing others to resist as well (Haack et al., 2020). The second question is usually recognized with research focused on behavioural and communication perceptions (Tolbert \& Zucker, 2020). The more precise concerns here comprise comprehending the nature of communication practices and understandings of others' 
behaviour that most probably affect individual reception or refusal of present common cognitions and therefore comprehending how this influences the diffusion of new action choices or schema (Haack et al., 2020). In this latter case, researchers can directly explore the processes related to the establishment, and possible rise, of new institutions (Tolbert \& Zucker, 2020). Any person who has constant connections with others can create these new cultural and societal components; not only institutional entrepreneurs (Haack et al., 2020). Therefore, many partake in redefining and enhancing the social contexts they live and work in (Tolbert \& Zucker, 2020). From here, this research explores the microfoundations of CSR in Lebanon to understand what stimulates managers' CSR initiatives and how CSR was consequently institutionalized in the country through their MNCs' CSR activities.

Microfoundational research in institutional theory can be considerably enhanced by boosting the analysis of levels and mechanisms (Weber, 2006; Weber \& Glynn, 2006). While theorizing microfoundations as "level-free" and as rooted in a horizontal or interpersonal ontology has received some currency, accepting a layered ontology offers some significant analytical benefits, especially regarding the identification of instrumental mechanisms (Haack et al., 2020, p. 24). A layered ontology provides a significant analytical heuristic to deal with how institutional phenomena unfold in micro-contexts and how these relations and dynamics merge into social structures at the macro-level (Jones, Lee, \& Lee, 2020). If researchers do not consider cross-level interactions, they risk examining micro-level practices with little importance further than the direct context (Haack et al., 2020).

Additionally, theorizing several layers makes otherwise multifaceted and theoretical macro-level concepts like institutional logics more concrete and quantifiable (Haack et al., 2020). Explaining microfoundations entails an analysis of various levels and of the relations across these levels, and more importantly, microfoundations need a description of the interdependence of various levels of analysis and therefore a concern for mechanisms i.e. 
micro, meso, and macro-levels (Tolbert \& Zucker, 2020). While not excluding the presence of pure macro-level mechanisms, microfoundational studies recognize the importance of the micro-level and relies on micro-level theorizing to explicate modifications and/or heterogeneity at more macro-levels (Haack et al., 2020). Unsurprisingly, the choice for highlighting more micro-levels and micro mechanisms has to be directed by theory instead of by perception, belief, or the usual research methods in a particular community (Tolbert \& Zucker, 2020).

Papers of microfoundations in institutional theory are disposed to claim that institutions are endorsed, although not inevitably created or reformed, by individual actors that may transfer institutions (Scott, 2008). Nevertheless, while institutional theorists have highlighted that micro-level entities, including individual actors, are institutional structures that are shaped or even determined by responsibilities, roles, models of actorhood, and behavioural writings (Meyer \& Jepperson, 2000). Macrofoundations of institutional theory should not be taken as a rule, rather, there is a need to understand that macrofoundations and the position of social truth and externality that is intrinsic to institutions come from somewhere (Haack et al., 2020). Applying a microfoundational perception makes it clear that the institutional context is the result of, and is formed by, a process of social co-creation that includes local interactions on the ground (Haack et al., 2020). These interactions and the unexpected results they produce at more combined levels constitute a significant outcome in their own right (Furnari, 2020; Hallett \& Hawbaker, 2020). Consequently, while the macro certainly impacts the micro, the micro also assists in illuminating the source and effects of the macro (Lizardo \& Limited., 2020).

One of the most challenging complications of multi-level hypothesizing in institutional theory is the transformation of micro-level practices into macro-level institutional results (Bitektine \& Haack, 2015). So, what occurs at the meso-level between micro-level activities 
and macro-level change in legitimacy helps facilitate the understanding of micro-to-macro conversion (Jepperson \& Meyer, 2011). By definition, micro-level is the level of individuals in a certain society, meso-level is the level of firms operating in a particular society, and macrolevel is the level of the society entailing factors like culture, law, politics, and social norms that impact all firms and individuals in a particular country/region or society (Zhai \& Su, 2019).

Microfoundational studies are vital because the understanding of how communication, cognition, and behaviour at micro-levels influence and are influenced by higher-level structures permits researchers to develop a better understanding of diversity in institutional results, and of the conditions under which institutions continue or vary (Powell, 2020; Zucker \& Schilke, 2020). In this outlook, microfoundations are indeed essential for institutional theory, as they simplify the development of better theory (Haack et al., 2020). Microfoundations, if assumed as a forefront of levels of analysis and micro-mechanisms, can increase the strength and descriptive power of institutional studies (Haack et al., 2020).

\subsection{Institutional Theory}

MNCs face many challenges to implement CSR because they have to fulfill the needs of different stakeholders in host countries to gain external legitimacy, other than conforming to the headquarters' requirements for CSR initiatives to gain internal legitimacy (Yang \& Rivers, 2009). There are enough proofs and studies in the CSR literature to put forward the important differences in CSR management and orientations across diverse countries (Baughn et al., 2007; Bondy, Matten, \& Moon, 2004; Welford, 2005). These institutional differences and their obvious impact on diverse CSR directions cause severe dilemmas and problems to MNCs (Yang \& Rivers, 2009). From here this research needs to use institutional theory because this theory has grown to eminence as a prevalent and potent explanation for both 
individual and corporate actions (Dacin, Goodstein, \& Scott, 2002). Moreover, this theory allows the exploration of the degree to which institutions impact CSR orientations of businesses (Muthuri \& Gilbert, 2011). Even though institutional theory has been extensively used to understand the implementation of environment related rules and practices (Christmann, 2004; Sharma, 2000), it has not been used a lot in CSR research (Husted \& Allen, 2006). Hence, this research will contribute to knowledge by using the institutional theory to explain CSR practices in Lebanon.

The question of why companies practice CSR in diverse national contexts has interested corporate and society researchers (e.g. Campbell, 2006, 2007; Matten \& Moon, 2008). Institutional theory, with its lengthy and diverse convention in social sciences (Scott, 2001), has been a valuable theoretical lens for acknowledging the impacts of the institutional environment on organizations' CSR practices (Aguilera \& Jackson, 2003; Campbell, 2006, 2007). Institutional theory is that institutions are created by people, by society, and by communities to insure that things like culture, values, and norms are kept (Muthuri \& Gilbert, 2011). The institutional environments take into consideration institutions such as culture, bylaws, and social standards which impact and which are impacted by the interactions of actors in a governance system (Muthuri \& Gilbert, 2011). Institutions are considered social constructs defined as official regulations and presupposed cultural structures, rational outlines, and routine procedures of reproduction and proposes that actors are more motivated by a reason of suitability whereby behaviour is restricted and allowed by cultural structures, outlines, and routines (Campbell, 2006). Diverse social actors in the private and public sectors come across, define, and impact the institutional standards, values, and rules in the institutional environments where they operate and only when these actors adopt a common 
definition of socially responsible conduct institutionalization occurs (Muthuri \& Gilbert, 2011).

To implement and evaluate CSR, managers use institutions as they offer common sense for CSR's suitability and instrumentality, and endorse and withstand systematic behaviour that offers stability to society (Muthuri \& Gilbert, 2011). There are various institutional elements that determine CSR practices such as public and private rules, the existence of NGOs and other independent establishments that control corporate practices, associative practices among companies themselves, and structured negotiations among companies and their stakeholders (Campbell, 2007; Matten \& Moon, 2008). These institutional determinants influence the acceptance and practice of CSR, and function as promoting or tempering tools for CSR agendas (Muthuri \& Gilbert, 2011).

Scott (2001) categorized institutions into three elements; regulatory, normative, and cognitive to demonstrate how institutions can delineate the nature and the degree of CSR. Regulatory elements comprise regulations, permissions, and procedures which are likely to order socially acceptable business conduct (Muthuri \& Gilbert, 2011). The government institutes rigid rules which serve as a coercive instrument for CSR application whereas industries institute lax rules which their participants voluntarily abide by (Campbell, 2007; Marquis, Glynn, \& Davis, 2007). The capability of the governments and industry associations to control actions and impose rules where they are present is of vital significance as these institutions do not permanently impose rules successfully (Matten \& Moon, 2008).

In developing countries, governments have been blamed of rejecting to impose principles and rules or facilitating corporate rules regarding CSR as an incentive for foreign investments (Campbell, 2007; Moon \& Vogel, 2008). For example, in Kenya the government hesitated to enforce rules for fear of disheartening local investment, and such fears have 
lessened the institution and application of more rigorous rules on firms (Mwaura, 2005). Additionally, ineffective legal systems and ambiguous regulatory structures allow for dissimilar understandings and variable levels of compliance (Marquis et al., 2007). Campbell (2007) argued that in some cases companies strive to control regulators in ways to make them inclined towards the will of the company they are supposed to supervise. As a result, diverse regulatory systems can create diverse CSR practices, and it entails the active attention of all social actors to safeguard the efficacy of the regulatory institutions (Moon \& Vogel, 2008).

Normative elements are the social standards and values that delineate the right things to be done in a certain context (Marquis et al., 2007). The normative structures establish the criteria for, and inspire conformism to what is considered adequate business conduct (Campbell, 2006). Companies need to conform to society's expectations such as presenting good corporate citizenship to keep on being accepted by society (Brammer \& Millington, 2004). Normative values are established by a number of social actors comprising NGOs, the media, educational, professional, and social movement organizations, and institutional investors (Muthuri \& Gilbert, 2011). These actors establish principles for legitimate business conduct (Muthuri \& Gilbert, 2011). They authenticate CSR depending on prevailing normative structures, exercise pressure on companies to follow social customs, inspire and impact the implementation of certain structures, actions, or processes considered socially responsible (Campbell, 2007; Doh \& Guay, 2006; Matten \& Moon, 2008). For example, because there was a lack of operational regulation to protect workforces, societies, and the environment, NGOs entered the regulatory environment locally and internationally (Moon \& Vogel, 2008). Thus, firms aim to be quick to respond to their stakeholders' needs, and in return, these stakeholders convene both socio-political and rational legitimacy to companies that obey their social norms (Muthuri \& Gilbert, 2011). Institutional theory proposes that 
companies will assume society's values in order to obtain a legitimate position within their environment (Dickson, BeShears, \& Gupta, 2004). Hence, Waldman et al. (2006) argued that social cultural values will impact the development of values in companies.

Cognitive elements comprise cultural values, philosophies, and identity and include common beliefs about what makes up responsible business conduct (Muthuri \& Gilbert, 2011). Managers understand these cognitive representations and construct shared definitions of socially responsible practices (Muthuri \& Gilbert, 2011). Companies that abide by the conventional cognitive frameworks behave in a culturally acceptable manner in the institutional environments where they conduct business (Muthuri \& Gilbert, 2011). For example, as proposed by Marquis et al. (2007) companies recognize and upkeep arts as a social concern if the local society recognizes and values cultural artifacts. Peer pressures are another operational way to facilitate socially responsible actions (Muthuri \& Gilbert, 2011). Isomorphism of CSR may transpire as companies imitate the best practices of corporate leaders notwithstanding their industry (Matten \& Moon, 2008). Isomorphism can also be the outcome of the pressure applied on businesses through industry criteria and codes of ethics (Muthuri \& Gilbert, 2011). At the international level, this may work in international networks, for example, the UN Global Compact (UNGC) is intended to force institutional pressures through imitation within a learning network (Levy \& Kaplan, 2007).

Isomorphism is a procedure that obliges one unit to imitate other entities in the population that faces comparable situations (Joseph et al., 2016). Institutional isomorphism endorses companies' success and survival (Joseph et al., 2016). Deegan (2007) argued that institutional theory is similar to the legitimacy theory in understanding how companies identify and respond to fluctuating social and institutional expectations and pressures and conform with social values and customs. Legitimacy is a crucial issue in institutional theory 
and a principal concern of bigger companies (Joseph et al., 2016). These facets are considered necessary for social approval by the general public (Joseph et al., 2016). The two foundations of the legitimacy principle come from the internal corporate dynamics and external stakeholders' impact (Pellegrino \& Lodhia, 2012).

Given the degree of appropriateness of its concepts, institutional theory is an appropriate underpinning framework given the objectives of this study. The following provides an argument based on institutional theory in demonstrating its appropriateness to be the underpinning framework of this research. In spite of progression towards theoretical approaches of CSR i.e. economic, strategic, ethics-based, and stakeholder-based, there is a deficiency of attention to the context in which companies conduct business (Avetisyan \& Ferrary, 2013). Put differently, whether institutional environments influence the predisposition of companies to act in a socially responsible way is still unexplored (Avetisyan \& Ferrary, 2013). Furthermore, there are few studies related to exploring whether CSR standards correspond to comparable initiatives in diverse countries and whether CSR is the outcome of the application of the same standards in diverse countries (Maignan \& Ralston, 2002). Institutional theory is, possibly, the leading approach to understand companies (Greenwood, Oliver, Sahlin, \& Suddaby, 2008). This theory is one of the most significant theoretical currents in contemporary sociology and studies the connection between a company and its larger institutional context by concentrating on the imposed restrictions by institutional forces such as ethical, cultural, and legal confines (Avetisyan \& Ferrary, 2013). Only in recent times have institutional theorists started exploring the role of local societies (Marquis et al., 2007) and domestic business systems (Matten \& Moon, 2008) in affecting CSR.

Deegan (2009) posited that institutional theory connects organizational practices, comprising CSR activities and other accounting actions, to the values and standards of a 
society in which a company operates. This link eventually pushes a firm to a need to preserve, gain, and recapture its legitimacy (Fernando \& Lawrence, 2014). Legitimated actions and/or structures transfer to companies in an industry through coercion, imitation, and normative pressures (Fernando \& Lawrence, 2014). Through these isomorphic practices, companies adopt institutional practices (Dillard, Rigsby, \& Goodman, 2004). Voluntary commitment to CSR actions and voluntary CSR disclosure by a company are regarded as a part of institutional practice (Deegan, 2009).

Institutional theory is an entrenched theoretical perception in the fields of financial reporting, social and organizational change, accounting controls, political science, and management accounting (Gray, Owen, \& Adams, 2010). Although institutional theory intrinsically has the ability to help explicate CSR compliance by companies (Campbell, 2007), researchers have not used it much in the CSR literature (Gray et al., 2010). A small number of studies can be found where institutional theory was used to explicate CSR practice (Amran \& Siti-Nabiha, 2009; Bansal, 2005; Berrone \& Gomez-Mejia, 2009; Campbell, 2007; Rahaman, Lawrence, \& Roper, 2004). Thus, this study will contribute to knowledge as institutional theory will be used as a lens to help explain CSR practices in Lebanon.

Institutional theory evolved through different phases, each phase focusing on one level of analysis; neo-institutionalism explicates institutionalization from a macro-level perspective, institutional entrepreneurship theory explains it from a meso-level i.e. organizational-level perspective, and institutional work clarifies it from a micro-level or individual-level perspective. Sections 2.3.1, 2.3.2, and 2.3.3 provide a detailed explanation of each of these theories and clarify their role in this study. 


\subsubsection{Neo-Institutional Theory}

While in the 1950s and 1960s, studies called old institutionalism explained the role of agency in building and transforming institution, in the late 1970s and the 1980s, the main focus of the institutional theory, frequently called neo-institutional theory, was to explain the similarity of organizations within organizational fields (Lawrence, Suddaby, \& Leca, 2009). This section will therefore develop institutional theory at a macro-level by providing an explanation of neo-institutional theory and its application to CSR decisions and actions. Neoinstitutional theory proposes that companies and their strategies are intensely affected by the characteristics of the institutional context where they operate and by the heritage revealed in the cultural principles, rule, and history of a particular region or country (Doh \& Guay, 2006). Furthermore, it provides an understanding of the convergence of CSR within countries and its divergence across countries without disregarding the option of international dissemination (Kostova \& Roth, 2002). Thus, institutional theory is actually contingent on where a person is in the world or where a company is conducting business. From here, contingency theory can be also added to the discussion to clarify the choice of Lebanon as a context for this study.

Components of the contingency theory were "repackaged as neo-institutionalism" (Suddaby, 2010, p. 15). "Contingency theory is represented in institutional theory with the implicit understanding that the symbolic or institutional world is simply another variant of the environment to which the organization must adapt" (Suddaby, 2010, p. 15). The view that companies should adapt their structures to important challenges i.e. contingencies is related to the extended tradition of research on contingency theory (Johnson et al., 2008). This theory has shown that managers' perceptions of the broad business environment impact strategy (Aragon-Correa \& Sharma, 2003). Managers may understand environmental problems as 
opportunities or as threats (Sharma, 2000) and may perceive environmental pressures from different stakeholders as having stronger or weaker impacts on their environmental strategies.

Recent research has started developing a contingency theory of institutionalism that examines why companies exposed to common institutional pressures nevertheless engage in dissimilar self-regulating institutions (King \& Toffel, 2007). Hoffman (2001) posited that such decisions reveal the relations between institutional pressures and internal corporate factors like corporate culture and structure. Environmental contingency theorists believe that the rate of change, complexity, and uncertainty impacts companies to a large degree (Helmig, Spraul, \& Ingenhoff, 2016). Subsequently, performance results of CSR actions are projected to differ across dissimilar environments (Goll \& Rasheed, 2004). For example, some firms engage in CSR in order to be responsive to stakeholder pressures and thus expect to gain legitimacy among stakeholders (Helmig et al., 2016).

Neo-institutional theory emphasized how companies take on institutionalized forms of behaviour in order to increase their external and internal legitimacy (Jackson \& Apostolakou, 2010). The resultant institutional isomorphism may transpire through a range of mechanisms, for example coercive political regulation (Jackson \& Apostolakou, 2010). Even though institutions function to offer structure and stability, they go through both incremental and radical change (Scott, 2008). Therefore, an institution is a process as well, comprising the processes of institutionalization and deinstitutionalization (Scott, 2008). In general, institutionalization is defined as "the process through which a social order or pattern becomes accepted as a social "fact"”'(Avgerou, 2000, p. 236). Deinstitutionalization is defined as "the process by which the legitimacy of an established or institutionalized organizational practice erodes or discontinues" (Wahid \& Sein, 2013, p. 78). 
The external environment influences institutional change (Wahid \& Sein, 2013). Companies are not submissive to the demand of their environments but are dynamic actors adept to strategically and creatively respond to environmental pressure (Orlikowski \& Barley, 2001; Weerakkody, Dwivedi, \& Irani, 2009). Three mechanisms pressure companies to be isomorphic with or to become accustomed to the external environment: coercive, mimetic, and normative (DiMaggio \& Powell, 1983, as cited in Wahid \& Sein, 2013).

Coercive isomorphism corresponds to external factors for instance, the influence of shareholders, employees, and government policy (Fernando \& Lawrence, 2014).

Consequently, this mechanism rises due to the pressure from influential or serious stakeholders, upon whom a company depends, to change a company's institutional practices like CSR reporting (Deegan, 2009). Legitimacy is legally imposed (Scott, 2008). Coercive isomorphism generates a kind of uniformity within companies (Fernando \& Lawrence, 2014). For example, Deegan (2009) explained that an organization could be pressured to bring its corporate reporting practices in line with the demands and expectations of its influential stakeholders, while probably disregarding the expectations of its less influential stakeholders. Thus, different companies will tend to adopt the same practices, leading towards a uniformity of institutional practices, because these influential stakeholders might hold the same expectations of other companies as well (Deegan, 2009).

Mimetic isomorphism links to companies trying to imitate the practices of other companies to primarily gain competitive advantage regarding legitimacy (Fernando \& Lawrence, 2014). Mimetic isomorphism is a reaction to growing uncertainty and assumes a new action as a part of a new culture (Wahid \& Sein, 2013). Legitimacy is based on culture (Scott, 2008). Throughout time, through replication, companies turn out to be more like other each other (Wahid \& Sein, 2013). Uncertainty is one of the dominant forces which inspire 
mimicry (DiMaggio \& Powell, 1983, as cited in Fernando \& Lawrence, 2014). Unerman and Bennett (2004) provided explanations for having mimetic isomorphism. Unerman and Bennett (2004) clarified that any company which could not follow the new practices and processes implemented by other companies in the same industry would be risking the loss of their legitimacy with respect to the rest of the industry. For example, publishing CSR reports would be one of these new practices that could assist in maintaining and enhancing the organizational legitimacy (Fernando \& Lawrence, 2014).

Normative isomorphism corresponds to the pressures evolving from common values to implement certain institutional practices (Fernando \& Lawrence, 2014). Legitimacy is directed by ethical values (Scott, 2008). Normative isomorphism is related to learning and professionalization (Wahid \& Sein, 2013). When companies frequently communicate together, they learn to act or think in the same way (Teo, Wei, \& Benbasat, 2003). This similarity is a result of a professionally trained workforce who impacts the practices in the companies where they work (Boons \& Strannegard, 2000). In fact, normative isomorphism stems from the professional practices of the managers responsible of the companies; managers obtain similar training and transmit the values from this training within companies (Dufour, Teller, \& Luu, 2014).

The three isomorphic mechanisms discussed above lead companies to implement similar managerial and structural practices in their sectors, notwithstanding their actual utility or corporate efficiency (Fernando \& Lawrence, 2014). In summary, organizations are pressured by the external environment to organize and become similar (Wahid \& Sein, 2013). Nevertheless, organizations are not passive and actively react to coercion from other companies, learn from other companies by communicating, or only mimic other companies (Wahid \& Sein, 2013). Carpenter and Feroz (2001) explained that institutional theory is based 
on the principle that companies react to pressures coming from their institutional environments and assume structures and processes that are accepted by society as being the proper corporate choice.

An institutional perception on CSR proposes that companies do not only make CSR decisions based on instrumental decision-making, but that such decisions are shaped in relation to a larger social context (Jackson \& Apostolakou, 2010). For instance, actors within companies aim to comprehend the meaning of CSR by building on existing descriptions and comparing ideas to predominant norms or current practices (Humphreys \& Brown, 2008). Companies will prospectively mimic competitors, abide by or aim to escape government rule, and react to the normative understandings of stakeholders (Jackson \& Apostolakou, 2010). An acknowledgment of the institutional environments is still underdeveloped in the field of CSR research (Jackson \& Apostolakou, 2010). Thus, this research aims to fill this gap by exploring the institutional environment of CSR in Lebanon.

Legitimacy is defined by neo-institutional theorists as the extent of cultural support for a company (Beddewela \& Fairbrass, 2015). Legitimization aims to impact the questions asked by institutional actors and offer answers regarding what is considered adequate corporate practice carried out by private actors (Hamann \& Acutt, 2003). By behaving in ways to seek legitimacy, firms generally aim to guarantee and preserve access to valued resources from main institutional constituents eventually leading to the future survival of the firm (Sonpar, Pazzaglia, \& Kornijenko, 2010).

Companies may take on two key strategies to gain legitimacy: they could be passive and adapt the isomorphic pressures, as previously discussed, that arise from external institutions or they could be proactive and manage these institutional pressures by implementing certain strategies to seek legitimacy (Beddewela \& Fairbrass, 2015). By 
complying with the three external institutional pressures discussed above, companies can backed up and earn legitimacy for their actions in particular institutional environments (Beddewela \& Fairbrass, 2015). These three isomorphic mechanisms can communally provide three connected but different foundations for legitimacy which institutional actors could convene to the companies (Beddewela \& Fairbrass, 2015). Organizations can achieve legitimacy by respecting the local law via coercive isomorphism, by complying with moral norms via normative isomorphism, and/or by adopting a shared frame of reference via mimetic isomorphism (Powell \& DiMaggio, 1991).

Conventionally, most CSR models and theories recommend businesses to actively practice CSR and effectively manage external social problems (Beddewela \& Fairbrass, 2015). From this perception, organizations cannot only conform to institutional pressures to gain legitimacy; they also have to proactively create CSR actions specially directed towards building legitimacy (Beddewela \& Fairbrass, 2015). Under such conditions, legitimacy turns out to be a "cultural currency" and an "operational resource" which can assist the company to capture intermediate inputs be it economic or non-economic from external parties, and in so doing reduce its transaction costs (Boddewyn, 2012, p. 100).

Moreover, earlier studies have shown that MNCs apply managerial agency through the implementation of a series of strategies such as pursuing market leadership and pushing for regulatory change (Holtbrugge \& Berg, 2004). Some researchers also studied the implementation of CSR by subsidiaries as the adoption of managerial agency to achieve legitimacy (Fooks, Gilmore, Collin, Holden, \& Lee, 2013; Lawrence, 2010; Miller, 2008). Previous research has looked at the role of CSR in corporate behaviours that seek legitimacy (Palazzo \& Richter, 2005; Trullen \& Stevenson, 2006), but they focused on examining the external regulatory and policy environment, instead of the internal firm-level strategy setting. 
In this context, former research found that host country institutions exerted pressures on the CSR of MNCs' subsidiaries like increasing the local adaptation of their CSR (Cruz \& Boehe, 2010; Kolk, Hong, \& Van Dolen, 2010; Yang \& Rivers, 2009). Research which have examined firm-level strategies that seek legitimacy concentrated on other CSR-related activities such as environmental management actions (Bansal \& Clelland, 2004; Clemens \& Douglas, 2006), corporate governance (Judge, Douglas, \& Kutan, 2008; Mason, Kirkbride, \& Bryde, 2007; Selekler-Goksen \& Oktem, 2009), or corporate communications (Castello \& Lozano, 2011). Consequently, it is challenging to find studies that show the forms and procedures of legitimacy-seeking behaviours of MNCs' subsidiaries' who practice CSR in the form of community activities (Beddewela \& Fairbrass, 2015). This study addresses this gap by examining how MNCs operating in Lebanon make use of such approaches.

Comparative studies have extended the neo-institutional view based on the explanations that such institutional contexts are subject to differences across countries and repeatedly constitute dissimilar types of national business systems with diverse logics of economic action (Crouch, 2005; Deeg \& Jackson, 2007). An understanding of the institutional differences between geographic areas will help researchers explain the perceptions of CSR and recognize which stakeholders are perceived as legitimate actors in this organizational field (Kostova \& Roth, 2002). Moreover, neo-institutionalism explicates why concepts are institutionalized from a macro-level perspective (Schultz \& Wehmeier, 2010). Therefore, this study will contribute to literature as it explores how the CSR practices of MNCs operating in Lebanon might be affected on a macro-level by the Lebanese institutional context. 


\subsubsection{Institutional Entrepreneurship}

Over the past decades, institutional theory became one of the most important theories in organizational analysis (Walsh, Meyer, \& Shoonhoven, 2006). In the 1980s, its focus was on the mimetic practice whereby companies ultimately adopt the same type of behaviour within a domain of action (Leca, Battilana, \& Boxenbaum, 2009). Over the past decade, its emphasis has moved to concerns of institutional change and agency (Dacin et al., 2002). One dominant notion in this line of research is the concept of institutional entrepreneurship primarily presented by DiMaggio (1988) as an approach to reintroduce the agency of actors to institutional analysis. This section will reference institutional theory at a meso-level by providing an explanation of institutional entrepreneurship and its application to CSR decisions and actions. Although early institutional research accounted for the agency of actors, succeeding institutional research was inclined to ignore actors' role in institutional change (Leca et al., 2009). Based on this latter research, institutional change was initiated by exogenous shocks that defied present institutions in a field of action (Leca et al., 2009). The concept of institutional entrepreneurship appeared as a potential new research path to offer endogenous clarifications for institutional change (Leca et al., 2009).

The rise of the institutional entrepreneurship theory has considerably shed light on the disturbing question within the neo-institutional theory concerning the methods in which new organizations arise (Avetisyan \& Ferrary, 2013). The institutional entrepreneurship theory explicates how companies change or create institutions such as voluntary CSR (Peters, Hofstetter, \& Hoffmann, 2011). Companies are not passive; they are active and they could change, revise, or resist institutions (Wahid \& Sein, 2013). DiMaggio (1988) stated that new institutions emerge when organized actors with adequate resources identify an opportunity to fulfill interests that they highly value. Therefore, the connections between agency, interests, 
and institutions are fundamental to institutional entrepreneurship (Avetisyan \& Ferrary, 2013). DiMaggio (1988) revived the scopes of old institutionalism that had less emphasis in institutional research led in the 1980s.

Institutional entrepreneurs are actors who control resources to create new or change existing institutions (Garud, Hardy, \& Maguire, 2007; Maguire, Hardy, \& Lawrence, 2004). They can be companies or groups of companies (Garud, Jain, \& Kumaraswamy, 2002; Greenwood, Suddaby, \& Hinings, 2002), or persons or groups of persons (Maguire et al., 2004). Moreover, institutional entrepreneurship theory explains the institution of concepts from a meso-level i.e. organizational-level perspective (Shaw, Kontos, Martin, \& Victor, 2017). Thus, when a firm-level analysis of CSR institution is conducted in this study, institutional entrepreneurs are considered organizations i.e. the MNCs operating in Lebanon.

Institutional entrepreneurs generate an entire new system of meaning that links together the functioning of different sets of institutions (Garud et al., 2002). In order to seize opportunities and actively change institutional demand, they incorporate their institutional environment in their strategic considerations (Durand \& McGuire, 2005; George, Chattopadhyay, Sitkin, \& Barden, 2006; Zimmerman \& Zeitz, 2002). When institutional entrepreneurs create new institutions, a divided social situation with a series of opposing institutional actions, opposing authority structures, and social networks may arise (N. J. Peters et al., 2011). These can be categorized into supporters of the institutional entrepreneur and opponents who defend the institutional status quo with regard to the proposed institutional change (Misangyi, Weaver, \& Elms, 2008). The institutional entrepreneur and its supporters should utilize resources to bargain for approval from more significant constituencies so that they win this competition in the institutional domain (Hargrave \& Van de Ven, 2006). 
Eisenstadt (1980) suggested that institutional entrepreneurs were considered one variable, among a group of others, that was pertinent to the process of societal change. Presenting the concept of institutional entrepreneurship in the context of institutional theory emphasizes the role of agency and actors in the processes of institutional change (Battilana, Leca, \& Boxenbaum, 2009). Battilana et al. (2009, p. 68) argued that "institutional entrepreneurs are change agents, but not all change agents are institutional entrepreneurs". Actors should satisfy two conditions to be considered institutional entrepreneurs; start deviating changes and actively take part in the application of these changes (Battilana et al., 2009).

Only actors who start deviating changes that disrupt the institutionalized model for organizing within a certain institutional context can be considered institutional entrepreneurs (Amis, Slack, \& Hinings, 2004; Battilana, 2006; D'Aunno, Succi, \& Alexander, 2000). The institutionalized model for organizing, frequently called an institutional logic, (Suddaby \& Greenwood, 2005; Thornton, 2004), is a domain's common understanding of the objectives to be followed and how they are to be followed. Changes that do not divert are lined up with the institutions in a domain, while opposing changes disrupt them (Battilana et al., 2009). Only when the changes presented are deviating from the institutional environment in which they are rooted are change agents suitable to be institutional entrepreneurs (Battilana et al., 2009). Deviating change can be introduced within the confines of a company and/or within the larger institutional context in which an actor is set in (Battilana et al., 2009). Active involvement in change efforts is the other condition for institutional entrepreneurship (Battilana et al., 2009). Actors should actively organize resources to apply change to be considered institutional entrepreneurs (Battilana et al., 2009). 
Studies on institutional entrepreneurship began to increasingly focus on emerging fields (Garud et al., 2002), even though the focus on comparatively mature fields (Greenwood et al., 2002; Lounsbury, 2002) takes place more frequently in academic papers that concentrate on institutional processes. Research on emerging fields proposes that even though members identify some degree of shared interest, comparatively little organized actions occur among them (Avetisyan \& Ferrary, 2013). In institutional theory literature, CSR is assumed to be an emerging field going through fast expansion and one missing a well-structured alignment of actors i.e. stakeholders (Avetisyan \& Ferrary, 2013). The emergence of the CSR domain comes from the growing international interest in this notion and the unexpected appearance of CSR rating agencies in the late 1980s (Avetisyan \& Ferrary, 2013). The prevalence of new practices may be challenging in emerging domains because there may be no prominent companies to imitate or a commonly mutual agreement as to what is suitable practice for actors in the domain (Avetisyan \& Ferrary, 2013).

Maguire et al. (2004) posited that features of emerging domain make them a significant field for the study of institutional entrepreneurship for numerous reasons. First, ambiguity in the institutional order offers a great opportunity for institutional entrepreneurs to be opportunistic and strategic (DiMaggio, 1988). Second, emerging domains promise extensive rewards for success because their structuring will offer some actors major advantages (Garud et al., 2002). Third, emerging domains present diverse levels of challenges than those caused by more structured domains (Avetisyan \& Ferrary, 2013).

Diverse perspectives have been taken to examine and explicate corporate practices related to CSR and sustainability (N. J. Peters et al., 2011). Institutional theorists claim that practicing CSR guarantees a company’s legitimacy (Bansal \& Roth, 2000). Companies that abide by social norms and standards and legislation have higher chances of long-term survival 
(DiMaggio \& Powell, 1983) and answer the demands of the company's strategic stakeholders (Sharma \& Henriques, 2005). They escape public protest campaigns, charges, penalties (Videras \& Alberini, 2000), or collective sanctions resulting from accidents related to the supply-chain or industry (King \& Toffel, 2007). Nonetheless, even when firm rules are not established, companies can be encouraged to adhere to certain environmental principles (N. J. Peters et al., 2011). In this situation, industry self-regulation may appear (Campbell, 2006) to avoid stakeholders like the media and NGOs revealing faulty corporate environmental practices. In this event, poor environmental performance such as not abiding by industry selfregulation is transformed into reduced legitimacy that is characterized by fines, negative public image, poorer consumer goodwill, and eventually, inferior corporate value (Dowell, Hart, \& Yeung, 2000; Godfrey, 2005).

Researchers of institutional entrepreneurship build on results from institutional theory and study how companies affect the institution of generally applied institutional demands and practices like regulations, norms, and principles (N. J. Peters et al., 2011). Fundamental ideas of institutional entrepreneurship have been associated to the domain of CSR (N. J. Peters et al., 2011).While being attentive to the disciplinary influence of institutional pressures, a company may proactively recognize CSR issues and shape or reshape the central nature of how public rules, norms, and principles for social and environmental performance are defined (Buysse \& Verbeke, 2003; Oliver \& Holzinger, 2008).

One important way to impact institutional demands is to inaugurate voluntary sustainability activities in the form of codes of conduct, rules, management systems, forums, programs, or certification schemes (Hamprecht, 2006). These voluntary sustainability activities may assist a group of companies to overcome the social or environmental problems that they usually face (Barnett \& King, 2008), restrict the risk of undesirable laws, principles, 
or social norms being externally enforced (King \& Lenox, 2000), and assist competing companies to raise the institutional expectations that they face (Aragon-Correa \& Sharma, 2003). As such, voluntary sustainability activities aid companies in controlling possible competitive disadvantages caused by the ultimately greater costs of socially and environmentally initiatives (Zadek, 2004), inspire environmental supervisory bodies to inspect more deeply into competitors' actions (Bansal \& Clelland, 2004), pressurize competitors to also finance comparable CSR strategies (McWilliams, Van Fleet, \& Cory, 2002), and form market entry barriers preventing socially or environmentally irresponsible supply chains from supplying the market (N. J. Peters et al., 2011).

\subsubsection{Institutional Work and Practice Theory}

There has long been a prominence in research in the field of institutional orientations of organizational studies focusing on the justification of corporate resemblance based on institutional circumstances (Lawrence \& Suddaby, 2006). However, over the past ten to fifteen years a new focus appeared in institutional research on acknowledging the role of actors in implementing, changing, and maintaining institutions and sectors (Lawrence \& Suddaby, 2006). Institutional studies have recognized the capability of actors, mainly those with some important strategic resources or other types of power, to have substantial influences on the development of institutions and fields (Greenwood et al., 2002) comprising both institutional change and deinstitutionalization (Ahmadjian \& Robinson, 2001). From here, Lawrence and Suddaby (2006, p. 215) came up with the concept of institutional work which they defined as the "purposive action of individuals and organizations aimed at creating, maintaining and disrupting institutions". The practice theory is also discussed as part of institutional work in this study because it is what happens when institutions are created, maintained, and disrupted (Lawrence \& Suddaby, 2006). The practice theory is more like a belief of what happens and 
how people do things is dependent on their immediate environment (Schatzki, 2005) as shown in the previous sections.

Early research on institutional theory underlined the circular relationship between individual activities and procedures of institutionalization (Empson et al., 2013). Succeeding expressions of neo-institutional theory highlighted the limiting influence of institutions on individual activities and, in the course, failed to take into account the individual as a main agent of change (Empson et al., 2013). Hence, the theory of institutional work provides a chance to improve the micro-sociological bases of institutional theory by investigating individuals in institutions, their work actions, their social relations, and meaning creating procedures (Hallett, 2010), to better understand "the lived experience of organizational actors, especially the connection between this lived experience and the institutions that structure and are structured by it" (Lawrence, Suddaby, \& Leca, 2011, p. 52). Lawrence et al. (2011) call for a comprehensive empirical examination of the micro-dynamics of institutional work, concentrating on the activities of individual actors within companies as they practice institutional work. They also call for investigating how the accrued activities and relations of individual actors within an institutional environment bring about creating, maintaining, and disrupting institutions (Lawrence et al., 2011).

By looking at the history and development of institutional theory in the previous sections, two key tensions can be noted regarding the issue of agency; one relating to the degree of agency belonging to corporate actors, and one relating to the extent to which a practice approach can effectively define the connection between agency and institutions (Lawrence et al., 2009). Lawrence and Suddaby (2006) introduced the institutional work theory in order to help get over these tensions by outlining an area of institutional research that focuses on the middle ground of agency and links the practice theory's insights with 
institutionalists' classic concerns for social change and collective action. Institutional work is founded on an increasing awareness of institutions as outcomes of human action and reaction, driven by both distinctive personal interests and programs for institutional change or conservation (Lawrence et al., 2009). The aim of the institutional work theory is that, through thorough analyses of these multifaceted incentives, efforts, and interests, institutional research will be capable of better understanding the general patterns of intent and capability to create, maintain, and change institutions (Lawrence et al., 2009).

Through institutional work, Lawrence and Suddaby (2006) aimed to offer a starting point for comprehending the relations between a wide series of studies and to pinpoint some important gaps in understanding how institutions and actors interrelate together. Most dominant in their definition of institutional work is its direction (Lawrence et al., 2009). If one believes that institutions and action exist in a recurrent relationship (Phillips, Lawrence, \& Hardy, 2004) in which institutions offer models for action, regulative instruments that impose those models, and action influences those models and regulative instruments, then the study of institutional work is mainly concerned with the direction from action to institutions. The theory of institutional work does not reject nor disregard the influence of institutions on action, and certainly those influences are vital to comprehending the nature of institutional work, but its analytical emphasis in the study of institutional work is on how action and actors influence institutions, which is nothing like most institutional studies of companies (Lawrence et al., 2009).

Lawrence and Suddaby (2006) were interested in creating an institutionally situated understanding of the influence of actions on institutions. This led them to claim that the study of institutional work should be concerned with three main elements: (1) it "would highlight the awareness, skill and reflexivity of individual and collective actors" (p. 219); (2) it would offer "an understanding of institutions as constituted in the more and less conscious action of 
individual and collective actors" (p. 219); and (3) "a practice perspective on institutional work suggests that we cannot step outside of action as practice - even action which is aimed at changing the institutional order of an organizational field occurs within sets of institutionalized rules" (p. 220).

Moreover, the emerging literature on institutional work is inclined towards prolonging the inherent supposition that institutional work is focused on one subject i.e. normally the collective unit of the institutional employee, one object i.e. the institution, and one type of institutional work i.e. creating, maintaining, or disrupting (Empson et al., 2013). Besides, the notion of institutional work has yet to be systematically applied to several experimental contexts (Empson et al., 2013). Noteworthy exceptions comprise Boxenbaum and Pedersen (2009), Hirsch and Bermiss (2009), Trank and Washington (2009), Jarzabkowski, Matthiesen, and Van de Ven (2009), Zietsma and McKnight (2009), and Zilber (2009). Still, the majority of these studies concentrate on one type of institutional work i.e. either creating or maintaining institutions. The only studies that inspect the simultaneous manifestation of several types of institutional work i.e. creating, maintaining, and disrupting are the ones conducted by Hirsch and Bermiss (2009) and Jarzabkowski et al. (2009). However, their examination fails to consider the micro-level emphasis encouraged by Lawrence et al. (2011). Therefore, this study will fill this gap in literature as it simultaneously explains the different types of institutional work by adopting a micro-level analysis i.e. individual managers and explores institutional work in a new context i.e. Lebanon which remains underexplored. Besides, Amaeshi et al. (2016) posited that the practices of CSR that go beyond philanthropy include institutional works. Thus, this research will be examining institutional work in CSR.

Lawrence and Suddaby (2006) classified the different types of institutional work into three categories; creating, maintaining, and disrupting. The practices related to creating institutions represent the category of institutional work which is primarily built on the 
institutional entrepreneurship theory (DiMaggio, 1988; Eisenstadt, 1980), to examine the types of actors who try to create new institutions, the circumstances under which they do so, and the strategies they utilize (Garud et al., 2002; Greenwood et al., 2002; Hargadon \& Douglas, 2001; Lounsbury, 2001; Maguire et al., 2004). Lawrence and Suddaby (2006) recognized ten forms of institutional work related to creating institutions, which were divided approximately into three types: openly political work in which actors reform rules, limits, and property rights that delineate the right to use material resources; actions in which actors' convictions are reshaped; and actions intended to change abstract classifications in which the confines of meaning systems are changed.

The second category of institutional work that Lawrence and Suddaby (2006) suggested, maintaining institutions, has comparatively received slight theoretical or empirical attention. Even though institutions are regularly defined as phenomena which are selfreplicating, either due to their taken-for-granted status (Phillips \& Malhotra, 2008; Scott, 2001) or due to their connection to the regulative mechanisms which make sure of their survival (Lawrence, Winn, \& Jennings, 2001), Lawrence and Suddaby (2006) argued that the institutional work of maintaining institutions is both essential and ignored. Even powerful institutions need maintenance to stay appropriate and operational (Lawrence et al., 2009). Lawrence and Suddaby (2006) found six types of institutional work; three that mainly tackle the maintenance of institutions by guaranteeing obedience to rules systems and three that concentrate efforts to maintain institutions on replicating present customs and belief systems.

Lawrence and Suddaby’s (2006) third category of institutional work, disrupting institutions, has been the focus of institutional concern since the early research of Selznick (1949), and gained noteworthy attention after Oliver's (1992) argument of deinstitutionalization. However, even with this long history, the practices related to actors trying to weaken institutional arrangements are not well documented outside the indirect 
practices related to creating institutions (Lawrence et al., 2009). In their survey of empirical work in this domain, Lawrence et al. (2009) did not really find a lot in terms of actual descriptions of actors disrupting institutions; what they found could be categorized in three forms: "work in which state and non-state actors worked through state apparatus to disconnect rewards and sanctions from some sets of practices, technologies or rules", efforts to "disrupt institutions by disassociating the practice, rule or technology from its moral foundation", and "undermining core assumptions and beliefs" which make institutions stable (Lawrence \& Suddaby, 2006, pp. 235-237).

Creating institutions includes inaugurating regulations and fashioning rewards and endorsements that impose those regulations (Empson et al., 2013). Types of institutional work included in the creating institutions table comprise: advocacy, defining, vesting, constructing identities, changing normative associations, constructing normative networks, mimicry, theorizing, and educating (Lawrence \& Suddaby, 2006). Advocacy means mobilizing the support of regulatory and political entities through direct and measured methods of social persuasion (Galvin, 2002). Lawrence and Suddaby (2006) explicated that defining is the creation of rule systems that convene identity or position, delineate participation confines or form status hierarchies within a domain. Vesting is the establishment of rule structures that convene property rights (Empson et al., 2013). Constructing identities is recognized as outlining the affiliation between a player and the environment in which that player works (Canning \& O’Dwyer, 2016).

Moreover, changing normative associations means reforming the links between groups of actions and the ethical and cultural grounds for those actions (Binz, Harris-Lovett, Kiparsky, Sedlak, \& Truffer, 2015). Constructing normative networks is depicted as the construction of inter-organizational relations through which actions become standardized and which create the related peer group concerning responsiveness, control, and assessment 
(Hayne \& Free, 2014). Lawrence and Suddaby (2006) explained that mimicry is the association of new activities with present sets of accepted activities, expertise, and regulations so as to facilitate implementation. In addition, theorizing is the act of developing and specifying theoretical classifications and elaborating the chains of cause and effect (Binz et al., 2015). Finally, educating is denoted as the education of actors in expertise and information essential to the sustenance of the new institution (Hayne \& Free, 2014).

Maintaining institutions includes backing-up, revamping, and reconstructing social mechanisms that guarantee obedience to institutional standards (Empson et al., 2013). The maintaining institutions table includes the following types of institutional work: enabling work, policing, deterring, valorizing and demonizing, mythologizing, and embedding and routinizing (Lawrence \& Suddaby, 2006). Enabling work means creating rules that ease, complement, and provision institutions, like creating authorizing managers or averting resources (Empson et al., 2013). Policing is a type of institutional work aiming to ensure obedience through execution, appraising, and controlling (Mena \& Suddaby, 2016). In addition, deterring is the establishment of coercive obstacles to institutional change (Hayne \& Free, 2014). Valorizing and demonizing means offering the general public positive and negative illustrations of the normative grounds of an institution (Binz et al., 2015). Lawrence and Suddaby (2006) defined mythologizing as conserving the normative foundations of an institution by producing and maintaining myths about its history. Finally, embedding and routinizing is considered as the active infusion of the normative bases of an institution into the contributors' daily routines and corporate practices (Hayne \& Free, 2014).

Empson et al. (2013) explained that disrupting institutions includes criticizing and destabilizing the instruments that lead participants to abide by institutions. Types of institutional work included in the disrupting institutions table contain: disconnecting sanctions, disassociating moral foundations, and undermining assumptions and beliefs (Lawrence \& 
Suddaby, 2006). Disconnecting sanctions is to work through state tools to separate rewards and permissions from certain sets of practices, regulations, or technologies (Hayne \& Free, 2014). Disassociating moral foundations means separating the practice, technology, or regulation from its ethical basis as suitable within a particular cultural setting (Fuenfschilling \& Truffer, 2016). Finally, Lawrence and Suddaby (2006) explained that undermining assumptions and beliefs is lessening the observed risks of modernism and diversity by impairing primary conventions and beliefs. Classifying these types of institutional work into three phases proposes that institutional change occurs in a direct way and that institutions are established to substitute others as they falloff (Empson et al., 2013). Nevertheless, earlier studies into corporate models suggest that reality may be more multifaceted and disordered (Empson et al., 2013) which is what is shown in this study.

Generally, fields of research concentrating on macro-level concerns have advanced without giving an important role to their microfoundations, which are embedded in individual action and interactions (Foss, 2011). CSR is a field that initially concentrated on the institutional level, while in the previous few decades it has greatly concentrated on the organizational-level of analysis (Lee, 2008). The lack of micro-level studies on CSR is a trend found in other domains and areas of research (Aguinis \& Glavas, 2012). For instance, macro theories initially dominated the economics field, and it is only in recent times that behavioural theory has been progressively discovered to comprehend fundamental processes (Akerlof, 2002). In institutional theory, nearly two decades ago researchers called for a comprehension of microfoundations (DiMaggio \& Powell, 1991; Zucker, 1991), however it was not until recently that micro-level practices have been examined as an approach to understand macrolevel actions and relations (Powell \& Colyvas, 2008). In the same way, in strategy, micro-level practices have only in recent times been examined (Foss, 2011; Powell, Lovallo, \& Fox, 2011). 
The knowledge gaps concerning fundamental processes and deficient work at the individual-level of analysis direct research that, based on the strategic management literature (Foss, 2011), this study labels microfoundations of CSR i.e. foundations of CSR that are built on individual action and interactions. Moreover, institutional work theory explains the institution of concepts from a micro-level i.e. individual-level perspective (Lawrence \& Suddaby, 2006). Thus, when an individual-level analysis of CSR institution is conducted in this study, the microfoundations of CSR are examined to explain the triggers and the role of individual managers in conducting institutional work to establish CSR in Lebanon.

\subsection{Summary of Chapter}

With the beginning of globalization, companies in diverse contexts have encountered the concept of CSR and are pressured to assume CSR practices (Jamali, Sidani, et al., 2009). However, in light of vastly divergent national cultures and institutional actualities, diverse discrepancies in CSR acknowledgment and exercise remain prominent in dissimilar contexts, with the dominance of traditional concepts of CSR still extensively conveyed in different countries (e.g. Deniz \& Suarez, 2005; Quazi \& O'Brien, 2000). Several MNCs have made important contributions to the expansion and influence of globalization (Forney, 2018). Western attitudes to business ethics in relation to globalization require examination because there may be restrictions to the reproduction of western attitudes in developing countries (Forney, 2018). Rules and governance vary across these countries, and acknowledging these variations can help in developing strategic rules to upkeep efforts relating to ethical work (Forney, 2018). In fact, Morrison (2015) explained that ethical values are relative to the particular social context where people live and hence ethics' expectations differ across cultures and countries. 
Moreover, researchers' and practitioners' interest in CSR is on the rise in terms of theory and practice (Angus-Leppan, Metcalf, \& Benn, 2010). For example, a contemporary trend in CSR research is to explore the institutional drivers for CSR (e.g. Campbell, 2006; Waddock, 2008) with CSR progressively perceived as an outcome of growing institutional forces (Angus-Leppan et al., 2010). More particularly, leaders i.e. managers may act as role models for what is believed to be right and may therefore form their employees' beliefs about the conduct of others (Gachter \& Renner, 2018). There is an increasing call for more empirical research regarding the role of business leaders in creating and applying CSR initiatives (Siegel, 2009). Thus, this study will answer this call by examining drivers of CSR in Lebanon and exploring how CSR is institutionalized in this developing country context by looking at the individual managers in MNCs operating in Lebanon. The institutional theory and more particularly the institutional work and practice theory underpin this research.

CSR has a contextual nature which is affected by the external environment where the company conducts business (Azmat \& Samaratunge, 2009) and the internal environment of the company itself (Brammer et al., 2007; Mehrdost, 2012; Rayton, 2006). More particularly, Munro (2013) found that there are considerable variations in how people understand CSR amongst different national cultures in the Middle East and Africa region. Therefore, there is a need to include cultural dissimilarities and the views of diverse nationality groups in planning CSR (Munro, 2013). There is a lot of variability in the Middle East because of historic reasons (Myhill, 2006). First, the Lebanese are Phoenicians they are not Arabs (Kaufman, 2004). Second, the role of colonialism; lots of Arab countries were colonized by British forces whereas Lebanon was under the French mandate (Jamali, 2007). Moreover, there are different types of ethnic groups in Lebanon that makes it unique (Jamali \& Neville, 2011). Thus, this study will adopt Lebanon as a case study to explore CSR as it is different from other Middle Eastern countries. The next chapter will provide a thorough understanding of Lebanon as it 
offers detailed information regarding its history and its political, legal, economic, technological, and socio-cultural environments. 


\subsection{Chapter Three - Lebanon as a Case Study}

\subsection{Introduction}

Jawad (2009) explained that Lebanon represents a remarkable case for research because it has diverse religious sects and a weak government. Historically, Lebanon has stood out among other Arab countries in the area because of its liberal political and social systems, its active laissez-faire economy which has constantly been opening its borders to external trade, its comparative liberty of the media, and its highly educated population (Jawad, 2009). The Middle Eastern wars were also hosted by Lebanon because it is susceptible to international interference from both Eastern and Western countries (Jawad, 2009). For all these causes, a disagreement emerged among observers regarding the degree to which Lebanon is an exception to or a microcosm of the remaining Middle Eastern countries and predominantly the Arab countries (Jawad, 2009). In addition, Khan, Al-Maimani, and Al-Yafi (2013) posited that there is limited research on CSR in Lebanon. For all these reasons, Lebanon was selected as the context of this study to better contribute to existing literature by examining the situational-level factors that influenced the adoption and implementation of CSR in a unique Middle Eastern country.

A company's national institutional context which comprises professional, regulatory, and legal structures impacts the company's sensitivity to CSR (Thorne et al., 2017). More significantly, the nature of relevant countries' institutional background may encompass crossnational dissimilarities in CSR rising from cross-national differences in stakeholder pressures (Thorne et al., 2017). Moreover, a country's institutional context consists of formal and informal restrictions on individual and corporate behaviour (Furrer et al., 2010). Formal restrictions comprise political, legal, and economic regulations and contracts, while informal restrictions comprise the codes of ethics, standards of behaviour, and agreements that are 
rooted in a country's culture and beliefs (Furrer et al., 2010). Thus, it is important to understand a country's characteristics to have a better understanding of corporate behaviour, more particularly CSR practices.

This chapter will provide an overview of Lebanon where this study was conducted. Section 3.2 will delineate Lebanon's political and legal environments. The next section 3.3 will provide an explanation of its economic and technological environments. Finally, section 3.4 will explicate Lebanon's socio-cultural environment. Appendix G offers a detailed history of Lebanon, its geography, and its competitiveness. As discussed in chapter two, there are three types of institutions that influence corporate behaviour; regulatory, normative, and cognitive (Scott, 2001). Subsequently, Lebanon's political, legal, economic, and technological environments will highlight the regulatory institutions of Lebanon and its socio-cultural environment will show the normative and cognitive institutions that characterize the Lebanese society.

\subsection{Political and Legal}

Lebanon's official name is the Republic of Lebanon characterized by a parliamentary republic form of state (The Economist Intelligence Unit, 2007). Lebanon has a centralized, multi-party, and multi-religious government (Jamali \& Neville, 2011). Its political system is quasi-democratic and built on power sharing amongst the nation's religious groups with representatives of the three biggest religious sects creating a governing "troika" (Jamali, 2010, p. 190). Grouping individuals by religion plays a dangerous role in Lebanon's social and political life and has intensified Lebanon's supreme tenacious and hostile conflicts (Jamali \& Neville, 2011). Lebanon's unstable multi-religious groups have influenced power division in the political system and this was also replicated in the dissemination of numerous civil service professions (Dirani, 2007). Within this established non-meritocracy, it is important to identify 
a vital cultural element which invades political-economic life; "Wasta" which refers to intermediary in Arabic (Jawad, 2002, p. 322). Wasta successfully transforms into exceptional privileges in circumstances where a person intervenes on behalf of another one to benefit the latter and underlines the role of personal connections in decision-making (Jawad, 2002).

Political parties in Lebanon are likely fragile and sectarian-based (The Economist Intelligence Unit, 2019). The alliance formed on March 14, 2005 is currently controlled by the Future Movement which includes the Sunni along with the Lebanese Forces which comprise some Christians in loose coalition with the Progressive Socialist Party i.e. some Druze citizens, and the Phalange i.e. some Christians (The Economist Intelligence Unit, 2019). The alliance formed on March 8, 2005 encompasses Hizbullah i.e. Shi'i, Amal also including Shi'i citizens, and the Free Patriotic Movement comprising some Christians (The Economist Intelligence Unit, 2019). Lebanon's political system is one of the most complex systems in the Middle East, based on the principle that a cautious equilibrium in all facets of political life should be sustained among all religious sects (Choucair, 2006). Although this religious system has saved Lebanon from the dictatorship experienced by several Arab governments in the twentieth century, ironically it has also prohibited the conversion to an actual democratic government (Choucair, 2006). Nor has the religious system reduced the sectarian conflict it was intended to escape (Choucair, 2006).

Sectarianism is highly established in Lebanon where citizens are mostly loyal to their religion with each of the eighteen religious groups backing up its common interests at the advantage of the country's larger interest (Dagher, 2000; Khalaf, 2002; Traboulsi, 2007). Sectarian pressures in Lebanon go back the 1840s, when the fight among the Ottomans, who suggested their own type of modern reform, and the growing European powers eventually devastated the nation's internal stability (Makdisi, 2000). Confessionalism was established in 
1943 when the National Pact, an unwritten agreement after the independence, distributed political positions along sectarian lines (Dabbous, Nasser, \& Dabbous, 2010). Confessionalism is a system of authority where political power is distributed over several groups, be it ethnic or religious, according to their stake of the population (Nassif, 2014). Laws relating to elections and personal status were also outlined by sectarianism (Makdisi, 2000). Confessionalism offered an insubstantial equilibrium but as the demographics of religious sects reformed, sectarian leaders and their overseas supporters became progressively disappointed with the distribution agreements (Dabbous et al., 2010).

Political leaders have long worked to maximize their efforts and coalitions, while disregarding significant problems like the need to develop the economy, to reform the administration, and to enhance public responsibility and the rule of law (Salamey, 2009). This also fortified corruption, benefaction, negligence, and favouritism in the political and administrative fields (Makdisi \& El-Khalil, 2013). Additionally, leader bargaining hindered decision-making and spoiled the merit system in the administrative, political, and military sectors (Makdisi \& El-Khalil, 2013). Social inequalities amplified, natural resources and environmental problems are completely abused, rural and urban plans do not exist, and corruption is prevalent (Makdisi, 2004). The state authorities were initially, as they claimed, concerned about safeguarding national security and alleviating the political system (Makdisi, 2004).

Lebanon adopts the universal direct suffrage over the age of twenty-one electoral system (The Economist Intelligence Unit, 2019). The constitution necessitates that the one hundred and twenty-eight seats in parliament be equally distributed among Christian and Muslim candidates (Choucair, 2006). The seats given to each religion are further split up between different sects based on their hypothetical stakes of the population (Choucair, 2006). 
On October 31, 2016 the parliament members designated Michel Aoun for a six-year presidential tenure (The Economist Intelligence Unit, 2019). According to The Economist Intelligence Unit (2019) the civil war in Syria and Iran's ambitions for the region will have serious sectarian, security, and economic ramifications on Lebanon and political uncertainty will continue. Even though the new government was finally created in January 2019, policymaking will be vulnerable to sectarian pressures and regional conflicts (The Economist Intelligence Unit, 2019).

The legal system in Lebanon is based on the 1926 constitution with modifications integrated in 1990, the Civil Procedure Code, the Criminal Procedure Code, and the Penal Code (The Economist Intelligence Unit, 2019). The Constitution and the laws under it secure the private ownership of property, the free movement of money and currencies in and out the nation, and the freedom of contract between entities on condition that these contracts do not breach public rule (Ministry of Finance, 2012). The Lebanese civil law is generally founded on the Code of Obligations and Contracts, which is based on the French Civil Code and was transmitted in 1932, and the Land Ownership Law (Ministry of Finance, 2010). Other main laws include the Commercial Code publicized in 1942, the Code of Money and Credit disseminated in 1963, and the corresponding jurisdictive decrees dispensed in 1967 regarding commercial agency representation, stock exchange, limited liability businesses, business concerns, and the New Code of Civil Procedure transmitted in 1983 (Ministry of Finance, 2012).

The private sector in Lebanon is restrained by obsolete legal and institutional governance structure, with a restricted indication presented proposing substantial room for progress in Lebanon's equity market and regulatory capability and implementation (Jamali, Safieddine, \& Rabbath, 2008). For example, the National Payment System in Lebanon is still 
constrained by an obsolete regulatory and legal structure, which does not effectively safeguard the operations of critical payment systems such as finality and collateral rights (World Bank, 2016). Besides, in countries like Lebanon, where most of the companies are for-profit or notfor-profit with restricted community representation, and where the legal system is weak regarding misconduct, pressures for good governance might be less emphasized (Jamali, Hallal, \& Abdallah, 2010). In addition, the Lebanese government did not yet establish any CSR laws and does not provide any incentives to encourage firms to practice CSR (Jamali \& Neville, 2011).

Moreover, it is well recognized that Lebanese women have constantly encountered a discriminatory legal environment regarding laws comprising inheritance, marriage, children custody, and citizenship rights (Jamali, Abdallah, et al., 2010). These biased actions directly and indirectly and intentionally or unintentionally invade the workplace which consecutively demoralize women as they take on lower expectations and power position (Jamali, Abdallah, et al., 2010). This consecutively replicates the complex interaction between single expectations and ambitions, corporate practices, and macro-national arrangements, which jointly shape forms of power equality and advantage within occupational settings (Syed \& Murray, 2009). Besides, several macro-level limitations were recognized comprising absence of government support, severe economic recession and stagnation, and legal types of restrictions pertaining to for instance extensive government procedures, proposing the prominence of structural barriers to women progression in the Lebanese economy (Jamali, 2009).

This section provided an overview of the political and legal frameworks of Lebanon to help unfold the regulatory institutions in this study and their impact on corporate behaviour. For example, CSR related laws are nonexistent in Lebanon and sectarianism is highly 
prevalent in the Lebanese society affecting people's mentality and behaviours. Thus, these situational factors will allow the researcher to better explain how and why CSR decisions are made in a certain way in Lebanon.

\subsection{Economy and Technology}

Since the inauguration of modern Lebanon, sectarianism became an informal system guaranteeing the continued existence of religious groups in an intensely laissez-faire economy (Khalaf, 2002; Traboulsi, 2007). The Lebanese economy is small, open, and mostly based on services (Jamali, 2010). The Lebanese pound or lira is the country's official currency with an average exchange rate of LBP1,508 for USD1 in 2018 (Sharaiha \& Ibrahim, 2008; The Economist Intelligence Unit, 2019). Lebanon has a liberal economy, where the government's role is restricted to framing the legal, institutional, and infrastructural background essential for economic development (Jawad, 2002).

After the war, Lebanese governments have pursued monetary stabilization policies aimed at decreasing inflation rates and reestablishing trust in the national currency (Jamali et al., 2008). Nevertheless, current governments have to advance their stabilization policy to fund the increasing budget deficit (Jamali \& Keshishian, 2009). The core economic challenge encountered by succeeding governments in latest years has indeed been huge repetitive budget deficits remaining above five percent of the gross domestic product (GDP) in 2019 (Lebanon Banking \& Financial Services Report - Q2 2019, 2019) and a public debt-to-GDP ratio of one hundred and fifty three percent in October 2018 (Emerging Markets Monitor, 2019).

Economic development will be moderate in 2019-2023 with a huge fiscal deficit of 7.7 percent of GDP and a current account deficit of 20.8 percent of GDP (Emerging Markets Monitor, 2019). Security concerns and conflict will precede economic and political reform (The Economist Intelligence Unit, 2019). 
Efforts to reestablish fiscal balance have mostly been diluted by the high costs and expenses assigned to nourishing the postwar restoration program (Jamali et al., 2008). Fiscal problems have consequently tended to govern policy making after the war, restraining the government's opportunity to assume more growth-oriented actions and heightening the need for larger dependence on the private sector to stimulate growth, create employment, and increase the standard of living (Jamali et al., 2008). The Lebanese private sector has conventionally been the main engine of growth in a moderately open and liberal economy, and its flexibility has been raised after the war to lead the comeback of Lebanon as a leading regional hub for trade and services (Jamali \& Keshishian, 2009). The private sector is exploiting its conventional strength in the banking and services sectors and growing to the challenge, but the limitations enforced by financial macroeconomic actualities are genuine and the range for private sector operation appears restricted at best (Jamali \& Keshishian, 2009).

Lebanon's total population is estimated to be 6.1 million including Syrians and Palestinians living in refugee camps (The Economist Intelligence Unit, 2019). Lebanon's GDP per capita is USD11,308.9 (World Economic Forum, 2017). According to the World Bank (2019), Lebanon's GDP is USD53.58 billion, foreign direct investment is USD2,559 million, poverty rate is 27.4 percent, life expectancy at birth is 80 years, primary school enrollment is 93.4 percent, and secondary school enrollment is 63 percent. The time to start a business in Lebanon is fifteen days with domestic credit provided by the financial sector accounting for 198.3 percent of GDP and tax revenue of 15.2 percent of GDP (World Bank, 2019).

Lebanon has the lowest import tariffs within the Middle East and North African region and benefits from advantageous access for its exports to international markets (Bankmed, 2016). However, during the past five years, the total trade in Lebanon has been suffering from an increased deficit (Bankmed, 2016). Lebanon's trade has been mostly affected by the Syrian 
war since 2011 as the majority of its exports and imports trade routes were closed (Bankmed, 2016). Trade deficit was USD20.3 billion at the end of 2017 (www.investinlebanon.gov.lb).

The four tables and figures below show Lebanon's major trading partners and import and export compositions in 2018.

Table 3.2: Lebanon's major export partners in 2018 (Source: www.investinlebanon.gov.lb)

\begin{tabular}{|c|c|c|}
\hline Country & $\%$ & Top Exported Products \\
\hline UAE & 15.5 & $\begin{array}{l}\text { Pearls and Precious Stones; Chemical Products; Food } \\
\text { and Beverages; Machinery and Electrical Equipment; } \\
\text { Vegetable Products }\end{array}$ \\
\hline KSA & 7.2 & $\begin{array}{l}\text { Food \& Beverages; Chemical Products; Vegetable } \\
\text { Products; Machinery and Electrical Equipment; Plastics }\end{array}$ \\
\hline Syria & 7 & $\begin{array}{l}\text { Plastics; Vegetable Products; Machinery and Electrical } \\
\text { Equipment; Chemical Products; Food and Beverages }\end{array}$ \\
\hline $\begin{array}{l}\text { South } \\
\text { Africa }\end{array}$ & 5.9 & $\begin{array}{l}\text { Pearls and Precious Stones; Vegetable Products; Pulp } \\
\text { of Wood; Plastics; Machinery and Electrical Equipment }\end{array}$ \\
\hline Iraq & 5 & $\begin{array}{l}\text { Chemical Products; Machinery and Electrical } \\
\text { Equipment; Food and Beverages; Pulp of wood; Plastics }\end{array}$ \\
\hline Qatar & 4.5 & $\begin{array}{l}\text { Food and Beverages; Vegetable Products; } \\
\text { Miscellaneous Manufactured Articles; Machinery and } \\
\text { Electrical Equipment; Chemical Products }\end{array}$ \\
\hline Switzerland & 4.4 & $\begin{array}{l}\text { Pearls and Precious Stones; Works of Arts; Textiles; } \\
\text { Food and Beverages; Pulp of Wood }\end{array}$ \\
\hline Turkey & 4.3 & $\begin{array}{l}\text { Metal Products; Chemical Products; Vegetable } \\
\text { Products; Food and Beverages; Machinery and } \\
\text { Electrical Equipment }\end{array}$ \\
\hline
\end{tabular}


Table 3.3: Lebanon's major import partners in 2018 (Source: www.investinlebanon.gov.lb)

MAIN ORIGIN OF IMPORTS (\% Share of Total Imports | 2018)

\begin{tabular}{|c|c|c|}
\hline Country & $\%$ & Top Imported Products \\
\hline China & 10.3 & $\begin{array}{l}\text { Machinery and Electrical Equipment; Textiles; Metal } \\
\text { Products; Miscellaneous Manufactures Articles; Plastics }\end{array}$ \\
\hline Greece & 8.5 & $\begin{array}{l}\text { Mineral Products, Chemical Products; Metal Products; } \\
\text { Food and Beverages; Machinery and Electrical Equipment }\end{array}$ \\
\hline Italy & 8 & $\begin{array}{l}\text { Mineral Products, Machinery and Electrical Equipment; } \\
\text { Chemical Products; Pearls and Precious Stones; Metal } \\
\text { Products }\end{array}$ \\
\hline USA & 7.2 & $\begin{array}{l}\text { Mineral Products, Vehicles and Other Transportation } \\
\text { Equipment; Chemical Products; Machinery and Electrical } \\
\text { Equipment; Optical Equipment }\end{array}$ \\
\hline Germany & 5.8 & $\begin{array}{l}\text { Vehicles and Other Transportation Equipment; Chemical } \\
\text { Products; Machinery and Electrical Equipment; Food and } \\
\text { Beverages; Optical Equipment }\end{array}$ \\
\hline Turkey & 4.7 & $\begin{array}{l}\text { Machinery and Electrical Equipment; Metal Products; } \\
\text { Textiles; Food and Beverages; Plastics }\end{array}$ \\
\hline France & 3.5 & $\begin{array}{l}\text { Chemical Products; Food and Beverages; Livestock; } \\
\text { Machinery and Electrical Equipment; Mineral Products }\end{array}$ \\
\hline UAE & 2.9 & $\begin{array}{l}\text { Pearls and Precious Stones; Metal Products; Chemical } \\
\text { Products; Food and Beverages; Mineral Products }\end{array}$ \\
\hline
\end{tabular}

Figure 3.1: Lebanon's import composition in percentage in 2018 (Source: www.investinlebanon.gov.lb)

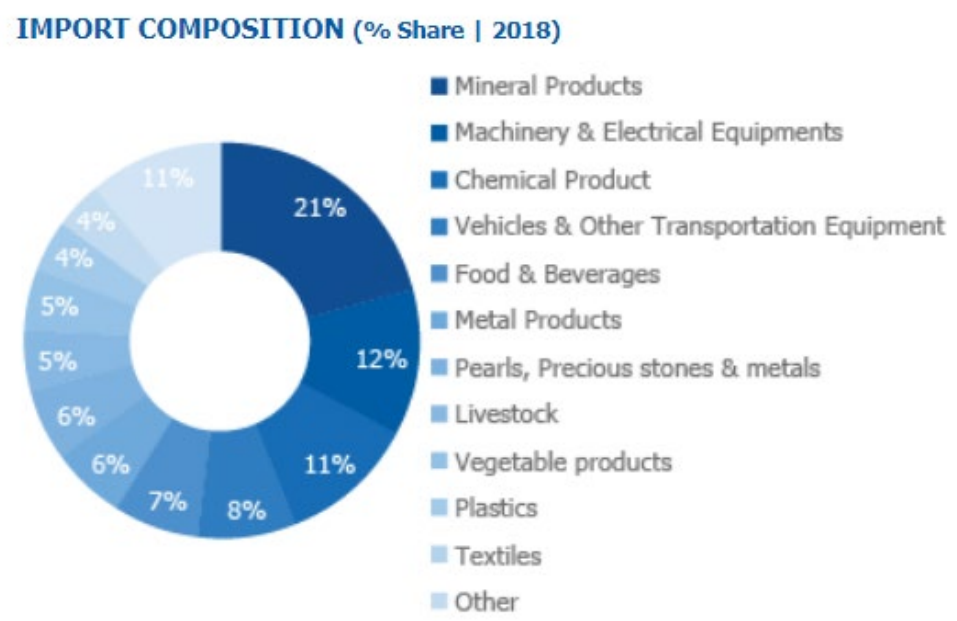




\section{Figure 3.2: Lebanon's export composition in percentage in 2018 (Source:}

www.investinlebanon.gov.lb)

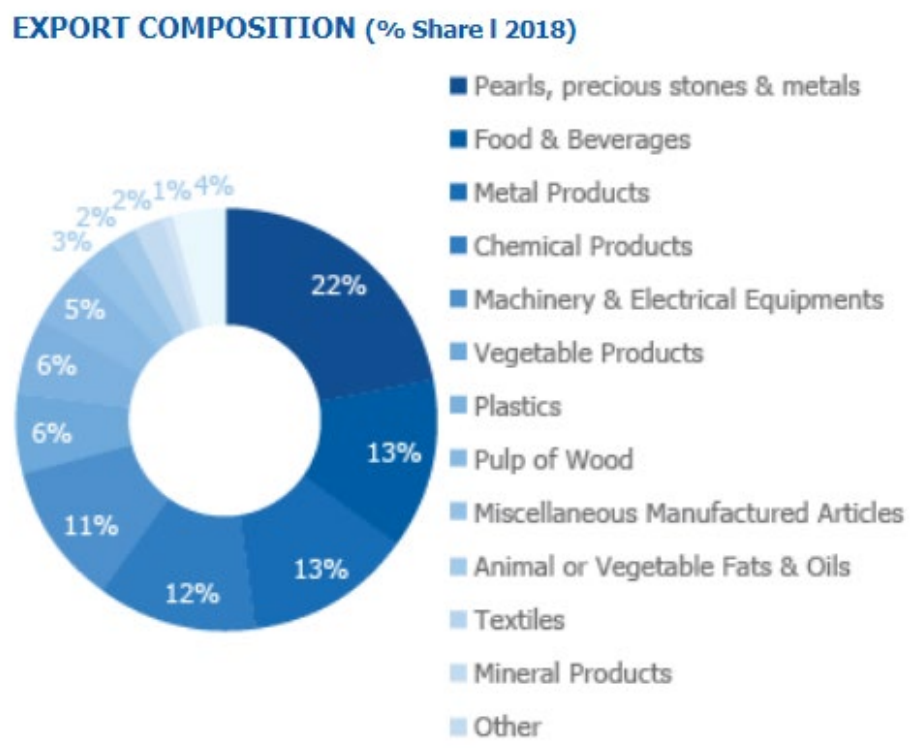

Historically, the tourism industry in Lebanon has been very vital to the national economy and continues till today to be a main source of revenue for the country (Jallat \& Shultz, 2011). Until the Lebanese civil war (1975-1990), Lebanon had an active tourism industry and appealed to a great number of tourists (Jallat \& Shultz, 2011). The capital of Lebanon, Beirut, was frequently called the "Paris of the Middle East" (Jallat \& Shultz, 2011, p. 478). Moreover, the agricultural sector makes up 5.5 percent of nominal GDP and the manufacturing sector represents 12 percent of nominal GDP (Jamali, 2010). The banking sector is the most vital source of the country's GDP making up approximately 40 percent of the GDP and is a major income-generator (Dirani, 2007). Beirut was the chief financial services center for the Middle East until the 1970s; nevertheless, it has lost its advantage to its regional competitors, mainly Dubai and Bahrain, after the civil war (Jamali \& Neville, 2011). The innovative banking system implemented by the government and the liberal economy compared to the neighboring countries lead to money and tourists flowing into the country and consequently categorized Lebanon as "Switzerland of the Middle East" (Dirani, 2007, p. 73). 
There has been an intensive effort by local organizations to somewhat reclaim Beirut's regional role while prominent Lebanese financial organizations such as Audi Bank and BLOM Bank are internationally held and lucrative, competition has become solid in latest years, demanding mergers and a regional concentration and growth (Jamali \& Neville, 2011). There are fifty-two commercial banks conducting business in Lebanon, ten investment banks, fifteen representatives of foreign banks, and fifty local and foreign-owned insurance companies (The Economist Intelligence Unit, 2007).

Currently, the Lebanese private sector which is mostly comprised of SMEs, the government, and NGOs largely the UN Economic and Social Commission for Western Asia (ESCWA), the UN Development Program (UNDP), and the World Bank are aggressively working to present a positive outlook of business and human development in Lebanon (Dirani, 2007). SMEs and start-ups are considered the backbone of current and future opportunities for economic and business advancement in Lebanon ("SMEs and Startups Form Backbone of Lebanon's Growth," 2018). The fact that most businesses in Lebanon are small and family owned is a strength to business-community relations in Lebanon because SMEs can easily access contacts, are located closer to their societies, and therefore can better understand the society's needs (UNDP, 2003).

Jamali, Zanhour, and Keshishian (2009) found that SMEs also highly contribute to CSR in Lebanon although not in the same dimensions as MNCs. For example, SMEs' CSR initiatives were less formalized and philanthropic based with CSR coming from the religious and personal values of their founders (Jamali, Zanhour, et al., 2009). On the other hand, CSR in MNCs was initiated by their foreign headquarters and were more professional (Jamali, Zanhour, et al., 2009). SMEs are important to the Lebanese economy and society because they contribute to community advancement, cultural amelioration, promotion of coexistence, 
employment of natives, restoration and lifting the face of buildings in deprived regions, donations to local community groups comprising low income families in the area, support to poor employees, donations to charitable associations, in-kind contributions to deprived sectors, and donations to several social and religious organizations like foundations, mosques, and children's homes (Jamali \& Neville, 2011).

In their study on MNCs operating in Lebanon, Jamali and Mirshak (2010) found that Lebanon remains an attractive market for MNCs in spite of its risky profile and continuous political pressures, which reveals a vote of assurance in its future and may have an amplified influence on reinforcing stability in the long run. Lebanon was also said to have an exceptional charm in the Arab region that appeals to tourists and investors which results in a fast economic recovery after situations of conflict (Jamali \& Mirshak, 2010). MNCs generate economic opportunities and jobs in Lebanon and are dedicated to charitable and humanitarian contributions (Jamali \& Mirshak, 2010). MNCs also provide several benefits to the Lebanese economy and society such as creating tobacco laws comprising consumer protection laws, working on projects to eradicate child labor and enhance children's lives in the South, offering scholarships to poor students, helping citizens gain access to technology and creating learning centers, encouraging employees to volunteer in community service initiatives, creating environmental campaigns, recycling paper and creating eco power projects, and presenting students to careers through on-site orientations and internships (Jamali \& Neville, 2011).

Jamali and Mirshak (2010) also found that MNCs have positive relationships with the Lebanese government, yet, because of the international nature of their business, they do not interfere in political conflict negotiations as this may have repercussions on their work in other countries. Large companies have experience, money, and more access to corporate, human, and technological resources (Jamali \& Mirshak, 2010). Thus, MNCs benefit the Lebanese 
economy by offering jobs, generating wealth, establishing good employment practices to guarantee gender and ethnic fairness, and engaging in philanthropy to assist victims of violence or funding relief associations (Jamali \& Mirshak, 2010).

This section offered a detailed explanation of the economic and technological frameworks of Lebanon to reveal other types of regulatory institutions in this research and their influence on business decisions and behaviours. Thus, this section allows the researcher to better understand the background of this type of companies in Lebanon and what role they play in the Lebanese economy and society. The situational factors discussed in this section allow the researcher to better analyze how the sampled MNCs instituted CSR in the Lebanese society.

\subsection{Socio-Culture}

The 1916 Sykes-Picot Agreement between the French and the British, defined Lebanon's borders against the will of its inhabitants in an attempt to guarantee the control of French colonists over a divided Syria (Traboulsi, 2007). Ever since, debates have arisen about what it means to be Lebanese which were the highest between the 1960s and 1980s (Dabbous et al., 2010). As a minority in an extensively Muslim area and because they were affected by their association to France, Christian Maronites promoted "Lebanonism” (Dabbous et al., 2010, p. 596). They regarded Lebanon as a westernized country, discarded Islam and Arabism, and put emphasis on western values like individualism (Dabbous et al., 2010). On the other end, the Sunni Arab Nationalists, the Shiites, the Druze, and the secular left were motivated by the Egyptian President Gamal Abdel Nasser and believed that Lebanon is part of a greater anti-Israeli Arab world (Dabbous et al., 2010). The Nationalists' impact increased in the 1960s and the 1970s, so they asked for a larger stake of the country's politics which threatened their Christian counterparts (Dabbous et al., 2010). 
Even though Lebanon is an Arab country and a founding member of the Arab league, it considerably diverges from Arab countries, predominantly in the field of culture (Jamali, Abdallah, et al., 2010). The Lebanese culture is a mixture of masculinity, conservatism and liberalism, high power distance, individualism, and collectivism (Sidani, 2002). This is without hesitation ascribed to Lebanon's history and its larger openness to the West than its neighbor Arab countries (Jamali, 2009). Therefore, the Lebanese culture has maintained significant remains of collectivism, masculinity, and patriarchy that are paired off by liberal values, predominantly in the capital Beirut and in Christian societies (Jamali \& Neville, 2011).

Lebanon is a pluralist multi-religious country (Jamali \& Keshishian, 2009). The Lebanese people are usually classified into two religions; Christian and Muslim (Jamali, Abdallah, et al., 2010). Approximately 57.7 percent of the Lebanese are Muslims, 36.2 percent are Christians, 5.2 percent are Druze, and the remaining small number includes the Jews (International Religious Freedom Report 2017, 2017). Nonetheless, divisions in the Lebanese social order go beyond the traditional Christian-Muslim classification because there are numerous complex sub-divisions within these two broad categories (Jamali \& Neville, 2011).

Lebanon has eighteen religious sects (Larkin, 2010). There are twelve Christian sects; the Maronites are the largest Christian sect that preserved its association to the Roman Catholic Church but has its personal patriarch, liturgy, and ecclesiastical customs; the second biggest Christian sect is Greek Orthodox; and other Christians are distributed among Greek Catholics, Armenian Orthodox i.e. Gregorians, Armenian Catholics, Syriac Orthodox i.e. Jacobites, Syriac Catholics, Assyrians i.e. Nestorians, Chaldeans, Copts, Evangelicals comprising Protestant groups like Baptists and Seventh-day Adventists, and Latins i.e. Roman Catholic (International Religious Freedom Report 2010, 2010). There are four Muslim sects in Lebanon where the central divisions of Islam are Shi'a and Sunni; the Alawites and the 
Isma'ili i.e. Sevener are small Muslim sects (Williams, 2012). There are also the Druze sect and the Judaism sect (Salamey, 2014).

Moreover, Lebanese people are known to be very religious and religious values play an important role in people's social, economic, and political life (Jamali, 2010; Jamali \& Sdiani, 2013; Khishfe \& BouJaoude, 2016). Besides, Jamali, Karam, Yin, and Soundararajan (2017) found that unique CSR directions among local companies in Lebanon have been linked to the prominent religious values, with an ethical filter identified, triggering ethical corporate behaviour, donations, and zakat (Jamali et al., 2017).

Lebanon is largely characterized by a patriarchal, family oriented, status conscious, and hospitable culture (Dirani, 2007). The Lebanese patriarchal culture assigns caring and family duties to women and is invaded by numerous classic masculine stereotypes (Jamali, 2009). For the Lebanese, family is the utmost essential institution and the most significant social organization (Sidani, 2002). Close family relationships, fidelity to family and friends, and honor are significant in the Lebanese society (Rassemblement Canadien pour le Liban, 2004). During their leisure time, Lebanese enjoy active discussions over Turkish coffee, taking part in outdoor activities, and eating good food (Rassemblement Canadien pour le Liban, 2004). Through its economic interests, associations, and values, a person's family highly affects his/her development of vocational inclination, accomplishment incentive, and personal actions (Dirani, 2007). Consequently, to a great degree, the family generally delineates persons' social status, their profession, and their social and political reputation (Dirani, 2007). More particularly, a person's family values influence her/his inclinations towards CSR (Jamali et al., 2017).

The Lebanese culture is also characterized by status consciousness where people respect others in relation to their social status (Dirani, 2009). In community and outside the 
family, respect is paid more to individuals who are considered worthy and have a superior social status (Dirani, 2007). Individuals attempt to gain influence and to gather and show wealth, which are symbols of success that gain respect (Rassemblement Canadien pour le Liban, 2004). The Lebanese community highly emphasizes social conformity instead of creativity or innovation (Dirani, 2007). Hospitability is also another characteristic of the Lebanese culture which is to graciously treat guests as it is considered offensive not to host visitors (Dirani, 2007). Besides, Lebanon is known to have a culture of giving as philanthropy is rooted in the Lebanese culture, history, traditions, and religious values of both Christians and Muslims (Sharaiha \& Ibrahim, 2008). Literature also suggests that CSR principles are very well grounded in the Lebanese philanthropic culture and traditions as it have shaped inherent forms of CSR (Jamali \& Neville, 2011; Jamali et al., 2008; Jamali, Zanhour, et al., 2009).

Lebanon is also characterized by an extremely literate, multilingual labor force, which reflects the country's comparative strength to its neighboring countries in the education field (Jamali \& Neville, 2011). The mother language in Lebanon is Arabic but French and English are extensively spoken (Rassemblement Canadien pour le Liban, 2004). Besides a minor percentage of the residents speak Kurdish, Syriac, and Armenian (Rassemblement Canadien pour le Liban, 2004). The Lebanese people highly value education and this is also revealed in the stable increase in women's educational enrollment, with approximately fifty percent of women enrolled in public and private post-secondary education (Jamali \& Neville, 2011).

Lebanon has one of the biggest, most active, and least controlled civil societies in the Middle East (Elbayar, 2005). Even though precise information about the size and range of NGOs in Lebanon is deficient, current research proposes that more than one thousand NGOs are registered in the capital Beirut only, and the Ministry of Health approximates that sixty 
percent of all Lebanese health centers are operated by NGOs (Jamali \& Keshishian, 2009). Lebanon's NGO sector is strong because NGOs played an important role during the war between 1975 and1990, as these establishments assumed typical governmental duties like education, healthcare, and emergency assistance (Jamali \& Keshishian, 2009; Jawad, 2002). Although a big number of NGOs are still operating in focus and structured along religious lines, they have frequently demonstrated their capability in going beyond sectarian limitations to deliver services to a lot of individuals outside their religious societies (Elbayar, 2005). As the Lebanese government lacks resources and capacity to fulfill rising social needs, the private sector has also been contributing to the Lebanese society through CSR, more particularly MNCs who have enough money and resources to do so (e.g. Jamali \& Neville, 2011; Jamali et al., 2017). From here, this study will be exploring CSR in MNCs operating in Lebanon.

\subsection{Summary of Chapter}

The word "Lebanon" invokes numerous images which keeps a person's information and experiences of the country and the Middle East pending (Jallat \& Shultz, 2011). Optimists imagine lovely seaside resorts, the assurance of multiculturalism, open-mindedness, collaboration, and a good reputation of banking, tourism, and other prosperous sectors that show a prospective regional leader for peace and success (Jallat \& Shultz, 2011). Others perceive ethnic and religious conflicts that at times turn into war, a broken country and society from which individuals and financiers escape and in which companies and individuals struggle to stay alive, and a predominant high political and business risks with disasters that would even challenge the most competent manager (Jallat \& Shultz, 2011). Lebanon's affluent history has been formed by numerous cultural customs, comprising Phoenician, Greek, Roman, Islamic, Crusader, Ottoman Turkish, French, and lately American (Rassemblement 
Canadien pour le Liban, 2004). The resulting culture is uniquely Lebanese, a mixture of East and West, past and present (Rassemblement Canadien pour le Liban, 2004).

Lebanon meets the requirements of a parliamentary republic having a centralized, multi-religious, and multiparty government (Rassemblement Canadien pour le Liban, 2004). For the reason that political authority and the system of government are structured in relation to religious clusters, a policy known as confessionalism, the Lebanese government has been labeled as a confessional democracy (Rassemblement Canadien pour le Liban, 2004). Categorizing individuals on the basis of their religion plays a serious role in Lebanon's political, economic, and social life and has caused Lebanon's most tenacious and hostile conflicts (Jamali \& Neville, 2011).

Lebanon is largely characterized by a patriarchal, family oriented, status conscious, and hospitable culture where family and religious values play a crucial role in individuals' lives (Dirani, 2007). The Lebanese society also has a culture of giving which was a main trigger for local companies' CSR adoption (e.g. Jamali \& Neville, 2011). Moreover, the private sector's role is very important to the Lebanese economy and society because the government is corrupt and lacks resources to handle the society's needs and problems (e.g. Jamali \& Neville, 2011; Jamali et al., 2017). Given that Lebanon is a unique country in many ways, it would be interesting to explore how a trend like CSR still works in such a complex context. Moreover, there is paucity in literature regarding how and why managers of MNCs operating in Lebanon engage in CSR (Khan et al., 2013; Pisani et al., 2017). Thus, this research will examine the role of personal and decisional factors, and actions that shape CSR in MNCs operating in Lebanon. This chapter offered an overview of the contextual background of this study. The next chapter four will provide a detailed explanation of the methodology adopted to conduct this research. 


\subsection{Chapter Four - Methodology}

\subsection{Introduction}

While planning for their study, researchers must think about their assumed philosophical worldview that is conveyed in their study, the research design relevant to this particular worldview, and the precise research methods that transform the approach into practice (Creswell, 2014). Therefore, this chapter will explain how this study was conducted by highlighting the researcher's philosophical stance which underpinned the research strategy, design, and methodology adopted in sections $4.2,4.3$, and 4.4 respectively. Section 4.4 will provide a detailed explanation of the purpose of the study, type of investigation, unit of analysis, time horizon, extent of researcher interference, and study setting. Moreover, this chapter will elaborate upon the rationale for selecting a qualitative research method. This will be done by explicating the interview protocol, sampling frame, the data collection method, and the administrative procedures. It will then shed light on the data analysis technique used by the researcher in section 4.5 and the ethical considerations of this study in section 4.6.

\subsection{Research Philosophy and Paradigm}

Bryman and Bell (2007) argued that epistemological and ontological orientations underpin every researcher's philosophical stance. Epistemological positions are concerned with the question of what is considered adequate knowledge in a discipline wherein whether or not the social domain can and must be studied in relation to the same values, processes, and beliefs as the natural sciences (Tolk, 2013). Ontological positions are concerned with the question of objective entities. Social structures here are considered to have a truth outside of social actors (Bryman \& Bell, 2007). 
Epistemological orientations are often considered to be two types or paradigms; positivism and interpretivism (Bryman \& Bell, 2007). Positivism advocates that there is a sole measurable truth which is directed by natural laws, where researchers can discover reality by using objective and value-free methods (Teddlie \& Johnson, 2009). Interpretivism is a contrasting paradigm to positivism and attempts to gain a deeper understanding of a social phenomenon by examining its complications (Collis \& Hussey, 2009). Collis and Hussey (2009) also explained that interpretivists believe that people's perceptions form social reality. These personal interpretations interact with the socially constructed institutions: individuals and their institutions differ from those of natural sciences (Bryman \& Bell, 2007).

Ontological positions are objectivism and constructionism (Bryman \& Bell, 2007). Objectivism holds that individuals deal with social phenomena as exterior facts that are further than their scope or impact (Wang \& Peyvandi, 2018). Constructionism assumes that people build understanding and meaning from their experiences (Sarita, 2017). Knight and Ruddock (2008) posited that constructionists believe that social phenomena and their meanings are created by the interactions of social actors and are therefore in an endless state of change. I am interested in understanding social phenomena through the subjective experiences, values, beliefs, ethics, and culture of those who are involved in them. Thus, I would consider myself an advocate of the interpretivist paradigm with a constructionist ontological stance. 


\subsection{Research Strategy}

The research strategy is the overall path that a research takes often divided into quantitative and qualitative (Bryman \& Bell, 2007). Falk and Blumenreich (2005) explicated that quantitative research strategies are used by researchers to produce numerical data and then evaluate the outcomes to test whether their hypothesis is correct or incorrect. Conversely, qualitative researchers investigate the data itself instead of the numbers generated (Hanson \& Grimmer, 2007). Qualitative methods are focused on the depth of information provided by the respondents to find out new meaning and offer a superior understanding of the problem at hand (Falk \& Blumenreich, 2005). Sometimes researchers use a mixed methods strategy for collecting and analyzing data by simultaneously using quantitative and qualitative techniques in a single study (Cameron \& Molina-Azorin, 2011).

When a study is looking at a new, complex, or active phenomenon, variables and theories directly explaining it cannot be easily identified and found (Golicic \& Davis, 2012). Hence, a qualitative research strategy would allow researchers to get a deeper understanding of the phenomenon being sought (Falk \& Blumenreich, 2005). Alternatively, when pertinent variables can be easily identified for their study and measures generated for their research instruments, researchers use quantitative methods (Golicic \& Davis, 2012). Moreover, Malina, Norreklit, and Selto (2011) explained that qualitative research usually answers research questions which address "how" and "why" whereas quantitative research normally answers those that address "how often" and "how many" (p. 61).

Similar to any research method, qualitative research has strengths and weaknesses. Qualitative methods are criticized as hard to replicate as they are often exploratory and contingent on a specific research that cannot be applicable to all other cases (Bryman \& Bell, 2007). Moreover, in qualitative strategies data analysis mostly depends on the researcher's subjective outlook of what is critical (Paley, 2000). By understanding these factors, an 
important strength of qualitative strategies is that they allow research to progress and build on prior knowledge (Gilmore \& Carson, 1996). This may be accomplished because qualitative researchers are directly involved in the context of their participants (Bogdanovic, Dowd, Wattam, \& Adam, 2012). Another important advantage is that qualitative methodologies offer researchers substantial insights into managerial practices (Cassell \& Symon, 2006).

As previously explained, this study uses two frames of analysis in order to examine micro level factors and implications for the other levels. Thus, a case study approach was adopted to do that through qualitative research. As will be discussed in section 4.4.4.3, ten MNCs were selected for this study. First, any available corporate documents and second-hand data of these organizations were explored. Second, an investigation was done through fourteen semi-structured face-to-face interviews in these organizations and this enabled the researcher to develop her ideas further and provide a contribution to institutional work. Therefore, this research is a case study of CSR microfoundations in Lebanon using ten MNCs.

Noting that CSR is a complex and context bound phenomenon, qualitative research offers chances for building theory and a detailed micro-level comprehension of context (Wang et al., 2016). An inductive approach to research allows researchers to build a theory and make inferences from the data findings (Collis \& Hussey, 2009). This will be the method chosen.

The case study has conventionally occupied, to a certain extent, a distinctive position within management and organization literatures (Gephart, 2004; Fiss, 2013). The case study is a study of a particular phenomenon - microfoundations of CSR - which occurs in a particular context - Lebanon (Eisenhardt, 1989). Theory building from case studies is a research strategy that includes using one or more cases to generate theoretical constructs, suggestions, and/or midrange theory from case-based practical proof (Eisenhardt \& Graebner, 2007; Byrne \& Ragin, 2013). It was considered that the investigation of CSR within this national context could reveal new knowledge about the operation of this concept at multiple levels. 
Theory evolves in the sense that it is found in and developed by identifying

relationship patterns amongst constructs within and across a case and its fundamental rational arguments (Eisenhardt \& Graebner, 2007). Using multiple sources of evidence within a case, this then develops contrasts, extensions, and replications to the emergent theory (Yin, 2009). The process of building theory happens through "recursive cycling among the case data, emerging theory, and later, extant literature" (Eisenhardt \& Graebner, 2007, p. 25). Even though at times building theory from a case study is viewed as subjective, but when it is welldone it is unexpectedly insightful because researchers stay honest by placing the emphasis on the rich and real-world context in which the phenomena transpire (Eisenhardt \& Graebner, 2007).

\subsection{Research Methodology and Design}

\subsubsection{Purpose of the Study}

Khan et al. (2013) posited that most studies were conducted in the West to explore the subjects that impede managers' decision-making and influence their CSR decisions, nonetheless, there is dearth in literature where the Middle East and particularly Lebanon is concerned. Besides, CSR is comparatively new in Lebanon and Nick Hartmann, the Deputy Resident Representative of the UNDP in Lebanon, emphasized the need to profoundly inspect the inner practices of firms operating in Lebanon to better comprehend CSR in the Lebanese community (Halawi, 2010). Therefore, this study will focus on businesses operating in Lebanon to fill the gap that preceding literature has not yet addressed. Additionally, conducting this research in a developing country will greatly contribute to knowledge and offer a deeper understanding of "the cultural context and dynamics of CSR" in Lebanon (Khan et al., 2013, p. 67). This study can later be used as well as a guide and a foundation for other 
researchers who want to conduct comparable studies in countries similar to or different from Lebanon.

In light of the stakeholder and shareholder models and theories pertaining to CSR as depicted in chapter two, this research paper aims to answer the following three research questions;

i) How and why do individual level factors play a role in the adoption of CSR in companies operating in Lebanon?

ii) How and why do situational factors influence the adoption and implementation of CSR?

iii) How is CSR institutionalized in Lebanon if at all?

In order to address these research questions this research aims to explore how CSR decision-making is done by managers of MNCs operating in Lebanon and attain deeper knowledge of the role of the personal and decisional factors and actions that shape CSR in Lebanon.

\subsubsection{Time Horizon}

Saunders, Lewis, and Thornhill (2009) argued that two types of time horizon are available for researchers; longitudinal and cross-sectional (Saunders, Lewis, \& Thornhill, 2019). In longitudinal research data is collected over a prolonged period of time, whereas in cross-sectional studies data is collected at a single point in time (Creswell, 2014). Collis and Hussey (2009) identified two advantages for cross-sectional research; it is inexpensive and conducted over a short period of time. In this research, data collection was conducted from July 15, 2016 to October 4, 2016 through a onetime face-to-face interview with each of the fourteen participants. 


\subsubsection{Extent of Researcher Involvement}

The extent of researcher involvement has effects on the replicability of the research; to what extent is the role of the researcher significant can be classified as minimal, moderate, or excessive depending on how much the researcher manipulates or controls the study (Sekaran, 2003). Minimal involvement is whenever research is conducted in the natural environment of the company and the researcher simply gathers data without manipulating or disrupting the regular workflow (Sekaran \& Bougie, 2016). Moderate involvement happens whenever the researcher intentionally engages with the regular course of work at the organization by amending certain variables (Sekaran \& Bougie, 2009). In other circumstances, the researcher might even want to construct a completely new fake setting where he/she can study the causeand-effect relationships by influencing certain variables and closely controlling others like in a laboratory (Sekaran, 2003). Under such circumstances, the extent of researcher involvement will be considered excessive (Sekaran \& Bougie, 2016).

This research has some level of researcher dependency because the researcher conducted face-to-face interviews with managers in their normal work setting at their corresponding organizations. There was no attempt to manipulate variables as this is a qualitative study and the researcher is not trying to find a relationship between variables. The researcher conducted a qualitative exploratory study because not much has been written about CSR institutionalization in Lebanon nor the population being examined i.e. managers of MNCs operating in Lebanon. The researcher listened to the participants to construct an understanding depending on what was heard. There was a conscious attempt to maintain a balanced view to prevent bias in the research findings. Using the same approach, it should be theoretically possible to replicate this study but various elements of it are dependent on the time and place where it occurred. 
Interviews are a very efficient technique to collect rich empirical data (Eisenhardt \& Graebner, 2007). Nevertheless, interviews also frequently provoke a reaction that the data are biased in which impression management and reflective sensemaking are considered the main culprits (Eisenhardt \& Graebner, 2007). Hence, interviewee bias, researcher bias, and power relations need to be taken into consideration to prevent bias in a study (Saunders et al., 2009). Interviewee bias is defined as an attempt by an interviewee to provide an explanation that hides some data or when he/she presents himself/herself in a socially appropriate role or circumstance (Saunders et al., 2003). Power relations is the extent to which there are power imbalances between the interviewer and the interviewee (Creswell, 2014).

Corporate gatekeepers have a very powerful position with respect to researchers who request access to corporate information (Saunders et al., 2009). They will stay in a powerful position when it comes to the extent and nature of the access that they permit (Bryman \& Bell, 2007). Nonetheless, researchers need to be sensitive about the way in which the granting of access influences this type of power relationship (Saunders et al., 2003). During the collection of data from managers through face-to-face interviews, researchers will be placed in a position of some power, although for a short period of time, because they will be able to ask questions, comprising probing ones, which may cause the interviewee some distress or even pressure (Saunders et al., 2019).

In this study, the researcher took several measures to prevent those biases. The researcher prepared an interview protocol that was used as a guide during all interviews in order to follow an objective data collection process (Saunders et al., 2009). The researcher was also very objective when asking probing questions and she did not attempt to affect the interviewees' answers to prompt them to give her specific answers nor drive them in particular directions. All participants were provided with a participant information letter that included all 
details of the study and the interview, including the approximate duration of the interview. The interview questions were also sent in advance to the interviewees who asked for them in order to gain their trust (Saunders et al., 2003). This helped the researcher strengthen the dependability of the study (Bryman \& Bell, 2007). Besides, the researcher gave the participants the full freedom to choose the location, date, and time of the interview for them to be comfortable and for the researcher to have enough time to gather all data needed (Saunders et al., 2019).

As previously explained, all interviews were conducted in the managers' offices at their corresponding MNCs. The interviewees seemed very comfortable and relaxed in this study setting i.e. in their offices (Sekaran \& Bougie, 2016). All of them mentioned that they feel at home and they work together in the organization as a family. The researcher was able to see this through the interactions and behaviours of the employees while waiting for her appointment and through some interruptions during the interviews with the managers. In this study, interviewing managers in their own offices improved their ability to talk openly and they readily had access to any additional information that they needed during the interview. Moreover, the interviewees were at ease, never got anxious, and seemed very honest when answering critical questions related to their MNCs.

The perception that the interviewees have of the interviewer is also an important aspect that may affect the interview process, more particularly power relations (Saunders et al., 2009). In this study, even though the researcher was a young woman, there was no problem in terms of power relations because of her job position and education level. As explained in chapter three, in Lebanon people really admire job titles, social status, and education level (Dirani, 2009). This helped the researcher a lot because she approached the participants as a university professor in Lebanon pursuing a $\mathrm{PhD}$ in the UK. She earned their respect because 
she was able to get to this status at a relatively younger age and all participants were very helpful and provided her with all needed information. This is also reflected in the durations of the interviews; most interviews were more than one hour as shown in table 4.1 below.

\subsubsection{Qualitative Case Study Research Method}

\subsubsection{Interviews and Records}

To answer the three research questions given in section 1.3 , this research aims to explore how CSR decision-making is done by managers of MNCs operating in Lebanon and attain deeper knowledge of the role of the personal, decisional, and situational factors and actions that shape CSR in Lebanon. Therefore, the examination of the interview protocol and the archival data were guided by and based on the three research questions.

Qualitative researchers usually use an interview protocol which is a form that helps them record and write down information obtained during an interview (Creswell, 2014). The following paragraphs explain the rationale of how the research question protocol was developed and how and why the questions evolved. The interview protocol of this study was designed in English because all participants were fluent in English and they were able to answer all the questions in English without facing any difficulty. The interview protocol is given in Appendix A.

As previously explained, the three research questions of this study were derived from the aim of the research and from the literature review where the knowledge gap lies. The questions in the interview protocol emerged from the background of the study and from the

literature review (Rout \& Aldous, 2016). In fact, through a thorough analysis of the literature review on CSR, the researcher was able to identify important constructs to be further examined in her study (Eisenhardt, 1989). For example, CSR, ethics, management decision- 
making, MNCs, Lebanon, national culture, family, religion, and values are some of the most important constructs in this research. The constructs underpinned the research questions in the interview protocol (Eisenhardt, 1989). For instance, the question "How long have you been practicing CSR and why do you engage in it? (Interviewee and organization)" in section D of the interview protocol was asked in order to understand the reasons that drive the participants and their MNCs to practice CSR. This issue came up in the literature review wherein several studies done around the world showed different results (e.g. Munro, 2013). Thus, the researcher was interested to hear the participants talk more about it (Bryman \& Bell, 2007) to first answer her three research questions and second to answer the call for more research relating to exploring further the foundations of CSR (e.g. Ng et al., 2019).

Moreover, as this was exploratory research, some questions were added at the time just in case the findings revealed something related to them. For example, gender was added to section A of the interview protocol just in case it turned out that it has any relation to CSR perception or practice. The researcher wanted to find out what was happening in particular organizations about which she did not have any definite view. The additional questions to the interview protocol through semi-structured interviews "allow the researcher to probe emergent themes or to take advantage of special opportunities which may be present in a given situation" (Eisenhardt, 1989, p. 539).

The sections in the interview protocol were constructed as follows. The first section A included questions relating to the personal, demographic, and educational background of the interviewees. Section B included two questions regarding the participants' professional background. Section C comprised six questions concerning the organization and its CSR. Two questions were included in Section D to help the researcher gain a deeper understanding of the managers' personal perceptions and definition of CSR. Section E related to decision-making 
and comprised three questions. The aim of these questions was to gain a thorough

understanding on how CSR decision-making was done in Lebanon and in the MNCs' international subsidiaries. Additionally, this section allows the researcher to identify the values and principles that drive the participants' decisions and behaviours in addition to the role models that inspire them and underpin their beliefs. Finally, section F included two questions about ethics. These questions allowed the researcher to depict what ethics meant to the participants and how managers rationalized their decisions when faced with an ethical dilemma. Supplementary questions ask for further details that show processes and reasons.

\subsubsection{Document Analysis}

Yin (2003, p. 6) advised researchers who want to answer research questions that include "how" and "why" to use a case study whereby the researcher examines archival data or documents in addition to conducting interviews. The archival data explored for this study were varied; for example, the researcher drew upon companies' documents, CSR reports, codes of conduct, corporate websites, and marketing materials. Corporate documents offer researchers valuable background information about the firm and provide some insights into the actions and decisions of managers (Bryman \& Bell, 2007).

Documents were given by eight of the organizations in the selected group. These are often public documents on the website. As such it is difficult to quote directly from these documents whilst being able to maintain confidentiality. The main value of these documents was to sensitize the researcher to the espoused aims of particular MNCs. In general, these documents gave a list of important aspects of CSR that were either principles, tenets, pillars, or values. The number of them ranged between five and thirteen, although one organization itemized 15 sub-headings. These top-level items were variously focused around integrity, responsibility, skills, and commitment. One of the organizations emphasized the human 
aspects of diversity, fairness, and respect. Some of them were focused around the purposes of the company such as nutrition, consultancy, or financial services. Other documents tended to focus on a code of conduct towards others in a more overt ethical stance. In a number of cases the CSR statements were also strongly informed by the issue of sustainability. In all cases the interviews were conducted with these documents in mind and they informed the supplementary questions in the interviews.

\subsubsection{Participant Selection}

There are a number of approaches to sampling available for researchers (Bryman \& Bell, 2007). A sampling technique is needed for researchers to cut the number of data to be collected and choose a suitable sample for their study (Saunders et al., 2003). Gina Marie (2004) distinguished between two types of sampling designs: probability and nonprobability sampling. When researchers use probability sampling, they randomly select the elements of a certain population so in that case the elements have the same probability of being chosen (Sekaran, 2003). Whereas in nonprobability sampling, researchers do not randomly choose elements for their research so the elements do not have an equal opportunity for being picked (Endacott \& Botti, 2005). These two sampling designs comprise several sampling strategies (Saunders et al., 2019). Probability sampling comprises unrestricted or simple random sampling and restricted or complex probability sampling (Sekaran \& Bougie, 2016). Nonprobability sampling include convenience sampling and purposive sampling (Sekaran, 2003).

When researchers use unrestricted sampling each population element has an identified and equivalent probability of being selected (Bryman \& Bell, 2007). Restricted sampling provides a practical and at times more efficient substitute for the unrestricted sampling design (Sekaran, 2003). In fact, restricted sampling is more efficient because the researcher can 
obtain more information for a certain sample size by using some of the restricted sampling processes than the unrestricted sampling design (Sekaran \& Bougie, 2009). Convenience sampling means collecting information from individuals in a certain population who are conveniently free to deliver it (Sekaran \& Bougie, 2016). Finally, researchers use purposive sampling when they want to get information from a specific target population (Sekaran, 2003). The sampling in that case is limited to specific types of individuals who can offer the wanted information, either because they alone have it or fit in the researcher's predetermined criteria (Sekaran \& Bougie, 2009).

This research used a nonprobability sampling design with a purposive sampling strategy to select the research elements (Sekaran, 2003). The researcher selected a small sample because she is conducting a qualitative study in order to deeply understand phenomena i.e. CSR within a specific context i.e. Lebanon (Mangan, Lalwani, \& Gardner, 2004). In fact, even if qualitative researchers only choose a sample of one, they get enough, rich, and authentic data from the sample (Collis \& Hussey, 2009). Thus, the researcher selected a sample of fourteen managers chosen from ten different MNCs operating in Lebanon. The MNCs were selected from different industries to prevent information bias as detailed in table 4.1 below.

Additionally, the firms were chosen for their CSR related initiatives and reputations. Consequently, the purposive sampling approach was used because the managers selected offered the best assistance in answering the research questions to meet the aims of the study (Saunders et al., 2019). Purposive sampling is suitable for this research because the sample is restricted to particular types of individuals who hold vital information and conform to the researcher's predetermined criteria (Sekaran, 2003). This research will be delimitated to senior managers because they are the ones in charge of the corporate budgets and CSR decisions. The 
sample consisted of five local MNCs headquartered in Lebanon and five foreign MNCs with subsidiaries operating in Lebanon. This selection enriched the interpretation of the findings.

The researcher started off by using CSR Lebanon as a sampling frame to get all the potential companies that do CSR in Lebanon. However, only seven companies were found and because that was not enough, Corporate Knights was used as a second sampling frame. Through these two steps the study's sample was selected and which includes ten MNCs. First, ten MNCs were chosen because these companies are active in CSR and therefore can reveal a lot of information about how and why CSR is practiced in Lebanon. Second, an investigation was done through fourteen semi-structured face-to-face interviews in all ten MNCs. The interviewees are in a good position to reveal how their individual factors influence their thinking and their action about CSR. Besides, the participants have many years of experience in their respective MNCs so they know very well how the work is done, culture, ethics, spirit, values, and CSR. For example, P12's first job was at the MNC selected and he has been working in it since then i.e. for 20 years. The table below includes the participants' information and details of the sample used for this study. 
Table 4.1: Participant information table

\begin{tabular}{|c|c|c|c|c|c|c|c|}
\hline Pseudonym & $\begin{array}{c}\text { Position of } \\
\text { Interviewees }\end{array}$ & Gender & $\begin{array}{c}\text { Duration } \\
\text { of } \\
\text { Interview }\end{array}$ & $\begin{array}{c}\text { Company } \\
\text { Type }\end{array}$ & Industry & $\begin{array}{c}\text { Organizational } \\
\text { Age in } \\
\text { Lebanon }\end{array}$ & $\begin{array}{l}\text { Source of } \\
\text { Sample }\end{array}$ \\
\hline Winery & $\begin{array}{l}\text { Quality, Human } \\
\text { Resource (HR), } \\
\text { and CSR } \\
\text { Manager }\end{array}$ & Female & $\begin{array}{l}80 \\
\text { minutes }\end{array}$ & $\begin{array}{l}\text { MNC of } \\
\text { Lebanese } \\
\text { origin }\end{array}$ & $\begin{array}{l}\text { Wine } \\
\text { industry }\end{array}$ & 162 years & $\begin{array}{l}\text { CSR } \\
\text { Lebanon }\end{array}$ \\
\hline Winery & $\begin{array}{l}\text { Managing } \\
\text { Director }\end{array}$ & Male & $\begin{array}{l}90 \\
\text { minutes }\end{array}$ & $\begin{array}{l}\text { MNC of } \\
\text { Lebanese } \\
\text { origin }\end{array}$ & $\begin{array}{l}\text { Wine } \\
\text { industry }\end{array}$ & 162 years & $\begin{array}{l}\text { CSR } \\
\text { Lebanon }\end{array}$ \\
\hline Bank 1 & Head of CSR & Female & $\begin{array}{l}84 \\
\text { minutes }\end{array}$ & $\begin{array}{l}\text { MNC of } \\
\text { Lebanese } \\
\text { origin }\end{array}$ & $\begin{array}{l}\text { Banking } \\
\text { industry }\end{array}$ & 89 years & $\begin{array}{l}\text { CSR } \\
\text { Lebanon }\end{array}$ \\
\hline Bank 2 & Head of CSR & Female & $\begin{array}{l}81 \\
\text { minutes }\end{array}$ & $\begin{array}{l}\text { MNC of } \\
\text { Lebanese } \\
\text { origin }\end{array}$ & $\begin{array}{l}\text { Banking } \\
\text { industry }\end{array}$ & 189 years & $\begin{array}{l}\text { CSR } \\
\text { Lebanon }\end{array}$ \\
\hline $\begin{array}{l}\text { Logistics } \\
\text { Company }\end{array}$ & $\begin{array}{l}\text { CSR } \\
\text { Representative }\end{array}$ & Female & $\begin{array}{l}50 \\
\text { minutes }\end{array}$ & $\begin{array}{l}\text { MNC of } \\
\text { foreign origin }\end{array}$ & $\begin{array}{l}\text { Logistics } \\
\text { industry }\end{array}$ & 31 years & $\begin{array}{l}\text { CSR } \\
\text { Lebanon }\end{array}$ \\
\hline $\begin{array}{l}\text { Logistics } \\
\text { Company }\end{array}$ & $\begin{array}{l}\text { Country } \\
\text { Manager }\end{array}$ & Male & $\begin{array}{l}30 \\
\text { minutes }\end{array}$ & $\begin{array}{l}\text { MNC of } \\
\text { foreign origin }\end{array}$ & $\begin{array}{l}\text { Logistics } \\
\text { industry }\end{array}$ & 31 years & $\begin{array}{l}\text { CSR } \\
\text { Lebanon }\end{array}$ \\
\hline $\begin{array}{l}\text { Information } \\
\text { Management } \\
\text { Company }\end{array}$ & $\begin{array}{l}\text { Partner and } \\
\text { General } \\
\text { Manager }\end{array}$ & Female & $\begin{array}{l}50 \\
\text { minutes }\end{array}$ & $\begin{array}{l}\text { MNC of } \\
\text { foreign origin }\end{array}$ & $\begin{array}{l}\text { Information } \\
\text { management } \\
\text { Industry }\end{array}$ & 13 years & $\begin{array}{l}\text { CSR } \\
\text { Lebanon }\end{array}$ \\
\hline
\end{tabular}




\begin{tabular}{|c|c|c|c|c|c|c|c|}
\hline $\begin{array}{l}\text { Information } \\
\text { Management } \\
\text { Company }\end{array}$ & $\begin{array}{l}\text { CSR } \\
\text { Representative }\end{array}$ & Female & $\begin{array}{l}50 \\
\text { minutes }\end{array}$ & $\begin{array}{l}\text { MNC of } \\
\text { foreign origin }\end{array}$ & $\begin{array}{l}\text { Information } \\
\text { management } \\
\text { Industry }\end{array}$ & 13 years & $\begin{array}{l}\text { CSR } \\
\text { Lebanon }\end{array}$ \\
\hline $\begin{array}{l}\text { Building } \\
\text { Materials } \\
\text { Company }\end{array}$ & $\begin{array}{l}\text { CSR/SD } \\
\text { Coordinator } \\
\text { Communication } \\
\text { Manager }\end{array}$ & Female & $\begin{array}{l}90 \\
\text { minutes }\end{array}$ & $\begin{array}{l}\text { MNC of } \\
\text { foreign origin }\end{array}$ & $\begin{array}{l}\text { Building } \\
\text { materials } \\
\text { industry }\end{array}$ & 90 years & $\begin{array}{l}\text { Corporate } \\
\text { Knights }\end{array}$ \\
\hline $\begin{array}{l}\text { Building } \\
\text { Materials } \\
\text { Company }\end{array}$ & CEO & Male & $\begin{array}{l}47 \\
\text { minutes }\end{array}$ & $\begin{array}{l}\text { MNC of } \\
\text { foreign origin }\end{array}$ & $\begin{array}{l}\text { Building } \\
\text { materials } \\
\text { industry }\end{array}$ & 90 years & $\begin{array}{l}\text { Corporate } \\
\text { Knights }\end{array}$ \\
\hline Bank 3 & $\begin{array}{l}\text { Head of } \\
\text { Communication } \\
\text { Department and } \\
\text { CSR Manager }\end{array}$ & Female & $\begin{array}{l}90 \\
\text { minutes }\end{array}$ & $\begin{array}{l}\text { MNC of } \\
\text { Lebanese } \\
\text { origin }\end{array}$ & $\begin{array}{l}\text { Banking } \\
\text { industry }\end{array}$ & 68 years & $\begin{array}{l}\text { CSR } \\
\text { Lebanon }\end{array}$ \\
\hline $\begin{array}{l}\text { Household } \\
\text { and Personal } \\
\text { Care } \\
\text { Company }\end{array}$ & $\begin{array}{l}\text { General } \\
\text { Manager }\end{array}$ & Male & $\begin{array}{l}125 \\
\text { minutes }\end{array}$ & $\begin{array}{l}\text { MNC of } \\
\text { Lebanese } \\
\text { origin }\end{array}$ & $\begin{array}{l}\text { Household } \\
\text { and personal } \\
\text { care } \\
\text { industry }\end{array}$ & 47 years & $\begin{array}{l}\text { CSR } \\
\text { Lebanon }\end{array}$ \\
\hline Coffee Shop & CSR Manager & Male & $\begin{array}{l}60 \\
\text { minutes }\end{array}$ & $\begin{array}{l}\text { MNC of } \\
\text { foreign origin }\end{array}$ & $\begin{array}{l}\text { Retail } \\
\text { coffee and } \\
\text { snack store } \\
\text { industry }\end{array}$ & 20 years & $\begin{array}{l}\text { Corporate } \\
\text { Knights }\end{array}$ \\
\hline $\begin{array}{l}\text { Food and } \\
\text { Beverage } \\
\text { Company }\end{array}$ & $\begin{array}{l}\text { Public Affairs } \\
\text { and Creating } \\
\text { Shared Value } \\
\text { Manager }\end{array}$ & Female & $\begin{array}{l}65 \\
\text { minutes }\end{array}$ & $\begin{array}{l}\text { MNC of } \\
\text { foreign origin }\end{array}$ & $\begin{array}{l}\text { Food and } \\
\text { beverage } \\
\text { industry }\end{array}$ & 85 years & $\begin{array}{l}\text { Corporate } \\
\text { Knights }\end{array}$ \\
\hline
\end{tabular}


Additionally, the rational for selecting these managers is for the researcher to have two perspectives; one is the firm perspective and one is their personal perspective. They are senior enough to give the researcher a general view of the firm. For example, the CEO has the knowledge to represent the firm but also, he/she can represent himself/herself on a personal level. However, the researcher is also using her sample i.e. managers or senior managers as a proxy for firms. Senior managers were interviewed because the views of the senior managers are the views of the company, so they are used as indicator. But it depends on the questions asked; if they are about personal things then it goes back to the micro-level because they talk about the personal aspects and the personal reasons that shape their beliefs, attitudes, and behaviours. When the questions asked are related to processes then it goes back to the mesolevel which is a firm level. Therefore, two levels of questions were asked to individuals in this study.

\subsubsection{Data Collection Method and Administrative Procedures}

There is wide variety of research instruments for researchers to collect data (Merriam, 2002). Data collection can tools comprise focus groups, questionnaires, observations, interviews, archival data, and many more (Bryman \& Bell, 2007). Studies of ten MNCs were conducted by reviewing their company documents and second-hand data such as CSR reports, codes of conduct, corporate websites, and marketing materials and by conducting semistructured interviews. This information was not always available for the local MNCs

Selecting these ten MNCs gave the possibility to review their company documents such as CSR reports and available data. Together with fourteen semi-structured interviews it was possible to develop theory at the micro level with implications for meso and macro levels. In fact, by examining corporate documents and second-hand data, the researcher can gain insights into the interdependent relationships of the MNCs sampled with other institutions and 
the external environment (Sekaran, 2003). In addition, Bryman and Bell (2007) explained that managers usually write company documents so when researchers both examine corporate documents and interview the managers, they can validate the information obtained from both sources.

Researchers in qualitative studies assume that people have distinctive, significant, and ascertainable facts about the social world and can be discussed through verbal communication (Hesse-Biber \& Leavy, 2011). Whilst there are three types of interviews; structured, unstructured, and semi-structured (Merriam, 2002). In structured interviews, respondents' answers can be compared because there is a high-level of standardization as the interviewer asks every interviewee the same questions and in the same order to obtain concrete answers (Sekaran, 2003). Unstructured interviews are used when the researcher has a precise research topic and not a set of predetermined and exact questions to be answered by the participants (Hesse-Biber \& Leavy, 2011). Merriam (2002) argued that the majority of interviews are called semi-structured interviews as they fall in between these two extremes. By using semistructured interviews, researchers can ask topic based questions and can vary their order based on the respondents' answers (Dearnley, 2005). It has already been observed that this study is an exploratory study therefore the interviewee is guided by the researcher through open-ended questions as they may reveal important information worth of being further explored (HesseBiber \& Leavy, 2011). These interviews are very useful when researchers strive to access the participants' values, ideas, thoughts, and memories that will be discussed in the respondents' own words (Hesse-Biber \& Leavy, 2011). This is particularly the case where the researcher needs the interviewee to elaborate the issues. Managers' values, cultural norms, thoughts, ethical stance, experiences, beliefs, and many other complex issues are required for the interpretation of this study. 
With regards to the administrative procedures of this study, the researcher first contacted every participant in person and explained to them the purpose of the study and data collection. After that, an e-mail was sent to every participant who agreed to be part of the study including an attached participant information letter to provide an official and written invitation to participate in the research project and agree on an interview date and time. The participant information letter also comprised the purpose of this research and some study details such as how the information collected will be used and how the participant's privacy will be protected (can refer to Appendix B for a sample of the participant information letter sent).

The researcher went in person to conduct the face-to-face interviews with the managers. At the beginning and before initiating any interview, the researcher provided the interviewee with a consent form to be signed by the participant who accepts to participate in the research project (can refer to Appendix $\mathrm{C}$ for a sample of the consent form). Besides, the researcher reminded every interviewee that participation was completely voluntary and she/he can withdraw from data collection anytime during the interview. The researcher also assured the interviewees that the interview will be strictly confidential and anonymous. In addition, all fourteen participants allowed the researcher to audio-record all their interviews. All interviews were conducted in the participants' offices at their respective MNCs, so the audio-recording was only paused when the interviewees got a phone call or when another employee entered their office.

As will be explained in the analysis and findings parts of this dissertation, all participants in this study were CSR decision-makers which explains why it was enough for the researcher to interview fourteen managers and not twenty i.e. two managers in each company. However, most CEOs, general managers, or owners were not available to conduct their 
interviews or did not have enough time to do it. Consequently, the researcher could not conduct more than fourteen interviews. Moreover, after conducting half of the interviews the researcher realized that the answers are approximately the same, she started to hear the same explanations, and she carried on with the interviews until the participants were no longer revealing any new information (Miles, Huberman, \& Saldana, 2014). In addition, as explained in section 4.4.6.2 regarding participant selection, the researcher selected ten MNCs for her interviews, which constitutes the majority, from the range of the sample of MNCs available. So here she was sure that her sample of ten MNCs or fourteen managers was enough for this research and that she had reached saturation (Miles et al., 2014).

\subsection{Data Analysis}

The interpretivist approach was used as a method of analysis for the results of this study. The main aim of an interpretivist researcher is to gain a deeper understanding of his/her respondents' subjective truth to better explicate the motives and gist affecting it (Saunders et al., 2003). Following Miles et al. (2014), contact summaries for every interview was created to capture and coordinate the interpretation of the data. All interviews were audio-recorded and transcribed but some notes were taken to complement the audio-records. The participants were provided with the transcriptions for accuracy. They were given a chance to read the transcriptions and they did not have any comments which proved that the researcher's understanding and transcriptions were correct.

While analysing transcriptions, the researcher was constantly checking every interview by listening to the audio record and reading the notes related to it. This helped the researcher stay close to her data to make sure no important idea was missed and better understand the initial text (Alcock \& Iphofen, 2007). The researcher coded and categorized the transcripts to identify important and similar subjects and patterns that arose during the analysis process 
(Saunders et al., 2009). The researcher also used the QSR NVivo software version 10 to better and more efficiently conduct a qualitative data analysis.

Thematic analysis was used to analyse the data on NVivo and nine themes emerged from the data as will be discussed in chapters five and six. Thematic analysis is a method of recognizing patterns whereby researchers analyze content by identifying codes or themes that emerge from the data which in turn become the categories to be analyzed (Roberts, Dowell, \& Nie, 2019). These methods of analysis report that to understand the material as one piece researchers study the parts, but they cannot understand the parts except in relation to this one piece or the whole thing (Roberts et al., 2019). The researcher conducted three rounds of analysis to do the coding. The first-order coding was done to analyze the information taken from the corporate documents and the important quotes taken from NVivo to describe them. Then, the researcher conducted a second round of analysis by combining the common coding together to find the second-order categories. Finally, a third round of analysis was done by combining the common second-order categories to find the third-order themes. Nine different third-order themes were found that contribute to knowledge. In this study, the researcher used inductive and abductive reasoning to conduct her analysis. It is inductive because the researcher found the themes from the data and it is abductive because she confirmed the themes that were discovered by someone else (Timmermans \& Tavory, 2012).

Qualitative researchers have to take into consideration three crucial concerns throughout their analysis process; authenticity, confirmability, and credibility (Bryman \& Bell, 2007). In this study, the researcher continuously checked the initial interview transcripts throughout the analysis process to maintain the authenticity of the results and make sure that they are a true reflection of the interviewees' answers and experiences (Saunders et al., 2003). Data resulting from qualitative research is usually context specific, temporary, and examined 
through an interpretive approach (Collis \& Hussey, 2009). Hence, qualitative research outcomes are associated with a high degree of authenticity (Collis \& Hussey, 2009). Half of the MNCs sampled in this study are CSR Lebanon official partners which are or could be considered a good indicator of the authenticity of this research. Leedy, Ormrod, and Johnson (2019) posited that qualitative studies can achieve authenticity if the research is beneficial, informs the readers, and motivates participants to take action. By conducting a CSR study in a Middle Eastern country, the researcher will enlighten readers about how management decisions are taken in a developing economy and encourage managers in Lebanon to take action with this regard.

The researcher maintained objectivity throughout the research process to preserve the confirmability of the results and research (Bryman \& Bell, 2007). Confirmability was also reinforced because the researcher provided a high transparency of the data source and clearly and deeply explicated the research process, how and what decisions were made, and the problems that arose during the study (Vivar, McQueen, Whyte, \& A., 2007). Furthermore, research positioning informed confirmability because the researcher explicitly stated and identified biases, values, and beliefs that may impinge of her research (Leedy \& Ormrod, 2001). Sekaran (2003) posited that when the researcher is aware of these biases, he/she can successfully obtain accurate information and objectively discuss them.

The editorial team of the Qualitative Research in Organizations and Management: An International Journal (QROM) believes that qualitative research is internally credible and valuable (Cassell \& Symon, 2006). To ensure this study's credibility, the interpretations of the interviews were approved by the researcher's supervisors (Riege, 2003). Besides, to sustain credibility, the researcher wrote a rich and meaningful interpretation indicative of consistent and coherent results and kept a systematic relation of the concepts (Riege, 2003). When the researcher is studying managers and employees in regional companies, qualitative research 
methods prove more credible than other methods (Erdem \& Gul Baser, 2010). This is due to the contextual completeness that qualitative studies can achieve when the researcher provides a comprehensive explanation of the participants' context, history, beliefs, culture, and meanings (Leedy \& Ormrod, 2001).

\subsection{Ethics}

Every researcher needs to take into consideration the ethical considerations of her/his study (Bryman \& Bell, 2007). This research abided by the rules and regulations of the University of Gloucestershire's Handbook of Research Ethics. Managers were first contacted by the researcher through the phone to schedule their interview date and time at their own convenience and inform them of the nature and purpose of the research. When the participants accepted to be interviewed, they were provided by an Informed Consent Form along with the research information. The interviews were audio-recorded and transcribed after the interviewees' approval and field notes were taken to complement the audio-record of the interviews. Besides, the researcher gave the participants the complete freedom to answer all or any of the questions, withdraw, or stop the interview at any time. The researcher further clarified that if an interviewee wishes to withdraw from the research all information related to her/him will be directly deleted. It is worth noting that no participant withdrew from the research.

The interviews were only used for research purposes, were stored in a secured location, and will be completely destroyed upon the $\mathrm{PhD}$ completion. The managers' and MNCs' names are anonymous and kept confidential. They were published neither in this thesis nor will be revealed after the study. Only the information obtained might be published in journals or discussed at conferences. Moreover, pseudonyms were used to keep participants anonymous 
during the interview and when writing the dissertation. Besides, when direct quotations were used, the researcher removed any information that may reveal the interviewees' identities.

\subsection{Summary of Chapter}

The choice of the proper research method is an important decision for academic researchers as it reinforces the relevance and accuracy of their research results. Consequently, the researcher identified the research philosophy, strategy, design, and methodology that informed the selection of a specific method. Besides, ethical concerns are crucial and all researchers need not to disregard during the course of the research process. Research ethics is essential because it safeguards the rights and wellbeing of all parties involved in and influenced by the research including researchers themselves.

This research aims to explore how CSR decision-making is done by managers of MNCs operating in Lebanon and attain deeper knowledge of the role of the personal and decisional factors and actions that shape CSR in Lebanon. Qualitative methodologies are suitable for such studies because they help the researcher get an in-depth understanding of the complex and changing nature of human beings. The researcher in this study adopted an interpretivist and constructionist philosophical stance because she considers social reality as socially constructed by the particular beliefs, meanings, ethics, cultures, and values that people hold in a certain context. In addition, semi-structured interviews were conducted with managers of these ten MNCs operating in Lebanon to infer meaning from their replies and build an inductive theory. Finally, this research abided by the guidelines of the University of Gloucestershire's Handbook of Research Ethics and was conducted in the most ethical and professional way. The next chapter will offer a detailed explanation of the study results. 


\subsection{Chapter Five - Results}

\subsection{Introduction}

The purpose of this qualitative research was to explore how managers of MNCs operating in Lebanon make decisions with regards to CSR. The focus of this study was to gain insights into the personal and decisional factors and actions that shape CSR in Lebanon. Chapter five presents the results and themes of this study. The findings demonstrate that managers' individual-level factors play an important role in their CSR adoption. The most important factors are religion, ethics, family values, and their personal belief systems that greatly affect their inclinations towards CSR. Another key finding is that ethics is a main driver of CSR.

Furthermore, the professional circumstances of the participants highly impact them because management and corporate values and their position in the hierarchy of their firms played an important role in their CSR adoption. Moreover, managers' stories of ethical dilemmas were imprinted in their minds and underpinned their future decisions and actions. Another significant result is that the participants' situational factors, more importantly the Lebanese culture, underpin their perception of CSR. In fact, the respondents view CSR as a vocation and believe in the concept of CSR starts at home whereby CSR in the sampled MNCs first started internally and then was taken outside. In addition, the findings reveal several types of work that MNCs engage in to disrupt, tailor, and maintain CSR in Lebanon.

Accordingly, section 5.2 is divided into nine subsections as the findings are grouped under nine themes. Section 5.2.1 offers a detailed explanation of the role that individuals' personal circumstances play in their inclinations towards CSR. The next section 5.2.2 provides an overview of the role played by an individual's professional circumstances on CSR. Section 
5.2.3 explicates the legacy stories from the participants pertaining to the ethical dilemmas they have faced at work. Section 5.2.4 explains the familial environment at the selected MNCs whereby CSR starts at home. Section 5.2.5 demonstrates how CSR is perceived as a vocation among the research participants. Section 5.2.6 clarifies how the Lebanese extraneous culture and values shape CSR. Section 5.2.7 explains how CSR is used to disrupt existing institutions in Lebanon. Section 5.2.8 highlights how CSR is undertaken to tailor new institutions in the Lebanese society. Finally, section 5.2.9 depicts how CSR is practiced to maintain institutions in Lebanon and section 5.3 summarizes chapter five.

\subsection{Findings}

As discussed in chapter four, ten MNCs operating in Lebanon were selected as a sample to collect data. These MNCs were studied by examining their company documents such as CSR reports and second-hand data and interviews were conducted in all MNCs as shown in Table 4.1. Fourteen face-to-face semi-structured interviews were conducted in English with top managers in these companies to enable in-depth exploration of the research questions with each participant. The interviews were transcribed and then analyzed using the QSR NVivo software version 10. After that, nine data analysis tables were created in order to have more transparent and systematic analyses. The tables show how the coding was undertaken.

The researcher conducted three rounds of analysis to do the coding. The first order coding was done to analyze the information taken from the corporate documents and the important quotes taken from NVivo to describe them. Then, the researcher conducted a second round of analysis by combining the common coding together to find the second-order categories. Finally, a third round of analysis was done by combining the common secondorder categories to find the third-order themes. 
A total of thirty-six first-order codes were identified across the nine tables; religion; ethics; patriotism, community spirit, and activism; role model; generational differences and individuals' beliefs; management values; corporate values; stories of ethical dilemmas; resilience; employees as the most important stakeholders; employees as family members; internal CSR taken outside; emotional devotion to CSR; job satisfaction and motivation; organizational citizenship; Lebanese culture; the impact of country needs on CSR decisions and activities; community service and development; environmental protection; employee wellbeing; corporate philanthropy; CSR's disruption of sectarianism; CSR's disruption of local laws; MNCs' best practices as disruptive; transparency and respect as disruptive; tailoring CSR to the Lebanese culture; tailoring CSR to the needs of local companies; bespoke adaptation of CSR activities and trainings to local MNCs; tailoring MNCs' CSR network for a bespoke implementation; tailoring CSR to local stakeholders; CSR development; CSR benefits; legitimizing local MNCs' work; eroding the negative practices through top management support; bottom-up approach of decision-making; and bespoke planning and implementation.

The second-order categories were found by aggregating the first-order codes. A total of twenty second-order categories were found; the strength of individual's religion and ethics in defining organizational CSR; the positive role of individual's family values and heritage in influencing convictions in CSR; the role of individual's belief systems in determining inclinations towards CSR; the effect of corporate and managerial values on the practice of CSR; legacy stories from individuals of ethical dilemmas and resilience; CSR starts at home; CSR as a vocation; the influence of national culture on managerial decisions relating to CSR and ethics; corporate culture; the impact of country needs on CSR decisions and activities; types of CSR activities practiced by MNCs; CSR disrupting local government practices; CSR 
disrupting practices of the local private sector; bottom up approach of CSR to shape new institutions; tailoring CSR to the local context; actions taken to tailor CSR to local MNCs; institutions sustained by the progress of CSR; maintaining institutions through authentic CSR; actions taken to retain CSR in local MNCs; and decision-making to maintain CSR.

Subsequently, a total of nine third-order themes were identified; the role of individuals' personal circumstances on CSR; the role of individual professional circumstances on CSR; legacy stories from individuals; familial environment; vocation and workplace settings; extraneous culture and values; CSR to disrupt existing institutions; CSR to tailor new institutions; and CSR to maintain institutions. Finally, the nine themes were classified into three categories and provided a threefold contribution to knowledge. Thus, the contribution of this study is a subset of the themes. The subsections below provide a detailed explanation of the themes and corresponding results. The findings are at the micro-level involving the participants' personal aspects, in particular, to reflect their beliefs, attitudes, and behaviours. These have implications at the meso-level relating to MNCs because by virtue of their position in MNCs, these individuals are able to speak on behalf of the firm. Furthermore, it is possible to draw conclusions at the macro-level relating to the context in which MNCs operate and the external factors that affect their operations and decisions. Table 5.1 below includes information regarding the demographics of the participants. 
Table 5.1: Demographics of the participants

\begin{tabular}{|c|c|c|c|c|c|}
\hline Organization & $\begin{array}{c}\text { Pseudonym } \\
\text { of } \\
\text { Organization }\end{array}$ & Participant & $\begin{array}{c}\text { Pseudonym } \\
\text { of } \\
\text { Participant }\end{array}$ & $\begin{array}{c}\text { Years in } \\
\text { Organization }\end{array}$ & Religion \\
\hline Winery & $\mathrm{MNC1}$ & $\begin{array}{l}\text { Quality, HR, } \\
\text { and CSR } \\
\text { Manager }\end{array}$ & $\mathrm{P} 1$ & 16 & $\begin{array}{l}\text { Christian - } \\
\text { Armenian } \\
\text { orthodox }\end{array}$ \\
\hline Winery & $\mathrm{MNC1}$ & $\begin{array}{l}\text { Managing } \\
\text { Director }\end{array}$ & $\mathrm{P} 2$ & 32 & $\begin{array}{l}\text { Christian - } \\
\text { Maronite }\end{array}$ \\
\hline Bank 1 & MNC2 & Head of CSR & P3 & 10 & $\begin{array}{l}\text { Christian - } \\
\text { Melkite } \\
\text { catholic }\end{array}$ \\
\hline Bank 2 & MNC3 & Head of CSR & $\mathrm{P} 4$ & 6 & $\begin{array}{l}\text { Christian - } \\
\text { Armenian } \\
\text { orthodox }\end{array}$ \\
\hline $\begin{array}{l}\text { Logistics } \\
\text { Company }\end{array}$ & MNC4 & $\begin{array}{l}\text { CSR } \\
\text { Representative }\end{array}$ & P5 & 27 & $\begin{array}{l}\text { Muslim - } \\
\text { Shi'it }\end{array}$ \\
\hline $\begin{array}{l}\text { Logistics } \\
\text { Company }\end{array}$ & MNC4 & $\begin{array}{l}\text { Country } \\
\text { Manager }\end{array}$ & P6 & 32 & $\begin{array}{l}\text { Christian - } \\
\text { Maronite }\end{array}$ \\
\hline $\begin{array}{l}\text { Information } \\
\text { Management } \\
\text { Company }\end{array}$ & MNC5 & $\begin{array}{l}\text { Partner and } \\
\text { General } \\
\text { Manager }\end{array}$ & P7 & 27 & $\begin{array}{l}\text { Muslim - } \\
\text { Shi'it }\end{array}$ \\
\hline $\begin{array}{l}\text { Information } \\
\text { Management } \\
\text { Company }\end{array}$ & MNC5 & $\begin{array}{l}\text { CSR } \\
\text { Representative }\end{array}$ & P8 & 27 & $\begin{array}{l}\text { Muslim - } \\
\text { Shi'it }\end{array}$ \\
\hline $\begin{array}{l}\text { Building } \\
\text { Materials } \\
\text { Company }\end{array}$ & MNC6 & $\begin{array}{l}\text { CSR/SD } \\
\text { Coordinator } \\
\text { Communication } \\
\text { Manager }\end{array}$ & P9 & 7 & $\begin{array}{l}\text { Christian - } \\
\text { Greek } \\
\text { orthodox }\end{array}$ \\
\hline $\begin{array}{l}\text { Building } \\
\text { Materials } \\
\text { Company }\end{array}$ & MNC6 & CEO & P10 & 18 & $\begin{array}{l}\text { Muslim - } \\
\text { Sunni }\end{array}$ \\
\hline Bank 3 & MNC7 & $\begin{array}{l}\text { Head of } \\
\text { Communication } \\
\text { Department and } \\
\text { CSR Manager }\end{array}$ & P11 & 5 & Christian \\
\hline $\begin{array}{l}\text { Household } \\
\text { and Personal }\end{array}$ & MNC8 & $\begin{array}{l}\text { General } \\
\text { Manager }\end{array}$ & P12 & 20 & $\begin{array}{l}\text { Christian - } \\
\text { Maronite }\end{array}$ \\
\hline
\end{tabular}




\begin{tabular}{|l|l|l|l|l|l|}
\hline $\begin{array}{l}\text { Care } \\
\text { Company }\end{array}$ & & & & & \\
\hline Coffee Shop & MNC9 & CSR Manager & P13 & 3 & Muslim \\
\hline $\begin{array}{l}\text { Food and } \\
\text { Beverage } \\
\text { Company }\end{array}$ & MNC10 & $\begin{array}{l}\text { Public Affairs } \\
\text { and Creating } \\
\text { Shared Value } \\
\text { Manager }\end{array}$ & P14 & 16 & $\begin{array}{l}\text { Christian - } \\
\text { Melkite } \\
\text { catholic }\end{array}$ \\
\hline
\end{tabular}

\subsubsection{The Role of Individuals' Personal Circumstances on CSR}

The role of individuals' personal circumstances on CSR is the first theme identified in this research. The subsections below provide a detailed explanation of what those personal circumstances are and how they shaped the participants' views and behaviours with regards to CSR. Table 5.2 shows the part of the coding which is relevant to theme 5.2.1. Specific quotes to support the coding are discussed in each relevant section.

Table 5.2: Coding of the first theme

\begin{tabular}{|c|c|c|}
\hline Third-order Themes & Second-order Categories & First-order Codes \\
\hline \multirow{6}{*}{$\begin{array}{l}\text { The role of individuals' } \\
\text { personal circumstances on } \\
\text { CSR }\end{array}$} & \multirow{2}{*}{$\begin{array}{l}\text { The strength of individual's } \\
\text { religion and ethics in } \\
\text { defining organizational CSR }\end{array}$} & Religion \\
\hline & & Ethics \\
\hline & $\begin{array}{l}\text { The positive role of } \\
\text { individual's family values } \\
\text { and heritage in influencing } \\
\text { convictions in CSR }\end{array}$ & \\
\hline & \multirow{3}{*}{$\begin{array}{l}\text { The role of individual's } \\
\text { belief systems in } \\
\text { determining inclinations } \\
\text { towards CSR }\end{array}$} & $\begin{array}{l}\text { Patriotism, community } \\
\text { spirit, and activism }\end{array}$ \\
\hline & & Role model \\
\hline & & $\begin{array}{l}\text { Generational differences and } \\
\text { individuals' beliefs }\end{array}$ \\
\hline
\end{tabular}




\subsubsection{The Strength of Individual's Religion and Ethics in Defining Organizational CSR}

\subsection{Religion}

There were nine Christian participants, P1, P2, P3, P4, P6, P9, P11, P12, and P14, and five Muslim participants, P5, P7, P8, P10, and P13, who were interviewed and they were from different sects as detailed in table 5.1. As mentioned in chapter three, Lebanese people are very religious and this was also reflected in the answers of all the research participants. P12 and P14 also associated themselves with Christianity when asked about their ethnic background because in Lebanon people see ethnicity and religion as one of the same.

The interviewees indicated that religion is an important aspect of their identity. For example, P12 stated: "So today if I want to associate myself I would associate myself with the Maronites in all means if we're talking about culture and traditions and stuff like that yes I am a real Maronite." Religion shapes a person's culture and traditions and it also affects a person's decisions and beliefs. According to the managers interviewed their decisions and actions are influenced by their religious values. Moreover, two of the fourteen participants, P2 and P12, stated that the founders' religious values are the foundations of corporate values and culture. For example, P12 said: “...the founder deeply believed in the Christian values and he copied many things from the Christian values..." He also explained that the founder was inspired from Jesus to create the corporate values and establish the culture of the company.

P2 and P12 indicated that Christian values teach and motivate people to engage in CSR. For example, P12 associated CSR to Christianity and said: “...I can attribute this to Christianity, Jesus tells you that if you give a bit you get a lot in return. CSR is the same. If you really give a bit you will get a lot in return". He also mentioned that he has been indirectly engaged in CSR as a Christian, because it is humane, and he was brought up on Christian values of helping others. Moreover, he posited that the founder believed that 
companies succeed if they work based on Christian values. Based on P12's MNC global sustainability report, the company has been successfully operating since 1972 based on corporate values derived from Christianity and today it is operating in fourteen countries. On the other hand, no Muslim participant was explicit in mentioning the link between CSR and religion.

\subsection{Ethics}

The research participants argued that ethical values differ from one religion to another and from one culture to another. Therefore, the impact of ethics on people's decisions and actions will differ among different individuals coming from various backgrounds. All participants posited that being ethical is when people do not do things against their personal values and convictions. Eight of the fourteen participants interviewed, P2, P4, P5, P6, P7, P8, P10, and P12, believe that ethics is a proper way of living, and being transparent, respectful, modest, and honest, keeping the heritage, and working as family members.

The research participants define ethics as doing the right thing even when no one is watching. P3, P11, and P12 serve as representative examples of this result. In fact, P3 said: "Hmmm...for me being ethical is doing the right thing if you want hmmm ...the morally right thing even if no one is seeing you for me this is being ethical. Doing the right thing when no one is watching and maybe no one will know what you did not certainly to show an objective or a target just because that's the thing that should be done". P11 mentioned that ethics is not having on ones' conscience anything wrong. P12 also claimed that being ethical is when he sleeps at night with a peace of mind.

Ethics was also seen as the driver of corporate values, behaviours, and decisions. For example, P3 defined ethics as “...the values and principles a person not only adopts to discipline his/her thoughts, decisions, and actions, but also is able to prove and validate to 
him/herself before demonstrating them and conveying them to the world." He also argued that this applies to companies whereby it is not enough to say what the organizational ethics is, there has to be an understanding of where those ethics are coming from, why, and how their integrity is preserved. He said that management should specify what systems are in place to uphold those ethics and recover them if they should be subject to change. This finding was also supported by the documents of the MNCs where the importance of and commitment to ethics by the organizations were explicitly shown. The companies had systems and procedures for ethics in place to drive corporate behaviours and decisions. Additionally, the interviewees mentioned that ethics is different from CSR; it is a trigger of CSR and it can help companies institute CSR faster.

Three of the fourteen participants, P9, P12, and P13, mentioned that ethics guides a person's behaviour and decisions. P9 and P12 serve as representative examples about how this transpires. In fact, P9 explained that people need ethics to guide them in everything they do in life and that ethics is what guides people to choose good and bad behaviours and decisions. P12 mentioned that ethics is a "lifestyle" and a base for his behaviours and decisions. He explained that having ethics as a lifestyle means basing his daily actions and decisions, be it professional or personal, on ethics.

Moreover, P12 and P13 believe that being ethical is when one puts the interest of others before his/her own interest. In addition, five of the fourteen interviewees, P4, P5, P7, $\mathrm{P} 8$, and P11, argued that the lack of business ethics is the reason behind the 2008 scandals and the ones happening today. P4, P5, P8 and P9's statements were selected as examples for this finding. P4 stated: “...I really believe Marguerite that the Earth is really on loan, we take it from our fathers we give it to our children and what human beings have done to the Earth is unacceptable and it's not just unacceptable it's downright stupid hmmm ...it's without any 
conscience...” Additionally, P5 posited that ethics is a way to build nations and societies. P8 stated that because people are not acting ethically and are being selfish, the world is going backwards, so ethics is the world's salvation. P9 argued that as a company grows and spreads worldwide, more people and NGOs observe it so it needs to focus more on ethics. This result was validated by the documentation of the MNCs especially in their CSR reports and codes of conduct where their business ethics was addressed and measured according to GRI, UNGC principles, and ISO 26000.

Furthermore, managers' personal ethics is crucial as it is perceived to be a requirement in corporate values. All research participants said that being ethical is one of the most important corporate values for MNCs and it is taken very seriously. The CSR reports and codes of conducts of the MNCs validate this finding because the procedures, measures, and actions taken with regards to ethics show a thorough commitment to and integration of ethics their values and cultures. P6, P10, P11, and P14 are selected as examples because they show the variedness about how this transpires.

P6 mentioned that the MNC's HR provides ethics training to employees. P10 explained that his company has induction courses for ethics and all employees have to fill a yearly questionnaire and do tests to make sure they understood what ethics means. He also added that he has to do three or four tests every year to make sure that he abides by the company's code of ethics and understands it. This way the company makes sure that he is always reminded of ethics. Likewise, he said that ethics is very important for the company to the point that it does yearly ethics exams for all its employees depending on their departments to make sure that they abide by and understand its code of ethics. In addition, the company has a compliance officer who makes sure that all employees and managers abide by the code of ethics. P11 stated that the bank makes employees sign its code of ethics when they are 
recruited. P14 said: “...So we have strong ethics and codes but we also have systems to audit them, make sure that you know feedback is there and continuous tracking is there."

Moreover, the research participants believe that ethics is integrated within governance management systems including culture of their MNCs. P9, P11, and P12 serve as representative examples for this result. P9 explained that the headquarters created a code of ethics which is applied the same way in all the company's branches worldwide and that the company gives the same level of importance to ethics in all countries. P11 stated: “...corporate governance which has to do with all the ethical and you know this thing is a top down you know approach it's what we call the tone of the top so and I can assure that this is the culture of the bank there's no tolerance at all..." P12 mentioned that behaving ethically is a must in the company and unethical employees cannot survive in its ethical environment. This is because the corporate culture enforces ethical practices, be it formally or informally, and all employees exhibit ethical behaviours and decisions. So unethical employees do not have a chance to exhibit any deviant practices as they know they will be formally and informally pressured. The participants, although mention culture, tend to be quite mechanistic in the way they look at it. This finding was also supported by the documents reviewed where a description of the government management system and corporate culture explicitly showed the importance and integration of ethics within the MNCs. 


\subsubsection{The Positive Role of Individual's Family Values and Heritage in Influencing Convictions in CSR}

One finding in this research is that there is a view that people cannot change the values they learned in their families. People will bring their values to work and anywhere else. In fact, the participants collectively stated that they and the MNCs' founders integrated their family values in their corporate cultures, actions, and decisions. In addition, all research participants argued that managers' national and personal values affect their CSR practices and decisions. P2 and P12 serve as representative examples for this finding. P2 explained that a businessman should believe in national, personal, and human values to practice CSR because if he is only business oriented then he would not understand the importance of engaging in CSR. P12 clarified that the founder of the company learned the value of helping others from his family and included it in the corporate culture. He said: "...And he has it and they all have it. Hmmm ...they are incredible, for them we should always think of others, of the poor, etc. because they were deprived during their lives."

Moreover, this study found that family affects managers' CSR decisions and practices. When asked about why they engaged in CSR, seven of the fourteen participants, P2, P3, P4, P5, P7, P8, and P14, answered that they did so because they were brought up to give back to the community. P5 and P14 were selected as representative examples for this result. P5 clarified that she comes from a family that strongly believes in the community and this added value to her beliefs and to how she deals with her employees and all other stakeholders. P14 said that she engages in CSR because she grew up in this spirit and mentality.

The research participants had different nationalities. Four participants, P3, P4, P10, and P11, held both foreign and Lebanese nationalities. One participant is of foreign nationality (not of Lebanese nationality); P13. Nine participants had only a Lebanese nationality i.e. P1, 
P2, P5, P6, P7, P8, P9, P12, and P14. P3 explained that the way of doing things differs from nationality to nationality; she has Austrian and Lebanese nationalities and lived in Europe and Lebanon so she saw and experienced the differences. She explained that social responsibility is part of the national values and culture abroad and people do it by nature in companies and in their personal lives. For example, a person walking down the street in Austria does not throw a tissue paper on the street; he/she throws it in a specific garbage bin, but in Lebanon this is not the case. Companies in Lebanon are integrating CSR practices in their corporate cultures and teaching their employees to adopt them at work hoping that one day these practices will be practiced in each Lebanese family as it is done in many developed countries abroad. When parents become socially responsible, they transfer this practice to their children by teaching them how to do it.

All research participants argued that values learned in the family shape a person's character. P2 and P11 serve as representative examples for this finding. P2 explained that his personality was shaped by his family and his parents taught him all the values he practices today. He stated: “...Yeah so that's it, this is usually in a person's character or personality I learned it and took it from my home from my family. It's not my own favor or values all of this is thanks to my parents who raised me, my parents did me this favor.” P11 said: “...I tell you again the values that I have from where did I take them? I didn't pick them up from the streets I took them from my family..."

This study also found that family shapes a manager's ethnic background. When the participants were asked with which group of people they would identify themselves, eight of fourteen participants (i.e. P2, P5, P7, P8, P9, P12, P13, and P14) associated themselves with their families and could not find any other association. The data also revealed that respect of heritage is essential to people's identities. For example, P4 explained that a person loses 
his/her identity when he/she forgets his/her heritage. She added that identity is who the person truly is and people's behaviours are a reflection of their identities.

Additionally, participants are very attached to their ethnic background. For example, P12 stated: "Personally, I will even name my children Phoenician names because for me these are my roots, we come from Phoenician origins." Four of the fourteen participants, P1, P3, P6, and P9, associated themselves with the region in which they lived when asked about their ethnic background. P1, P3, and P6 serve as representative examples for this finding. P1 mentioned: "I associate myself with the Lebanese Armenian people because I do not associate myself with for example the Armenians of Armenia." P3 stated: “European... I have lived in Europe and I feel that I connect more as ways of thinking...From a values perspective, hmmm ... a values perspective more, hmmm ...they are more organized, respect of rules, and so on..." P6 said: "I have lived all my life in Beirut I think I belong to Beirut." Moreover, three of ten MNCs, MNC1, MNC3, and MNC9, had a corporate culture that encourages people to respect their heritage. For example, P13 explained in this regard that the company values being proud of oneself and one's origins. This fact motivated employees and managers to work according to their heritage and to what they believe in. 


\subsubsection{The Role of Individual's Belief Systems in Determining Inclinations towards CSR}

\subsection{Patriotism, Community Spirit, and Activism}

Seven of the fourteen participants, P2, P4, P5, P7, P8, P12, and P13, had a strong feeling of patriotism and were very attached to their community and country. These participants also explained that managers and employees in their respective companies believe that they should always do what is best for their country. This belief is in line with CSR because when employees work in ways that take the country's interest into consideration they will be working in a socially responsible manner. In addition, four of the ten MNCs, MNC4, MNC5, MNC8, and MNC9, encourage their employees to have a sense of patriotism and have this value instilled in their corporate cultures. P2 and P13 are selected because they show the variedness about how this transpires. P2 explained that companies who value patriotism understand and appreciate the importance of practicing CSR more than companies who are only business oriented. This is because patriotism motivates managers to take care of their countries and enhance their wellbeing. P13 stated that one of the corporate values was: “...and being themselves and staying proud of who they are as individuals and where they come from."

P3 posited that CSR cannot succeed if a sense of community spirit does not already exist in the company. Six of the fourteen participants, P2, P5, P7, P8, P9, and P10 argued that CSR is not something one starts, it is in the person. P5 and P10 serve as representative examples for this finding. P5 argued: "Let me tell you something Marguerite, CSR is not something you start, it's either it's in you or not... You don't start CSR. Community service, sharing, witnessing, feeling, being passionate, it's in you, you don't plan this.” P10 explained that CSR is in his DNA and he cannot conduct business without it or manage a company that 
does not practice CSR. Five of the fourteen participants, P2, P5, P7, P8, and P11, also mentioned that CSR is a personal belief and a way of life.

Five of the fourteen interviewees, P3, P4, P5, P7, and P8, stated that they are activists in the Lebanese society. They said that they are part of many associations and are on the steering committee of the UNGC. They are working hard to institute CSR in their MNCs and bring about social change in the Lebanese society. For example, P3 stated: “...I am part of the UNGC steering committee for CSR where we work on promoting the 10 UNGC principles in Lebanon..."

\subsection{Role Model}

Five of the fourteen participants, P2, P4, P5, P7, and P8 stated that they have patriarchal role models in relation to the latter's' values and behaviours. Another five, P3, P9, P10, P11, and P13, argued that they do not have a role model but they are inspired from different people depending on the situation. For example, P11 explained: "Now I have people I don't know if you can call them role models but definitely in my life experience I have people who passed through my life who if you want gave me some hmmm... advices or they had an impact on the choice that I wanted to do...He was an advisor in the bank, he was an advisor to the chairman but I had a very good relation with him. He was the one who reminded me and developed this challenge in me my challenge. That person was a role model at that time and in that situation did you get me?... I read a book entitled "who says elephants can't dance" by the IBM chairman hmmm...I forgot now his name ok? I read it, this book as well serves as a role model on how to do business, I keep on remembering it. Then when you say role model, why am I telling you I don't have one? Because role model is a person or something that you follow to reach ok..." 
Four of the managers interviewed, P1, P6, P12, and P14, have their CEO, general manager, president, or owner of the company as their role models because of the way they conduct business, their ethics, and their values. P1 and P14 serve as representative examples of this result. P1 said: "Conducting business who is my role model? Internally, it is ...the GM of...our manager...Because he has the vision, he has the right leadership style hmmm...And I like the ethical and transparent part in his personality, professional personality." P14 stated: “...but in here I would say our CEO for a specific reason because I also see his firmness in hmmm...not jeopardizing on any short business decision that is not on the long-term as per other principles because sometimes in business you might be confronted to do short business decisions that just for the business not necessarily in line with everything, it's hard. However, I see him how he doesn't compromise and how you know he makes it relevant and he hmmm...supports these to make it alive. At the end of the day principles are there but it's only people who can make them happen hmmm...break them or make them."

\subsection{Individuals' Beliefs and Generational Differences}

Ego strength assesses the strength of an individual's beliefs (Robbins \& Coulter, 2016). Individuals who have high ego strength will probably resist desires to behave unethically and alternatively follow their beliefs (Robbins \& Coulter, 2016). Ten of the fourteen interviewees, P1, P2, P3, P4, P6, P10, P11, P12, P13, and P14, exhibit high ego strength because they follow the same values at work and in their personal lives and do not behave unethically. P3 and P4 serve as representative examples of this finding. P3 claimed that it is very hard for employees to work in a company that has different values and she would not work for a company that has different values than hers. She stated: "Yeah... maybe not consciously in your private life it's not consciously but it's something in you I never thought of it yes but of course ethics, responsibility, integrity, of course humanism, of course 
this is something I follow in my personal life of course this is not something far from my own values." P4 explained that she follows the same values and principles at work and in her personal life because this is who she is and she believes in them.

P1, P2, P3, and P11, collectively argued that they believe that one should conduct business without causing harm. P1, P3, and P11 are selected as they show the variedness about how this transpires. P1 explained that the Managing Director does not accept to hurt anyone to benefit the company; on the contrary he believes that by working ethically and fairly and respecting employees, suppliers, and the environment they will give the company back and the company will maintain its credibility. P3 solved an ethical dilemma by reporting an unethical act to prevent more harm in the future. P11 argued that a company should advertise in an ethical way that does not hurt anyone.

The results show that there are generational differences concerning inclinations towards CSR more particularly millennials are a generation which is predisposed to ethics and CSR and embrace these concepts in business. For example, P4 stated that millennials are a particular age group that is inclined towards ethics and CSR and integrate these concepts at work. She also argued that as of 2013, fresh graduates joining the company learned about ethics and CSR at the university. This facilitated their understanding of and contribution to CSR as opposed to their fellow colleagues from older generations. 


\subsubsection{The Role of Individual Professional Circumstances on CSR}

The second theme depicted in this research is the role of individuals' professional circumstances on CSR. The section below provides an explanation of what those professional circumstances are and how they affected the participants' inclinations towards CSR. Table 5.3 demonstrates the part of the coding which is relevant to theme 5.2.2. Specific quotes to support the coding are discussed below.

Table 5.3: Coding of the second theme

\begin{tabular}{|l|l|l|}
\hline \multicolumn{1}{|c|}{ Third-order Themes } & Second-order Categories & \multicolumn{1}{c|}{ First-order Codes } \\
\hline $\begin{array}{l}\text { The role of individuals' } \\
\text { professional circumstances } \\
\text { on CSR }\end{array}$ & $\begin{array}{l}\text { The effect of corporate and } \\
\text { management values on the } \\
\text { practice of CSR }\end{array}$ & Management values \\
& & Corporate values \\
\hline
\end{tabular}

When inquired to explain based on what values and principles managers made their managerial decisions, they listed the following values: autonomy and employee empowerment, competencies, dignity, empathy, ethics, gender equality, honesty, humbleness, integrity, openness, quality, respect, responsibility and engagement, transparency, and trust. Besides, the respondents clarified that their personal and family values are very similar to the corporate values. So, their answers are consistent because as earlier explained the participants abide by the same values in all settings be it personal or professional.

Another outcome of this research is that managers interviewed value ethics and consider it of high importance. P11 and P13 are representative examples of this outcome. P11 stated that her most important value is ethics and that she is ethical by nature and does not even think about it. P13 said: "Having a sound ethical conduct is key to instilling trust in relationships, be it on a personal level or at an organizational level, and ensuring the 
soundness and integrity of that ethical conduct entails a great level of transparency and accountability towards those who are influenced or impacted by that conduct."

All interviewees were categorized as top managers and had the following job titles: Quality, HR, and CSR Manager, Managing Director, Head of CSR, CSR Representative, Country Manager, Partner and General Manager, CSR/SD Coordinator Communication Manager, Head of Communication Department and CSR Manager, General Manager, CEO, CSR Manager, and Public Affairs and Creating Shared Value Manager. Top managers are the ones responsible of setting the rules and implementing them and guiding employee behaviour. The data shows that top managers are the ones who set the ethical tone in companies. For example, P10 explained that companies worry if top managers are corrupted and not employees at a lower level because they are the ones who set the ethical tone at the company and if the head of the company is corrupted the whole company will be corrupted.

Additionally, when the respondents were asked to list the values of their respective MNCs, they mentioned the following corporate values: autonomy and employee empowerment, competencies, equality, gender equality, hard work, honesty, humbleness, integrity, precision, respect, responsibility and engagement, servant leadership, and transparency. Those values were also apparent in the corporate documents of the MNCs where available. The study also showed that these corporate values are the base of the corporate culture and are practiced not just stated. As depicted earlier, these values are very similar to the managerial values listed by the participants, which also shows consistency in the participant's answers. In fact, the respondents mentioned that they fit with the corporate culture and hence have a sense of belonging to their organizations. This facilitated the integration of CSR within the corporations. Furthermore, the corporate values and cultures of 
three out of ten MNCs are inspired by the ten principles of the UNGC; MNC4, MNC5, and MNC10. This made CSR adoption and implementation evident in these MNCs.

Six of the ten sampled MNCs, MNC3, MNC4, MNC5, MNC6, MNC7, and MNC9, value equality, have a diverse workplace, practice inclusivity, and hire employees who differ based on for example nationality, gender, age, and religion. P4, P10, and P11 serve as representative examples for this result. P4 explained that she practices inclusivity by coordinating a lot and taking different opinions into consideration to implement CSR projects. P10 mentioned: “...there is a combination of different nationalities. We have hmmm... a local executive committee for ...Lebanon, we have hmmm...the HR director she's Lebanese, the CEO is Lebanese or dual nationality but we consider him Lebanese, we have a Swiss CFO, the sales and marketing is Lebanese, and the plant director I think from Croatia." P11 stated that the bank respects people from different religions.

Moreover, this study shows that the corporate values and the code of ethics established in the sampled MNCs are another driver of CSR decisions and corporate actions. P4, P10, and P13 are selected as they show the variedness about how this transpires. They formed the base for CSR and they assisted the participants in structuring CSR in their respective MNCs. P4 argued: "...so the essence of CSR is in the values, in the code of ethics and conduct of the bank and in the actual leaders of the bank, so that helped very much, to go into CSR that was structured in about 56 years ago." P10 explicated that the code of ethics includes topics on integrity and business practices, anti-bribery, gifts and hospitality, fair competition, accurate recording and reporting, conflict of interest, insider trading, contacting international business, and preventing money laundry. P13 said: “...globally does have a code of ethics which does guide the kind of policies we adopt towards our community involvement, and we also let some 
of the policies that... applies in its company-owned markets influence our thinking forward in terms of improving our sustainability practices."

In this research, ethics was given two definitions. The first one was explicated in the previous section and reflected how individual managers in this study define ethics based on their personal convictions. The second one reflects how MNCs in which these managers work define ethics and it turned out to be as follows: ethics means integrity, trust, openness, transparency, respecting the rules, people who are different, and employees, and not being corrupted. This definition includes some of the corporate values previously listed when the respondents were asked about the corporate values of their MNCs. Thus, a business' definition of ethics clarifies how it perceives ethics and will be reproduced in its actions. For example, the preceding paragraph shows how a corporate value was reflected into tangible corporate actions. In fact, these MNCs' values included respect, they also mentioned respecting people who are different in their definition of ethics and they actually applied this by practicing inclusivity and hiring diverse employees.

\subsubsection{Legacy Stories from Individuals}

Legacy stories from individuals is the third theme that emerged from the data. The section below highlights some stories told by the participants regarding how they solved the ethical dilemmas they have faced at work. Table 5.4 illustrates the part of the coding which is relevant to theme 5.2.3. Specific stories and quotes to support the coding are discussed below.

Table 5.4: Coding of the third theme

\begin{tabular}{|l|l|l|}
\hline \multicolumn{1}{|c|}{ Third-order Themes } & Second-order Categories & \multicolumn{1}{c|}{ First-order Codes } \\
\hline $\begin{array}{l}\text { Legacy stories from } \\
\text { individuals }\end{array}$ & $\begin{array}{l}\text { Legacy stories from } \\
\text { individuals of ethical } \\
\text { dilemmas and resilience }\end{array}$ & Stories of ethical dilemmas \\
\cline { 3 - 3 } & Resilience \\
\hline
\end{tabular}


Resilience is quite evident in this research as the participants had to maintain an ethical stance in light of very challenging times. Resilience is observed from the fact that some of the participants' resolve to ethical had been tested. There are many definitions of resilience, but for the interviewees, resilience means being steadfast. In fact, the participants suffered because they refused to change their ethical values and convictions. All respondents except P6 told several stories to explain how they solved their ethical dilemmas and how their MNCs suffered. P6 could not remember any story on the day of the interview. Four good examples will be provided in the following paragraphs to show the variety of ethical dilemmas faced by the participants.

One story of solving an ethical dilemma was told by P7 who explained that Lebanon is a very corrupt country and companies can make easy money and a lot of money if they follow this corrupt system. For example, if companies misrepresent their financial numbers they pay fewer taxes to the Lebanese government and benefit. So P7 is always facing ethical dilemmas wherein unethical practices can lead to increased profits, more business, and success while ethical practices may reduce profit generation at some point in time. However, P7 does not accept to act unethically for the sake of making more money. P7 stated:

“...first of all, we fight corruption, we don't accept bribes, we are not part of it and if we had accepted to be a part of the corruption cycle in Lebanon it would've been the best company in Lebanon, but because we have our transparency obligations we have our standards of compliance we do not, we are not part of any corruption hmmm ...system our business performance suffers and we lose money and face delays in our papers because we simply work by the law, we adhere to the law, we are fully declared on the level of social security, insurance, hmmm...our figures to the government tax everything. We are a 100\% complying company and we refuse to pay bribes or be bribed. So, one of the ethical dilemmas I face in Lebanon is whether to make the company number one by accepting bribes and making a lot of money or 
follow my ethics and convictions and only conduct business appropriately. In fact, if I accept bribes to for example transport illegal stuff my company will make a lot of money, a huge amount of money, but if I don't then the company will suffer from money loss and a decrease in its rank in the Lebanese and regional markets ... but I am a very stubborn person; I go by the code of ethics, I never take a decision that is against my convictions and I paid harshly for that and highly but as I said I'm a stubborn person. I face anybody, I can face the whole world for my principles and I will never deviate. So even in times of war and chaos when it was very easy to make money and benefit I did not accept to do anything against my convictions although it was an ethical dilemma for me because if I accepted to conduct unethical business or practices the company would have made a lot of money hmmm...you also know that Lebanon is currently facing bad economic conditions and all companies are suffering from money loss and a reduction in sales and we are in the logistics business so it is very easy for us to make money by accepting to ship and transport illegal goods or operate unethically but we don't so again this is an ethical dilemma because the company's financial performance is suffering because we refuse to deviate from our ethics."

Another story was told by P10 who continuously suffers from delays in business' operations because he refuses to bribe the police officers to release the company's trucks. In fact, police officers in Lebanon take away the company's trucks for no legal reason but only to receive bribes from the $\mathrm{CEO}$. The ethical dilemma here is that $\mathrm{P} 10$ has to decide whether to just pay the bribe to prevent the business from suffering or maintain his ethical convictions of not paying bribes and see the business go through the pain resulting from delays in operations or loss of profits. Every time P10 refuses to change his ethical convictions even at the expense of delaying or stopping some business operations. Thus, P10 is being steadfast in never changing his ethical stance while the firm recovers from poor performance due to those incidences. 
P13 explicated that the company came up with a community program whereby they allowed their employees to screen their neighborhoods for and choose NGOs and schools in need of support. So, the employees' choices of schools conflicted with the customers' opinion because they were expatriate schools and not national ones. Therefore, the company asked its employees to restrict their choices to national schools which were better funded and not in need of any help. Consequently, an ethical dilemma emerged wherein P13 had to find a solution because there was a conflict of interest between employees and customers. In fact, on one hand and from an ethical perspective it was not right to exclude expatriate schools from this CSR program just because expatriate children learn there and knowing they were really in need. On the other hand, if customers are dissatisfied with the company's choice of schools then it will be losing them and thus losing money and profits. P13 stated:

"One of the situations I faced within my area of responsibility concerned the Community Connections program and its implementation in some Gulf Cooperation Council (GCC) markets. In its previous framework, the program enabled partners i.e. employees to go out and screen their neighborhoods for NGOs and schools who are in need for support. In the GCC region, our partners predominantly come from expatriate communities, and such communities have their own small-scale schools that are usually underfunded and could use the help of donors and supporters to improve their facilities and the learning environment they offer to children. Therefore, it was perfectly sensible for our partners to want to work with such schools, however the business was concerned that working with expat schools may have negative repercussions on the business as locals may interpret that as a betrayal to them as customers. As a result, partners were asked to keep their focus towards national schools - which in reality were better funded and equipped than their expatriate counterparts. This of course has created an ethical dilemma where the interests of our partners who are volunteering their time potentially clashed with those of our customers. If that had been allowed to continue, then our partners' morale and confidence in our honest intent to serve communities could have been damaged. This was taken in as a top priority when we worked on revamping the program's 
framework, as a result, the new framework required that themes such as Adopt a School would apply market-wide as opposed to be applied on district level or groups of stores as previously done. By doing this, the number of schools we supported in every market grew, giving us the flexibility to support schools of different backgrounds without alienating one background or the other. This was widely celebrated by our partners, and now they feel even more motivated to go out and volunteer their time to support local schools knowing that another group of their colleagues are out supporting an expatriate school. This was also positively perceived by our customers in such markets, which further enhanced the business' confidence in CSR and its ability to listen to stakeholder groups' concerns and bring forward solutions that create positive impact and strengthen those stakeholder relations. This was only possible by:

- Engaging our stakeholders in a two-way dialogue and listening to their interests and concerns;

- Incorporating stakeholder inputs into our decision-making;

- Declining our thought process with our values and intent to maintain the fairness and integrity of our CSR;

- Coming forward with a clear guideline and framework that ensures the fairness of the program as it goes to implementation; and

- Ultimately reporting back to our stakeholders on the outcomes of the program to maintain their confidence."

The last example is the ethical dilemma faced by P14. She explained that her company invested a lot of money in a project and it was very profitable and successful. However, after a period of time she discovered that it was unethical because it was using an indirect way of marketing to children. So, she worked on convincing management to stop it because it was an unethical practice and against the rules and her personal ethical convictions. Thus, the ethical dilemma that she faced in that case is whether she had to choose ethics over profits and stop a profitable project that cost her company a lot or keep the project and make more money because till that time no one knew it was a different way of marketing to children. P14 stated: 
“...two years back we have launched like a mini museum like a children gallery in our manufacturing facility about chocolate. So schools come and they see how chocolate is made so it's like a mini museum but it's about chocolate... and it was big quite an investment to do this and we were proud of it and schools were asking for it to come and visit because it's also part of you know them learning, them learning how manufacturing happens. Hmmm ... and also in this gallery we also made a special also activation room where they learn about nutrition so it's not like marketing they learn there's a lot of learning happening. However, when this policy came it was a dilemma we are being contradictory. We say we don't at all communicate to children when it comes to chocolate and we have this museum that we bring them and we are indirectly marketing chocolate to children and they are not its they are not with their parents they are with the school it's not like they are participating with their parents in something it's hmmm...it's not right, it's unethical because we are marketing to children. So it wasn't right...so this is where we did so many meetings internally on how to solve it how to evolve it or how to fix it or what to do about it hmmm... and we were like hmmm...pushing the higher management and not pushing, communicating so they understand what's the ethical dilemma. The ethical dilemma here was that the way we were marketing to children was unethical however we invested a lot of money in the project and we were making a lot of money out of it so if we stop it the company will lose some profits and its investment in the museum. I also explained to management why our current practices are unethical and eventually we stopped this museum... Yeah, ethically it's wrong. If we're saying we don't communicate to children then we're doing something wrong. Even though they are visiting us and so on there's still a line where it's not right hmmm...now we changed our whole concept in our new manufacturing facility we have a visiting area for adults and stakeholders and it could be university students but no more for you know kids learning about manufacturing...I was against I mean I pushed for the for it to stop. That's why it was a dilemma, at the end of the day it's a place where we have invested money, it's needed, it's wanted but it was unethical so there was a compromise to make." 


\subsubsection{Familial Environment in the Organization}

The fourth theme is familial environment in the organization. The section below explicates how the work environment of the MNCs selected influenced CSR adoption and implementation. The part of the coding which is relevant to this theme is shown in table 5.5. Explicit quotes to upkeep the coding are discussed below.

Table 5.5: Coding of the fourth theme

\begin{tabular}{|l|l|l|}
\hline \multicolumn{1}{|c|}{ Third-order Themes } & Second-order Categories & \multicolumn{1}{|c|}{ First-order Codes } \\
\hline $\begin{array}{l}\text { Familial environment in the } \\
\text { organization }\end{array}$ & CSR starts at home & $\begin{array}{l}\text { Employees as the most } \\
\text { important stakeholders }\end{array}$ \\
& $\begin{array}{l}\text { Employees as family } \\
\text { members }\end{array}$ \\
\cline { 2 - 3 } & Internal CSR taken outside \\
\hline
\end{tabular}

The CSR reports of the MNCs revealed that these companies consider their employees as family. Besides, the research participants collectively stated that employees work together as family members in their respective MNCs. For example, P12 stated:

“...today, if you talk to any employee in...or in any other company within... Group he tells you I am living within a family...Let us say we are Lebanese but at the same time we are living as a family...I am just saying but we really act this way from CEO till the lowest level employee in the company...I was telling you that ethically we are living as a family in all means...This is our home we sit in our offices for 9 hours per day. All employees came and chose their offices and they asked us to tell them how do we want to sit in our offices? Where do you want us to put the Air Conditioner $(A C)$ for you? Do you want a big or a small AC? Hmmm...I didn't do this only to create a good environment but at the same time for them to feel that these are their own offices. I told my employees if you come and open your own company how would you like your office to be? Do it..." 
Eight of the fourteen interviewees, P1, P2, P5, P7, P8, P9, P10, and P12, also claimed that they are operating in a friendly and informal work environment with an open-door policy. $\mathrm{P} 1$ and $\mathrm{P} 2$ serve as representative examples for this result. P1 explained that the corporate culture encourages a friendly and familial atmosphere and an informal work environment. P2 mentioned that the company has a very low turnover because of its friendly environment.

Another major finding is that CSR starts at home. In fact, all participants stated that their MNCs take care of their employees a lot and are socially responsible towards them. For example, $\mathrm{P} 2$ indicated that an employee had to stay in the hospital with her sick son and she could not come to work for the last six months. The company kept on paying her salary every month, brought another person to replace her, and checks on her and her son on a daily basis. The participants explained that they take care of their employees first because if employees do not understand what CSR is and if the company is not socially responsible towards them, then how can they implement CSR or help the company engage in it?; it will be contradictory. P1, P11, and P14 are selected because they show the variedness about how this transpires. P1 argued that employees do not get absent a lot, do not like to take days off, and never lie or hide anything because the company respects them and treats them ethically. P11 clarified that the company values stewardship and is always strongly committed to protect and improve the wellbeing of its employees. P14 explained that when employees understand the true meaning of CSR, they become prouder to be part of the company.

The corporate documents of the MNCs showed that these organizations place a high importance on employees. All respondents also claimed that their MNCs consider their employees as one important stakeholder. P7 and P13 serve as representative examples for this finding. P7 stated: “...our stakeholders are our employees we treat them well, we encourage them, we train them, we support them on all levels..." P13 explained that the most important 
stakeholder group of the company is its employees because they are the biggest brand ambassadors, they are the company's largest resource, they are a reflection of the communities in which the company operates, and they positively influence CSR.

Additionally, the managers interviewed collectively posited that being socially responsible towards employees is part of their MNCs' corporate cultures. This finding was also validated by the available documents of the MNCs. P2, P4, P9, and P11 are selected because they show the variedness about how this transpires. P2 supports and motivates employees to engage in CSR. P4 claimed that she was first hired to be part of the employee well-being program. She added that employees are recognized for their CSR contribution but it is not yet included in their performance appraisal. She also wants employees to have CSR as their main goal and trigger their thinking for future CSR initiatives. P9 explained that her MNC considers human rights, employment practices, trainings, and employee engagement part of CSR. P11 posited that her MNC does not only value its employees a lot but it also involves them in CSR decision-making.

Furthermore, all participants mentioned that CSR started internally first then was taken outside of the company. Besides, CSR actions are part of the internal operations and day to day activities at the companies sampled. P1, P4, P11, P12, and P14 are selected because they show the variedness about how this transpires. P1 posited that companies should start working on CSR internally before taking it outside. She indicated: “...then we realized, the management realized that CSR was much more than just employee well-being and let's take it out of the HR and have it report directly to management...we must begin internally then help people you know? So, we don't have to harm the ecosystem and then plant some trees you know?...” P4 claimed: “...We loved the carbon footprint idea a lot. We said this is, and before the garbage epidemic I really like to highlight that, we said this is something we can give to our youth and this is something we can externalize our environmental protection to the 
community, listen Marguerite we are not one of those institutions who would put a green leaf on our logo and just say we're green no, we have to have piloted, monitored, assessed, run the program internally before we even talk about it, we've done it, we've done our own recycling we've done the carbon we came to the maturity and we said this would be a great way to engage Lebanon's youth on environmental impact it happened..."

P11 argued that CSR activities that are external to the company are the end result of internal CSR. She said: “...Everybody thinks that CSR, because again it's the easiest to be advertised and which everybody does that is the community and activities, these are just activities this is not really CSR, it's if you want, it's the end result of the internal CSR..." P12 posited that his MNC created an internal policy to empower women and encourage them to breastfeed as part of their CSR initiative. P14 explained that employees and other managers in the MNC are committed to CSR and have it as one of their roles and objectives.

Moreover, the analysis of the companies' documents show that they try to externalize CSR by motivating their stakeholders to be socially responsible. For example, MNC6 did an awareness session to its suppliers to explain to them its CSR strategy and activities. It also evaluates its suppliers every year to make sure that they are meeting its social requirements. 


\subsubsection{Vocation and Workplace Settings}

Vocation and workplace settings is the fifth theme that emerged from the data. The section below highlights how the participants perceive CSR as a vocation. Table 5.6 illustrates the section of the coding which is relevant to theme 5.2.5. Precise quotes that underpin the coding are shown below.

Table 5.6: Coding of the fifth theme

\begin{tabular}{|l|l|l|}
\hline \multicolumn{1}{|c|}{ Third-order Themes } & Second-order Categories & \multicolumn{1}{c|}{ First-order Codes } \\
\hline $\begin{array}{l}\text { Vocation and workplace } \\
\text { setting }\end{array}$ & CSR as a vocation & Emotional devotion to CSR \\
\cline { 3 - 3 } & & $\begin{array}{l}\text { Job satisfaction and } \\
\text { motivation }\end{array}$ \\
\cline { 3 - 3 } & & Organizational citizenship \\
\hline
\end{tabular}

All CSR managers interviewed saw CSR as a vocation more than merely part of their job. They appear to be emotionally invested in CSR. They stated that CSR is a reflection of who the person really is and what he/she believes in. P3 and P4 serve as representative examples for this result. P3 explained that she loves it that her work is in CSR. She also believes that there is a link between her and CSR and she finds it very interesting. She said: “...because I hadn't heard of the term CSR before I felt that this is what I want but I didn't know how to express myself or how to call it CSR if you want so yeah CSR doing business this way, I woke up and I felt that this was me...Yeah, I found myself that's it. And I really loved this job a lot it was local development with municipalities, with youth groups it was amazing..." P4 stated that she is very passionate about her job and believes that this is what she is; she is a triple bottom line person and cares about people, planet, and profit. She stated: “Hmmm...I laughed because I don't know if you've noticed that but I get this a lot that I'm so passionate about what I do and it is what I am it is what I am so nothing changes..." 
Furthermore, all research participants exhibited job satisfaction, motivation, and organizational citizenship. In fact, job satisfaction and motivation were perceived because the interviewees collectively stated that they are happy and motivated at work. Besides, organizational citizenship was relevant because the participants voluntarily committed to actions within their companies that were not part of their contractual tasks such as volunteering in cleaning the Lebanese beaches as part of the firm's CSR activities. This finding was also validated by the CSR reports of the MNCs where there were several descriptions and statistics showing how much employees were engaged in and contributed to their companies. The interviewees also mentioned that they have a feeling of belonging to the companies they work in because they believe in the same values. For example, P2 explained that employees never leave the company even for higher salaries because they are comfortable and happy with the corporate culture, values, and spirit that are predominant in the firm.

\subsubsection{Eextraneous Culture and Values}

The sixth theme is extraneous culture and values. This section explains how the participants' CSR actions and decisions were affected by the Lebanese culture, values, and needs. Table 5.7 shows the part of the coding which is relevant to theme 5.2.6. Specific quotes that support the coding are shown below.

Table 5.7: Coding of the sixth theme

\begin{tabular}{|l|l|l|}
\hline \multicolumn{1}{|c|}{ Third-order Themes } & Second-order Categories & \multicolumn{1}{c|}{ First-order Codes } \\
\hline $\begin{array}{l}\text { Eextraneous culture and } \\
\text { values }\end{array}$ & $\begin{array}{l}\text { The influence of national } \\
\text { culture on managerial } \\
\text { decisions relating to CSR } \\
\text { and ethics }\end{array}$ & $\begin{array}{l}\text { Lebanese culture } \\
\text { on CSR decisions and } \\
\text { activities }\end{array}$ \\
\hline
\end{tabular}


The companies' documents showed how important family was to the Lebanese culture and revealed several activities that these MNCs did that are related to family. Participants stated that dealing with people as family members is a characteristic of the Lebanese culture. For example, P1 mentioned: “...There is really the tradition in the way the Lebanese traditional way of dealing with people as a family..." Another characteristic of the Lebanese culture was noted by P12 who argued that Middle Eastern women envy Lebanese women because they are more open-minded and work; this is something special that characterizes the Lebanese society. In fact, all CSR managers interviewed were women except for one who was a man i.e. P13.

Another finding is that people differ from culture to culture and thus understand and perceive things differently. In fact, the documents of the selected MNCs showed that the same CSR activity should be implemented differently in every country because people are different and will not embrace it the same way. Another result is that managers differ from culture to culture which affects how they conduct business and make decisions. P10 and P12 serve as representative examples of this result. P10 explained that an individual's personal background and culture affect how fast they grasp CSR. He also added that managers make decisions differently because they have different management styles, characters, values, and cultures. P12 explicated that foreign employees and managers coming from a different culture get surprised when they visit the company and see how Lebanese people behave and decide at work in an informal and very friendly manner.

Furthermore, all participants argued that people define ethics differently depending on their own values and perceptions of what is right and wrong. They also posited that a person's culture affects his/her ethics. For example, P3 explained that in Austria it is unethical to throw garbage or a tissue paper on the street but in Lebanon it is not viewed as an unethical practice. 
She also added that paying or receiving bribes is a common practice in Lebanon and is not perceived as unethical while in Austria this is considered unethical.

The companies' documents revealed a pattern that MNCs customize CSR activities depending on the needs of every country. This was also further explained in the interviews wherein all participants explained that when making CSR decisions in Lebanon and abroad, their MNCs assess the local needs of the community and the environment and then set a plan to tackle them. P10 and P13 serve as representative examples of this finding. P10 stated that P9 selects the initiatives that make a difference in the community. He also mentioned that his company hires people to work on CSR depending on the needs of every country; some countries need a department with several employees, others only need one employee. P13 explained: “...As part of this approach, the MENA i.e. Middle East and North Africa, the MENA CSR team looks at global responsibility programs being implemented by ... and investigates how feasible they are to be implemented at MENA level. This of course takes into account regional and national needs and how the global framework can actually be redesigned to meet such needs..."

Furthermore, all research participants explained that the headquarters suggest a list of CSR initiatives but the local managers choose according to the needs of the local community. P8 and P14 serve as representative examples for this result. P8 clarified that the company customizes its engagement to suit each of its stakeholders' unique context and needs and it conducts annual stakeholder consultations, surveys, and meetings. P14 explained that CSR activities need to be customized and relevant to the local needs of each society because people are different and have different needs. 


\subsubsection{CSR to Disrupt Existing Institutions}

CSR to disrupt existing institutions is the seventh theme that emerged from the data.

The subsections below explicate how the participants used CSR to disrupt existing institutions in Lebanon. Table 5.8 reveals the part of the coding which corresponds to this theme.

Particular quotes that support the coding are shown below.

Table 5.8: Coding of the seventh theme

\begin{tabular}{|c|c|c|}
\hline Third-order Themes & Second-order Categories & First-order Codes \\
\hline \multirow[t]{9}{*}{$\begin{array}{l}\text { CSR to disrupt existing } \\
\text { institutions }\end{array}$} & \multirow[t]{4}{*}{$\begin{array}{l}\text { Types of CSR activities } \\
\text { practiced by MNCs }\end{array}$} & $\begin{array}{l}\text { Community service and } \\
\text { development }\end{array}$ \\
\hline & & Environmental protection \\
\hline & & Employee wellbeing \\
\hline & & Corporate philanthropy \\
\hline & \multirow[t]{4}{*}{$\begin{array}{l}\text { CSR disrupting local } \\
\text { government practices }\end{array}$} & $\begin{array}{l}\text { CSR's disruption of } \\
\text { sectarianism }\end{array}$ \\
\hline & & $\begin{array}{l}\text { CSR's disruption of local } \\
\text { laws }\end{array}$ \\
\hline & & $\begin{array}{l}\text { MNCs' best practices as } \\
\text { disruptive }\end{array}$ \\
\hline & & $\begin{array}{l}\text { Transparency and respect as } \\
\text { disruptive }\end{array}$ \\
\hline & $\begin{array}{l}\text { CSR disrupting practices of } \\
\text { the local private sector }\end{array}$ & \\
\hline
\end{tabular}

\subsubsection{Types of CSR Activities Practiced by MNCs}

\subsection{Community Service and Development}

The CSR reports of the MNCs described several types of CSR activities that they engaged in. Community service was part of their CSR activities. The research participants also explained through the interviews that their MNCs encourage their employees and customers to 
volunteer in community service. P4 and P12 serve as representative examples of this finding. P4 specified that her company spends USD 4.6 million yearly as community contributions. P12 explained that they sponsor all monasteries that take care of the elderly and clinics of municipalities because the government does not provide a full support. He also added that they created a foundation that supports farmers and students. MNCs from the sample conduct CSR activities to fill the gap that the Lebanese government cannot and does not fill. Many societies including developed societies cannot flourish without the help of charities and the private sector.

The study also revealed that the MNCs engage in community development as part of their CSR activities. The following list of activities clarifies the types of community development initiatives that MNCs practice:

- Supporting municipalities to improve infrastructure, install water networks for citizens, and other types of community service.

- Improving the quality of life.

- $\quad$ Educating the young generation on many important topics.

- Supporting schools and helping them develop social and environmental programs for the students to engage in community development.

- Creating water tanks for locals in order not to get cut off from water.

- $\quad$ Building soccer fields for kids.

- Enhancing the infrastructure of the roads.

MNC2 and MNC3 engage in CSR projects that have a cultural impact. For example, P3 stated: “...we have also the community pillar where we traditionally had been supporting a lot of arts and culture and we are still doing it. We support a lot of festivals across the country like Baalbek Festival and Beit El Dine Festival, Beirut Art Center as well and there is a lot I will not list them all but there is a lot of support..." 


\subsection{Environmental Protection}

All CSR reports of the selected MNCs show that they take care of the environment. The research participants also stated that their MNCs consider the impact of their decisions on the environment. The following list of activities clarifies what these companies do to take care of the environment:

- $\quad$ The company first started community connections and Lebanon reforestation.

- Cleaning the environment.

- Producing environmentally friendly products.

- Biodiversity and rehabilitation projects.

- The company works to reduce its greenhouse gas emissions, invests in solar energy, is committed to green building, and has certified warehouses built as per the Leadership in Energy and Environmental Design (LEED) specifications.

- Utilizing low emission vehicles and electric vans and bikes that meet Euro 5 standards.

- Investments to reduce water pollution.

- $\quad$ Sponsoring camps and festivals by donating products especially trash bags and bins to preserve the environment.

- Ecological engagements.

- $\quad$ Using degradable supplies.

- Taking care of the rural environment, water, and nutrition.

- Recycling. 


\subsection{Employee Wellbeing}

Employee wellbeing is a different type of CSR activity that was apparent in the MNCs' CSR reports. The interviewees also mentioned that employee wellbeing was an important CSR activity at their MNCs. P4, P7, P9, P10, and P11 are selected because they show the variedness about how this transpires. P4 specified that the bank has a grievance mechanism that includes topics such as supporting a positive work environment, violence and harassment free workplace, discrimination free workplace, alcohol drugs free, acting responsibly, working hours, affiliations, gambling, working etiquette, and communicating. P7 mentioned that corporate values include helping employees move forward. P9 clarified that the firm established a health program to take care of its employees and conducts health awareness sessions, health-related tests, and blood tests. P10 explained that his MNC values employees a lot because they are the ones who drive the companies. P11 said that she makes her managerial decisions based on the value of stewardship.

\subsection{Corporate Philanthropy}

Educational projects were another type of CSR activity that was identified in the CSR reports and this also validates what the interviewees mentioned regarding educational projects. For example, P4 specified that the bank spends USD 8.9 million yearly on educational programs. She mentioned that the bank provides scholarships to scholastic institutions to help children who cannot afford to pay their tuition fees. The bank also gives zero percent educational loans to Saint Joseph University (USJ) students and they get to repay the loans when they graduate. P4 indicated as well that the bank sincerely believes in human development and spends USD 2.8 million yearly on trainings.

Any CSR reports show that they engage in sponsorships, charity, donations, and collaborations with NGOs. All research participants also mentioned this during their 
interviews. P12 and P13 serve as representative examples for this finding. P12 explained that the company collaborates with an NGO for disabled people to hire disabled employees. He also mentioned that his MNC collaborated with an NGO and the ministry of health in Lebanon to spread awareness about the importance of breastfeeding. P13 mentioned that his MNC provides funds to social entrepreneurs as part of its CSR initiatives. He stated: “...Another example would be our...in Jordan in partnership with the International Youth Foundation through which we have been supporting 65 young social entrepreneurs in Jordan through funding and capacity building for the past 5 years to help them sustain and grow their social ventures..."

Economic development was also another type of corporate philanthropy which was apparent in the data collected from the CSR reports of the MNCs and from the interviews. P5, P7, P8, and P13 serve as representative examples because they show a strong single pattern of this result. P5 and P7's MNCs established CSR programs to support SMEs. P8 explained that the company provides commercial support, mentorship, and guidance to help small businesses and startups integrate sustainability in their business processes. P13 explicated that the company established a special CSR program to provide education and employment opportunities for young people.

Moreover, social development was apparent as a kind of corporate philanthropy among the participants' answers and in the MNCs' CSR reports. The following examples are selected because they show the variedness about how this transpires. P5 explained that the company offers scholarships and professional training programs for the youth. P14 mentioned that the firm conducts business through commitments to society to implement its social development programs. MNC4, MNC5, and MNC6 have CSR programs to support the youth. MNC4, 
MNC5, MNC7, and MNC8 support women through several CSR initiatives as women are an important agent in developing societies and raising generations.

\subsubsection{CSR Disrupting Local Government Practices}

\subsection{CSR's Disruption of Sectarianism}

All research participants argued that CSR is disrupting sectarianism. P5 and P7's statements serve as representative examples of this finding. P5 mentioned that as part of its CSR activities the company teaches the younger generation the value of the human being, of citizenship, and of respecting people from different religions. P7 explained that she only believes in working for the community without taking politics into consideration. In fact, in Lebanon people tend to be inclined towards and help others who have the same political and religious beliefs by neglecting those who have the opposite. Thus, the research participants explained that by helping everyone equally through CSR this ideology is being disrupted.

\subsection{CSR's Disruption of Local Laws}

All participants mentioned that governments of foreign countries have direct and indirect laws that oblige companies to engage in CSR. P3, P4, and P11's statements are used as representative examples of this result. P3 explained that there is no need to implement all CSR initiatives done in Lebanon abroad because governments in foreign countries like Cyprus, France, and Geneva impose laws on companies to be socially responsible. So many CSR initiatives are already mandatory. She also mentioned that companies face many environmental changes in the Lebanese market and today companies need to find alternative ways for the world to be sustainable. P4 explained that the European law obliges companies to be socially responsible. P11 mentioned that in Europe companies get two percent of their taxes back if they engage in CSR. P11 also stated that the Indian government requested that 
companies use two percent or five percent of their profit for CSR. So, CSR is done differently abroad because governments are stricter.

Moreover, the participants believe that the Lebanese government should start imposing CSR laws on companies. P4 and P9 are examples of this research outcome. P4 argued that it is unfair not to take any incentive from the Lebanese government for practicing CSR because many competitors are not engaging in CSR. P9 posited that CSR is the company's license to operate in the community. Likewise, the participants argued that CSR became a must in Lebanon.

The former results can be called normalization because MNCs from the sample are paving the way. This impacts government policy, even local government policy, which eventually will allow CSR to be reflected at that national level so that it becomes pervasive i.e. all companies in Lebanon are then obliged to undertake these activities. It is disruptive in terms of local Lebanese government because it is not something Lebanese governmental officials do and therefore if these companies are changing the way of what they do, it is disruption. These organizations are showing up the government.

\subsection{MNCs' Best Practices as Disruptive}

The research participants explained that the business operates as such: set objectives, set a business plan, and review results. This shows that their work is structured and organized. MNCs from the sample take their customers into consideration and place a high importance on results, innovation, entrepreneurship, and risk taking. This explains the previous finding where managers stated that their MNCs value and practice autonomy and employee empowerment. In fact, innovation cannot exist without decentralization and empowerment as employees cannot unleash their creativity if they are obliged to abide by too many rules and regulations and to follow a centralized decision (Hempel, Zhang, \& Han, 2012). Additionally, all MNCs 
have a value statement. This shows that they take their values seriously. Besides, as previously discussed corporate values are not just stated they are practiced.

Additionally, all MNCs from the sample were among the first companies that practiced CSR before it became a trend in Lebanon. This finding was also validated from the secondhand data collected from the MNCs. P12 and P14's statements serve as representative examples of this finding. P12 mentioned that the company officially started CSR in 1981. P14 stated that her company was the first MNC in the Middle East to publish forward looking commitments to society. She also mentioned that the company was the first to adopt the creating shared value concept published in Harvard Business Review as its official strategy. She explained that after a discussion between the company's chairman and Michael Porter and Mark Kramer, they published a paper in Harvard Business Review on creating shared value in 2006. In addition, P14 claimed that the company engages in fair trade.

In addition, the companies' documents revealed that these MNCs conduct business in a socially responsible way. This also supported what their corresponding interviewees explained during their interviews. P4 from MNC3, P9 from MNC6, and P14 from MNC10 are selected because they show the variedness about how this transpires. P4 explained that the company pushes employees to conduct business while being ethical, environmentally protective, and socially responsible. P9 even mentioned that the company only works with suppliers who are socially responsible and enforce certain CSR rules on them as well. She also added that the company does not allow child labor. P14 stated: “...So we don't see benefit of society at the margin of our business we see it at the core of business so it's part of our strategy, part of the way we do business..." Moreover, the corporate documents and second-hand data support the conclusion that these MNCs are highly engaged in CSR in all their branches worldwide regardless of the country in which they operate. 
MNCs bring with them best practice; they show locals what the world does and how the top organizations practice CSR because it is not only efficient but it is also effective. Therefore, the former results are categorized as disruptive because they lead and they could possibly change the way in terms of how local Lebanese companies operate for three main reasons. First, these practices are defused to employees because people who work for MNCs may work one day for local companies and therefore take these practices with them. Second, MNCs' practices can be disruptive via exchanging practices of suppliers by urging them to follow their CSR values if they want to work with them. Third, MNCs can lobby governments particularly the Lebanese government by pushing it to do things better and set up certain policies.

\subsection{Transparency and Respect as Disruptive}

All research participants also argued that their MNCs do not accept to work in an inappropriate way and transparency and responsibility are very important for them. These organizations try to impress upon their staff the notion of responsibility and accountability to make them more responsible and accountable. It starts with the basic thing about the law and that extends to the spirit of CSR which is about responsibility and accountability. For example, P11 explained that the bank implements a zero-tolerance policy with regards to ethical issues and employees have no excuse to act unethically. She stated: “...but I tell you again what I felt here at the bank what I agree with is what we call the zero-tolerance meaning there is no way that someone makes a mistake. It's forbidden. We helped you and we told you and so on and so forth..." She further explained that because many Lebanese are by nature chaotic and do not follow the law, private companies impose certain policies when they want to enforce a certain behaviour and penalize people who deviate. So, this is disrupting the way the Lebanese 
government operates because the Lebanese government established some laws but fails to implement them appropriately.

All participants stated that their MNCs believe in anti-corruption and social human rights. For example, P6 stated: "We believe in anti-corruption this is why there are a lot of businesses we can't touch...As a logistics company we never accept to transport or get involved in any illegal or unethical operations..." This finding was also validated by available documents of the MNCs. Thus, if MNCs operating in Lebanon believes in anti-corruption then they will not accept a benefit at the expense of hurting someone else. This finding is in line with the previous one when managers explained that they take the interest of all stakeholders involved into consideration when making decisions because it shows that decisions taken are not only for the benefit of the company. It is disrupting because Lebanon is a known country to be a corrupt country and any force that comes in that fights corruption is disruptive, it is disrupting the norm.

All managers interviewed respect human rights and humanity. The following three examples are selected because they show a very strong single pattern of how this transpires. P2 stated: “...and I have to tell you something that I am a member of the committee of Human Rights which gathers only fifty members out of nine thousand or ten thousand members of the lawyers registered in the body, so I am a member in this committee since two decades, so this is my values in human rights and etc. and I am very close to this philosophy." He also posited that he makes his managerial decisions based on the values of respecting human rights and ethics. P3 argued that the values of the company include humanism. P4 explained that the CEO is very active when it comes to human rights and he is in the human rights watch NGO. Moreover, as explained in the previous section, respect is one important value that MNCs sampled have. This explains why managers and their MNCs respect human rights a lot and 
shows consistency in the participants' answers. This is disruptive because the participants made a point that human rights are not cherished or given any real importance in Lebanon and the practice of CSR hopes to change that over the long-run.

All participants collectively argued that to be ethical one should be objective when conducting business. For MNCs from the sample, to be ethical a company should give its employees all their rights, be transparent, not harm its stakeholders, and take care of the environment and the economy. The companies' documents and second-hand data of the MNCs show that they promote ethics. All the interviewees also stated that their companies did not face yet any serious unethical issue and in case some small issues occur, they are directly solved. P1 and P7 are selected as examples because they show the variedness about how this transpires. P1 argued that with regards to business ethics, the company engages in fair competition, is transparent, and does not hurt the environment. $\mathrm{P} 7$ posited that with regards to business ethics, the company does not accept bribes, is not corrupted, has a legal compliance, and is transparent. This is disrupting the norm in Lebanon because people are used to paying bribes to get their work done, not respecting the law, not being transparent, and hurting the environment.

This research shows that whistle-blowing is an important aspect of CSR. MNCs from the sample established a hotline for whistleblowing and a protective mechanism for employees who report unethical practices. For example, P11 stated: “Through whistle-blowing, this works a lot. And I think until now that the employees have been protected meaning the employees who use this system have been protected, I don't think there were any problems. So, I think having, this didn't exist in other banks, I worked in two other banks there was no system like this. This whistle-blowing if you look at CSR it's one of the most important and already when I came in 2011 there was already." Whistle-blowing is not a common practice in Lebanon. So, 
this is disruptive because when the sampled MNCs encourage their employees to practice whistleblowing, they will be encouraging them to be socially responsible and care for the public interest.

\subsubsection{CSR Disrupting Practices of the Local Private Sector}

All interviewees also explained that CSR is strategic for them. P11, P13, and P14's statements serve as representative examples of this result. P11 explained that the company works according to a CSR strategy with a plan of five years. She also stated that CSR is the new business model and the new strategic thinking. She also added: “... Very simple because I believe. I believe in it, very simple, why do I engage? Because I tell you again I believe that it is a new way of doing business...” $\mathrm{P} 13$ said: “...but what we are witnessing in recent years is that there is a lot more confidence in CSR's ability to serve as a business function as opposed to a nice-to-have initiative..." P14 stated: “It's our strategic, it's our fundamental way we do business...” Those MNCs' CSR strategies are informing the new business models and are disrupting the practices of local companies because they are changing the mindsets of local managers.

The research participants stated that employees, management, shareholders, suppliers, society, and customers are the primary stakeholders of their MNCs. But all of them emphasized the importance of employees as stakeholders because everything starts internally first be it a CSR activity or a regular business operation or decision. Moreover, engaging customers in CSR projects was also relevant in all the sampled MNCs. For example, P13 explained: "Our customers are also an important stakeholder group as we aspire to involve them in our CSR projects; be it as direct beneficiaries or as enablers who volunteer with us. Therefore, every time we have a CSR project taking place we build an awareness campaign 
around it that has a clear call to action to help them engage with it." The CSR reports of the MNCs validate this finding as well.

All interviewees stated that NGOs, the government, and the competitors are the secondary stakeholders of their MNCs. This was also found from the documentation of the organizations studied. As previously explained and as found in the second hand data, the Lebanese government does not enforce any law on businesses to engage in CSR. Moreover, as mentioned in chapter three, there is a high level of corruption in the Lebanese governmental body and generally in Lebanon. This explains why MNCs operating in Lebanon do not really consider the government as a primary stakeholder. This is disruptive because when these MNCs engage communities and those people considered as primary stakeholders, they are empowering them and helping them as a business to rely on themselves and not on the Lebanese government.

This research shows that CSR decision-making in the sampled MNCs works as such: need identification, check if need is relevant to the company, alternative evaluation in the CSR committee, proposal submission to top management, approval, implementation, follow up, and evaluation. In addition, the research participants explained that some CSR ideas are bottom up while others are top down. For example, P5 stated: "Some of them they come from the head office, they have good ideas that apply for everybody, and most of the time it's our own policy, locally."

Moreover, the research participants stated that CSR decision-making is the same in Lebanon and abroad. This shows consistency in CSR decision-making in all MNCs' branches worldwide. For example, P14 highlighted: "Yeah but that doesn't mean that we as Middle East because we are one entity we are 13 countries we are all hmmm...homogeneous that doesn't mean that Lebanon does something which is different from hmmm... United Arab 
Emirates (UAE), as relevant to the country but in the same direction... We have the same programs hmmm...they are implemented for example tomorrow's program started in Lebanon we replicated it in UAE then in Saudi Arabia then in Jordan now, now now... just last week we started it in Palestine and we didn't yet spread the news, you are the first one to know."

The results included in the former two paragraphs are disruptive because the best practices that have been laid out by large organizations just change the landscape in terms of how CSR is practiced. These MNCs basically make themselves as role models so by virtue of that they change the way things go. This is why it gives MNCs such a unique role and position because of the three-pronged impact they have on institutions. It disrupts because it brings in best practices that change the way CSR is practiced. It is also about tailoring because it allows for local adaptation of CSR activities. But at the same time, it maintains the CSR institution of large MNCs at headquarters because it still contributes, even though practiced locally or activities adapted locally, to the overall goal or principle of the global MNCs' CSR. 


\subsubsection{CSR to Tailor New Institutions}

The eighth theme is CSR to tailor new institutions. The subsections below explicate how the participants tailored CSR to suit the Lebanese context. The part of the coding which is relevant to theme 5.2.8 is shown in table 5.9. Specific quotes that support the coding are shown below.

Table 5.9: Coding of the eighth theme

\begin{tabular}{|c|c|c|}
\hline Third-order Themes & Second-order Categories & First-order Codes \\
\hline \multirow[t]{6}{*}{$\begin{array}{l}\text { CSR to tailor new } \\
\text { institutions }\end{array}$} & $\begin{array}{l}\text { Bottom up approach of CSR } \\
\text { to shape new institutions }\end{array}$ & \\
\hline & \multirow[t]{2}{*}{$\begin{array}{l}\text { Tailoring CSR to the local } \\
\text { context }\end{array}$} & $\begin{array}{l}\text { Tailoring CSR to the } \\
\text { Lebanese culture }\end{array}$ \\
\hline & & $\begin{array}{l}\text { Tailoring CSR to the needs } \\
\text { of local companies }\end{array}$ \\
\hline & \multirow[t]{3}{*}{$\begin{array}{l}\text { Actions taken to tailor CSR } \\
\text { to local MNCs }\end{array}$} & $\begin{array}{l}\text { Bespoke adaptation of CSR } \\
\text { activities and trainings to } \\
\text { local MNCs }\end{array}$ \\
\hline & & $\begin{array}{l}\text { Tailoring MNCs' CSR } \\
\text { network for a bespoke } \\
\text { implementation }\end{array}$ \\
\hline & & $\begin{array}{l}\text { Tailoring CSR to local } \\
\text { stakeholders }\end{array}$ \\
\hline
\end{tabular}

\subsubsection{Bottom up Approach of CSR to Shape New Institutions}

The data shows that there is a bottom up approach for CSR in the sampled MNCs of Lebanese origins; MNC1, MNC2, MNC3, MNC7, and MNC8. This is because it was not a management initiative or decision rather CSR managers proposed it to management to implement it. CSR managers are the ones who developed CSR in those companies along with some other employees who were interested in it. For example, P3 proclaimed: “...so when CSR was initiated it was initiated by me it didn't come from the management of the company. 
It wasn't the management who requested to appoint me a CSR head of unit for example neither the CEO who said let's do CSR strategies, it was the other way around it came internally, I created something that didn't exist called CSR and it started growing... ” P3 added that she is the one who sets the CSR strategy and coordinates with other departments and entities.

Moreover, P1, P2, P3, P4, P11, and P12 collectively agreed that the CSR department has empowerment. Those participants also mentioned that the CSR manager is the one who initiated CSR in the company and emphasized the need to have a CSR plan and strategy and more conscious decisions. Furthermore, CSR decisions are taken through a committee. These participants also said that employees and other managers in the company come up with CSR ideas and the CSR manager is the initiator and the creator of the action plan to implement CSR ideas.

Furthermore, the research participants of MNCs of Lebanese origins i.e. P1, P2, P3, P4, P11, and P12 explained that at the start, CSR was a bottom up approach and not a top down approach. But with time, CSR eventually became the bedrock of the organizations. So, CSR became the foundation of or what underpins the sampled MNCs; it became important and adopted by top management. $\mathrm{P} 2$ and $\mathrm{P} 14$ are representative examples of this result. P2 mentioned that CSR is within the company's values to be socially responsible towards the society. P14 stated: "At the end of the day hmmm...our mission as a company is to enhance people's quality of life with good foods and beverages everywhere and to help people lead healthier lifestyles I mean that as a mission of a company this is what we do..." She also clarified that the company developed all its documents from its CSR strategy. Moreover, MNCs from the sample wanted to go beyond legal compliance. For example, P11 stated: "I tell you again for me CSR it is first hmmm...it's a voluntary act I stress on voluntary because 
this means that there are things and decisions that must be taken before it becomes a law..."

The results depicted in the former three paragraphs are included under tailoring because CSR shapes new institutions. In fact, the owners and top managers in those MNCs gave CSR managers the opportunity to improve and change things because they already had a CSR spirit in their companies.

\subsubsection{Tailoring CSR to the Local Context}

\subsection{Tailoring CSR to the Lebanese Culture}

All managers interviewed believe that CSR is different from sustainability; CSR is one element of sustainability. P9 and P13's statements serve as representative examples of this result. P9 explained that sustainability means taking care of the environment, economy, and society. P13 stated: “...business responsibility be it social, economic, or environmental altogether is not a synonym for sustainability like it is widely believed, but rather a stepping

stone towards it." Moreover, MNCs from the sample are committed to sustainability and have it embedded in their values and at the heart of their business. Those MNCs are building CSR step by step to reach sustainability. Organizations give meaning to CSR itself by making CSR bespoke.

All participants and their MNCs believe in corporate citizenship and social responsibility. The following five examples are selected because they show the variedness about how this transpires. P3 stated: “...like I said the bank was socially responsible since its early inception, meaning the way it dealt with its employees, giving back to the community, especially arts and culture. It was behind the development of the economy in Lebanon as a role of a bank..." P4 posited that when the Lebanese civil war increased people's needs, the company increased its contributions to the community. P4 also argued that companies can make a profit and do good to society at the same time. P10 mentioned that employees and top 
managers are now aware that they live in this community and it is their responsibility to help this community through their business. Moreover, P13 said that the company started taking measures now to reduce energy consumption. P14 explained that the company had a clear vision for the future that it wants to improve people's quality of life through its creating shared value strategy i.e. through CSR.

The research participants collectively agreed that CSR is not new in Lebanon and it is integrated in the Lebanese culture because its concepts existed before the official use of the term CSR around the world. For example, P9 stated: "Now you know the idea of CSR in Lebanon is not new meaning hmmm... a company or people helping a community or helping an $N G O$, in Lebanon it's in our culture. Politicians do it, political parties do it, it's it's out there but it's not called CSR...” In fact, the ten MNCs chosen are old. For example, MNC1 was established in 1857, MNC6 in 1929, and MNC10 in 1866.

Additionally, all participants said that their MNCs were socially responsible since their early inception. P9 and P13 serve as representative examples of this finding. P9 mentioned that the company used to practice CSR for a long time without calling it CSR but as it became a multinational there were improved policies of which CSR. She added that Lebanese employees knew about the value and importance of CSR before it became an obligation from the foreign headquarters. P13 explained that it takes time to achieve breakthroughs in CSR because of the uncertainty of the outcomes and not the lack of will. As previously mentioned, religion highly influences culture so the participants practice CSR because of religion and it is old in Lebanon although the term CSR is new. Thus, those participants were tailoring CSR to suit the practices of the Lebanese culture and religion.

The interviewees collectively agreed that CSR started abroad first. The following four examples are used because they show varied answers of this result. P1 said: “...we received a 
lot of questionnaires from our customers abroad asking us questions related to CSR so really the first need came from the export department so what is this why they are asking us questions about our employees hmmm...The age of employees if we have minors working for us hmmm...Yes exactly child labor, do we have a CSR strategy etc. so that's why we began thinking about CSR ok?...” P3 stated: “...I worked in the UN here the UNDP and I had a project that was the promotion of public private partnership and here I started hearing of CSR..." P11 explained that the chairman of the company was very collaborative with her and asked her to be on the CSR committee because he believes in CSR and he was exposed to it in the USA. P12 mentioned that the founder of the company had a company in the USA, so he saw CSR there and he brought the concept to Lebanon. This is why he was very open to the official use of the term CSR and to officially integrating CSR into the company. CSR can be seen as a typical western institution but when managers apply it in Lebanon, it needs to be tailored because CSR needs to be applied in Lebanon in a bespoke manner.

\subsection{Tailoring CSR to the Needs of Local Companies}

P1, P2, P3, P10, P11, and P12 explained that they engage in CSR because they like to help others, make a difference, and they are good people. These participants also mentioned that the CSR spirit that was prevailing in their companies triggered their interest in adopting CSR. They also stressed on the importance of integrating CSR in all the company. For example, P12 explained that the company engages in CSR because the founder is a descendent of a very poor family and when he became rich he started thinking of ways to help others. He also stated: “...they used to believe, based on the founder, that what is good for the community is good for the company..." and he explained that the founder integrated this idea in the corporate culture. 
The interviewees mentioned that CSR imposes business ethics. People may have certain types of values and ethics but by doing CSR people's ethics and values can be reshaped and tailored. Ethics comes first, it is a value. Business ethics is the way a company does business and CSR is the strategy of business ethics. For example, P14 said: “...now I would say business ethics is part of the way we do business and for us CSR is the strategy of the fundamental way we do business, so I can't see them as each one alone." So, business ethics and CSR are interrelated.

All research participants stated that the Lebanese government does not impose any CSR laws on companies and that their MNCs voluntarily engage in CSR. This finding is validated by second-hand data as well. P4 and P12 serve as representative examples of this finding. P4 stated: “Absolutely not, nor any rules hmmm...The government does not and you don't get any tax rebates or any incentives or ...there's nothing. ” P12 explained that the company voluntarily hires disabled employees although there is no law in Lebanon that obliges companies to hire disabled people. The research participants are taking CSR and prioritizing what is important to a social context and addressing the immediate concern of local environments. Thus, they are tailoring CSR.

The interviewees explained that the role of CSR in their companies is to generate ideas and guide employee and business actions. They also clarified that ideas generated differ from country to country and they are customized depending on the needs of the local community and the business itself. For example, P4 explained that the role of CSR in a company is more like a conductor that monitors, assesses, measures, and reports employee and business performance. She stated: “...The role of CSR in an institution is a chef d'orchestre it is not main implementer, maybe it is the idea generator, but it's not the role of CSR to push things through, it's the role of each and every member of the institution and each and every 
department in a company to come up with services and products... and the role of CSR then becomes monitoring, assessing, measuring, reporting..."

This study shows that MNCs from the sample are committed to continuously practice CSR. P7 and P11 are representative examples of this result. P7 mentioned that the company is always ready to help in times of distress. She stated: “...during the 2006 war all... within the region mobilized to collect donations, to send their donations, to distribute those donations all over Lebanon on daily basis. We used to receive full load of trucks from the region hmmm ... and we emptied our warehouses to receive those donations and distribute them, this shows you that whenever a country is in distress the whole...goes for that. When the tsunami happened in Pakistan and in Sri Lanka everybody in...donated whether food, whether different commodities, clothes, we used to manage aircrafts to go to Sri Lanka and Pakistan to help them in their distress. When Cairo had problems, when was that? And...started, something happened in Cairo 7, 8 years ago I don't know, but this is how we react." P11 argued that Lebanese companies always look for advancements and CSR is one of them. Lebanese companies are very varied i.e. MNCs, small companies, SMEs, and all that and what I found is that there is commonality in terms of how CSR is taking form in terms of MNCs but definitely there is variability where local MNCs are concerned. Thus, Lebanese companies are still trying to tailor CSR to their own personal needs. 


\subsubsection{Actions Taken to Tailor CSR to Local MNCs}

\subsection{Bespoke Adaptation of CSR Activities and Trainings to Local MNCs}

The research participants collectively agreed that CSR is embedded within governance management systems including culture. Culture is very automatic; it includes things that people do without consciously doing it. Governance reflects how a company is governed and managed so CSR was embedded in managerial practices. Thus, by embedding CSR in the corporate culture and the daily managerial practices, they are making it a routine practice. For example, P4 stated: “...corporate governance at bank...I always say when we make an induction it's like a religion you know it comes over you and you are just sanctified by the holy ghost of the corporate governance of...that's the way it is." This is the participant espousing ideals as in this is where they want to be one day not where they are now. That shows that they are realistic but also optimistic i.e. half-full people not half-empty. It is not too good to be true because these are ideals. The participants seem to have high ideals about the CSR systems and also the culture.

Moreover, eight of the ten MNCs i.e. MNC1, MNC2, MNC3, MNC4, MNC5, MNC6, MNC7, and MNC9 sent their CSR managers to do trainings and attend several seminars and workshops on CSR. These CSR managers did several trainings to better get acquainted with CSR. For example, P4 claimed that she had the opportunity to meet representatives of international organizations and global firms when she attended the Global Reporting Initiatives conference in Amsterdam and the CSR course in Harvard Business School. These CSR managers did trainings but they came back to the organization and provided training internally it is like train the trainer and these are annualized; they do it on an annual basis. So, the new skills and the new knowledge that have been acquired have been brought back to the organization and are disseminated and distributed in terms of internal training and this is 
provided on a regular basis. When a company sends people to trainings and they come back, they try to see how does the general training about CSR fit their organization and if it does not fit then how to adapt the training. When that training is delivered in house there is some sort of bespoke adaptation to what is being delivered.

CSR managers of five out of ten MNCs want to integrate CSR in employees' objectives, job descriptions, and evaluation process; MNC2, MNC3, MNC4, MNC5, and MNC7. An employee's job description highlights his/her identity in the company and shows how she/he relates to the department where she/he operates. Thus, by adding CSR to employees' job descriptions, objectives, and evaluation process, CSR managers will be instituting CSR in MNCs by creating a new corporate identity. They will also shed light on the fact that employees need to accomplish socially responsible goals and will be evaluated on that basis.

Moreover, the CSR reports of the MNCs provided a description of their employee volunteering programs. These MNCs reoriented the identities of their employees and encouraged them to volunteer in community service and other CSR activities. For example, P9 explained that as part of its CSR activities, the company engages employees' families as well in volunteering programs to spread the spirit of CSR. The CSR managers of these MNCs are also encouraging employees and other managers to come up with CSR ideas to involve them even more. These findings are under tailoring because CSR materializes and is conveyed in very different ways. So as an organization matures in its CSR activities, it will have more variety. The reason why they will have more variety is because they will realize that people value things differently so they need to give them options in terms of how they want to express this. 
All research participants collectively argued that CSR is integrated in the business and CSR activities are relevant to the business. This was supported by the review of available publications. $\mathrm{P} 4$ and $\mathrm{P} 13$ are representative examples of this result. $\mathrm{P} 4$ posited that the company should focus on economic development as this is its core business. P13 explained that for the company, CSR is seen as an integrated part of the business which defines how the business conducts itself throughout its value chain; from coffee farmers, to suppliers, to employees, and to customers. MNCs from the sample are connecting CSR to their business activities and operations. P13 stated: “...While... MENA mostly focuses on brand-owned projects and programs as they can be more systematic and strategic, there still is a room to support community-driven initiatives on ad-hoc basis as long as they align with the global platform and provide the appropriate involvement for the brand and our partners i.e. employees". This finding is put under tailoring because these MNCs are catering their CSR activities to be relevant to their business. These MNCs are changing their normal relationships with their suppliers in a way that reflects their CSR values.

\subsection{Tailoring MNCs' CSR Network for a Bespoke Implementation}

The data shows that CSR Lebanon influences companies operating in Lebanon. This finding was also validated by the CSR reports and second-hand data collected from the MNCs. CSR Lebanon tries to form inter-organizational connections to further develop CSR in Lebanon. In fact, CSR Lebanon invited several companies to a round table to see how to spread awareness about CSR in Lebanon as there was a big gap; some companies understand what CSR is while others believe that it is only philanthropic. For example, MNC7 is a CSR Lebanon partner and P11 stated that Khaled Kassar is the founder of CSR Lebanon and every year he organizes the Annual CSR Lebanon Forum. She said: “...we know CSR Lebanon specifically Khaled Kassar he was really of the very few first people to believe in this and he 
was also the first person to do these kinds of events etc. and hmmm...we found interest in his event, every year he does it in October it's a way of supporting, being advocate..." Moreover, the CSR reports of the selected MNCs show that they collaborate with their competitors and other institutions to promote and enhance CSR. All interviewees also explained that their MNCs encourage their competitors and other organizations to engage in CSR through their CSR initiatives. For example, P13 explained that the company believes that by using its influence it can encourage others to contribute to societies and that more can be achieved through collaborating and bridging resources. Every organization's network is unique; therefore, this finding is under tailoring.

The data also shows that MNCs from the sample were taking certificates that help institute CSR in their companies but they used different ways to tailor CSR implementation depending on their suitability. For example, P2 stated that the company got the Lebanese excellence award for being the best company in Lebanon in terms of being a national role model and developing a solid history of continuous improvement. In order to get the Lebanese excellence award a company should abide by seven principles of which taking care of employees, respecting nature, and serving the community. Moreover, seven participants voiced the importance of having ISO certificates in facilitating the process of CSR i.e. P1, P2, P3, P4, P5, P7, and P8.

The data indicates that all interviewees defined CSR and all CSR managers from the sample are continuously working to develop and enhance CSR. The sampled CSR managers are defining and improving CSR and its boundaries. For example, P9 explained that she created a structure for CSR; she was hired as the company needed someone to structure CSR and follow it up. Work was done for the company to understand its environment and the views of people in the local community and their needs. Moreover, the companies' documents and 
second-hand data, where available show that the MNCs have a CSR policy. The interviewees also stated that employees and managers are obliged to follow the CSR policy of their MNCs. For example, P9 mentioned that CSR became more structured when a policy was set in place. These findings are under tailoring because this is defining and construing for oneself.

The CSR managers of eight out of ten MNCs i.e. MNC1, MNC2, MNC3, MNC4, MNC5, MNC6, MNC7, and MNC9 institute CSR by educating employees and other managers. They are also the ones who spread awareness on CSR in those MNCs. Moreover, these MNCs consult with experts to better understand how to practice CSR. For example, P13 argued that he feels he has a role to play to continue educating internal stakeholders about what CSR and sustainability are, why they have an obligation to continue elevating the maturity of what they do in CSR, and the potential it holds for the business on the long run. This result is put under tailoring because it is about absorbing and assimilating new information so in some sense it is about self-learning and learning is always unique and bespoke to the organization.

\subsection{Tailoring CSR to Local Stakeholders}

The sampled MNCs define CSR as a voluntary act that companies engage in to establish trust, act ethically and responsibly with all their stakeholders, and give back to the community. These MNCs named CSR and gave it a definition to explain it and to find the cause and effect relationship between its elements. Moreover, the research participants argued that CSR has many definitions but the meaning is the same. They gave various definitions of CSR but they all had something in common. All participants define CSR as conducting business by taking the interest of all stakeholders into consideration and enhancing society's welfare. The definitions of CSR reflect how the interviewees view and understand CSR in Lebanon. For example, P2 explained that CSR is a way for employees to be themselves and to 
cope with the corporate culture. People or organizations are conjecturing how CSR could work, should work, and may work in the future. Organizations have their own theories in use; they have a particular perspective on how CSR should work and they behave or they act based on those theories in use. Therefore, it is tailoring because it is unique; everyone's theories in use are different.

The CSR reports show that these MNCs conduct stakeholder panels to seek their critical input and monitor their expectations. Additionally, the interviews revealed that seven of ten MNCs i.e. MNC2, MNC3, MNC4, MNC5, MNC6, MNC9, and MNC10 listen to their stakeholders to understand how to better help them. P4, P10, and P13's statements are selected as examples because they show the variedness about how this transpires. P4 specified that the company engages competitors, partners, suppliers, customers, and employees, in its CSR panel, takes their ideas and opinions into consideration, and gets inspirations for its CSR activities. P10 mentioned that CSR has been growing and developing in the company. The company is paying more attention now and listening to the communities to invest in good things that make a difference. P13 explained that when the company wants to do a CSR project in a certain society, it consults and involves all its local employees. He also added that he solved an ethical dilemma by engaging all stakeholders in the CSR decision-making process, by taking their interests and inputs into consideration, and by reporting to them the outcome of the program to maintain their confidence. However, P13 argued that the company's stakeholders and their level of engagement differ from CSR project to another. This result is under tailoring because the interviewees are getting feedback from various people and depending on the feedback they shape and change action.

In addition, all sampled MNCs take the interest of all their stakeholders into consideration when making decisions. P4 and P11 serve as representative examples of this 
finding. P4 stated: “...yes but we do put some weight on, we consider them all yes but we weigh differently customers, suppliers, management, employees then we would NGOs and the media and government..." P11 even mentioned that for the company ethics means taking a decision which is good for the company and not at the advantage of the customer. So here there is a link between ethics, CSR, and decision-making. As previously mentioned, the participants define CSR as conducting business by taking the interest of all stakeholders into consideration and enhancing society's welfare. So, the interviewees believe that they are ethical if they make decisions in a socially responsible way by taking the interest of all stakeholders involved into consideration and not hurting any party.

The CSR reports of the MNCs list the following stakeholders: employees, competitors, government, society, customers, shareholders, media, environment, NGOs, and suppliers. However, all interviews said that employees were considered as the most important stakeholder. This finding is in line with the previous one that CSR starts at home. In fact, the sampled MNCs take care of their employees a lot because it would be inconsistent to practice CSR externally while neglecting the company's internal social responsibilities. Moreover, eight participants explained that stakeholders are considered depending on the decision to be taken i.e. P1, P2, P3, P6, P9, P11, P13, and P14. Furthermore, the participants define stakeholders as entities and individuals with whom the company interacts directly or indirectly, and are in its sphere of impact by assessing its operations and their reach. Stakeholders include every party who is influencing or is influenced by the company. The findings of the last two paragraphs are under tailoring because the choice of stakeholders is dependent on the company, its situation, and the decision to be taken. 


\subsubsection{CSR to Maintain Institutions}

The ninth and last theme that emerged from the data is CSR to maintain institutions. The subsections below explain how the managers interviewed used CSR to maintain institutions. Table 5.10 below shows the part of the coding which is relevant to theme 5.2.9. The exact quotes that support the coding are shown below.

Table 5.10: Coding of the ninth theme

\begin{tabular}{|l|l|l|}
\hline \multicolumn{1}{|c|}{ Third-order Themes } & \multicolumn{1}{|c|}{ Second-order Categories } & \multicolumn{1}{c|}{ First-order Codes } \\
\hline CSR to maintain institutions & $\begin{array}{l}\text { Institutions sustained by the } \\
\text { progress of CSR }\end{array}$ & CSR development \\
\cline { 2 - 3 } & $\begin{array}{l}\text { Maintaining institutions } \\
\text { through authentic CSR }\end{array}$ & $\begin{array}{l}\text { CSR benefits } \\
\text { in local MNCs }\end{array}$ \\
\cline { 2 - 3 } & $\begin{array}{l}\text { Legitimizing local MNCs' } \\
\text { work }\end{array}$ \\
\cline { 2 - 3 } & $\begin{array}{l}\text { Eroding the negative } \\
\text { practices through top } \\
\text { management support }\end{array}$ \\
\cline { 2 - 3 } & $\begin{array}{l}\text { Decision-making to maintain } \\
\text { CSR }\end{array}$ & $\begin{array}{l}\text { Bottom-up approach of } \\
\text { decision-making }\end{array}$ \\
\cline { 3 - 4 } & $\begin{array}{l}\text { Bespoke planning and } \\
\text { implementation }\end{array}$ \\
\hline
\end{tabular}

\subsubsection{Institutions Sustained by the Progress of CSR}

\subsection{CSR Development}

The research participants stated that CSR in Lebanon developed from being pure philanthropic to being integrated in all business decisions and actions. This finding was also supported by the companies' documents in which CSR development throughout the years was apparent. P3 and P4 serve as representative examples of this result. For example, P3 explained that in the past, companies thought that CSR was only donations and sponsoring. Moreover, 
CSR is continuously improving in Lebanon. P3 specified that next year recruitment is planned to add more employees to the CSR department because the scope of CSR is increasing. P4 indicated that the company measures and reports its carbon footprint and uses the data to enhance its CSR activities.

Furthermore, the CSR reports of the sampled MNCs show that they officially started CSR after 2000. All research participants also said that they have been officially engaged in CSR after 2000. Besides, P2, P3, P4, P5, P6, P7, P8, P9, P12, and P14 collectively posited that they used to practice CSR without knowing that it was called CSR. All research participants pointed out that CSR evolved over the years in the MENA region and all over the world. P6 and P13 serve as representative examples for this result. P6 explicated that CSR developed through the years in terms of money and number of organizations assisted. He also said that CSR started as a corporate culture and developed with time to become integrated in the company. P13 explained that over the past nine years, CSR activities moved from individual projects towards more comprehensive platform-driven programs. He also added that investment in CSR projects and programs has expanded significantly despite the economic instability of the Middle East. CSR development is put under maintaining because to maintain CSR managers have to grow it otherwise it may decline.

\subsection{CSR Benefits}

P2, P3, P6, P10, P11, P12, and P14 collectively argued the significance of communicating internally about CSR because this positively affects employees and the company's reputation. They also posited that CSR enhances a company's image and reputation. For instance, P3 stated: “...definitely a socially responsible company definitely has a nicer reputation, it's a fact I tell them this but this is not the purpose." Moreover, all interviewees think that companies that practice CSR and are ethical are the ones who will 
succeed in the future. The following three examples are selected because they show the variedness about how this transpires. P2 posited that CSR is the crown of being well organized, having good management, and having a good process. P10 explained that a company cannot succeed without business ethics and CSR; they are needed together otherwise it will be a chaos. P14 argued that working ethically and based on corporate values may be costly today but it is the right thing to do on the long-term.

The participants of five of ten MNCs from the sample mentioned that their companies add value to society through CSR i.e. MNC1, MNC6, MNC8, MNC9, and MNC10. P2 argued that he believes that it is a pity when a person does not give an added value to his environment and does not increase society's welfare. P9 explained that the company invests in CSR projects that improve society's welfare for the long-term and not only for the short-term. P12 stated: “you have...Foundation it's a foundation that supports farmers, supports students, etc. you know how many good deeds...family does hmmm...they have free schools, buses that transport students for free, they finance the tuitions of several students in Notre Dame University (NDU), USJ, everywhere." P13 clarified that he believes that acting responsibly and acknowledging one's abilities to create goodness or evil through his/her words, decisions and actions is an absolute necessity if a person wants to fulfill their role at home, school, the workplace, and in society. P14 mentioned that she feels that it is very rewarding to be in a place where she makes sure that the company is doing good to society. She also claimed that the company had CSR as a fundamental structure and believes that CSR adds value to society.

Seven participants voiced the importance of CSR in helping companies enhance their performance and offering them many benefits i.e. P3, P6, P9, P10, P11, P12, and P13. The following six examples are selected because they show a variety of answers. P3 stated: “There are a lot of benefits, benefits in terms of the employee motivation and engagement are alone 
enough..." P9 argued that managers and employees in Lebanon are aware that CSR is essential because it will improve the company's relationship with the community and will achieve good results. P10 clarified that some people take time to understand that CSR is not money or time wasted and that they should engage in things that are not business related because they do not see the direct benefit of CSR for the company. P11 explained that CSR helps a company improve and have a vision for the future. P12 explicated that the founder of the MNC believes that engaging in CSR pays back. P13 said: “...And also we started looking at ways to make CSR a platform to maximize operational efficiency."

The research participants also stated that employees prefer to work for a company that practices CSR because managers in such companies are willing to take positive decisions to work on work-life balance, trainings, and developments of employees. The results related to the benefits that CSR offers are included under maintaining because there is a selfperpetuation when companies practice CSR. There is a vicious circle that comes with CSR because if companies do good, good things will happen to them. So, CSR is maintained this way.

\subsubsection{Maintaining Institutions through Authentic CSR}

MNCs from the sample do not use CSR as a marketing tool. P2, P4, and P10 serve as representative examples of this finding. P2 stated: “...I tried first to understand what CSR is and then I understood that it's not a marketing tool, at all, and that we cannot use it and we should not use it in order to push our sales or our maybe...” P4 argued that she will always make sure that CSR does not become a marketing tool for the company. She also said: “...I don't believe in green washing..." P10 stated: “We don't use it for marketing to be honest with you. So, it doesn't help or not, I really don't think it works this way. So, I don't think we're doing it for business; that's for us pure commitment to CSR. Cause if we're doing it 
thinking that it's going to give us a better image and then better sales eventually and then more profit. Then I'm really not being a real community service. So, I really never look at it this way." This authenticity maintains CSR because anything less than being genuine will fail and will not last for the long-term.

Awareness of CSR is increasing and it is a trend worldwide and in Lebanon. The research participants also highlighted this during their interviews. P3 and P6 are representative examples of this result. P3 stated: “...it's beneficial as well if you are creating products hmmm...in an environmentally friendly manner if you pioneer in this and you become the leader, you would have established yourself because this is the trend in the world..." P6 explained that awareness on CSR is increasing among MNCs worldwide. He also mentioned that the company started developing CSR, building it, and increasing its budget as it started growing in the market and making more money. Furthermore, the participants from the three banks, P3, P4, and P11, mentioned that the banking sector in Lebanon is highly and officially engaged in CSR. They explained that the Lebanese central bank issued a memo obliging all banks to be transparent with their clients and is also pushing banks to issue solar heating loans and other green loans. It did not call it CSR but banks consider these decisions as part of their CSR initiatives. This result is under maintaining because it is not only about CSR for MNCs but also about industries that are there to invest in CSR, so all these different institutions reinforce the institution of CSR.

The data taken from the MNCs' documents showed a strong single pattern across the cases where all MNCs are legally compliant and abide by the local laws. During the interviews, all research participants also elaborated on this. P8 and P14 serve as representative examples of this finding. P8 clarified that the company abides by the UNGC ten principles, the ILO's labor laws i.e. International Labor Organization, international and local human rights, 
labor rights, anti-corruption, and anti-bribery policies. P14 mentioned that with regards to business ethics, the company's compliance is nonnegotiable, it abides by the World Health Organization (WHO) code of marketing, it has internal and external audits, and it is included in food safety goods and in the responsible index. This result is included under maintaining because these companies enable the strengthening and the maintenance of the institution of CSR in Lebanon through abiding by the law.

\subsubsection{Actions Taken to Retain CSR in Local MNCs}

\subsection{Legitimizing Local MNCs' Work}

All the sampled MNCs publish CSR reports and they were readily available for the researcher to download and analyze. All research participants also stated that their MNCs publish CSR reports. By publishing CSR reports companies are providing examples of and explaining their CSR activities and numbers. For example, P11 created a CSR mission statement and a brochure to briefly show the customers at the bank what the company is doing with regards to CSR. Maintaining institutions comes in many forms. Publishing CSR reports is one way; companies say this is a good thing, people work towards it, and it has got a lot of positives. Like anything else the organization does, if it is something that is given adequate publicity and people can see the benefits of doing it then it tends to be championed not just by those who are specifically allocated that role but even the normal colleagues.

All research participants mentioned that CSR is in the DNA, mission statement, and corporate culture of their MNCs. Furthermore, corporate values and CSR are integrated in the corporate culture of all MNCs from the sample and in all their international branches. The companies are trying to maintain CSR by integrating it in their mission statements and corporate cultures. For example, P12 explained that the founding family of the company has a storied history of good endeavors and CSR practices so many stories can be told with these 
regards. He clarified that it does a lot of good deeds like building free schools, buses transporting students for free, and financing the tuition fees of university students. This practice was transmitted to the company and maintained throughout its history until the present time.

MNC10 is a founding member of the UNGC, MNC4, MNC7, and MNC8 are signatories, and MNC2 and MNC3 are participants. Additionally, as previously mentioned, P3, P4, P5, P7, and P8, stated that they are on the steering committee of the UNGC. In this case, MNCs founded or worked with UNGC to establish principles for MNC practices around the world of which responsible business. MNCs are creating processes and activities that allow them to support what they signed up to, so this legitimizes their work and help them maintain CSR.

Moreover, CSR is formal and controlled by top managers in all MNCs from the sample. P2, P4, and P14 serve as representative examples of this result. P2 stated that he wants to make CSR institutional. P4 argued that CSR is taken seriously as the company reports according to ISO and UNGC, monitors according to ISO, and follows the benchmark indicators of the GRI. P14 mentioned that the CSR strategy of the company is based on the ten principles of the UNGC. Having a strategy shows that CSR is official and practiced in a formal and structured way. This shows that CSR in MNCs from the sample is in line with internationally agreed upon standards. The CSR reports of the MNCs validate this result. It is maintaining because MNCs have mature CSR systems at a global level but more importantly the local Lebanese subsidiaries have got experience behind them; maybe not from themselves but from their headquarters. So, the experience from the headquarters allows them to maintain CSR. 
Research participants stated that CSR cannot succeed without employee engagement and collaboration. Additionally, the sampled MNCs engage their stakeholders in their CSR activities. Employees and other stakeholders are helping in the implementation of CSR activities and CSR is being disseminated through their collaboration. For example, P13 explained that although it is complicated to engage suppliers due to the geographic size of the market, the company informs them of its CSR initiatives and calls upon them to partake in its CSR projects whenever it is applicable to them.

\subsection{Eroding the Negative Practices through Top Management Support}

The CSR reports and codes of conduct of the MNCs show that these firms are against bribery and corruption. All participants also mentioned this fact during their interviews. There is a common practice in Lebanon where people bribe to get what they want. Thus, by not accepting to bribe, these MNCs are disrupting this practice in the Lebanese society. For CSR to be maintained, it needs to grow because if CSR is tightened i.e. maintained it will actually almost by default decline. CSR is a lot of work and when people do not reap the rewards of CSR, if there are still bad things going on even after doing everything, it is very demoralizing. So, when it is demoralizing then people may stop putting effort into CSR activities. So, it has got that psychological impact, it cannot stagnant and the way it can only be maintained is if it actually grows. The growth is eroding the negative aspects in society. So, it is like the battle between good and evil. Bad people win when good people keep silent. The bad things will win if CSR is stagnant, so to maintain CSR it must keep growing; it must be active and proactive.

All the respondents posited that they are committed to CSR, lead it towards success, and have the full support of top management. Moreover, P1, P3, P4, P5, P7, P8, P10, P12, P13, and P14 collectively argued that their personal view of CSR and the collective view are the same. Besides, P1, P3, P4, P5, P7, P8, P11, P13, and P14 and their MNCs have the same 
definitions of CSR and ethics. Thus, CSR gained support in those MNCs through the support of top managers and CSR managers. The following three examples are selected because they show the variedness about how this transpires.

P3 stated: "... if someone is throwing papers in the regular bin or not and if there is non-respect and it happened on several cases and in this case we report it back and they receive an email from the general manager that they are not respecting this policy..." $\mathrm{P} 3$ also explained that she influenced management to gain advocacy for further developing CSR. P4 argued: "the... and our CEO...who I call have CSR in the DNA of the persona and that reflects on our organization and these two gentlemen really believed in education, believed in the culture and the arts, believed in health, believed in employing young people of a certain caliber and empowering these young people so that the company at the end of the day flourishes together with its community..." P4 also explained that her personal view of CSR impacts the collective view. P10 mentioned that he believes that it is very important for him to be personally involved in many CSR initiatives for the community to feel proud about the company and believe that everyone in it cares. These results are under maintaining because the participants are growing their support network. 


\subsubsection{Decision-making to Maintain CSR}

\subsection{Bottom-up Approach of Decision-making}

Research participants explicated that the big CSR strategy is set by the headquarters but the local executive committee adapts decision-making and implementation to the local community. This finding is in line with the previous finding where managers explained that people are different and thus their cultures and needs differ. This is why Lebanese managers need to amend CSR decisions to better cater to the needs of the local communities.

In addition, P10 argued that sometimes managers have only one choice to make. P10 advanced that the more alternatives he has the more he is saying he does not want to make a decision. P10’s opinion contradicts Kalantari's (2010) explanation of the decision-making process where the decision maker starts by evaluating his/her alternatives then eliminates his/her options to reach the final decision stage and decide. Nevertheless, all participants mentioned that decision-making is the heart of the company and that decisions that managers take drive business actions and affect their triple bottom line.

Furthermore, MNCs from the sample have a bottom approach to decision-making. This is reflected in the corporate values discussed in the previous section where managers stated that their MNCs value and practice autonomy and empowerment. P2 argued that it is very important to have a bottom up approach to decision-making as many good ideas come from employees. He also claimed that he never imposes his decisions on employees as he believes that the company becomes stronger and employees are more at ease when decisions are not imposed on them. Besides, P10 proposed that corporate values and the code of ethics simplify decision-making as employees may use them as a foundation and a guide for their decisions. As formerly mentioned, the sampled MNCs have strong corporate cultures where everyone believes in and practices the same values. Consequently, in the Lebanese context, it is easier to 
use the corporate values and the code of ethics as basis for decision-making because there is less likelihood to have conflicts of values and ethics.

In MNCs from the sample, CSR is represented by a small department or one person as there is still no need for a bigger department. In MNC1, MNC2, MNC7, MNC8, MNC9, and MNC10, CSR is part of another department; communications, HR, or marketing department. In fact, the research participants explained that at the early stages of CSR in Lebanon, it was represented by the HR or the communications departments. Moreover, the sampled CSR managers are considered top managers. For example, P8 explained that the company has a sustainability champion in each of its offices, who supports in development and coordination of its sustainability projects. It also has a central sustainability team led by a Chief Sustainability Officer who is also part of the management team. She also added that the CSR department reports, follows up, and collects data on CSR.

Additionally, MNC1, MNC2, MNC3, MNC6, and MNC7 have CSR committees that meet on a regular basis to discuss and solve issues related to CSR activities and decisions. For example, P4 explained that the bank has a CSR committee composed of different managers from different departments. CSR is given a specific focus so this means that it is not buried under the HR or the communications department but it has its own department. The managers within CSR have a degree of seniority so they are not subordinate to another department; they have got access to senior management forum. That allows CSR to be maintained because only if it has these profiles it will be allowed to flourish.

According to the research participants, the management decision-making process in their MNCs is as such: issue identification, alternative evaluation, proposal for top managers or the corresponding party to review it, approval, implementation, follow up, and evaluation. This decision-making process is similar to the process previously described by the participants 
to make CSR decisions. Thus, I can deduce that CSR decision-making is taken as seriously as any other business decision in MNCs from the sample. The recurrence of CSR as being a strategic consideration and the fact that it has got representation at senior management allows it to be better maintained.

\subsubsection{Bespoke Planning and Implementation}

The participants of eight out of ten MNCs mentioned that their companies set a yearly budget for CSR activities; MNC1, MNC2, MNC3, MNC6, MNC7, MNC8, MNC9, and MNC10. P10 and P11 serve as representative examples of this result. P10's personal view of CSR is that CSR is not a cost that the company is trying to avoid; on the contrary, it is something the company needs to do given that it is operating in this local community. He completely supports it and has a budget for it. P11 explained that when making decisions on CSR in Lebanon and abroad, the CSR committee discusses CSR projects and works according to a yearly CSR budget. This finding aligns with the notion of maintaining because these MNCs have a dedicated rolling budget for CSR that perpetuates on a yearly basis.

Reviewing the documents of the MNCs shows that they have measurable CSR objectives that are in line with their CSR strategy. The research participants also explained this during their interviews. By measuring CSR objectives, companies can better monitor their CSR activities and can hence improve their future CSR plans and strategies by basing their decisions on facts and numbers. This way CSR can be better maintained. For example, P13 explained that the company revamped its existing CSR programs to make their objectives more progressive and their outcomes more measurable.

The CSR reports of eight out of ten MNCs from the sample revealed that they form partnerships to implement CSR programs; MNC3, MNC4, MNC5, MNC6, MNC7, MNC8, MNC9, and MNC10. These MNCs' interviewees also revealed the same information. MNC6 
and MNC9 are used as illustrative examples. P9, the interviewee from MNC6, said: “...we currently have a partnership with Lebanon Reforestation Initiative (LRI) hmmm...the team and Ehden Reserve, we started last year with them, we do a plantation day because they have a project to reforest part of the reserve and because we want activities for employees to volunteer in we did this partnership but plantation is not a condition. We do other activities. We did with SOS two years, I am talking about it as volunteering..." P13, the interviewee from MNC9, stated: “...Every CSR project we work on involves partnering with external specialized organizations which we either support through our project, or helps guide the project and ensure it is creating the impact we are set out to create."

Moreover, the research participants communally discussed that CSR goes from idea to implementation as such: the CSR manager writes a proposal to top management for approval. Once approved the idea is implemented after discussing it with the concerned entities. By adopting such an approach in identifying and implementing CSR initiatives, these MNCs adopt a bottom up approach whereby they enable staff throughout the organization to provide input into these CSR activities therefore gaining buy in and commitment. Thus, it is easier for CSR to be maintained if there is these collective buy in. 


\subsection{Summary of Chapter}

This chapter provided a detailed explanation of the findings that emerged from the data. The findings were grouped under nine themes depending on the patterns identified. The first theme highlighted the respondents' personal-level circumstances that underline their CSR related decisions and actions. The most significant factors were religion, ethics, and family values. The second theme depicted the participants' professional circumstances such as management and corporate values and their level in the hierarchy of their firms that had a very high influence on their CSR adoption. The third theme illustrated some examples of stories of ethical dilemmas that the participants faced at work. These stories were imprinted in their minds and underlined their future behaviours and decisions.

The fourth theme explicated how the familial environment in the selected MNCs affected CSR adoption and implementation. Theme five pinpointed how the CSR managers interviewed saw CSR as a vocation. The sixth theme described how the extraneous Lebanese culture and values played a role in shaping the CSR practices of the selected MNCs. Finally, themes seven, eight, and nine depicted how CSR was used to disrupt, tailor, and maintain institutions. Subsequently, chapter six will reveal how these nine themes contribute to knowledge. 


\subsection{Chapter Six - Discussion and Conclusion}

\subsection{Introduction}

The objective of this qualitative study was to discover how CSR decision-making is done by managers of MNCs operating in Lebanon. The emphasis of the research was to attain deeper knowledge of the role of the personal and decisional factors, and actions that shape CSR in Lebanon. Chapter one described the contextual background and the gap in literature that led to the need for this research. Chapter two included a literature review pertaining to the history of CSR, an explanation of its impacts and antecedents, a comparison of CSR in developed and developing economies, and an overview of relevant institutional theory. Chapter three provided an overview of Lebanon. Chapter four defined the methodology used for the study, research design, data collection, and data analysis of the research. Chapter five presented the research results directed by the research questions. Chapter six explains how the themes and findings depicted in chapter five contribute to knowledge and theory. In addition, this chapter offers some recommendations for future research and for managers and companies in the field. It also delineates the limitations faced while the research was being undertaken.

The findings detailed in chapter five can be categorized into three major groups; each group providing a contribution to knowledge. The first group of findings contributes to microfoundations of CSR in Lebanon and relates to the participants' personal-level circumstances such as religion and ethics that underpin their decisions and actions. Moreover, the respondents' professional circumstances had a significant impact on the participants. Management and corporate values along with the participants' hierarchical level in the organization played an important part in CSR adoption. The second group of findings contributes to the contingency theory in CSR wherein CSR is context bound. These results related to the participants' situational factors that influenced their adoption and 
implementation of CSR. These factors related to the Lebanese culture and values which influenced how the respondents saw CSR as a vocation and established a familial work environment in their corresponding MNCs. The third category of findings relates to how CSR was institutionalized in Lebanon and contributes to institutional work and practice theory. The selected MNCs engaged in various types of work to disrupt, tailor, and maintain CSR in Lebanon. The following subsections address the research questions by highlighting the major findings that contribute to theory.

\subsection{Addressing the Research Questions}

The results depicted in chapter five can be categorized into three groups and accordingly answered three research questions. The first research question was: how and why do individual level factors play a role in the adoption of CSR in companies operating in Lebanon? The first group of findings answer the first research question and are related to the respondents' personal-level circumstances that reinforce their behaviours and decisions. This research shows that individual level factors play a role in the adoption of CSR in companies operating in Lebanon. These factors are religion, ethics, family values and heritage, patriotism, community spirit, activism, role model, individuals' beliefs, and generational differences that highly affected their inclinations towards CSR. The respondents argued that Lebanese people are very religious and hence CSR practices are mostly triggered by religious values such as servant leadership in Christianity and zakat as one of the five pillars of Islam. Besides, the findings strengthen the view that ethics was seen as a driver for CSR.

Furthermore, the participants' professional circumstances highly influenced them, as management and corporate values along with their hierarchical level in the company played a crucial role in CSR adoption. In fact, the results show that top managers are the ones who set the ethical tone in the company and hence establish CSR practices. Besides, the respondents 
explained that they faced several ethical dilemmas at work. Subsequently, their businesses could suffer from lower performance because they were being steadfast and did not change their values and convictions despite all the pressures. These stories of ethical dilemmas were imprinted in the participants' minds and formed their future choices and actions.

The second research question was: how and why do situational factors influence the adoption and implementation of CSR? The second group of findings answer the second research question and relate to the respondents' situational factors that impacted their acceptance and application of CSR. This research found that Lebanon is a country where people strongly believe in God irrespective of religion and that means that they believe in giving back to others because Islam and Christianity believe in that. It also means doing good to the environment. But the one thing that is different from how CSR is perceived or makes sense in other studies in other parts of the world is how the practitioners of CSR see it as a vocation. Equally important is how they see CSR as taking care of the organization internally. So, it is almost like charity begins at home. This was largely due to the unique Lebanese culture and values which is characterized by dealing with people as family members. This also affected how these managers conduct business more particularly how and why they make their CSR related decisions.

There is clearly an interaction between individual and situational factors. It appears that because family is something people grow up with and they are most comfortable with, so clearly that plays a big role and that shapes people's worldview in terms of what they want in life and what they want to be in their careers. But of course, the thing about working life and the country that people work with interact with one another. Given from the data, it can be seen that people see CSR as a vocation but they adapt their practices accordingly depending on the contextual factors of the country. 
The third research question was: How is CSR institutionalized in Lebanon if at all? The third category of findings answers the third research question and is related to how CSR was institutionalized in Lebanon. The selected MNCs engaged in several forms of work to disrupt, tailor, and maintain CSR in Lebanon. In fact, the sampled MNCs engaged in various types of CSR activities like recycling, reducing pollution, enhancing the country's infrastructure, and proving scholarships to students. These initiatives appear to fill the gap in the Lebanese society that the government is unwilling and unable to fill. Moreover, the CSR practices of the selected MNCs seem to disrupt sectarianism in Lebanon because they teach employees and other stakeholders to respect diversity in all its forms and treat everyone equally through these initiatives. Besides, these MNCs are bringing with them best practices and they are showing the local Lebanese public and private sectors how things should be done. For example, through their CSR policies, reports, and practices they can show the Lebanese government what type of laws to enact to make CSR obligatory. These MNCs' anti-corruption and anti-bribery policies and respect of basic human rights along with an appropriate whistleblowing mechanism also had a major impact on society.

Furthermore, this study demonstrates that foreign MNCs had a top down or meso, approach of CSR because their headquarters initiated CSR decisions. Nonetheless, managers of their local subsidiaries were granted a level of freedom to tailor those decisions to the needs of Lebanon but under the specified guidelines. This is how CSR played out at the meso level. In contrast, Lebanese MNCs had a bottom up approach of CSR because the founders of these MNCs included the spirit of giving back in their companies, CSR managers were the ones who formally started CSR in those businesses. Another difference between local and foreign MNCs is that local MNCs voluntarily engaged in CSR because the Lebanese government and society do not exert any pressure on them. On the contrary, foreign governments and societies 
pressure the sampled foreign MNCs to practice CSR. So, this is how the ideas of family and vocation was worked out in organizational practice.

In addition, the sampled CSR managers are broadening the CSR scope by, for example planning to include CSR in employees' objectives, job descriptions, and evaluation process. The selected MNCs also have employee volunteering programs and engaged various stakeholders in their CSR decisions and activities. Feedback of various stakeholders was also of major importance to the participants for them to enhance their CSR practices. Besides, this research showed that CSR Lebanon is an established organization in Lebanon whose aim is to spread awareness on CSR in the country and the region. Additionally, the results show that the selected MNCs acquired ISO certificates, that supported them in inaugurating CSR in their firms but they used diverse methods, depending on their suitability, for their CSR applications. The following subsections address the research questions by highlighting the major findings that contribute to theory. This section highlighted the findings that answered the three research questions. Each research question was answered through results distributed across three themes. The next section discusses how the thematic analysis constitutes a contribution to knowledge. 


\subsection{Contribution to Theory}

Researchers have conducted studies on individual, company, and macro-level factors that influence managers' attitudes to CSR in general or in developed countries (e.g. Aguilera et al., 2007; Crilly, 2011; De Luque, Washburn, Waldman, \& House, 2008; Devinney, 2009; Husted \& Allen, 2006; Van Oosterhout, 2010). Surprisingly, little attention has been dedicated to how these factors may play a role in a particular context, more specifically in developing countries of the Middle Eastern region. Moreover, very few studies have combined the three factors in one research and for one specific context. Existing research often did not look at it from an institutional work and practice theory perspective but tended to look at one or two factors such as religion (e.g. Longenecker et al., 2004), or stakeholder pressures (e.g. Crilly, 2011). Hence, this research has a threefold contribution to knowledge wherein it looks at these three factors simultaneously in a Middle Eastern developing country context i.e. Lebanon. It studies all possible factors in place indicating their particularities and distinctions in a specific context. This research is a case study within Lebanon using ten MNCs that practice CSR and the data presented in Chapter Five shows collectively how it develops the institutional micro level with implications for the meso, and macro-levels.

The results gathered for this study are distributed among three main parts. The first part is associated with the factors that form individuals' common sense and rationalisations about CSR such as ethics and values. These microfoundations are outlined as significant antecedents. The second part is about the work that the research participants do concerning CSR at organisational level. The third part is how CSR is understood and how CSR transpires in Lebanon as a whole. Consequently, these three major contributions will be discussed in details in this section. 
Two frames of analysis were used in this study; intrapersonal and strategic. Each frame related to different findings; microfoundations and institutional. The intrapersonal frame was adopted when the selected managers talked about themselves as individuals and the resultant findings relate to the microfoundations of CSR. The strategic frame was adopted when the managers interviewed talked about the macro-level factors i.e. the country where they conduct business and the meso-level factors i.e. their companies that influence CSR. The resultant findings relate to the institutional context and how CSR was institutionalized in Lebanon by these MNCs.

As previously explained, the three aspects of institutional theory are currently separate. So, this research is contributing to all three different aspects of institutional theory at the macro, meso, and micro-levels. In fact, neo-institutionalism was used as a lens in this study because it helps explicate why CSR is institutionalized from a macro-level perspective (Schultz \& Wehmeier, 2010) and how the CSR practices of MNCs operating in Lebanon might be affected on a macro-level by the Lebanese institutional context. Neo-institutional theory proposes that companies and their strategies are intensely affected by the characteristics of the institutional context where they operate and by the heritage revealed in the cultural principles, rule, and history of a particular region or country (Doh \& Guay, 2006).

Additionally, it provides an understanding of the convergence of CSR within countries and its divergence across countries without disregarding the option of international dissemination (Kostova \& Roth, 2002).

Institutional entrepreneurship was also used as a lens to help explain the institution of CSR from a meso-level i.e. organizational-level perspective (Shaw et al., 2017). The institutional entrepreneurship theory explains how MNCs change or create institutions like voluntary CSR (N. J. Peters et al., 2011). MNCs are not passive; they are active and they could 
change, revise, or resist institutions (Wahid \& Sein, 2013). Entrepreneurial change activities within the organization show how CSR initiatives are produced through active involvement in change. Returning to institutional work theory this identifies the institution of CSR from a micro-level i.e. individual-level perspective (Lawrence \& Suddaby, 2006). Institutional work is founded on an increasing awareness of institutions as outcomes of human action and reaction, driven by both distinctive personal interests and programs for institutional change or conservation (Lawrence et al., 2009). The production of CSR initiatives within a cultural context can only be achieved through the work of active organizations. The aim of the institutional work theory is that, through thorough analyses of these multifaceted incentives, efforts, and interests, institutional research will be capable of better understanding the general patterns of intent and capability to create, maintain, and change institutions (Lawrence et al., 2009).

\subsubsection{Microfoundations of CSR}

My first contribution is developing a microfoundational perspective to CSR. Previous research has looked at macro aspects of CSR in particular strategy and policies (Pisani et al., 2017). However, very few have explored the microfoundational intra-individual dynamics that play a pivotal role in influencing an organization's CSR activities in developing countries. Moreover, microfoundations had been looked at in various other fields for example strategy and operations management (Barney \& Felin, 2013). Microfoundations have helped advance other fields and therefore my research is doing the same but for CSR.

Moreover, as in other domains regarding individuals' conduct in companies (Foss \& Pedersen, 2016), there is a solid need to recognize the microfoundations of CSR to develop theory (Ng et al., 2019). In short, microfoundations are inspected in studies aimed to unpack the "black box" or mediational procedures in strategic management studies by incorporating 
understandings from organizational behaviour, applied psychology, and HRM (Bridoux \& Stoelhorst, 2014; Helfat \& Peteraf, 2015). Thus, this research is explicating the microfoundations of CSR in Lebanon.

As previously discussed, the role of individual's personal circumstances on CSR, the role of individual's professional circumstances on CSR, and legacy stories from the individuals are the three themes that answered the first research question. The answers to the first research question form the first contribution to theory which is the microfoundations of CSR. My first contribution deepens the theoretical underpinnings of CSR and this is done by looking at the microfoundations and in this way provides the ground of the study. The following three subsections highlight the most important antecedents of CSR.

\subsubsection{Individual's Personal Circumstances as Microfoundations of CSR}

\subsection{Individual's Religion and Ethics as Microfoundations of CSR}

This study demonstrates the strength of a person's religion and ethics in defining organizational CSR. All participants posited that religion is an essential aspect of their identity and that their religious values form their personal culture, traditions, beliefs, decisions, and actions. Based on the research of Jamali and Sdiani (2013) on religion and CSR, I included a question on religion in my interviews. Their finding is that a person's religiosity affects his/her affinities to CSR (Jamali \& Sdiani, 2013). In fact, managers interviewed in this study are very religious and religion does play a role in motivating people to practice CSR as religious values like servant leadership push people to practice CSR and help others. Similarly, Angelidis and Ibrahim (2004) found that the educational aspects of different religions have a substantial effect on managers' attitudes and behaviours. Thus, religion is the first antecedent of CSR and contributes to microfoundations. This is the first contribution that tightly links to the Lebanese 
context i.e. religion that also differentiates from the other studies (e.g. Longenecker et al., 2004).

Weaver and Agle (2002) found three kinds of experimental findings. Some studies did not find any difference between the daily behaviour of religious and nonreligious managers, some found a negative relationship between religiosity and CSR, and others found a positive correlation. These contradictory results can be attributed to the fact that most experimental studies use undergraduate and MBA students (Weaver \& Agle, 2002). Thus, this study provides a better contribution to the concept of microfoundations as it uses top managers as participants

Furthermore, the respondents argued that diverse religions and cultures have different ethical values. Accordingly, ethics' impact on persons' decisions and actions will vary depending on their corresponding backgrounds. A person's ethics will shape how he/she decides things, views things, and selects information to make decisions; the perspective that the person takes. Along similar lines, Jamali and Neville (2011) argued that in Lebanon, distinct CSR directions among local businesses have been associated with the prominent religious values, generating ethical corporate behaviours, donations, and zakat (Jamali and Neville, 2011). Similarly, Graafland, Mazereeuw, and Yahia (2006) conducted a study on Muslim entrepreneurs in the Netherlands, and found that Muslim business people weigh differently various features of CSR practices than their non-Muslim colleagues. These features included the conviction that exceptional consideration should be given to working with clients, taking care of employees, and backing up local society projects (Graafland et al., 2006).

In addition, all participants said that being ethical is when people do not act against their personal beliefs and values. Hence, they defined ethics as doing the right thing even when no one is watching. This shows to some extent the genuineness and the sincerity of some of the CSR initiatives that they undertake because then it shows how important culture and a 
person's ethical stance is. This finding also offers a contribution to ethics as it provides a new perspective on ethical behaviour. They also were convinced that ethics is the driver of CSR. In fact, these managers contended that business ethics was vital for CSR to work, succeed, and get inaugurated faster. This is consistent with the studies of Logsdon and Wood (2002) and Heugens, Kaptein, and Van Oosterhout (2008) who found that to better understand CSR one should understand the values and ethics of the managers involved. Therefore, ethics is the second antecedent of CSR and contributes to microfoundations.

As discussed in Chapter Five, ethics is included in both the corporate values but most importantly in the personal values of top managers. Thus, organizational ethics is coming from the individuals who founded and are managing these firms. The participants also appear to have strong systems and processes in place regarding business ethics. For instance, P14 stated: “...So we have strong ethics and codes but we also have systems to audit them, make sure that you know feedback is there and continuous tracking is there." In fact, the establishment of ethics within the corporate values, culture, and governance management system frequently encourage employees to strongly believe that their companies are ethical (Valentine, Nam, Hollingworth, \& Hall, 2014). These beliefs frequently result in a range of positive reactions at work, comprising improved job satisfaction and organizational commitment (Herndon, Fraedrich, \& Yeh, 2001; Jaramillo, Mulki, \& Solomon, 2006; Kim, Lee, Lee, \& Kim, 2010; Koonmee, Singhapakdi, Virakul, \& Lee, 2010; Rego, Leal, Cunha, Faria, \& Pinho, 2010; Stites \& Michael, 2011; Turker, 2009), reduced staff turnover (Herndon et al., 2001; Mulki, Jaramillo, \& Locander, 2009; Valentine, Godkin, Fleischman, \& Kidwell, 2011), and other positive work observations and inclinations (Herrbach \& Mignonac, 2007; Jaramillo et al., 2006; Valentine \& Barnett, 2002).

CSR in MNCs operating in Lebanon came out of business ethics but business ethics is based on the founder's values. The founder's values are based on the Lebanese culture of 
philanthropy which affects the company's policy. But with regards to operationalization, there is the CSR manager or officer. This finding justifies why it is important to consider the individual in CSR in Lebanon. Because it is this one person, obviously within certain confines, that drives CSR. Institutional work here is accomplished through individual actors and their agency. This is different from other studies conducted in different countries. For instance, Fassin et al. (2015) found that philanthropy is unfamiliar to Norwegian managers and business owners because the government and NGOs are the ones who handle the needs that philanthropy usually tackles.

\subsection{Individual's Family Values and Heritage as Microfoundations of CSR}

This research indicates that people's family values and heritage play a positive role in influencing convictions in CSR. Values are defined as the codes or standards of behaviour; a person's verdict of what is essential in life (Fritzsche \& Oz, 2007). Hence, they are the drivers of people's beliefs, attitudes, decisions, and actions. The participants expounded that individuals cannot modify their taught family values. Consequently, persons will use these values everywhere; at work and in their personal life. Along similar lines, Noorderhaven and Harzing (2003, p. 54) found that people become "mentally programmed" by the way they are bought up by their family and organizations, specifically educational organizations, in the country in which they were raised. This will shape their values and preferences for certain business behaviours (Noorderhaven \& Harzing, 2003).

This research describes imprinting (Marquis \& Tilcsik, 2013) in the context of CSR, with the founders' family values spilling over to form the identity of the MNCs and their CSR directions. Imprinting denotes the course through which, during a couple of delicate phases in an individual's life, that individual "develops characteristics that reflect prominent features of 
the environment, and these characteristics persist despite significant environmental changes in subsequent periods" (Marquis \& Tilcsik, 2013, p. 199).

All participants also argued that managers' national and personal values influence their CSR practices and decisions. For example, P2 expounded that a businessman should believe in national, personal, and human values to engage in CSR because if he is only business oriented then he would not understand the significance of practicing CSR. This is the connection between the three levels of CSR. The participants are gender bias in terms of who a businessperson is. As explained in chapter three, this is due to the fact that the Lebanese society is dominated by a patriarchal culture and several traditional masculine stereotypes (Jamali, 2009).

The worldview of the participants was underpinned by what was appropriate for Lebanon: its unique position in the Middle East. This finding is in line with the comprehensive study of Jackson (2001) who conducted research on ten countries; the USA, Britain, France, Germany, Spain, Switzerland, India, China, Australia, and Japan and found that ethical attitudes are different among managers from different nationalities. Similarly, Tsalikis, Seaton, and Tomaras (2002) compared people from Greece and the USA and found that nationality had an important effect on people's different ethical perceptions and responsibility.

Businesses in Lebanon are incorporating CSR practices in their corporate cultures and teaching their personnel to adopt them at work with the hope that one day these practices will be implemented by each Lebanese family the same way it is done in many developed countries. When parents come to be socially responsible, they transmit this practice to their children by teaching them how to do it. Thus, institutional work is transmitted into family values and heritage. These microfoundations are considered as the third antecedents of CSR because family is the most fundamental factor that affects a person. In a country where the 
family is central people learn everything from their families (Parke, 2004), and it becomes their heritage. Heritage usually refers to a cultural trait or tradition that has been transferred through different generations (Konsa, 2013). It can also designate an individual's ethnic or cultural background (Konsa, 2013). Ethnicity is defined as societal characteristics that are common to a certain group of people (Robbins \& Coulter, 2016).

This may also explain why MNCs operating in Lebanon value patriotism and why managers are patriotic as well. People cannot be strongly attached to and respect their heritage if they do not have a sense of patriotism. So, in that sense, I can say that MNCs from the sample are allowing managers and employees to work according to their heritage and to what they believe in. Along similar lines, Shah and Ramamoorthy (2014) explained that the responsibility of the company is to itself, to the heritage, to society, and to the lifestyle. There are connections between CSR practices at the three different levels. These connections are not fixed, but dynamic: they interplay.

\subsection{Individual's Belief Systems as Microfoundations of CSR}

Additionally, CSR was also seen in this study as a personal belief and a way of life. These practices at corporate level try to change the institution for the better. This activism is, in fact, the coming of a new approach. Mijatovic and Stokic (2010) found that activism is an important predictor of good CSR initiatives. This research shows that being an activist is essential for CSR adoption and the participants are working hard to inaugurate CSR in their businesses and bring about social change in Lebanon. Being an activist means intentionally acting in ways to create political or social change (Joyce, 2014). Activism is considered as a microfoundation because an activist thinks and acts in different ways than a non-activist. Similarly, Elms (2006) argued that the lack of activism in Central and Eastern Europe is the reason behind poor CSR performance. 
Someone having a role model was also considered as an important trigger for CSR. A role model is defined as a source of aspiration to another individual or is a person who people look up to (Carey, 2012). When people have a role model, they tend to get inspired by her/him and act in similar ways or take similar decisions. Thus, role model can be looked at as a microfoundation because it can be a driver for people's increased agency. Additionally, exhibiting high ego strength was also noticeable in this study because the participants abide by the same values at home and at work (Robbins \& Coulter, 2016). Individuals who have high ego strength will probably resist desires to behave unethically and alternatively follow their beliefs (Robbins \& Coulter, 2016).

In addition, it seems that there are generational differences regarding predispositions towards CSR because this study showed that millennials are a generation which fosters ethics and CSR and include these concepts in business. This is consistent with the results of the 2006 Cone Millennial Cause Study (Ramasamy \& Yeung, 2009) wherein sixty-one percent of millennials felt responsible of making the world a better place, while seventy-eight percent consider businesses responsible in joining them in their efforts. A generation is defined as a unique group of people who have the same birth year and age, and subsequently, remarkable life events at developmental stages (Jonck, Van, \& Sobayeni, 2017). Life events that many generations experience have an influence on the development of their beliefs and attitudes (Jonck et al., 2017). This is why the generation to which a person belongs can be considered as a microfoundation because it frames their individual values. 


\subsubsection{Individual's Professional Circumstances as Microfoundations of CSR}

In this study, managers have a strong belief in ethics and consider it of high significance. Godos-Diez, Fernandez-Gago, and Martinez-Campillo (2011) argued that socially responsible companies cannot exist without socially responsible managers who are ready to sacrifice the goals, interests, and needs of the business for the sake of CSR. Actually, top managers are the ones who develop interest in CSR and ethics throughout the company (Waldman et al., 2006) and make decisions regarding how to include these into the strategic management process (Singhapakdi, Gopinath, Marta, \& Carter, 2008). Although the role that top managers play in executing CSR is very important, previous research has narrowly tackled it and call for future research (Waldman \& Siegel, 2008). Hence, this study provides a contribution to knowledge as it links the microfoundations of individual beliefs to the practice of institutional entrepreneurship in developing CSR.

This explains why an individual's professional circumstances are considered as a contribution to microfoundations and the fifth antecedent of CSR. In fact, Filatotchev and Nakajima (2014) argued that by linking firm-level CSR with managers' individual characteristics, researchers can pinpoint important antecedent factors of responsible managers and their CSR approaches, and this is one of the things done in this study to contribute to theory.

Servant leadership is one important corporate value explaining why companies engage in CSR. Servant leadership is defined as a belief where helping other people is of high importance (Kincaid, 2011). Additionally, Jesus is considered a servant leader and the value of helping others is therefore highly present in the Christian religion (Ingram, 2003). Ingram's (2003) idea was also reflected in this study. For example, P12 said: “...the founder deeply believed in the Christian values and he copied many things from the Christian values...for 
example, you have servant leadership where he was inspired from Jesus as a role model." Moreover, as previously mentioned, Christian values teach and encourage people to practice CSR and the founders' religious values are the basics of corporate values and culture. Besides, religiosity has a strong effect on corporate values (Parboteeah, Paik, \& Cullen, 2009). Thus, religious values underpin corporate values that in turn shape CSR in the selected MNCs.

Furthermore, the managers interviewed explained that they fit with the corporate culture and therefore feel that they belong to their MNCs. Studies relating to personorganization fit have revealed that organizational commitment is intensely affected by the extent to which corporate values are compatible with personal values (Mueller, Hattrup, Spiess, \& Lin-Hi, 2012). Because of the increasing significance of CSR for stakeholders and more specifically employees (Brammer \& Millington, 2003; Dawkins \& Lewis, 2003; Porter \& Kramer, 2006), people can anticipate it to become an even more significant element contributing to employees' affection, devotion, and participation in the company (McWilliams \& Siegel, 2001). By the same token, social identity theory proposes that personnel should intensely relate to firms that express values that they consider as predominantly appealing to relevant others (Bhattacharya \& Sen, 2004; Brown, Dacin, Pratt, \& Whetten, 2006). Kim et al. (2010) found that employees' views of CSR had a positive influence on observed employer reputation, which consecutively resulted in a greater identification and commitment.

In this study, respecting diversity is reflected in the values of MNCs and managers. Both corporate and managerial values included autonomy and employee empowerment. If a person does not respect others who are different, he/she cannot practice decentralization and empowerment and take the opinions of others into consideration. If a person has this openmindedness and respect diversity, then he/she will take decisions and act in ways that are different from a person who does not have it. Besides, the participants mentioned that they 
respect people from different religions. In Lebanon, this is a very important step because as explained in chapter three, Lebanese people tend to be inclined towards individuals from the same religion (Munro, 2013) and prejudice usually prevails. Furthermore, Lebanon is still a country where job positions in the public sector and in all governmental institutions are allocated based on a person's religion (Jamali \& Keshishian, 2009). Fortunately, the younger generation is more open minded, is now trying to change this old mentality, and trying to implement the concept of competencies for job positions. This step towards change can be seen in the participants' answers. Moreover, diversity is considered as one important type of CSR activities that have many positive implications on the company such as positive employee morale (Forney, 2018).

\subsubsection{Legacy Stories from the Individuals as Microfoundations of CSR}

As detailed in chapter five, the respondents communicated numerous stories to explicate how they solved their ethical dilemmas. Resilience was to a certain point obvious in this research as the managers had to uphold an ethical position under very challenging conditions. There are numerous definitions of resilience, but for the respondent's resilience meant being steadfast. In fact, the managers selected suffered because they did not amend their ethical values and beliefs. This research indicates that microfoundations such as religion, ethics, and heritage help support routines and decisions about CSR that are dilemmatic. For example, P10 decided not to pay bribes to corrupt Lebanese officers because it contradicts his ethical principles, and the result was to go through the pain of business interruption or poor business performance. This is explained by the unique microfoundations of this study such as heritage, ethical stance, and even values. In many ways this story helps CSR because one thing about CSR is to build reputation. 
Moreover, a lot of these dilemmas are unique to Lebanon although some dilemmas could be faced by managers in other parts of the world. So, the previous sections and chapter five explained my themes but what makes them unique to Lebanon is that they help CSR managers resolve those dilemmas. In fact, stories of solving ethical dilemmas are included under microfoundations because it is consistent with and contributes to the imprinting theory (Marquis \& Tilcsik, 2013). In fact, certain events that people remember are imprinted in their minds, so when people look at stories from the past, it is a guiding light for their organizational conduct (Marquis \& Tilcsik, 2013). Along similar lines, Holburn and Zelner (2010) explained that imprinting forms managers' conceptual models which they use to understand the environment and direct their behaviours. Besides, ethical dilemmas that participants faced created in them a feeling of cognitive dissonance. Cognitive dissonance is a feeling of discomfort that sets in when an individual's values, attitudes, and behaviour are in conflict (Demuth, 2006). The participants were trying to reduce their feeling of cognitive dissonance by reinterpreting their ethical dilemmas in a manner that is in accordance with their previous beliefs and values (Lin-Hi \& Blumberg, 2018).

This section featured the microfoundations of CSR in Lebanon including for example values, ethics, heritage, professional circumstances, and overcoming ethical dilemmas that play a role in shaping CSR. Microfoundations are about the individual because the individual is the most important thing in all organizations for everything starts from the individual $(\mathrm{Ng}$ et al., 2019). So, this is the main premise of microfoundations. Thus, in order to understand how CSR is shaped in Lebanon one must first understand the people involved in CSR. One needs to understand the decisions that people make and the reasons behind their choices and actions.

Following the discussion on the link between microfoundations and institutional theory in chapter two, all articles and books related to microfoundations explain that researchers are penetrating down to the origins of the issue (e.g. Tolbert \& Zucker, 2020). Institutions are 
created due to organizations and organizations are created to defend or protect certain values and certain cultural norms.

\subsubsection{Contingency Theory in CSR}

My second contribution is context. Previous research has looked at CSR in developed countries like the UK but very few studies have explored it in developing countries like Lebanon (Pisani et al., 2017).This study also contributes to the CSR theory because I am looking at CSR from a contextual point of view and I am contributing to theorizing in the field of CSR. A theory is usually composed of an independent variable, a dependent variable, and contingent factors. When people theorize in the field of CSR, they always talk about what are the independent variables to point out successful CSR implementation. There are also a lot of contingent factors, for example CSR in the UK (Idowu, 2011) and CSR in the USA (Sheldon \& Park, 2011). So, this research contributes to the whole theory of CSR, I am making it richer, but in particular to the contingent factors. Therefore, this adds to Tsui's (2004) argument of context bound theorizing. This is consistent with Tsui's (2004) conceptualization of context bound theory. The context bound theory says that the success of CSR is dependent on different factors depending on which country a person is from (Tsui, 2004).

As discussed earlier, familial environment, vocation and workplace settings, and extraneous culture and values are the three themes that answered the second research question. The answers to the second research question form the second contribution to theory which is contingency theory in CSR. My second contribution is that I am saying that CSR is context bound and my research shows how it is context bound in Lebanon. It is context bound through familial environment, vocation and workplace settings, and extraneous culture and values that underpin CSR in Lebanon. The following three subsections highlight the themes that contribute to context. 


\subsubsection{Familial Environment as a Contextual Difference}

All managers interviewed specified that their staff work together as family members in their particular companies where the workplace is friendly and informal with an open-door policy. The concept of familial environment is a reflection of the Lebanese culture in the workplace of the sampled MNCs. In fact, the Lebanese society is characterized by a collectivist culture where citizens consider the role of the family as highly important, with robust family bonds persistent in the country (Jamali, 2009). Thus, I contribute to literature by explaining how the features of a workplace environment i.e. familial environment that are affected by a specific national context i.e. Lebanon can in turn affect employees' and managers' CSR related values and behaviours.

In their study on how global international CSR research was, Pisani et al. (2017) found that studies on international CSR in developing and emerging country contexts are somewhat more directed towards firm-level topics that influence the practices and rules of MNCs. There was dearth in research relating to the macro-level factors affecting the international business environment (Pisani et al., 2017). Hence, this research fills this gap in literature as it tackles how individual-level, firm-level, and macro-level dynamics are linked together and influence CSR in MNCs operating in a developing country i.e. Lebanon.

Another major result is that CSR starts at home. In fact, all participants clarified that their organizations are socially responsible towards their personnel, take good care of them, and consider them as one central stakeholder. In fact, all participants affirmed that CSR started first inside of the organization and then was taken outside. These findings also differentiate Lebanon from other countries because stakeholders considered differ based on context (Avetisyan \& Ferrary, 2013). Along similar lines, in her study on stakeholders in the Middle East, Africa, and Asia, Munro (2013) found that CSR was highly associated with taking care 
of the environment and society rather than stakeholders. Hence, although Lebanon is a Middle Eastern country, its CSR emphasis, practices, and perceptions differ from other neighbor countries or developing countries.

\subsubsection{Vocational CSR as Unique to the Lebanese Context}

All the sampled CSR managers saw CSR as a vocation more than solely a part of their job. They give the impression of being emotionally invested in CSR. They stated that CSR as a job reveals who individuals are and what they actually believe in. Vocation and charity start in the home/familial environment which does not exist in other studies. For example, the main drivers that motivate managers in Hong Kong to engage in CSR are competitive advantage, improved reputation, and better management (Studer, Welford, \& Hills, 2006). Along similar lines, Jamali and Mirshak (2007) found that many managers in foreign countries like Finland and Cyprus argued that the main driver of CSR activities was the profits and benefits of their CSR initiatives. Jamali and Mirshak (2007) also indicated that there is a clear cultural dimension to CSR that needs to be further explored. People do not see CSR as a vocation and they usually see it as external; helping other people and helping the environment but not really looking at it internally. So, people see CSR as a vocation/familial work environment in Lebanon because of their individual-level reasons such as values and ethics. This impacts how people do things, so it is related to practice theory and institutional work that are described in the section that follows. Institutional work explains what people do and the practice theory explains why they do it.

In a related study, Maignan and Ralston (2002) explored managers in France, the Netherlands, the UK, and the USA by taking a sample of one hundred firms from each country. They found important differences in managers' reasons and stakeholders' pressures to practice CSR among the four countries (Maignan \& Ralston, 2002). In another study, Chapple 
and Moon (2005) explored fifty firms in India, Indonesia, Malaysia, the Philippines, South Korea, Singapore, and Thailand and found that differences in national factors affect the differences in CSR performance. From here, this study contributes to knowledge by showing the factors in the national context that lead to differences in CSR drivers and practices.

\subsubsection{The Lebanese Extraneous Culture and Values}

This research demonstrates that national culture impacts managerial decisions regarding CSR and ethics. In fact, national culture impacts the behaviour of MNCs not because it is intentionally considered in decisions, but because of the implicit beliefs and values of MNCs' main decision makers (Noorderhaven \& Harzing, 2003). Research also suggests that cultural differences influence CSR's underlying forces among businesses in dissimilar contexts displaying diverse reactions to changes in the business setting (Jamali \& Mirshak, 2007). All interviewees posited that the Lebanese culture is characterized by dealing with people as family members. This was also apparent in the documents of the selected MNCs. This explains why the selected MNCs adopted a familial work environment. In fact, the managers sampled integrated aspects of their national Lebanese culture into the workplace.

Another result is that people from different cultures are dissimilar and they henceforth grasp and identify things in different ways. In fact, all managers interviewed explicated that the same CSR action should be differently performed in every country because citizens diverge and will not embrace it the same way. Freeman and Hasnaoui (2011) conducted a study in the UK, France, the USA, and Canada and found that people understand and perceive CSR differently across and within the four countries. Along similar lines, Morgeson et al. (2013) explained that people are included within businesses and businesses within social and cultural contexts. Thereby, this study contributes to literature as it helps reduce the gap between micro-level and macro-level factors in the management field. 
The companies' documents of international MNCs adapt their CSR initiatives to the needs of every country. In fact, literature suggests that CSR and its observed relevance are dependent on the cultural context (Mueller et al., 2012). When making CSR decisions in Lebanon and abroad, all participants expounded that their MNCs evaluate the community's local needs and situation and then set a plan to address them. In addition, all managers interviewed clarified that the headquarters suggest a list of CSR actions but the local managers select activities based the community's local needs. Peters, Miller, and Kusyk (2011) posited that firms should recognize that CSR methods based on western programs and rules should not necessarily be the same in the east or in developing countries. Similarly, in their study on companies operating in seven Asian countries Chapple and Moon (2005) found that MNCs adapt their CSR initiatives to the particular local contexts where they operate. Along similar lines, the particularity of culture was significant in more general studies such as Lenartowicz and Johnson (2002) and (Beekun, Westerman, \& Barghouti, 2005) who highlighted differences and similarities across regions and the need to be careful before depicting general conclusions. The national Lebanese culture does not really care about the environment but the research participants do. There are regional differences as countries are not the same all over. There are differences in terms of heritage that does impact people's values. Thus, the contingency theory is part of the discussion on context because the contingency theory says that how CSR comes about is dependent not only on national culture but also subculture and heritage so it goes beyond national culture. So, CSR is contingent upon context. CSR is not something that extended, it depends on (Pisani et al., 2017).

Another finding is that managers coming from varied cultures differ, which influences their business actions and decisions. Hambrick (2007) suggested that managers' personal ethics, values, experiences, and personalities influence their interpretations, their selective perceptions, and their line of vision. Similarly, Tetrault Sirsly (2009) found that top managers' 
values and ethics will affect managers' decisions, the company's CSR, and the understanding of the corporate code of ethics when implementing CSR. In Lebanon this may be mainly due to the fact that the Lebanese culture is a tight culture (Jamali, Abdallah, et al., 2010) because as Lebanese, a person should behave in certain ways and will be penalized for not following the culture. This is different from the American culture for example where people are not obliged to follow the culture and have a level of freedom in behaviour (Hannah, 2016).

Muslims around the world are not the same, Christians around the world are not the same there are many things that differentiate them (Darakchi, 2018). There is religion, there is culture, and there is that notion of regional culture and family culture, something that is distinctive that is the Lebanese culture. For example, P1 stated: "I associate myself with the Lebanese Armenian people because I do not associate myself with for example the Armenians of Armenia." It is the interesting mix of Lebanon of the Christians and the Muslims, the history they have had, that makes it unique. This is one source of differentiation. People in Lebanon have got a strong belief in God, whether they are Muslims or Christians it does not matter. So religion plays a big role in CSR where both religions have this element of giving back (Jamali \& Sdiani, 2013). For example, the Muslims have the zakat which is an obligatory contribution to charity and the Christians also give a lot of charity and help people (Hemingway \& Maclagan, 2004). In addition, the Lebanese culture itself has this sense of giving (Jamali, Zanhour, et al., 2009).

The whole thing about the social aspect in the Lebanese culture is very strong but the environment is always second place. As my findings show, it is getting better but still, it is not as strong as it should be. Animal welfare in Lebanon is also very poor (Davey \& Zhao, 2018). They believe in helping another human being, they believe in not polluting but there is a lot of mistreatment to animals like street dogs and cats. So, there is still room for improvement on the national level. By taking CSR per se, on a country level in Lebanon there is a lot to be 
done but on a private level like MNCs in the sample of this study, it is mature. Nevertheless, there is still room for improvement for the companies to reach a higher level of CSR which could be similar to companies operating in more developed countries like the UK. Thus, from a maturity point of view, the scope of CSR in Lebanon can be further improved.

Context is a contribution to knowledge because there is limited research on CSR in Lebanon (Khan et al., 2013) and because this study looks at CSR from ground up. In this research, the term CSR was used as a concept, as a label to identify who to talk to. This is the most obvious way because CSR is a well-known term, people know what it means, and it is something that unifies people in terms of the kind of work that it does. But nonetheless, I can say that CSR was used as a top down approach, but only to a certain extent, because it was used to find the interviewees. However, the real contribution here is bottom up because this is where sense making comes in. It is a context bound phenomenon because people who work in CSR in Lebanon make sense of CSR differently. As depicted in the previous sections and in chapter two, comparable research and studies were done in different countries regarding a person's ethics, cultural background, and even religion that shape the way managers look at CSR (e.g. Katz, Swanson, \& Nelson, 2001; Matten \& Moon, 2008). Literature also suggests that how people make sense of CSR has been undertaken in for example the USA and China but Lebanon and in particular the Middle East is missing (Pisani et al., 2017). Hence, this is one of the reasons why this study is being done and therefore it is a contribution in itself.

From my findings, the results show that people play a big role not only in the interpretation of CSR but also in how CSR is operationalized. The results are expanding the theoretical foundations of CSR and building upon an existing theory. Besides, this study is a contribution to knowledge by itself because it is the first of its kind to be done in Lebanon; it is unique because it has not been done in another part of the world. It provides a more nuanced 
view of CSR. CSR is like democracy; every country has a different way of practicing democracy.

\subsubsection{CSR from an Institutional Theory Perspective}

My third contribution is institutional work and practice theory. Institutional theory suggests that companies are rooted within extensive social structures, encompassing diverse types of institutions that exercise substantial power on businesses' decision-making (e.g. Campbell, 2007). Furthermore, contemporary research on CSR has discussed that CSR actions are shaped in respect of the social context, and are consequently affected by the predominant institutions in such contexts (Jackson \& Apostolakou, 2010). This research contributes to institutional theory because it explains how MNCs operating in Lebanon are institutionalizing CSR in Lebanon or are implementing CSR in Lebanon. Additionally, every time an interviewee mentions CSR, he/she refers to things like Lebanon and culture. Institutional theory helps explain how culture and institutions evolve and develop and how it is applied in Lebanon. Institution is the establishments or set of organizations that are basically mechanisms to shape social order (Muthuri \& Gilbert, 2011). When talking about institution it refers to something that impacts society (Scott, 2001). In this research, MNCs operating in Lebanon are moving into CSR and using that as a way to legitimize their operations in Lebanon to create social order. By practicing CSR, MNCs are conveying a message that they are good organizations and see themselves as fabric to the Lebanese society.

Literature suggests many types of institutional theories but this study contributes to the institutional work theory (Lawrence \& Suddaby, 2006). The research participants are trying to maintain, extend, and develop CSR within their organizations so it is institutional work in Lebanon. They do it in different ways and this research explored how they are contributing to CSR institution and how they are managing their stakeholders and operations in order to do 
that. Many studies were underpinned by the institutional theory to explain the institution of CSR in various contexts such as the USA and France (Avetisyan \& Ferrary, 2013) but there is paucity in literature where Lebanon is concerned. Moreover, no study in Lebanon used the institutional work theory to elaborate on the specific types of work done in Lebanon regarding CSR. Hence, this study is a contribution in itself to the institutional work and practice theory as it explains how CSR was instituted in a developing country context and the types of work that was done in order to do that.

Lawrence et al. (2011) call for ample examination of the micro-dynamics of institutional work with a focus on the actions of individual actors within firms as they practice institutional work. They also call for exploring how the accrued activities and relations of individual actors within an institutional environment bring about creating, maintaining, and disrupting institutions (Lawrence et al., 2011). So, this research will contribute to theory and answer the call of Lawrence et al. (2011) as it reveals the role of individual managers in conducting institutional work to establish CSR in Lebanon and provides an empirical analysis of the micro-dynamics of institutional work. Besides, the majority of the studies concentrate on one type of institutional work i.e. either creating or maintaining institutions (Empson et al., 2013). There are some exceptions (e.g. Hirsch \& Bermiss, 2009; Jarzabkowski et al., 2009), nevertheless, their examination fails to consider the micro-level emphasis encouraged by Lawrence et al. (2011). Consequently, this research will fill this gap in literature as it simultaneously explains the different forms of institutional work by adopting a micro-level frame of analysis i.e. individual managers and explores institutional work in a new context i.e. Lebanon which was never explored before in this domain. Above and beyond, Amaeshi et al. (2016) argued that the practices of CSR that go beyond philanthropy include institutional works. Thus, this study will be examining institutional work in CSR. 
Practice theory is basically a collection of theories (Lindberg \& Rantatalo, 2015). It is more like a belief of what happens and how people do things is dependent on their immediate environment (Schatzki, 2005). Practice theory is part of institutional work because in some sense it is what happens (Lawrence \& Suddaby, 2006). This is what happens in Lebanon because what happens in practice is due to the fact that people are forced to take a centrifugal approach and be ambidextrous in their process. The answers to the third research question form the third contribution to theory which is institutional work and practice theory. The following three subsections highlight the themes that contribute to institutional work and practice theory.

Lawrence and Suddaby (2006) explained and categorized the different types of institutional work into three tables entitled creating institutions, maintaining institutions, and disrupting institutions. As previously mentioned, this study explains the institution of CSR in Lebanon. This research shows what the interviewed managers in Lebanon have done and what are they doing to make the institution of CSR better.

\subsubsection{CSR to Disrupt Existing Institutions}

\subsection{Disruption Created by CSR Activities}

This theme is underpinned by theories of institutional work and practice theory. As detailed in chapter five, the reports of the MNCs included various types of CSR activities that these companies performed. Some examples of such actions comprise supporting municipalities to improve the infrastructure and install water networks for citizens, educating the young generation, recycling, and employee well-being programs. Matten and Moon (2008) explained that different values may be possibly reflected in similar forms of behaviour. Similarly, Muller and Kolk (2010) posited that internal drivers may be embedded in different values but still appear in the same types of CSR activities in developed and developing 
countries such as recycling. It seems that MNCs from the sample conduct CSR activities to fill the gap that the Lebanese government is unable to and does not fill. In related studies, feelings regarding the failings of government were underlined in Lebanon (Jamali \& Neville, 2011) and in Nigeria (Renouard \& Lado, 2012). Several countries of which developed countries cannot prosper without the support of charities and the private sector. CSR activities contribute to institutional work and practice theory because they reflect what MNCs operating in Lebanon do to institute CSR.

Corporate philanthropy is another CSR initiative that the sampled MNCs practice. In fact, CSR reports of the MNCs show that they take part in sponsorships, charity, donations, and collaborations with NGOs. Along similar lines, Jamali (2009) highlights the importance of the role of the private-public alliances in helping the Lebanese government solve today's problems because the traditional division of responsibilities between the private and public sectors in Lebanon does not seem to work. Moreover, in related studies conducted in India and Lebanon, strong philanthropic traditions seem to have formed inherent forms of CSR (Balasubramanian, Kimber, \& Siemensma, 2005; Jamali \& Neville, 2011; Jamali et al., 2008). This shows that the participants integrated the Lebanese tradition of giving back into their CSR practices in Lebanon.

Besides, offering funds to young social entrepreneurs was also another contributing CSR activity in Lebanon. This initiative is important because it is a good way to instill the spirit of social efficacy in the minds of the younger generations who will be the future employees and business leaders. This activity also helps entrepreneurs come up with innovative ways to sustain society's welfare for future generations. In addition, the participants stress on economic development as part of their CSR initiatives and explained that some of their firms created a distinct CSR program to offer education and employment 
opportunities for young individuals. As previously mentioned in chapter three, the unemployment rate is very high in Lebanon. Thus, this CSR initiative can really help the Lebanese economy.

\subsection{CSR's Disruption of the Lebanese Public and Private Sectors}

This study shows that many CSR programs were initiated to back up SMEs and offer commercial support, mentorship, and guidance to assist small businesses and startups in integrating sustainability in their business processes. This initiative is very important as it helps CSR institution in all types of companies in Lebanon and not only MNCs. This develops the institution of business as an effective force. The data also shows that the practice of CSR undermined existing assumptions and beliefs in Lebanon (Lawrence \& Suddaby, 2006, p. 235). All interviewees advanced that CSR is disrupting sectarianism often through the logic of economic opportunity.

Lawrence and Suddaby (2006) explained that disrupting institutions can be accomplished by undermining central assumptions and beliefs. Institutions are sustained and adapt by agents drawing back from accepted norms of operation, technologies, and instructions (Zietsma \& Lawrence, 2010). In fact, in the Lebanese community individuals have a propensity towards and assist individuals who hold the same political and religious principles by disregarding those who have the opposite (Jamali \& Neville, 2011).

Subsequently, the managers interviewed clarified that by assisting everyone equally through CSR this ideology is being disrupted. Therefore, this finding can be included in the disrupting institutions table and categorized as undermining assumptions and beliefs. The alternative really is something that is more about bringing people together which is what CSR does. In terms of contribution, one was disrupting and it was really about an elaboration of how some 
institutions, particularly the institution of sectarianism, has been disrupted by CSR; undermining assumptions and beliefs of sectarianism.

Moreover, the interviewees believe that the Lebanese government should start applying CSR laws on businesses. These findings can be called normalization because the sampled MNCs are paving the way and are showing up the government. This disrupts local Lebanese government practices because it is not something Lebanese governmental officials do and henceforth if these businesses are modifying the way they operate, it is disruptive. In fact, the Lebanese government's financial issues (Jamali et al., 2008) along with its high level of corruption were dominating policy making after the war. This is constraining the government's opportunity to assume more growth-oriented actions, and heightening the need for larger dependence on the private sector to support advancement, create employment, and increase the standard of living (Jamali et al., 2008).

This study shows that MNCs bring with them best practice; they demonstrate to local communities what the world does and how the top businesses conduct CSR because it is efficient and effective. Accordingly, the previous findings are categorized as disruptive because they lead and they could most likely alter the way local Lebanese businesses operate. Along similar lines, literature suggests that there are typical best practices for CSR that can be used as an international benchmark (Jamali et al., 2017). In China for example, Yin and Zhang (2012) found that trade associations are influencing CSR strategies by providing training and recommendations, predominantly in more competitive and less controlled industries such as the textile industry. Besides, CSR is offering opportunities for the international supply chains to create standard regulations for labor (Knudsen, 2013) and partnerships with certified training institutions comprising technical schools and test centers (Graafland \& Zhang, 2014). In a related study in Nigeria, Olowokudejo, Aduloju, and Oke (2011) found that CSR is 
perceived as a contribution to the development of managers' whole practical and professional performance.

All sampled MNCs emphasized their belief in anti-corruption and social human rights. Corruption is when people exploit their power to achieve a personal gain (Funaki \& Glencorse, 2014). Hence, these MNCs will not accept to abuse anyone for their self-interest. This disrupts the norm because Lebanon is known to be a corrupt country and any force combatting corruption is disruptive. In fact, Lebanon's rank in the corruptions perceptions index was 143 in 2017 which indicates the high level of corruption in the Lebanese public sector (Transparency International, 2017).

Furthermore, all interviewees respect human rights and humanity. This is also disruptive because the interviewees argued that human rights are not appreciated or given any sincere importance in Lebanon and by practicing CSR MNCs hope to change that in the longrun. This is disruptive because it changes the landscape in Lebanon whereby elements within human rights in Lebanon are not as pervasive as they should. For example, Lebanese women who get married to non-Lebanese cannot transmit the Lebanese nationality to their children (Grung, 2018). There is not a lot of research about the negative facts of Lebanon because Lebanese people assume it is normal, so why talk about it or there is nothing to talk about. Articulating opposition is difficult. For a foreigner or outside party this is terrible. Thus, this research contributes to knowledge as it fills the gap in literature regarding negative aspects of a developing country i.e. Lebanon.

Additionally, this research reveals that whistle-blowing is a vital feature of CSR. The sampled MNCs created a hotline for whistle-blowing and a protective mechanism for their staff who report unethical practices. Bok (2003, as cited in Tavani \& Grodzinsky, 2014) defines a whistle blower as a person who discloses information destined to shed light on 
neglect, exploitations, or hazards that intimidate the public interest. Whistle-blowing is unusual in Lebanon due to national norms

The institutional theory impinges on the stakeholder theory because it specifies which stakeholders are more important and it is shown explicitly in chapter five in the participants' answers. This study contributes to the stakeholder theory because it specifies who the stakeholders are for the sampled managers in Lebanon, in what order companies rank them, and why it differs from context to context. So, the contribution is more nuanced because it reveals how the stakeholder theory transpires. In the sampled MNCs operating in Lebanon, employees are the most important stakeholders. The research participants explained that in Lebanon CSR started internally and then was taken outside of the companies. They also mentioned that it would be paradoxical to ask employees to engage in external CSR and be ethical if the company is not socially responsible towards them and if they do not understand and sense what CSR truly is.

Stakeholder theory is discussed under institutional work because I am not contributing to stakeholder theory per se and institutional theory and stakeholder theory have a lot of overlaps. Institutional theory is about the institution itself whereas stakeholder theory is about the organizations and the individuals (Soppe, Schauten, Soppe, \& Kaymak, 2011).

Stakeholders are important because that is something that CSR theory has always been associated with (Lauesen, 2013). But stakeholder theory does not really say in terms of what should be done and what should be exactly changed (Lauesen, 2013). The stakeholder theory says that companies must engage with stakeholders but it does not really say what should be done in terms of making change. Institutional work is more informative in that perspective; it is actually more clear and informative in terms of how change is made or what change needs to happen from a broader perspective (Lawrence \& Suddaby, 2006). Identifying the individual 
stakeholders as micro level forms of engagement focuses these two perspectives on the operations of individual actors in institutions and how CSR is accomplished.

\subsubsection{CSR to Tailor New Institutions}

\subsection{Tailoring CSR to Indigenous Community}

This research reveals differences between MNCs of foreign origins and MNCs of local origins. MNCs of foreign origins have a top down approach of CSR because CSR decisions are initiated in the headquarters outside Lebanon. However, freedom is given to managers in local branches to customize those decisions and cater to the needs of the local communities; under the umbrella of guidelines that they specify. On the contrary, MNCs of Lebanese origins have a bottom up approach of CSR because although the spirit of giving back was instilled by the founders of these MNCs, CSR managers were the ones who officially initiated CSR in those companies. Hemingway and Maclagan (2004) argued that individual managers' corporate decisions are frequently determined by their personal values and concerns and business goals. Therefore, CSR activities can be the outcome of "championing by a few managers, due to their personal values and beliefs" (Duarte, 2010, p. 357). These values are usually expressed through the managers' opportunity to decide based on their personal judgment in a certain circumstance (Duarte, 2010). A significant idea made by Hemingway and Maclagan (2004) is that managers' actions may be a trigger for positive social change, in that it lets managers begin or adapt particular projects according to their personal values.

The sampled MNCs operating in Lebanon had CSR since their early inception whether they were foreign MNCs or local MNCs. But what is more important here is how these companies created a more bespoke approach to CSR in Lebanon. For indigenous Lebanese MNCs, their CSR program is very much based on the Lebanese culture of giving back and the 
need to integrate the firm with the local community whereas for foreign MNCs it is more policy driven.

This research shows an evolution of CSR. Foreign MNCs arrive with certain policies and they need to adapt them to the local environment but it is still largely policy driven. Participants mentioned that the evolution of CSR in local MNCs was from HR and there was an overlap with HR because they used to take care of employees and help people. It appears that for indigenous Lebanese companies, internal communication had a significant role in eventually shaping the CSR function within the companies. The reason is that to integrate the different functions within the firm and to integrate the internal company with the external environment, public relations of the firm is done through CSR. I use stakeholder theory as a lens to contribute to another theory i.e. to institutional work and practice theory.

Another difference between local and foreign MNCs is that local MNCs practice CSR voluntarily with no pressure from the government and society, but foreign MNCs are pressured by the government and society to practice CSR. Part of their legitimacy is based on a contribution to Lebanon. In fact, Lebanese companies do not take advantage of tax reductions or other direct financial inducements when practicing CSR (Jamali \& Neville, 2011). They may not be pressured per se but they have to meet the expectations of society. So, in Lebanon people are doing it willingly. This difference is attributed to their individual reasons like values, ethics, and Lebanese culture as depicted in Chapter Five.

With regards to decision-making, there is the external environment that prompts MNCs to take action and what sort of action to be taken, but of course there is also the department that gives them ideas of what they can do in Lebanon. In fact, individuals view, understand, analyze, and assess the world depending on their conceptual sets or cognitive models that they have established by interacting with their physical and social surroundings (Wuyts, Colombo, 
Dutta, \& Nooteboom, 2005). Hence, individuals view and identify the world in a different way because their cognition was established in dissimilar circumstances such as national culture, social values, and corporate culture (Wuyts et al., 2005). This is in line with the concept of cognitive distance (Nooteboom, 2000). In an organizational setting, people need to accomplish common goals and need to share common values to line up those goals (Frey \& Stutzer, 2002). Hence, selected MNCs with foreign headquarters are doing their best to reduce this cognitive distance by setting general guidelines to CSR initiatives but allowing some degree of adaptation to the local context i.e. Lebanon.

The findings also show that there is a CSR committee in the sampled MNCs, but this committee is largely rubber stamping to say that there is a committee because CSR managers drive the committee and everything. A lot of their decisions are based on their personal values and upbringing. Largely, the CSR initiatives are a combination of the policy and the CSR managers' personal initiatives and basically the merger or the overlap between the two is what they can usually implement. For example, P9 explained that she is obliged to abide by the policy set by the headquarters regarding which CSR initiatives to pursue and set her personal interests aside. She said: “...even if I am personally interested in helping disabled people through CSR, I am not allowed to do that as this is not in line with the company's policy that is set by our headquarters abroad..." 


\subsection{Tailoring CSR to Indigenous MNCs}

The data shows that the practice of CSR contributes to embedding and routinizing corporate practices (Lawrence \& Suddaby, 2006, p. 230). In fact, CSR is integrated in governance management systems including culture of the sampled MNCs. This finding can be included in the maintaining institutions table and categorized as the embedding and routinizing type of institutional work. This class of institutional work encompasses a vigorous introduction of an institution's normative grounds into the members' daily routines and corporate practices (Zilber, 2002). Hence, CSR was introduced in routine managerial practices as a process of governance.

The CSR managers of Winery, Bank 1, Bank 2, Bank 3, Building Materials Company, Logistics Company, Information Management Company, and Coffee Shop conduct training and participate in several seminars and workshops on CSR. This finding can also be included under embedding and routinizing. According to Lawrence and Suddaby (2006), institutions are maintained and repeated through the constant impact of instilled customs and monotonous practices like "training, education, hiring and certification routines and ceremonies of celebration" (p. 233). When managers embed, the way they do it is different. Train the trainer is one way for one organization, and in another organization, it could be a different way; it could be having expatriates to come in to do it for them. Another way could be enculturation; there is training involved but it is more internal training rather than send a few of them out, get the external trainer to come in to give everyone training. There could be coaching and mentoring while they are in classroom training. It is tailoring because it is embedding CSR in a manner that is bespoke.

The data also demonstrates that the practice of CSR contributes to the construction of identities (Lawrence \& Suddaby, 2006, p. 221). The CSR managers of Bank 1, Bank 2, Bank 
3, Information Management Company, and Logistics Company want to include CSR in employees' objectives, job descriptions, and evaluation process. This finding can be incorporated in the constructing identities type. Canning and O'Dwyer (2016) explained that the construction of identities as a type of institutional work is vital to creating institutions, as identities refer to the connection between an agent and the sector in which that agent functions.CSR managers are broadening the CSR scope. For example, P4 posited that she is planning to collaborate with the HR department to include employee volunteering efforts in CSR in employees' performance evaluation form, as she believes that employees who give some of their time to do CSR activities should be thanked in a way for their extra efforts. It can also be a motivational tool for other employees to volunteer.

Additionally, the Building Materials Company, Bank 1, Bank 2, the Household and Personal Care Company, and the Coffee Shop have employee volunteering programs. This finding can also be added to the constructing identities type in the creating institutions table. Lawrence and Suddaby (2006) gave the example of the Alberta historical museums where the governmental department in charge of museums reoriented the identities of museum employees. Employees were motivated to consider themselves as working in companies instead of museums that operate like businesses (Lawrence \& Suddaby, 2006). In this study, MNCs reoriented the identities of their employees and encouraged them to volunteer in community service and other CSR activities. Volunteers are a vehicle to create tailored CSR because volunteers will adapt a western approach to CSR to a one that fits the environment naturally.

Moreover, the data determines that engaging in CSR changed normative associations (Lawrence \& Suddaby, 2006, p. 221). The interviewed managers discoursed that CSR is incorporated in the firm and CSR initiatives are in line with the business. Changing normative 
associations means reshaping the relations between sets of actions and the ethical and cultural grounds for those actions (Binz et al., 2015). Thus, this finding can be considered as the changing normative associations type of institutional work in the creating institutions table.

Furthermore, the data indicates that the practice of CSR contributes to the construction of normative networks (Lawrence \& Suddaby, 2006, p. 221). This study demonstrates that CSR Lebanon influences businesses operating in Lebanon. Constructing normative networks means building inter-organizational networks through which actions become normatively authorized and which create the related peer group regarding obedience, control, and appraisal (Hayne \& Free, 2014). CSR Lebanon attempts to construct inter-organizational connections to further advance CSR in Lebanon. Thus, this outcome can be included in the constructing normative networks type in the creating institutions table.

CSR Lebanon was founded in 2009 by Mr. Khaled Kassar, founder and CEO, with the purpose of increasing awareness about CSR and sustainability in Lebanon and the area (Kassar, Baraka, Musharbash-Tannous, \& Nour, 2017). The organization follows a strategic program in order to enhance the engagement of companies in neighboring societies by incorporating responsible practices in their work settings, markets, environment, and society (CSR Lebanon, 2016). CSR Lebanon is characterized by the following documents as depicted on its website (www.csrlebanon.com):

- $\quad$ The first ever expert CSR organization in Lebanon.

- $\quad$ The first to conduct CSR seminars, conferences, international CSR forums, and CSR trainings in Lebanon.

- The only CSR databank in Lebanon.

- Broadest global and regional network of CSR specialists.

- Official representative of the UNGC in Lebanon. 
- Delegated by the Business in the Community (BITC) and the Global Reporting Initiative (GRI).

- $\quad$ The first and only company to publish a specialized CSR magazine in the Middle East.

- $\quad$ The first Arab CSR consultancy offering quality assurance.

- Main reference for senior education students in Lebanon.

Throughout this period, CSR Lebanon was able to create more than fifty permanent and temporary job opportunities and motivate one hundred and fifty banks and firms in Lebanon to engage in CSR or include it in their future agendas (CSR Lebanon, 2016). Besides, more than one thousand students and professors from twelve universities in Lebanon have profited from the resources and initiatives of CSR Lebanon (CSR Lebanon, 2016). Additionally, more than three hundred professionals, lecturers, companies, journalists, associations, and NGOs formed partnerships with CSR Lebanon (CSR Lebanon, 2016). Between 2009 and 2015, CSR Lebanon was able to increase the number of participants from Lebanon in UNGC by eighty-eight percent (CSR Lebanon, 2016). Lebanon is remarkably evolving as a leader in vigorously endorsing new models and commitment to CSR in the Middle East despite its economic uncertainties (Lebanon builds up leadership, 2013). This fact differentiates Lebanon from other countries with similar or different cultures in the Middle East and hence serves as another contribution to knowledge.

The future steps on the agenda of CSR Lebanon is to increase CSR literacy among university students, SMEs, and business professionals in Lebanon in order to increase CSR adoption and implementation across the country (Kassar et al., 2017). Besides, CSR Lebanon is calling for collective collaboration among all parties in order to push the Lebanese government to enact CSR laws (Kassar et al., 2017). Although the actions initiated by CSR 
Lebanon are tailored to the Lebanese context, they can also be considered under maintaining or even growing the institution of CSR in Lebanon.

Besides, the data demonstrates that the sampled MNCs took ISO certificates, that assist them in instituting CSR in their organizations but they used different methods to tailor CSR application based on their suitability. This finding can also be considered as constructing normative networks type of institutional work in the creating institutions table. Guler, Guillen, and Macpherson (2002) did an analysis on the dissemination of ISO 9000 practices and found that the primary dissemination of ISO 9000 in manufacturing occurred through the efforts of engineers and production managers in forming a normative network intended to promote manufacturing principles and operations. By learning about ISO through the workshops, the MNCs are using external institutions as a form of legitimizing CSR. The ISO standard is a form of trying to legitimize CSR. So, what MNCs operating in Lebanon are doing is actually a bona fide code of practice that is proposed by ISO and this shows that what they are doing is a good thing and is genuine and legitimate.

All CSR managers from the sample are persistently working to advance and improve CSR. Contrary to the unreasonable type of most controlling activities, managerial definitions frequently focus on instituting the limits of future or possible institutional structures and practices (Lawrence \& Suddaby, 2006). Guidelines of affiliation, official approval, and social conscience involve agents in procedures concentrating on defining and redefining frontiers and outlines within which new institutions can be shaped (Lawrence \& Suddaby, 2006). The sampled CSR managers are defining and enhancing CSR and its boundaries. Thus, this outcome can be included in the defining type in the creating institutions table.

Moreover, Bank 1, Bank 2, Logistics Company, Information Management Company, and Building Materials Company have an enforced CSR policy that all employees have to 
abide by. Pedersen and Nygaard (2018) posited that defining is the creation of rule systems that convene characteristics, define limits of membership, or create hierarchies of status within a field. An important component of institutional work includes the validation of rule systems to create definitional classes of deference (Lawrence \& Suddaby, 2006). Defining, vesting, and advocacy are forms of institutional work that focus on rules (Guillemette, Mignerat, \& Pare, 2016). This finding can also be included in the defining type in the creating institutions table and not in the vesting type because vesting is when the government sets the rules while defining is internal when the company creates its own policy. These results are under tailoring because this is defining and construing for oneself.

The data also shows that CSR managers in Winery, Bank 1, Bank 2, Bank 3, Building Materials Company, Logistics Company, Information Management Company, and Coffee Shop institute CSR by educating employees and other managers (Lawrence \& Suddaby, 2006, p. 221). Binz, Harris-Lovett, Kiparsky, Sedlak, and Truffer (2015) defined educating as educating agents in skills and knowledge which are essential to back up the new institution. CSR managers in Lebanon are spreading awareness and educating employees on CSR. Thus, this result can be added to the educating form of institutional work in the creating institutions table.

Besides, these MNCs consult experts to improve their CSR practices. While explaining the educating form of institutional work, Lawrence and Suddaby (2006) gave the example of two firms that hired Japanese consulting companies to assist them in introducing the unique Toyota manufacturing model in their businesses. Therefore, this finding can also be added to the educating type in the creating institutions table.

The data demonstrates that managers in MNCs from the sample theorize about CSR to institute it (Lawrence \& Suddaby, 2006, p. 221). In fact, these MNCs define CSR as a 
voluntary act that firms practice to create trust, behave ethically and responsibly with all their stakeholders, and give back to the community. A significant feature of theorizing is giving names to new ideas and activities so that they could become part of the intellectual plan of the discipline (Hayne \& Free, 2014). These MNCs named and defined CSR to explain it and to find the cause and effect relationship between its elements. Thus, this outcome can be included in the theorizing type in the creating institutions table.

CSR is not a new notion and it has constantly changed over time to better suit the purpose of the work of diverse researchers (Hack et al., 2014). Dahlsrud (2008) posited that although there are several definitions of CSR written in different expressions, they are mostly similar, making the lack of one common definition less problematic than it might first appear. The definitions of CSR portray a phenomenon, but do not offer any direction on how to cope with the challenges arising (Dahlsrud, 2008). Thus, companies' concern is not to define CSR but to understand how CSR is socially fashioned in a particular context and how managers take this into consideration when developing their business strategies (Dahlsrud, 2008). Based on Dahlsrud's (2008) argument, it can be inferred that this study will contribute to knowledge and will help managers understand how CSR is socially constructed in the Lebanese context. In addition, CSR managers from the sample believe that there should be more scholarly research on CSR. This is why this research contributes to knowledge. For instance, P13 believes that there should be more scholarly researches around CSR to help business gain a better understanding of CSR, its challenges and potentials, and they also help CSR practitioners with insights that support their arguments for improving CSR. 


\subsubsection{CSR to Maintain Institutions}

\subsection{CSR's Evolution and Maintenance in Indigenous MNCs}

The sampled MNCs officially instigated CSR after 2000. The managers interviewed also collectively said that they have been officially engaging in CSR after 2000. Thus, I can say that CSR officially started in Lebanon as of 2000. CSR as an official activity is relatively new in Lebanon. However, there are many activities undertaken that do not fall under the CSR label but they do share common characteristics of CSR activities. With regards to the evolution of CSR in the Lebanese culture, it had a strong philanthropic value or giving and the founders have it but it had to evolve in terms of formalization for more than donations. There are two stories here in terms of how CSR plays a role in indigenous Lebanese firms. The first one is that some of the principles of CSR are very well grounded within the Lebanese culture of philanthropy and giving (Jamali, Zanhour, et al., 2009). But at the same time there is another theme in terms of how CSR evolved in Lebanon via the communications functions within the firms in wanting to integrate the different functions within the firm, but also eventually in integrating the internal aspects of the organization with the external environment.

The data also indicates that engaging in CSR contributes to valorizing and demonizing CSR activities (Lawrence \& Suddaby, 2006, p. 230). All participants stated that their MNCs publish CSR reports. This finding can be included in the maintaining institutions table and categorized as the valorizing and demonizing type of institutional work. This work maintains institutions by supplying the public with particularly positive and negative illustrations showing the standards of an institution (Lawrence \& Suddaby, 2006). When businesses publish CSR reports, they offer examples of and clarify their CSR practices and numbers. Maintaining can be done in many ways. For example, companies have champions in place, 
have got people who are interested and invested in the whole CSR project, and have got people whose full-time role is about CSR. Managers put it into systems and culture that is maintaining because it is about the long-term.

Furthermore, the data demonstrates that MNCs from the sample are mythologizing CSR. All selected MNCs have CSR is in their DNA, mission statement, and corporate culture. This result can be incorporated in the maintaining institutions table and considered as a mythologizing type of institutional work. Lawrence and Suddaby (2006) mentioned that the keystones of an institution can be preserved by generating and conserving myths about its history. Corporate values and CSR are integrated in the corporate culture of all MNCs from the sample and in all their global subsidiaries. Culture is understood as social customs that are transmitted from a generation to another (Johnston, 2008). One example in this regard was told by P12. He explained that the firm's founding family has an extensive history of good deeds and CSR initiatives so several stories can be communicated using narrative (Humphreys \& Brown, 2008). He added that it undertakes many good deeds such as building free schools, providing free buses to transport students, and financing the tuition fees of university students. This practice was transferred to the business and maintained throughout its history till today. Thus, by integrating CSR in the corporate culture, it becomes a part of its history which helps in maintaining its institution.

The data also shows that the practice of CSR contributes to enabling work (Lawrence \& Suddaby, 2006, p. 230). In fact, the Food and Beverage Company is a founding member of the UNGC, the Household and Personal Care Company, Bank 3, and the Logistics Company are signatories, and Bank 1 and Bank 2 are participants. This outcome can be included in the maintaining institutions table and considered as enabling work. Greenwood, Suddaby, and Hinings (2002) explained that professional associations frequently participate in this type of work by constructing and maintaining intra-professional agreements over restrictions, 
participation, and behaviour. Galvin (2002) also explained that by presenting constitutional guidelines of participation, principles, or characteristic, associations operate in a predominantly guiding dimension as they support the establishment, diffusion, and replica of shared definitions and knowledge in an organizational field. In this case, MNCs founded or worked with UNGC to establish principles for MNC practices around the world of which responsible business.

Besides, all participants jointly expressed the importance of employee engagement and collaboration in CSR's success. All sampled MNCs also engage their stakeholders in their CSR activities. These findings can also be incorporated in the maintaining institutions table and considered as enabling work (Empson et al., 2013). Personnel and other stakeholders are assisting in the application of CSR actions and the span of CSR is increasing through their collaboration. Co-creation or coproduction (Scandelius \& Cohen, 2016) is done in Lebanon to enhance the legitimacy of the institution that is being created. Co-creation means cooperation with greater participation and creativity resulting in shared value (Ind, Iglesias, \& Schultz, 2013). For institutions to be created or maintained people must have a voice. MNCs collectively co-create or co-produce what is CSR because when they do that, whatever that they create together with their employees and stakeholders becomes more legitimate. It will be accepted by all parties involved because they all had a say in creating it. Besides, dynamic cooperation and co-creation with a variety of stakeholders is very important and fits predominantly well in the context of CSR (Crane et al., 2014; Sakarya et al., 2012; Savage et al., 2010; Vurro, Russo, \& Perrini, 2009).

In addition, the data indicates that MNCs operating in Lebanon maintained CSR by policing it (Lawrence \& Suddaby, 2006, p. 230). CSR is formal and controlled by top managers in all MNCs from the sample. Policing means making sure that people are compliant through imposition, assessment, and observation (Mena \& Suddaby, 2016). Because top 
managers are monitoring and controlling CSR, this finding can be included in the maintaining institutions table and categorized as policing. This result is under maintaining because managers are legitimizing CSR by controlling it in order to maintain it.

MNCs from the sample are against bribery and corruption. Institutional work has the possibility of disrupting institutions by setting apart the routine, regulation, or technology from its ethical grounds as suitable for a particular cultural context (Fuenfschilling \& Truffer, 2016). In Lebanon, people have a habit to bribe to get what they want. In fact, Jeong and Weiner (2012) conducted a study on forty-eight countries to check the bribery level of each country. Lebanon had a very high coefficient indicating a high level of bribery and ranked fifth out of the forty-eight countries explored. Consequently, by not bribing, these MNCs are disrupting this practice in Lebanon. Ethics is what is considered good and bad in a certain society, so this is why disassociating moral foundations and bribes are related to ethics. Thus, this finding can be included in the maintaining institutions table and categorized as disassociating moral foundations.

The data illustrates that managers practicing CSR gained advocacy in MNCs operating in Lebanon (Lawrence \& Suddaby, 2006, p. 221). All participants expressed the importance of their leadership and of top management's complete support in the success of CSR. They also emphasized their commitment to CSR. The first crucial thing for creating institutions is advocacy which is the deployment of governing and political support through direct and measured methods of social persuasion (Pedersen \& Nygaard, 2018). In this case, top managers were advocates to CSR and were doing their best to establish it and enforce it in their respective companies. These results use agency as maintaining because CSR in Lebanon gained advocacy in these MNCs as managers are developing their support network. 


\subsection{CSR's Maintenance through Appropriate Decision-Making}

The participants elucidated that their headquarters set the big CSR strategy but the local executive committee adapts decision-making and implementation to the local country. CSR in Lebanon has a simple structure of principles and adaption. Adapting decision-making is tailoring. However, it is also maintaining because of the principle of equifinality. Equifinality means that there is more than one means to reach the same final state (Barrett, 2018). But it does not really matter because at the end of the day they are all still meeting the same principles or the same goals. Therefore, in some sense it is also maintaining the CSR principles of the organization be it at the global level or at the Lebanese level. It is just that the way it is undertaken is different.

CSR in Lebanon is a bona fide institution because it is about a cluster of companies doing CSR, it is about associations, it is about government, and it is about NGOs and charities working together in a space called CSR Lebanon. After confirming that it is an institution, they initiated a series of actions to change this institution or make it better. Chapter five and the previous sections highlighted the details of the institutional work that they do. This research looks at the approach and the process to institutional work. There are three major steps here; creating, maintaining, and disrupting institutions. I look at the individual types of work in my analysis and the nine forms of institutional work identified by Lawrence and Suddaby (2006). I talk about the types in my analysis because it is focused so much on types, but perhaps the contribution is not the types, it is the fact that CSR in Lebanon is the approach and it is very unique. I look at the landscape of CSR in Lebanon and people are doing different things, there is a lot of unevenness. But for some reason it is still advancing, it is still progressing, and it still works because of the approach and the process that companies undertake in institutional work. 
One way of contributing to institutional work is how CSR was approached. CSR in Lebanon is a centrifugal approach because there are different generations understanding what CSR is, different aspects of CSR have got different meanings, have got different acceptance, and other aspects such as social and environmental. Centrifugal means that it is not a standard approach; it is not a harmonized approach, because society has different levels of understanding of what CSR is and different aspects. The second way of contributing to institutional work is through the process of instituting CSR. The process is one that is ambidextrous. Ambidextrous is whenever individuals do two things at one time. Thus, my contribution to institutional work in terms of not so much of the work itself, it is about the approach and process to institutional work in Lebanon.

Lebanon learns a lot from other countries and also its own practice. The participants know what CSR is because they have got all these external best practices. They know what works and what does not work in Lebanon locally. But they cannot take the best practice and implement in Lebanon because there is unevenness and disparity; the progress of CSR is uneven so they have to take a centrifugal approach. When they create a new institution, it is not a linear process of creating, maintaining, and disrupting. They are actually doing all three at the same time for different parts of CSR. Thus, the process is ambidextrous. So, for example, they could be advancing CSR in terms of social awareness but at the same time they could be very low in terms of awareness about environment and also in terms of animal welfare. It is also quite centrifugal in terms of educating different generations. So, they must be ready to take an approach that is centrifugal that does not look as it is harmonized or coherent because of the environment in Lebanon. These are the approach and process that underpin this work. But in my research, I am taking Lawrence and Suddaby's (2006) theory as a guideline but I am extending it based on the things in the context that emphasize certain effects. In fact, I am extending the approach and process of institutional work. 


\subsection{Practical Implications}

\subsubsection{Implications on Practitioners}

My study confirms that managers have personal values, religion, and ethics taken from their family and upbringing that shape their decisions and actions. Moreover, a managers' national culture and the specific context in which their companies operate differ from one country to another. Hence, the types of work that businesses engage in to implement CSR and the CSR initiatives to be adopted need to be tailored to the specific national context because people differ and their needs differ as well. Henceforth, this study provides practical implications that will be very helpful for practitioners i.e. businesses engaging in or planning to embark on CSR and CSR practitioners as it informs them how to conduct CSR, particularly in a developing country context. It will help them better understand and enhance CSR and it will give them insight on how to tackle CSR challenges and ethical dilemmas that may emerge along the way.

Based on this study, CSR practitioners can start by appointing CSR managers who view CSR as a vocation, this way they can make sure that these individuals will then take CSR to heart and implement it genuinely, appropriately, and even enhance it. Secondly, corporations can consider their employees as their most important stakeholders thereby starting CSR at home and then taking it outside. In fact, as this study suggests, the essence of CSR success lies in the people who will implement it. Hence, businesses should take care of their personnel first because if the company is not socially responsible towards them and if they do not appreciate what CSR is, then how can they practice CSR or assist the company in engaging in it? it will be paradoxical. Similarly, literature suggests that companies who are socially responsible towards their employees are said to have a better performance, positive 
work environments, and increased job satisfaction among employees (e.g. Jones, Comfort, \& Hillier, 2013; Ng et al., 2019).

In a similar vein, companies can establish a familial work environment where every employee is treated as a family member rather than merely as an asset in the firm. This enhances CSR adoption and implementation and also results in a loyal workforce who would not leave the business even for a better salary. In fact, literature suggests that socially responsible companies who support, respect, and take care of their employees like family have a more loyal workforce, a better quality of employees, and more satisfied personnel (e.g. Worthington, Ram, \& Jones, 2006). Companies can also adopt a work setting that reflects the local national culture i.e. not necessarily familial environment. This will make employees feel at ease and identify with the corporate culture as suggested by the social identity theory (e.g. Bhattacharya \& Sen, 2004).

For practitioners in countries where people are very religious, an advice would be to consider specific religious, ethical, and, cultural values in order to tailor their CSR initiatives to the specific context in place because these constructs play an important role in facilitating CSR understanding, adoption, and implementation. People will then identify with the CSR ideologies and values in place and will positively embrace them. This will legitimize the company's operations in a particular context especially in countries like Lebanon where citizens are very religious and attribute everything to religion.

Furthermore, companies planning to embark on CSR in developing countries can initiate CSR activities to fill the gap that local governments are unable or unwilling to fill (e.g. Jamali \& Neville, 2011). This will enhance their reputation in society and will be seen positively by the local consumers, workforce, and government. For example, companies can enhance the infrastructure of the roads, provide scholarships to students, and establish employee well-being programs. 


\subsubsection{Implications on Organizational Policy}

The second implication of this research is on organizational policy as it helps managers understand what they can change in their internal policy based on my findings. My research focuses on the complexities of a developing country and how these complexities can sensitize managers to the need to carefully plan CSR initiatives, which are consistently linked to local sense making and analysis. Moreover, this study proves that ethics is the driver of CSR and CSR cannot succeed without proper business ethics. Hence, companies operating in countries characterized by a high level of corruption like Lebanon (Transparency international, 2017), will have to deal with employees who are used to chaos and not respecting the law. Therefore, managers need to establish and enforce a well-defined code of ethics and link it to organizational policy in order to ensure better business, managerial, and CSR performance. Along similar lines, Schwartz (2001) found that one of the most important reasons for abiding by the code of ethics was the actual enforcement of the code where employees and managers were afraid of being punished.

Similarly, my research provides evidence that bribery and corruption are prevalent in Lebanon. Subsequently, managers operating in such contexts need to integrate clear anticorruption and anti-bribery rules in their organizational policy to make sure their employees abide by their ethical convictions and socially responsible practices. Managers may also establish whistle-blowing policies with effective protective mechanisms where employees can report any unethical behaviour they perceive. Whistle-blowing is still uncommon in Lebanon but it proved successful in other countries like Norway (Skivenes \& Trygstad, 2010). Therefore, if implemented appropriately, this policy can really help companies operating in developing countries overcome unethical practices. Additionally, as this study indicates, managers will be facing ethical dilemmas but should maintain their position in order not to jeopardize the company's ethical stance and reputation. For example, managers in Lebanon 
may be put in positions where lorries are compounded until they pay a bribe. So, with proper policies and contingency plans set in place, managers can reduce the negative impact on business performance resulting from such circumstances.

Moreover, this research shows that the whole thing about the social aspect in the Lebanese culture is very strong but the environment is always second place. This made the CSR managers in this study create a CSR policy in order to make sure that employees abide by the CSR guidelines. For example, P3 audits and checks if employees are abiding by the CSR policy related to recycling and in case of non-conformity the general manager sends a warning to the corresponding employees. P3 also appointed individuals in different branches of the bank to check if employees are conforming to their CSR policy. Therefore, managers conducting business in such a context need to establish a CSR policy with clear guidelines and trainings for employees to understand what should and should not be done. Besides, top managers need to support and enforce the CSR policy in place; otherwise there will not be a successful implementation (e.g. Shah \& Ramamoorthy, 2014).

\subsubsection{Implications on Governmental Policy}

The third implication of this research is on governmental policy in terms of how the Lebanese government incentivizes the adoptions of CSR. As previously explained, the Lebanese government did not yet establish any CSR laws and does not provide any incentives to encourage firms to practice CSR (Jamali \& Neville, 2011). Moreover, Dirani (2014) clarified that the Lebanese governmental chambers, business associations, ministries, and bureaus that are usually expected to control CSR are not interested in or even exercising the minimal inspecting role they are expected to exercise. Therefore, this study can be useful to Mr. Khaled Kassar, the founder and CEO of CSR Lebanon (Kassar et al., 2017), wherein he

can use the results in order to make the Lebanese government more CSR conscious in terms of 
how it can get companies to adopt CSR. In fact, if all companies operating in Lebanon and engaging in CSR collaborate together to institute and create CSR through the help of CSR Lebanon, they can make a bigger and better impact. They can understand from this research that Lebanon is very unique for various reasons such as CSR managers viewing CSR as a vocation and creating familial work environments where CSR starts from within the organization. So, whilst those companies are taking the best practices from the UNGC, international associations, and certifying bodies like ISO that are very good, ultimately not all of them fit into the Lebanese environment. Consequently, to measure themselves completely against these measures may not be correct because they know that based on the circumstances, they will never one hundred percent meet them. So together they can create their own benchmarks rather than seek external benchmarks and by virtue of doing so what they do is that they legitimize this new institution.

Furthermore, the practice of CSR is disrupting sectarianism in Lebanon. In fact, Lebanon is a country where sectarianism is highly institutionalized and underpins all organizations (Jawad, 2002). Lebanese people are loyal to their religions with each of the eighteen religious sects backing up its mutual benefits to the detriment of the national interest (Dabbous et al., 2010). The sampled MNCs are teaching employees and other stakeholders how to respect, help, and accept people from different religions, gender, age, and political ideologies through the practice of CSR. Therefore, these companies are acting as social agents for change and can exemplify for the Lebanese government the types of laws to enact and the best practices that its government officials should engage in to reduce the conflicts emerging out of the Lebanese sectarianism. The Lebanese government can start by enforcing laws related to CSR and business ethics focusing on equal employment rights based on competencies rather than religion or politics. 
Moreover, Lebanon is currently going through a very intensive pollution crisis which is negatively affecting its environment (Chalhoub, 2018; Coppini et al., 2011). Thus, this research can offer the Lebanese government solutions to its environmental crisis through the various CSR initiatives that MNCs are conducting. Besides, the government can have an idea of what types of environmental related laws it can enact in order to lessen the negative impacts of pollution coming from the Lebanese private sector.

\subsection{Limitations and Future Research}

Despite this research's contributions, its limitations need to be noted. The first limitation is that this study adopted an exploratory cross-sectional research design because it studied a particular phenomenon at a precise moment (Bryman \& Bell, 2007). In fact, this research explored CSR as a phenomenon in Lebanon by collecting data at a specific point in time. Thus, future research can address this limitation by using a longitudinal research design. A longitudinal facet of several qualitative studies allows the collection of data over a time period and hence gives the researcher time to practically understand the phenomenon at hand (Gilmore \& Carson, 1996). This offers an opportunity to thoroughly describe the phenomenon, behaviours, and practices within a complete context (Gilmore \& Carson, 1996). Therefore, future research can study how CSR evolved in Lebanon throughout time and during different phases. For example, not all local MNCs or companies publish detailed CSR reports as they adopt a strategy of tailoring their activities at a micro level. This is difficult to detail and is valued more than reporting and becomes a form of institutional entrepreneurship. Other departmental managers are reluctant to give or write such information. However, most foreign MNCs publish CSR reports. So, there is room for improvement here with regards to local MNCs and other types of businesses. 
The second limitation of this research is that sample size could have been bigger, more geographically dispersed, and included other types of companies like SMEs. Thus, future research may address this limitation by selecting a bigger sample and doing a comparison between MNCs and SMEs in various regions of the Lebanese market. Moreover, future research can increase sample size and can also select participants from different genders. For example, from my observation I noticed that all participant females were CSR managers and there was only one male. It happened that most CSR managers interviewed were women. So future research may try to investigate if and how gender plays a role in CSR.

The third limitation of this study is that this research is qualitative and thus not confirmatory because was not designed to show a correlation between events. Therefore, future research could be confirmatory and focus on correlations. For example, future research can test the association between microfoundational factors with the success of CSR activities. It can also test the situational factors. Onwuegbuzie and Leech (2005) argued that exploratory research normally attempts to create theories regarding how and why a phenomenon functions in a certain way, whereas, confirmatory research includes testing hypotheses that emerge from new or present theories. The goals of exploratory studies focus on introducing and building theory, while goals of confirmatory studies emphasize testing and modifying theory (Onwuegbuzie \& Leech, 2005). This study explored why and how CSR is practiced in MNCs operating in Lebanon so future research can later test hypothesis related to its findings.

The sampling is queued or purposeful because the main aim of this research is to understand the decision-making process that is associated with CSR activities rather than the absence of CSR activities. Thus, what is left may be the aim of future research. Future research may investigate similar phenomena, such as the decision-making process, in companies that have not undertaken CSR activities or those who have only undertaken partial CSR activities. As with all things regarding CSR, although all participants say that they 
embrace CSR for its principles, there is utility for CSR and all companies know it. Besides, it is hard to assess whether or not they have leverage upon their CSR reputation and they are using it for marketing purposes. That in itself is another study, so future research can explore it further. Moreover, as explained in chapter three and in this chapter, the Lebanese culture is a tight culture where citizens are obliged to follow certain standards of behaviour (Jamali, Abdallah, et al., 2010). Thus, future research may do a comparative study of how CSR decision-making and implementation is done in tight versus loose cultures.

\subsection{Conclusion}

This research has three broad contributions; microfoundations, context, and institutional work and practice theory. The findings on microfoundations explain why CSR is understood and practiced this way in Lebanon. Here I explained many individual level factors like religion, ethics, heritage, ethnicity, and what explains the Lebanese culture. In terms of themes those things play a role, they make up the themes contributing to microfoundations. There is no work in terms of microfoundations of CSR in Lebanon. So, all these themes put together is in itself quite unique i.e. it is what is being explained in terms of Lebanese culture, it is one of the first if not the first study of this kind about CSR in Lebanon. It is a contribution to help other countries that are similar to Lebanon understand CSR better, but every country is different in its own ways even if they might have similar cultures. Definitely there is no one hundred per cent similarity but it can be used as a guide for similar countries in the Middle East sharing similar values and cultures to use it.

Moreover, Lebanon is unique to all countries because a lot of countries are multicultural, multi-ethnic, and multi-religions. A lot of countries will be singular culture, singular religion, or singular religion but multi-ethnic. In Lebanon, the people have language and heritage to some extent in common but they are varied in terms of the religion adopted. 
That makes Lebanon a very interesting case. Lebanese people are similar in terms of heritage because they speak the same language. For example, the UK also has people with different religions because they are also from different heritage (White, 2019). Whereas in Lebanon, there is something common that holds the people together but people also got something that is different from one another. With the different religions for example Shi'I and Sunni are both Muslims but they have a different understanding and obviously Islam and Christianity have similarities but of course they also have differences.

Lebanon is characterized as a country with various religious sects and what makes these microfoundations unique i.e. religion and heritage is that companies in Lebanon have to deal with paradoxes on a regular basis. For example, animal welfare extends to all animals including pigs. In Lebanon, Christians eat pork but it is paradoxical because the Muslims will not like it because they do not eat pork (Quek \& Ling, 2013) and for them pigs are not in the picture so why take care of them. But in general, irrespective of whether a person is Christian or Muslim he/she does the same thing well in the sense of social good but also at the same time there are things to improve because both will also litter and harm their environment. When companies are doing CSR in Lebanon they have to tread carefully because they are dealing with different paradoxes and sensitivities.

The theoretical contribution of the context is the fact that the participants view CSR as a vocation and familial environment. I am adding the types of contingencies that could change how theory is about CSR in Lebanon or how CSR theory is applied in Lebanon i.e. the concepts of vocation and familial environment. Institutional work explains what the participants are doing now to maintain or to advance the Lebanese CSR institution. An institution is a set of organizations including companies, governments, and associations that furthers the advancement of CSR in Lebanon. The research participants are trying to maintain, prolong, and advance CSR within their companies so it is institutional work in Lebanon. This 
is how this study contributes to institutional work from a microfoundation level. The participants do it in various ways and this study examined how they are contributing to the institution of CSR and how they are managing their stakeholders and processes in order to do that. The reason why I included practice theory here is because practice theory says that people do what they do because of their environment. So, to understand how people do things I have to understand the Lebanese environment as a case study of this environment.

In conclusion, this research has three contributions, microfoundations, context, and institutional work and practice theory, and they are interrelated. The microfoundations explain why CSR is practiced in Lebanon, context explains what is being done in Lebanon at the macro level, and institutional work and practice theory explain the so what at the meso level. The sampled managers understand what good practice is and what good practice is not from a global perspective and from a local perspective. The development of CSR in Lebanon is uneven and inconsistent; is uneven so they have to take a centrifugal approach. When the respondents create a new institution, it is not a direct process of creating, maintaining, and disrupting. They are essentially doing all three simultaneously for diverse parts of CSR. Therefore, the process is ambidextrous. But nonetheless it still works, it still works because CSR in Lebanon is characterized by the centrifugal approach and the ambidextrous process. Thus, the mediation between meso levels and microfoundations is the ambidexterity and this process moves outwards or centrifugally from this dynamic. Using their advocacy, the managers embed routines from their microfoundational position and thus imprint a CSR culture on the institutions.

As a final note, P12 who was representing a local MNC from the sample explained that the corporate culture and values were based on Christianity. As a personal observation, I personally saw by chance the owner of this MNC praying in church and attending the mass; he even served the Mass by walking through the altar to present the offerings and reading the 
liturgy of the Word. Moreover, in 2018, he was elected as a deputy in the Lebanese parliament where he chose as a title for his electoral campaign "human first" which is also the basis of the Christian values. Furthermore, this owner and his family are known in the Lebanese society for their charitable work and belief in God. Thus, after this observation, I was one hundred percent sure that there is consistency in what the participant was saying and the MNC's practice in real life. 


\section{References}

Aaronson, S., \& Reeves, J. . (2002). Corporate Responsibility in the Global Village: The Role of Public Policy. Washington, DC: National Policy Association.

Abboud, S. N., \& Muller, B. J. (2013). Geopolitics, Insecurity and Neocolonial Exceptionalism: A Critical Appraisal of the UN Special Tribunal for Lebanon. Security Dialogue, 44(5-6), 467-484. doi: 10.1177/0967010613502377

Agatiello, O. R. (2008). Ethical Governance: Beyond Good Practices and Standards. Management Decision, 46(8), 1132-1145. doi: 10.1108/00251740810901345

Agle, B. R., \& Van Buren III, H. J. (1999). God and Mammon: The Modern Relationship. Business Ethics Quarterly, 9(4), 563-582.

Aguilera, R., Rupp, D., Williams, C., \& Ganapathi, J. (2007). Putting the S Back in Corporate Social Responsibility: A Multilevel Theory of Social Change in Organizations. The Academy of Management Review, 32(3), 836-863.

Aguilera, R. V., \& Jackson, G. (2003). The Cross-National Diversity of Corporate Governance: Dimensions and Determinants. Academy of Management Review, 28(3), 447-465.

Aguinis, H. (2011). Organizational Responsibility: Doing Good and Doing Well. In S. Zedeck (Ed.), APA Handbook of Industrial and Organizational Psychology (Vol. 3, pp. 855879). Washington, DC: American Psychological Association.

Aguinis, H., \& Glavas, A. (2012). What We Know and Don't Know About Corporate Social Responsibility: A Review and Research Agenda. Journal of Management, 38(4), 932. doi: $10.1177 / 0149206311436079$ 
Aguinis, H., \& Glavas, A. (2013). Embedded Versus Peripheral Corporate Social Responsibility: Psychological Foundations. Industrial and Organizational Psychology, 6, 314-332. doi: 10.1111/iops.12059

Aguinis, H., \& Glavas, A. (2019). On Corporate Social Responsibility, Sensemaking, and the Search for Meaningfulness Through Work. Journal of Management, 45(3), 10571086. doi: $10.1177 / 0149206317691575$

Ahmadjian, C. L., \& Robinson, P. (2001). Safety in Numbers: Downsizing and the Deinstitutionalization of Permanent Employment in Japan. Administrative Science Quarterly, 46(4), 622-654.

Akerlof, G. A. (2002). Behavioral Macroeconomics and Macroeconomic Behavior. American Economic Review, 92(3), 411-433.

Albareda, L., Lozano, J. M., \& Ysa, T. (2007). Public Policies on Corporate Social Responsibility: The Role of Governments in Europe. Jounal of Business Ethics, 74(4), 391-407. doi: 10.1007/s10551-007-9514-1

Alcaniz, E. B., Caceres, R. C., \& Perez, R. C. (2010). Alliances Between Brands and Social Causes: The Influence of Company Credibility on Social Responsibility Image. Jounal of Business Ethics, 92(2), 169-186. doi: 10.1007/s10551-010-0461-x

Alcock, J., \& Iphofen, R. (2007). Computer-assisted Software Transcription of qualitative interviews. Nurse Researcher, 15(1), 16-26.

Alexius, S., \& Grossi, G. (2018). Decoupling in the Age of Market-embedded Morality: Responsible Gambling in a Hybrid Organization. Journal of Management and Governance, 22, 285-313. doi: 10.1007/s10997-017-9387-3 
Alvord, S. H., Brown, L. D., \& Letts, C. W. (2004). Social Entrepreneurship and Societal Transformation: An Exploratory Study. The Journal of Applied Behavioral Science, 40(3), 260-282.

Amaeshi, K., Adegbite, E., Ogbechie, C., Idemudia, U., Kan, K. A. S., Issa, M., \& Anakwue, O. I. J. (2016). Corporate Social Responsibility in SMEs: A Shift from Philanthropy to Institutional Works? Jounal of Business Ethics, 138(2), 385-400. doi: 10.1007/s10551015-2633-1

Amaeshi, K. M., Ogbechie, C., Adi, B. C., \& Amao, O. O. (2006). Corporate Social Responsibility in Nigeria: Western Mimicry or Indigenous Influences? The Journal of Corporate Citizenship, 24, 83-99.

Amis, J., Slack, T., \& Hinings, C. R. (2004). The Pace, Sequence, and Linearity of Radical Change. The Academy of Management Journal, 47(1), 15-39.

Amran, A., \& Siti-Nabiha, A. K. (2009). Corporate Social Reporting in Malaysia: A Case of Mimicking the West or Succumbing to Local Pressure. Social Responsibility Journal, 5(3), 358-375. doi: 10.1108/17471110910977285

Anastas, J. W. (2000). Research Design for Social Work and the Human Services (2nd ed.). New York: Columbia University Press.

Andriof, J., \& McIntosh, M. (2001). Perspectives on Corporate Citizenship. United Kingdom: Greenleaf Publishing Limited.

Angelidis, J., \& Ibrahim, N. (2004). An exploratory study of the impact of degree of religiousness upon an individual's corporate social responsiveness orientation. Jounal of Business Ethics, 51(2), 119-128. 
Angus-Leppan, T., Metcalf, L., \& Benn, S. (2010). Leadership Styles and CSR Practice: An Examination of Sensemaking, Institutional Drivers and CSR Leadership. Jounal of Business Ethics, 93, 189-213. doi: 10.1007/s10551-009-0221-y

Aragon-Correa, J. A., \& Sharma, S. (2003). A Contingent Resource-Based View of Proactive Corporate Environmental Strategy. The Academy of Management Review, 28(1), 7188.

Arevalo, J. A., \& Aravind, D. (2010). The Impact of the Crisis on Corporate Responsibility: The Case of UN Global Compact Participants in the USA. Corporate Governance, 10(4), 406-420. doi: 10.1108/14720701011069641

Armstrong, M. (2011). How to be an Even Better Manager (8th ed.). London: Kogan Page.

Ashman, I. (2005). The ethics of organisational commitment. Paper presented at the 9th annual EBEN-UK and 7th ethics \& HRM joint conference, Royal Holloway - University of London, UK.

Avetisyan, E., \& Ferrary, M. (2013). Dynamics of Stakeholders' Implications in the Institutionalization of the CSR Field in France and in the United States. Jounal of Business Ethics, 115, 115-133. doi: 10.1007/s10551-012-1386-3

Avgerou, C. (2000). IT and Organizational Change: An Institutionalist Perspective. Information Technology \& People, 13(4), 234-262.

Ayadi, M. A., Kusy, M. I., Minyoung, P., \& Trabelsi, S. (2015). Corporate Social Responsibility, Corporate Governance, and Managerial Risk-taking. The Journal of Theoretical Accounting Research, 11(1), 50-113. 
Azmat, F., \& Samaratunge, R. (2009). Responsible Entrepreneurship in Developing Countries: Understanding the Realities and Complexities. Jounal of Business Ethics, 90(3), 437452. doi: 10.1007/s10551-009-0054-8

Baddache, F., \& Nicolai, I. (2013). Follow the Leader: How Corporate Social Responsibility Influences Strategy and Practice in the Business Community. Journal of Business Strategy, 34(6), 26-35. doi: 10.1108/JBS-01-2013-0002

Balasubramanian, N. K. , Kimber, D., \& Siemensma, F. (2005). Emerging Opportunities or Traditions Reinforced? An Analysis of the Attitudes Towards CSR, and Trends of Thinking about CSR, in India. The Journal of Corporate Citizenship, 17, 79-92.

Bankmed. (2016). Analysis of Lebanon's External Sector - September 2016

Bansal, P. (2005). Evolving Sustainably: A Longitudinal Study of Corporate Sustainable Development. Strategic Management Journal, 26, 197-218. doi: 10.1002/smj.441

Bansal, P., \& Clelland, I. (2004). Talking Trash: Legitimacy, Impression Management, and Unsystematic Risk in the Context of the Natural Environment. The Academy of Management Journal, 47(1), 93-103.

Bansal, P., \& Roth, K. (2000). Why Companies Go Green: A Model of Ecological Responsiveness. Academy of Management Journal, 43(4), 717-736.

Barnett, M. L., \& King, A. A. (2008). Good Fences Make Good Neighbors: A Longitudinal Analysis of An Industry Self-regulation Institution. The Academy of Management Journal, 51(6), 1150-1170.

Barney, J., \& Felin, T. (2013). What Are Microfoundations? Academy of Management Perspectives, 27(2), 138-155. 
Barrett, B. J. (2018). Equifinality in Empirical Studies of Cultural Transmission. Behavioural Processes. doi: 10.1016/j.beproc.2018.01.011

Battilana, J. (2006). Agency and Institutions: The Enabling Role of Individuals' Social Position. Organization: The Interdisciplinary Journal of Organization, Theory and Society, 13(5), 653-676. doi: 10.1177/1350508406067008

Battilana, J., Leca, B., \& Boxenbaum, E. (2009). How Actors Change Institutions: Towards a Theory of Institutional Entrepreneurship. The Academy of Management Annals, 3(1), 65-107. doi: 10.1080/19416520903053598

Baughn, C. C., Bodie, N. L., \& McIntosh, J. C. (2007). Corporate Social and Environmental Responsibility in Asian Countries and Other Geographical Regions. Corporate Social Responsibility and Environmental Management, 14(4), 189-205. doi: 10.1002/csr.160

Beddewela, E., \& Fairbrass, J. (2015). Seeking Legitimacy Through CSR: Institutional Pressures and Corporate Responses of Multinationals in Sri Lanka. Jounal of Business Ethics, 136(3), 503-522. doi: 10.1007/s10551-014-2478-z

Beekman, A. V., \& Robinson, R. B. (2004). Supplier Partnerships and the Small, HighGrowth Firm: Selecting for Success. Journal of Small Business Management, 42(1), $59-77$.

Beekun, R. I., Hamdy, R., Westerman, J. W., \& HassabElnaby, H. R. (2008). An Exploration of Ethical Decision-making Processes in the United States and Egypt. Journal of Business Ethics, 82, 587-605. doi: 10.1007/s10551-007-9578-y

Beekun, R. I., Westerman, J., \& Barghouti, J. (2005). Utility of Ethical Frameworks in Determining Behavioral Intention: A Comparison of the U.S. and Russia. Jounal of Business Ethics, 61(3), 235-247. doi: 10.1007/s10551-005-4772-2 
Bennett, J. (2002). Multinational Corporations, Social Responsibility and Conflict. Journal of International Affairs, 55(2), 393-410.

Benziman, Y. (2013). “Mom, I’m Home”: Israeli Lebanon-War Films as Inadvertent Preservers of the National Narrative. Israel Studies, 18(3), 112-132.

Berrone, P., \& Gomez-Mejia, L. R. (2009). Environmental Performance and Executive Compensation: An Integrated Agency-institutional Perspective. The Academy of Management Journal, 52(1), 103-126.

Berthouzoz, R. (2000). Efficacité économique, base éthique et valeurs spirituelles dans le management d'entreprise. In T. C. Pauchant (Ed.), Pour un management Ethique et Spirituel: Défis, Cas, Outils et Questions (pp. 245-260). Montréal, Québec: Fides.

Bhattacharya, C. B., \& Sen, S. (2004). Doing Better at Doing Good: When, Why, and How Consumers Respond to Corporate Social Initiatives. California Management Review, 47(1), 9-24.

Bickerstaffe, G. (2002). Culture Club: An Interview with Fons Trompenaars. Business Strategy Review, 13(1), 31-35.

Binz, C., Harris-Lovett, S., Kiparsky, M., Sedlak, D. L., \& Truffer, B. (2015). The Thorny Road to Technology Legitimation - Institutional Work for Potable Water Reuse in California. Technological Forecasting \& Social Change, 103, 249-263.

Bitektine, A., \& Haack, P. (2015). The "Macro" and The "Micro" of Legitimacy: Toward A Multilevel Theory of The Legitimacy. The Academy of Management Review, 40(1), $49-75$. 
Blanchet, K., Fouad, M. F., \& Pherali, T. (2016). Syrian Refugees in Lebanon: The Search for Universal Health Coverage. Conflict and Health, 10(1). doi: 10.1186/s13031-016$0079-4$

Bless, C., Higson-Smith, C., \& Kagee, A. (2006). Fundamentals of Social Research Methods: An African Perspective (4th ed.). Cape Town, South Africa: Juta and Company Ltd.

Blindheim, B-T., \& Langhelle, O. (2010). A Reinterpretation of the Principles of CSR: A Pragmatic Approach. Corporate Social Responsibility and Environmental Management, 17(2), 107-117. doi: 10.1002/csr.235

Blowfield, M., \& Frynas, J. G. (2005). Setting New Agendas: Critical Perspectives on Corporate Social Responsibility in the Developing World. International Affairs, 81(3), 499-513.

Boatright, J. (2006). What's Wrong and What's Right With Stakeholder Management. Journal of Private Enterprise, 21(2).

Boatright, J. R. (2000). Ethics and the Conduct of Business (3rd ed.). Upper Saddle River, New Jersey: Prentice Hall, Inc.

Boddewyn, J. J. (2012). Beyond 'The Evolving Discipline of Public Affairs'. Journal of Public Affairs, 12(1), 98-104.

Bogdanovic, D., Dowd, M., Wattam, E., \& Adam, A. (2012). Contesting Methodologies Evaluating Focus Group and Privacy Diary Methods in a Study of On-line Privacy. Journal of Information, Communication and Ethics in Society, 10(4). doi: $10.1108 / 14779961211285854$ 
Bondy, K, Moon, J, \& Matten, D. (2012). An Institution of Corporate Social Responsibility (CSR) in Multi-National Corporations (MNCs): Form and Implications. Journal of Business Ethics, 111, 281-299. doi: 10.1007/s10551-012-1208-7

Bondy, K., Matten, D., \& Moon, J. (2004). The Adoption of Voluntary Codes of Conduct in MNCs: A Three-Country Comparative Study. Business and Society Review, 109(4), 449-477. doi: 10.1111/j.0045-3609.2004.00205.x

Boons, F., \& Strannegard, L. (2000). Organizations Coping with Their Natural Environment: A Laboratory for Institutionalization? International Studies of Management and Organization, 30(3), 7-17.

Borell, K. (2008). Terrorism and Everyday Life in Beirut 2005: Mental Reconstructions, Precautions and Normalization. Acta Sociologica, 51(1), 55-70. doi: $10.1177 / 0001699307086818$

Bowen, H. R. (1953). Social Responsibilities of the Businessman. New York: Harper \& Row. Boxenbaum, E., \& Pedersen, S. J. (2009). Scandinavian Institutionalism - A Case for Institutional Work. In T. Lawrence, R. Suddaby \& B. Leca (Eds.), Institutional Work: Actors and Agency in Institutional Studies of Organizations (pp. 178-204). Cambridge: Cambridge University Press.

BP. (2003). Sustainability Report 2003: Defining Our Path. London.

Brammer, S., \& Millington, A. (2003). The Effect of Stakeholder Preferences, Organizational Structure and Industry Type on Corporate Community Involvement. Jounal of Business Ethics, 45(3), 213-226. 
Brammer, S., \& Millington, A. (2004). The Development of Corporate Charitable Contributions in the UK: A Stakeholder Analysis. Journal of Management Studies, 41(8), 1411-1434.

Brammer, S., \& Pavelin, S. (2006). Corporate Reputation and Social Performance:The Importance of Fit. Journal of Management Studies, 43(3), 435-455. doi:

10.1111/j.1467-6486.2006.00597.x

Brammer, S., Williams, G., \& Zinkin, J. (2007). Religion and Attitudes to Corporate Social Responsibility in a Large Cross-country Sample. Journal of Business Ethics, 71, 229243. doi: 10.1007/s10551-006-9136-Z

Bridoux, F., \& Stoelhorst, J. W. (2014). Microfoundations for Stakeholder Theory: Managing Stakeholders with Heterogeneous Motives. Strategic Management Journal, 35(1), $107-125$.

Brown, D. L., Vetterlein, A., \& Roemer-Mahler, A. (2010). Theorizing Transnational Corporations as Social Actors: An Analysis of Corporate Motivations. Business and Politics, 12(1), 1-37.

Brown, T. J., Dacin, P. A., Pratt, M. G., \& Whetten, D. A. (2006). Identity, Intended Image, Construed Image, and Reputation: An Interdisciplinary Framework and Suggested Terminology. Journal of the Academy of Marketing Science, 34(2), 99-106. doi: $10.1177 / 0092070305284969$

Browne, J., \& Nuttall, R. (2013). Beyond Corporate Social Responsibility: Integrated External Engagement. The McKinsey Quarterly, March.

Bryman, A., \& Bell, E. (2007). Business Research Methods (2nd ed.). New York: Oxford University Press. 
Burgis-Kasthala, M. (2013). Defining Justice during Transition? International and Domestic Contestations Over the Special Tribunal for Lebanon. The International Journal of Transitional Justice, 7, 497-517. doi: 10.1093/ijtj/ijt014

Buysse, K., \& Verbeke, A. (2003). Proactive Environmental Strategies: A Stakeholder Management Perspective. Strategic Management Journal, 24(5), 453 - 470. doi: 10.1002/smj.299

Byrne, D., \& Ragin, C. C. (2013). The Sage Handbook of Case-Based Methods (1st ed.). London: SAGE Publications Ltd.

Cameron, R., \& Molina-Azorin, J. F. (2011). The Acceptance of Mixed Methods in Business and Management Research. International Journal of Organizational Analysis, 19(3), 256-270. doi: 10.1108/19348831111149204

Campbell, J. L. (2006). Institutional Analysis and the Paradox of Corporate Social Responsibility. The American Behavioral Scientist, 49(7), 925-938. doi: $10.1177 / 0002764205285172$

Campbell, J. L. (2007). Why Would Corporations Behave in Socially Responsible Ways? An Institutional Theory of Corporate Social Responsibility. The Academy of Management Review, 32(3), 946-967.

Canning, M., \& O’Dwyer, B. (2016). Institutional Work and Regulatory Change in the Accounting Profession. Accounting, Organizations, and Society, 54, 1-21.

Carey, K. L. (2012). Role Models and Racial Identity for African American Males at Historically Black and Predominantly White Colleges and Universities. (PhD), Ball State University, Ann Arbor, United States. Retrieved from https://search-proquest- 
com.neptune.ndu.edu.lb:9443/docview/1035152867?accountid=28281 ProQuest

Dissertations \& Theses Global database. (3521755)

Carpenter, V. L., \& Feroz, E. H. (2001). Institutional Theory and Accounting Rule Choice: An Analysis of Four US State Governments' Decisions to Adopt Generally Accepted Accounting Principles. Accounting, Organizations and Society, 26(7-8), 565-596. doi: 10.1016/S0361-3682(00)00038-6

Carroll, A. B. (2002). Ethics in management. In R. E. Frederick (Ed.), A companion to business ethics (pp. 141-152). Malden, Massachusetts: Blackwell Publishers Inc.

Carroll, A.B. (1979). A three-dimensional conceptual model of corporate performance. Academy of Management Review, 4(4), 497-505.

Carroll, A.B., Lipartito, K. J., Post, J. E., \& Werhane, P. H. (2012). Corporate Responsibility: The American Experience. Cambridge: Cambridge University Press.

Cassell, C., \& Symon, G. (2006). Taking Qualitative Methods in Organization and Management Research Seriously. Qualitative Research in Organizations and Management: An International Journal, 1(1), 4-12. doi: 10.1108/17465640610666606

Castello, I., \& Lozano, J. M. (2011). Searching for New Forms of Legitimacy Through Corporate Responsibility Rhetoric. Jounal of Business Ethics, 100, 11-29. doi: $10.1007 / \mathrm{s} 10551-011-0770-8$

Caulkin, S. (2002, April 7). Good thinking, bad practice. The Observer, 11.

Chalhoub, M. S. (2018). Public Policy and Technology Choices for Municipal Solid Waste Management A Recent Case in Lebanon. Cogent Environmental Science, 4(1). doi: $10.1080 / 23311843.2018 .1529853$ 
Chapple, W., \& Moon, J. (2005). Corporate Social Responsibility (CSR) in Asia: A SevenCountry Study of CSR Web Site Reporting. Business \& Society, 44(4), 415-441. doi: $10.1177 / 0007650305281658$

Choi, Y. J. (2017). Corporate Social Responsibility (CSR) as a World Cultural Norm? A Comprehensive Analysis of Global CSR Governance. (Doctor of Philosophy), George Mason University. (10275921)

Choucair, J. (2006). Lebanon: Finding A Path from Deadlock to Democracy. Carnegie Endowment for International Peace.

Chouinard, Y., \& Stanley, V. (2012). The Responsible Company. Ventura, CA: Patagonia Books.

Christmann, P. (2004). Multinational Companies and the Natural Environment: Determinants of Global Environmental Policy Standardization. The Academy of Management Journal, 47(5), 747-760.

Clark, G. L., \& Hebb, T. (2005). Why Should They Care? The Role of Institutional Investors in the Market for Corporate Global Responsibility. Environment and Planning A, $37(11)$.

Clemens, B., \& Douglas, T. J. (2006). Does Coercion Drive Firms to Adopt "Voluntary" Green Initiatives? Relationships Among Coercion, Superior Firm Resources, and Voluntary Green Initiatives. Journal of Business Research.

Codruta, D., \& Driga, I. (2017). The Impact of Multinational Companies from Romania on Increasing the Level of Corporate Social Responsibility Awareness. Contemporary Economics, 11(1), 45-66. 
Collis, J., \& Hussey, R. (2009). Business Research: A Practical Guide for Undergraduate \& Postgraduate Students (3rd ed.). Basingstoke: Palgrave Macmillan.

Confederation of British Industry. (2001). Issue Statement: Corporate Social Responsibility.

Cook, S. (2003). Who cares wins. Management Today, 40-47.

Coppini, G., De Dominicisa, M., Zodiatis, G., Lardner, R., Pinardi, N., Santoleri, R., .. . Kallose, G. (2011). Hindcast of Oil-Spill Pollution During the Lebanon Crisis in the Eastern Mediterranean, July-August 2006. Marine Pollution Bulletin, 62(1), 140-153. doi: 10.1016/j.marpolbul.2010.08.021

Coulter, M. (2010). Strategic Management in Action (5th ed.). Upper Saddle River, New Jersey: Pearson Prentice-Hall.

Cowan, K., \& Guzman, F. (2018). How CSR Reputation, Sustainability Signals, and Countryof-origin Sustainability Reputation Contribute to Corporate Brand Performance: An Exploratory Study. Journal of Business Research. doi: 10.1016/j.jbusres.2018.11.017

Crane, A, Matten, D., \& Spence, L. (2008). Corporate social responsibility: in a global context. In A. Crane, D. Matten \& L. Spence (Eds.), Corporate social responsibility: Readings and cases in a global context (pp. 3-20). Abingdon, UK: Routledge.

Crane, A., \& Matten, D. (2004). Business Ethics: A European Perspective. New York: Oxford University Press.

Crane, A., Palazzo, G., Spence, L. J., \& Matten, D. (2014). Contesting the Value of "Creating Shared Value". California Management Review, 56(2).

Creswell, J. W. (2014). Research Design: Qualitative, Quantitative, and Mixed Methods Approaches (4th ed.). Thousand Oaks, California: SAGE Publications, Inc. 
Crilly, D. (2011). Predicting Stakeholder Orientation in the Multinational Enterprise: A MidRange Theory. Journal of International Business Studies, 42(5), 694-717.

Crook, C. (2005, January 22). The Good Company: A Survey of Corporate Social Responsibility. The Economist, 374, 1-22.

Crouch, C. (2005). Capitalist Diversity and Change: Recombinant Governance and Institutional Entrepreneurs. Oxford: Oxford University Press.

Cruz, L. B., \& Boehe, D. M. (2010). How do Leading Retail MNCs Leverage CSR Globally? Insights from Brazil. Jounal of Business Ethics, 91, 243-263. doi: 10.1007/s10551010-0617-8

Cuervo-Cazurra, A. (2012). Extending Theory by Analyzing Developing Country Multinational Companies: Solving the Goldilocks Debate. Global Strategy Journal, 2(3), 153-167.

Cullen, J. B., Parboteeah, K. P., \& Hoegl, M. (2004). Cross-national Differences in Managers' Willingness to Justify Ethically Suspect Behaviors: A Test of Institutional Anomie Theory. Academy of Management Journal, 47(3), 411-421.

Cumming, D., Leung, T., \& Rui, O. (2015). Gender Diversity and Securities Fraud. academy of Management Journal, 58(5), 1572-1593. doi: 10.5465/amj.2013.0750

D'Aunno, T., Succi, M., \& Alexander, J. A. (2000). The Role of Institutional and Market Forces in Divergent Organizational Change. Administrative Science Quarterly, 45(4), 679-703.

Dabbous, Y., Nasser, K., \& Dabbous, F. (2010). Across the Bridge of Death: The Culture of Martyrdom in Lebanon 1960s-1980s. International Journal of Cultural Studies, 13(6), 593-615. doi: 10.1177/1367877910376578 
Dacin, M. T., Goodstein, J., \& Scott, W. R. (2002). Institutional Theory and Institutional Change: Introduction to the Special Research Forum. The Academy of Management Journal, 45(1), 45-56.

Dagher, C. (2000). Bring Down the Walls: Lebanon's Post-war Challenge. New York: Palgrave Macmillan.

Dahlsrud, A. (2008). How Corporate Social Responsibility is Defined: an Analysis of 37 Definitions. Corporate Social Responsibility and Environmental Management, 15, 113. doi: $10.1002 / \mathrm{csr}$

Dalton, T. M. (2004). An Approach for Integrating Economic Impact Analysis into the Evaluation of Potential Marine Protected Area Sites. Journal of Environmental Management, 70(4), 333-349. doi: 10.1016/j.jenvman.2003.12.012

Darakchi, S. (2018). Gender, religion, and identity: Modernization of gender roles among the Bulgarian Muslims (Pomaks). Women's Studies International Forum, 70, 1-8.

Davey, G., \& Zhao, X. (2018). Free-Roaming Cat (Felis Catus) Management and Welfare Policies in Two University Campuses in Beirut, Lebanon: Strengths, Weaknesses, and Opportunities. Journal of Applied Animal Welfare Science. doi: $10.1080 / 10888705.2018 .1550721$

Davis, K. (1960). Can business afford to ignore social responsibilities? California Management Review, 2(3), 70-76.

Dawkins, J., \& Lewis, S. (2003). CSR in Stakeholder Expectations: And their Implication for Company Strategy. Jounal of Business Ethics, 44(2), 185-193. 
De La Cuesta Gonzalez, M., \& Valor Martinez, C. (2004). Fostering Corporate Social Responsibility Through Public Initiative: From the EU to the Spanish Case. Jounal of Business Ethics, 55(3), 275-293.

De Luque, M. S., Washburn, N. T., Waldman, D. A., \& House, R. J. (2008). Unrequited Profit: How Stakeholder and Economic Values Relate to Subordinates' Perceptions of Leadership and Firm Performance. Administrative Science Quarterly, 53(4), 626-654.

De Schutter, O. (2008). Corporate Social Responsibility European Style. European Law Journal, 14(2), 203-236. doi: 10.1111/j.1468-0386.2007.00411.x

Dearnley, C. (2005). A Reflection on the Use of Semi-structured Interviews. Nurse Researcher, 13(1), 19-28.

Deeg, R., \& Jackson, G. (2007). Towards A More Dynamic Theory of Capitalist Variety. Socio-Economic Review, 5, 149-179. doi: 10.1093/ser/mw1021

Deegan, C. (2007). Organizational Legitimacy as A Motive for Sustainability Reporting. In J. Unerman, J. Bebbington \& B. O'Dwyer (Eds.), Sustainability Accounting and Accountability (pp. 127-149). London, United Kingdom: Routledge.

Deegan, C. (2009). Financial Accounting Theory. Australia: McGraw Hill.

Deloitte. (2009). Corporate Social Responsibility: Verankert in der Wertschöpfungskette. http://www.deloitte.com/assets/DcomGermany/Local20Assets/Documents/deCBCSRR80409.pdf

Demuth, R. L. F. (2006). Antecedents and Consequences of Value Expression in the Workplace. Northern Illinois University. (3227644) 
Deng, X., \& Xu, Y. (2017). Consumers' Responses to Corporate Social Responsibility Initiatives: The Mediating Role of Consumer-Company Identification. Jounal of Business Ethics, 142(3), 515-526. doi: 10.1007/s10551-015-2742-x

Deniz, M. D. L. C. D., \& Suarez, M. K. C. (2005). Corporate Social Responsibility and Family Business in Spain. Jounal of Business Ethics, 56(1), 27-41. doi: 10.1007/s10551-004$3237-3$

Desai, A. B., \& Rittenburg, T. (1997). Global ethics: An integrative framework for MNEs. Journal of Business Ethics, 16(8), 791-800.

Desjardins, J. (2003). An Introduction to Business Ethics. New York: McGraw-Hill.

Devinney, T. (2009). Is the Socially Responsible Corporation a Myth? The Good, the Bad, and the Ugly of Corporate Social Responsibility. Academy of Management Perspectives, 23(2), 44-56.

Dickson, M., BeShears, R., \& Gupta, V. (2004). The Impact of Societal Culture and Industry on Organizational Culture: Theoretical Explanations. In R. House, P. J. Hanges, M. Javidan, P. W. Dorfman \& V. Gupta (Eds.), Culture, Leadership, and Organizations: The GLOBE Study of 62 Societies (pp. 4-93). Thousand Oaks, CA: Sage.

Dillard, J. F., Rigsby, J. T., \& Goodman, C. (2004). The Making and Remaking of Organization Context: Duality and The Institutionalization Process. Accounting, Auditing \& Accountability Journal, 17(4), 506-542.

DiMaggio, P. (1988). Interest and Agency in Institutional Theory. In L. G. Zucker (Ed.), Institutional Patterns and Organizations: Culture and Environment (pp. 3-20). Cambridge: Ballinger Publishing Co. 
DiMaggio, P. J., \& Powell, W. W. (1983). The Iron Cage Revisited: Institutional Isomorphism and Collective Rationality in Organizational Fields. American Sociological Review, 48(2), 147-160.

DiMaggio, P. J., \& Powell, W. W. (1991). Introduction. In P. J. DiMaggio \& W. W. Powell (Eds.), The New Institutionalism in Organizational Analysis (pp. 1-38). Chicago: University of Chicago Press.

Dirani, A. (2014). What Do We Know About CSR in Lebanon? Responsible Business: Tthe Middle East Magazine for Sustainability \& Corporate Social Responsibility October November, 34-35.

Dirani, K. M. (2007). The Relationship Among Learning Organization Culture, Job Satisfaction, and Organizational Commitment in the Lebanese Banking Sector and the Effect of Social Patterns as Moderator Variables. University of Illinois, Urbana, Illinois.

Dirani, K. M. (2009). Measuring the Learning Organization Culture, Organizational Commitment and Job Satisfaction in the Lebanese Banking Sector. Human Resource Development International, 12(2), 189-208. doi: 10.1080/13678860902764118

Doh, J. P., \& Guay, T. R. (2006). Corporate Social Responsibility, Public Policy, and NGO Activism in Europe and the United States: An Institutional-Stakeholder Perspective. Journal of Management Studies, 43(1), 47-73.

Dowell, G., Hart, S., \& Yeung, B. (2000). Do Corporate Global Environmental Standards Create or Destroy Market Value? Management Science, 46(8), 1059-1074. 
Duarte, F. (2010). Working with Corporate Social Responsibility in Brazilian Companies: The Role of Managers' Values in the Maintenance of CSR Cultures. Jounal of Business Ethics, 96, 355-368. doi: 10.1007/s10551-010-0470-9

Dufour, D., Teller, P., \& Luu, P. (2014). A Neo-institutionalist Model of the Diffusion of IFRS Accounting Standards. Computational Economics, 44(1), 27-44. doi: 10.1007/s10614-013-9384-9

Durand, R., \& McGuire, J. (2005). Legitimating Agencies in the Face of Selection: The Case of AACSB. Organization Studies, 26(2), 165-196. doi: 10.1177/0170840605049465

Ebert, R. J., \& Griffin, R. W. (2015). Business Essentials (13th ed.). England: Pearson.

Eisenhardt, K. M. (1989). Building Theories from Case Study Research. Academy of Management Review, 14(4), 532-550.

Eisenhardt, K. M., \& Graebner, M. E. (2007). Theory Building From Cases: Opportunities and Challenges. Academy of Management Journal, 50(1), 25-32.

Eisenstadt, S. N. (1980). Cultural Orientations, Institutional Entrepreneurs, and Social Change: Comparative Analysis of Traditional Civilizations. American Journal of Sociology, 85(4), 840-869.

Elbayar, K. (2005). NGO Laws in Selected Arab States International Journal of Not-for-Profit Law, 7(4), 3-27.

Elliott, L. (2007, July 9). Economics: Plc: Prerogative of the Unaccountable Few: Adam Smith Argued for Free Trade and Self-interest, but Not This Kind of Capitalism., The Guardian.

Elms, H. (2006). Corporate (and Stakeholder) Responsibility in Central and Eastern Europe. International Journal of Emerging Markets, 1(3), 203-211. 
Emerging Markets Monitor. (2019). London: Fitch Solutions Group Limited.

Emiliani, M. L. (2000). Supporting Small Businesses in their Transition to Lean Production. Supply Chain Management: An International Journal, 5(2), 66-71. doi: $10.1108 / 13598540010319975$

Empson, L., Cleaver, I., \& Allen, J. (2013). Managing Partners and Management Professionals: Institutional Work Dyads in Professional Partnerships. Journal of Management Studies, 50(5). doi: 10.1111/joms.12025

Endacott, R., \& Botti, M. (2005). Clinical Research 3: Sample Selection. Intensive \& Critical Care Nursing, 21(1), 51-55.

Erdem, F., \& Gul Baser, G. (2010). Family and Business Values of Regional Family Firms: A Qualitative Research. International Journal of Islamic and Middle Eastern Finance and Management, 3(1), 47-64. doi: 10.1108/17538391011033861

European Commission. (2002). Corporate Social Responsibility: A business contribution to Sustainable Development. Brussels: Retrieved from http://rade.ec.europa.eu/doclib/docs/2006/february/tradoc_127374.pdf.

European Union. (2004). Euro Abstract: Corporate Social Responsibility (Vol. 42): European Commission: Directorate-General for Enterprise.

ExxonMobil. (2004). Corporate Citizenship Report. Irving, TX.

Falk, B., \& Blumenreich, M. . (2005). The Power of Questions: A Guide to Teacher and Student Research. Portsmouth, NH: Heinemann.

Farmer, D. . (1997). Contemporary Conceptual Space: Reading Adam Smith. Journal of Management History, 3(3), 246-255. 
Fassin, Y., Werner, A., Van Rossem, A., Signori, S., Garriga, E., Von Weltzien Hoivik, H., \& Schlierer, H. . (2015). CSR and Related Terms in SME Owner-Managers' Mental Models in Six European Countries: National Context Matters. Jounal of Business Ethics, 128(2), 433-456. doi: 10.1007/s 10551-014-2098-7

Fernando, S., \& Lawrence, S. (2014). A Theoretical Framework for CSR Practices: Integrating Legitimacy Theory, Stakeholder Theory, and Institutional Theory. The Journal of Theoretical Accounting Research, 10(1), 149-178.

Ferrell, O.C., Hirt, G., \& Ferrell, L. (2014). Business: A Changing World (9th ed.). New York: McGraw-Hill/Irwin.

Fieser, J. (1996). Do Businesses Have Moral Obligations Beyond What the Law Requires? Journal of Business Ethics 15(4), 457-468. doi: 10.1007/BF00380365

Filatotchev, I., \& Nakajima, C. (2014). Corporate Governance, Responsible Managerial Behavior, and Corporate Social Responsibility: Organizational Efficiency Versus Organizational Legitimacy? The Academy of Management Perspectives, 28(3), 289306.

Fiss, P. C. (2013). Case Studies and The Configurational Analysis of Organizational Phenomena. In D. Byrne \& C. C. Ragin (Eds.), The Sage Handbook of Case-Based Methods (1st ed.). London: SAGE Publications Ltd.

Fooks, G., Gilmore, A., Collin, J., Holden, C., \& Lee, K. (2013). The Limits of Corporate Social Responsibility: Techniques of Neutralization, Stakeholder Management and Political CSR. Jounal of Business Ethics, 112(2), 283-299.

Forney, W. (2018). Corporate Social Responsibility: Understanding the Strategy and Impact of CSR Implementation. Sullivan University. (10788718) 
Fortanier, F., \& Kolk, A. (2007). On the Economic Dimensions of Corporate Social Responsibility: Exploring Fortune Global 250 Reports. Business \& Society, 46(4), 457478. doi: 10.1177/0007650306296088

Fortanier, F., Kolk, A., \& Pinkse, J. (2011). Harmonization in CSR Reporting: MNEs and Global CSR Standards. Management International Review, 51(5), 665-696. doi: 10.1 007/s1 1575-01 1-0089-9

Foss, N. J. (2011). Why Micro-foundations for Resource-based Theory are Needed and What They May Look Like. Journal of Management, 37(5), 1413-1428. doi: $10.1177 / 0149206310390218$

Foss, N. J., \& Pedersen, T. (2016). Microfoundations In Strategy Research. Strategic Management Journal, 37(13). doi: 10.1002/smj.2362

Freeman, I., \& Hasnaoui, A. (2011). The Meaning of Corporate Social Responsibility: The Vision of Four Nations. Journal of Business Ethics, 100, 419-443. doi: $10.1007 / \mathrm{s} 10551-010-0688-6$

Frey, B. S., \& Stutzer, A. (2002). What Can Economists Learn from Happiness Research? Journal of Economic Literature, 40(2), 402-435.

Fritzsche, D. J., \& Oz, E. (2007). Personal Values' Influence on the Ethical Dimension of Decision Making. Journal of Business Ethics, 75(4), 335-343. doi: 10.1007/s10551006-9256-5

Frynas, J. G. (2005). The False Developmental Promise of Corporate Social Responsibility: Evidence from Multinational Oil Companies. International Affairs 81(3), 581-598. 
Fuenfschilling, L., \& Truffer, B. (2016). The interplay of institutions, actors and technologies in socio-technical systems - An analysis of transformations in the Australian urban water sector. Technological Forecasting \& Social Change, 103, 298-312.

Fulop, G., Hisrich, R. D., \& Szegedi, K. (2000). Business Ethics and Social Responsibility in Transition Economies. Journal of Management Development, 19(1), 5-31.

Funaki, Y., \& Glencorse, B. (2014). Anti-corruption or Accountability? International Efforts in Post-conflict Liberia. Third World Quarterly, 35(5), 836-854. doi: $10.1080 / 01436597.2014 .921433$

Furnari, S. (2020). Situating Frames and Institutional Logics: The Social Situation As A Key Institutional Microfoundation. In P. Haack, J. Sieweke \& L. Wessel (Eds.), Microfoundations of Institutions (pp. 193-210). Bingley: Emerald Publishing Limited.

Furrer, O., Egri, C. P., Ralston, D. A., Danis, W., Reynaud, E., Naoumova, I., . . FurrerPerrinjaquet, A. (2010). Attitudes toward Corporate Responsibilities in Western Europe and in Central and East Europe. Management International Review, 50(3), 379398. doi: 10.1 007/s 11575-01 0-0034-3

Gachter, S., \& Renner, E. (2018). Leaders as Role Models and 'Belief Managers' in Social Dilemmas. Journal of Economic Behavior and Organization, 154, 321-334.

Galey, P. (2009, October 7). 20,000 Educated Lebanese Leave Per Year: UNDP Report Warns Exodus Contributes to Crippling? Brain Drain, McClatchy - Tribune Business News.

Gallagher, S. (2005). A strategic response to Friedman's critique of business ethics. Journal of Business Strategy, 26(6), 55-60. doi: 10.1108/02756660510633028 
Galvin, T. L. (2002). Examining Institutional Change: Evidence from the Founding Dynamics of U.S. Health CareInterest Associations. The Academy of Management Journal, 45(4), 673-696.

Garriga, E., \& Domenec, M. (2004). Corporate Social Responsibility Theories: Mapping the Territory. Journal of Business Ethics, 53, 51-71.

Garriga, E., \& Mele, D. (2004). Corporate Social Responsibility Theories: Mapping the Territory. Jounal of Business Ethics, 53, 51-71.

Garud, R., Hardy, C., \& Maguire, S. (2007). Institutional Entrepreneurship as Embedded Agency: An Introduction to the Special Issue. Organization Studies, 28(7), 957-969. doi: $10.1177 / 0170840607078958$

Garud, R., Jain, S., \& Kumaraswamy, A. (2002). Institutional Entrepreneurship in the Sponsorship of Common Technological Standards:The Case of Sun Microsystems and Java. The Academy of Management Journal, 45(1), 196-214.

George, E., Chattopadhyay, P., Sitkin, S. B., \& Barden, J. (2006). Cognitive Underpinnings of Institutional Persistence and Change: A Framing Perspective. The Academy of Management Review, 31(2), 347-365.

George, G., Schillebeeckx, S. J. D., \& Liak, T. L. (2015). The Management of Natural Resources: An Overview and Research Agenda. Academy of Management Journal, 58(6), 1595-1613. doi: 10.5465/amj.2015.4006

Gephart, R. P. (2004). Qualitative Research and the Academy of Management Journal. Academy of Management Journal, 47(4), 454-462. doi: 10.5465/AMJ.2004.14438580

Gilmore, A., \& Carson, D. (1996). “Integrative” Qualitative Methods in A Services Context. Marketing Intelligence \& Planning, 14(6), 21-26. 
Gina Marie, A. H. (2004). Sampling Issues in Qualitative Research. Nurse Researcher, 12(1), 7-19.

Godfrey, P. C. (2005). The Relationship between Corporate Philanthropy and Shareholder Wealth: A Risk Management Perspective. The Academy of Management Review, 30(4), 777-798.

Godos-Diez, J. L., Fernandez-Gago, R., \& Martinez-Campillo, A. (2011). How Important Are CEOs to CSR Practices? An Analysis of the Mediating Effect of the Perceived Role of Ethics and Social Responsibility. Jounal of Business Ethics, 98, 531-548. doi: $10.1007 / \mathrm{s} 10551-010-0609-8$

Golicic, S. L., \& Davis, D. F. (2012). Implementing Mixed Methods Research in Supply Chain Management. International Journal of Physical Distribution \& Logistics Management, 42(8/9), 726-741.

Goll, I., \& Rasheed, A. A. . (2004). The Moderating Effect of Environmental Munificence and Dynamism on The Relationship Between Discretionary Social Responsibility and Firm Performance. Journal of Business Ethics, 49(1), 41-54. doi:

10.1023/B:BUSI.0000013862.14941.4e

Gond, J., Akremi, A. E., Sawen, V., \& Babu, N. (2017). The Psychological Microfoundations of Corporate Social Responsibility: A Person-centric Systematic Review. Journal of Organizational Behavior, 38, 225-246. doi: 10.1002/job.2170

Graafland, J., Mazereeuw, C., \& Yahia, A. (2006). Islam and Socially Responsible Business Conduct: An Empirical Study of Dutch Entrepreneurs. Business Ethics: A European Review, 15(4), 390-406. 
Graafland, J., \& Zhang, L. (2014). Corporate Social Responsibility in China: Implementation and Challenges. Business Ethics: A European Review, 23(1), 34-49. doi:

10.1111/beer.12036

Gray, R., Owen, D., \& Adams, C. (2010). Some Theories For Social Accounting?: A Review Essay and A Tentative Pedagogic Categorisation of Theorisations Around Social Accounting. In M. Freedman \& B. Jaggi (Eds.), Sustainability, Environmental Performance and Diclosure: Advances in Environmental Accounting and Management (pp. 1-54). Bingley, UK: Emerald Group Publishing.

Grebitus, C., Steiner, B., \& Veeman, M. (2013). Personal Values and Decision Making: Evidence from Environmental Footprint Labeling in Canada. American Journal of Agricultural Economics, 95(2), 397-403.

Greenwood, R., Oliver, C., Sahlin, K., \& Suddaby, R. (2008). Introduction. In R. Greenwood, C. Oliver, K. Sahlin \& R. Suddaby (Eds.), Handbook of Organizational Institutionalism (pp. 1-49). London: Sage.

Greenwood, R., Suddaby, R., \& Hinings, C. R. (2002). Theorizing Change: The Role of Professional Associations in the Transformation of Institutionalized Fields. The Academy of Management Journal, 45(1), 58-80.

Grewal, D., \& Levy, M. (2016). Marketing (5th ed.). New York: McGraw-Hill Education.

Griseri, P. , \& Seppala, N. (2010). Business Ethics and Corporate Social Responsibility. Andover: South-Western Cengage Learning.

Gruber, V., \& Schlegelmilch, B. B. (2015). MNEs' Regional Headquarters and their CSR Agenda in the African Context. International Marketing Review, 32(5), 576-602. doi: 10.1108/IMR-03-2014-0100 
Grung, A. H. (2018). Negotiating Gender Justice between State, Religion, and NGOs: A Lebanese Case. Religions, 9(6). doi: 10.3390/re19060175

Gugler, P., \& Shi, J. Y. J. (2009). Corporate Social Responsibility for Developing Country Multinational Corporations: Lost War in Pertaining Global Competitiveness. Jounal of Business Ethics, 87, 3-24. doi: 10.1007/s10551-008-9801-5

Guillemette, M. G., Mignerat, M., \& Pare, G. (2016). The Role of Institutional Work in The Transformation of The IT Function: A Longitudinal Case Study in The Healthcare Sector. Information \& Management, 54, 349-363.

Guler, I., Guillen, M. F., \& Macpherson, J. M. (2002). Global Competition, Institutions, and the Diffusion of Organizational Practices: The International Spread of ISO 9000 Quality Certificates. Administrative Science Quarterly, 47(2), 207-232.

Gunderson, G. (1997). Faces of Lebanon Sects, Wars, and Global Extensions. Domes, 6(2), 78.

Haack, P., Sieweke, J., \& Wessel, L. (2020). Microfoundations of Institutions. Bingley: Emerald Publishing Limited.

Habisch, A., Wegner, M., R., Schmidpeter., \& Jonker, J. (2005). Corporate Social Responsibility Across Europe. Berlin: Springer.

Hack, Lucy, Kenyon, Alexandra J, \& Wood, Emma H. (2014). A Critical Corporate Social Responsibility (CSR) Timeline: How Should It

Be Understood Now? International Journal of Management Cases, 16(4), 46-55.

Halawi, D. (2010, May 19). UNDP Urges Local Firms to Deliver Better Services, McClatchyTribune Business News. 
Hallett, T. (2010). The Myth Incarnate: Recoupling Processes, Turmoil, and Inhabited Institutions in an Urban Elementary School. American Sociological Review, 75(1), 5274. doi: $10.1177 / 0003122409357044$

Hallett, T., \& Hawbaker, A. (2020). Bringing Society Back In Again: The Importance of Social Interaction In An Inhabited Institutionalism. In P. Haack, J. Sieweke \& L. Wessel (Eds.), Microfoundations of Institutions (pp. 317-336). Bingley: Emerald Publishing Limited.

Hamann, R. (2006). Can Business Make Decisive Contributions to Development? Toward A Research Agenda on Corporate Citizenship and Beyond. Development Southern Africa, 23(2), 175-195. doi: 10.1080=03768350600707587

Hamann, R., \& Acutt, N. (2003). How should Civil Society (and the Government) Respond to “Corporate Social Responsibility?"A Critique of Business Motivations and the Potential for Partnerships. Development Southern Africa, 20(2), 255-270. doi: $10.1080 / 03768350302956$

Hamann, R., \& Sprague, C. (2008). The Business of Sustainable Development in Africa; Human Rights, Partnerships, Alternative Business Models. South Africa: Unisa Press Book.

Hambrick, D. C. (2007). Upper Echelons Theory: An Update. Academy of Management Review, 32(2), 334-343.

Hamprecht, J. (2006). Sustainable Purchasing Strategy in the Food Industry. University of St. Gallen.

Hannagan, T. (2005). Management: Concepts and Practices (4th ed.). Harlow: Pearson Education. 
Hannah, M. P. (2016). Spaces of Autonomy and Polarization: Toward a Theory of the Globalization of Economic and Political Cultures Characteristic of American Journalism. University of Southern California. (10801390)

Hanson, D., \& Grimmer, M. (2007). The Mix of Qualitative and Quantitative Research in Major Marketing Journals, 1993-2002. European Journal of Marketing, 41(1/2), 5870. doi: 10.1108/03090560710718111

Hargadon, A. B., \& Douglas, Y. (2001). When Innovations Meet Institutions: Edison and The Design of The Electric Light. Administrative Science Quarterly, 46(3), 476-501.

Hargrave, T. J., \& Van de Ven, A. H. (2006). A Collective Action Model of Institutional Innovation. The Academy of Management Review, 31(4), 864-888. doi: 10.5465/AMR.2006.22527458

Hart, S. L., Milstein, M. B., \& Caggiano, J. (2003). Creating Sustainable Value [and Executive Commentary]. The Academy of Management Executive (1993-2005), 17(2), 56-69.

Hayne, C., \& Free, C. (2014). Hybridized Professional Groups and Institutional Work: COSO and The Rise of Enterprise Risk Management. Accounting, Organizations, and Society, 39, 309-330.

Helfat, C. E., \& Peteraf, M. A. (2015). Managerial Cognitive Capabilities and the Microfoundations of Dynamic Capabilities. Strategic Management Journal, 36(6), 831-850. doi: $10.1002 / \mathrm{smj} .2247$

Helmig, B., Spraul, K., \& Ingenhoff, D. (2016). Under Positive Pressure: How Stakeholder Pressure Affects Corporate Social Responsibility Implementation. Business \& Society, 55(2), 151-187. doi: 10.1177/0007650313477841 
Hemingway, C. A., \& Maclagan, P. W. (2004). Managers' Personal Values as Drivers of Corporate Social Responsibility. Journal of Business Ethics, 50(1), 33-44.

Hempel, P. S., Zhang, Z., \& Han, Y. (2012). Team Empowerment and the Organizational Context: Decentralization and the Contrasting Effects of Formalization. Journal of Management, 38(2), 475-501. doi: 10.1177/0149206309342891

Herndon, N. C. Jr., Fraedrich, J. P., \& Yeh, Q. (2001). An Investigation of Moral Values and the Ethical Content of the Corporate Culture: Taiwanese Versus U.S. Sales People. Journal of Business Ethics, 30(1), 73-85. doi: 10.1023/A:1006493907563

Herrbach, O., \& Mignonac, K. (2007). Is Ethical P-O Fit Really Related to Individual Outcomes? A Study of Management-Level Employees. Business \& Society, 46(3), 304-315,317-330.

Hesse-Biber, S.N., \& Leavy, P. (2011). The Practice of Qualitative Research. Los Angeles: SAGE.

Heugens, P. M. A. R., Kaptein, M., \& Van Oosterhout, J. (2008). Contracts to Communities: A Processual Model of Organizational Virtue. Journal of Management Studies, 45(1). doi: $10.1111 / \mathrm{j} .1467-6486.2007 .00738 . x$

Hirsch, P., \& Bermiss, Y. (2009). Institutional “Dirty” Work: Preserving Institutions Through Strategic De-coupling. In A. T. Lawrence, R. Suddaby \& B. Leca (Eds.), Institutional Work: Actors and Agency in Institutional Studies of Organizations (pp. 262-284). Cambridge: Cambridge University Press.

Hirst, D. (2010). Beware of Small States: Lebanon, Battleground of the Middle East. New York: Nation Books. 
Hitt, M. A., Franklin, V., \& Zhu, H. (2006). Culture, Institutions and International Strategy. Journal of International Management, 12(2), 222-234.

Hoffman, A. J. (2001). Linking Organizational and Field-level Analyses: The Diffusion of Corporate Environmental Practice. Organization \& Environment, 14(2), 133-156.

Hofman, P. S., Moon, J., \& Wu, B. (2015). Corporate Social Responsibility Under Authoritarian Capitalism: Dynamics and Prospects of State-Led and Society-Driven CSR. Business \& Society, 1(2). doi: 10.1177/0007650315623014

Hofstede, G. (1980). Culture's Consequences: International Differences in Work-related Values. Beverly Hills, CA: Sage Publications.

Hofstede, G. (2001). Culture's Consequences: Comparing Values, Behaviors, Institutions, and Organizations across Nations (2nd ed.). Thousand Oaks, Calif.: Sage Publications.

Holburn, G. L. F., \& Zelner, B. A. (2010). Political Capabilities, Policy Risk, and International Investment Strategy: Evidence from the Global Electric Power Generation Industry. Strategic Management Journal, 31(12), 1290-1315.

Holtbrugge, D., \& Berg, N. (2004). How Multinational Corporations Deal with their Sociopolitical Stakeholders: An Empirical Study in Asia, Europe, and the US. Asian Business \& Management, 3(3), 299-313.

Hopkins, M. (2007). Corporate Social Responsibility and International Development: Is Business the Solution? London: Earthscan.

Horrigan, B. (2010). Corporate Social Responsibility in the 21st Century: Debates, Models, and Practices Across Government, Law and Business. Cheltenham: Edward Elgar Publishing Limited. 
Hoskisson, R. E., Eden, L., Lau, C. M., \& Wright, M. (2000). Strategy in Emerging Economies. The Academy of Management Journal, 43(3), 249-267.

Hosmer, L. T. (2011). The Ethics of Management: A Multidisciplinary Approach (7th ed.). New York: McGraw-Hill/Irwin.

Hughes, D. W. (2003). Policy Uses of Economic Multiplier and Impact Analysis. Choices, 18, 25-29.

Humphreys, M., \& Brown, A. D. (2008). An Analysis of Corporate Social Responsibility at Credit Line: A Narrative Approach. Jounal of Business Ethics, 80(3), 403-418. doi: $10.1007 / \mathrm{s} 10551-007-9426-0$

Husted, B. W. (2015). Corporate Social Responsibility Practice from 1800-1914: Past Initiatives and Current Debates. Business Ethics Quarterly, 25(1), 125-141. doi: 10.1017/beq.2014.1

Husted, B. W., \& Allen, D. B. (2006). Corporate Social Responsibility in the Multinational Enterprise: Strategic and Institutional Approaches. Journal of International Business Studies, 37(6), 838-849.

Idowu, S.O. (2009). The United Kingdom of Great Britain and Northern Ireland. In S. O. Idowu \& W. L. Filho (Eds.), Global Practices of Corporate Social Responsibility (pp. 11-35). Berlin: Springer.

Idowu, S.O. (2011). An Exploratory Study of the Historical Landscape of Corporate Social Responsibility in the UK. Corporate Governance, 11(2), 149-160. doi: $10.1108 / 14720701111121029$ 
Ind, N., Iglesias, O., \& Schultz, M. (2013). Building Brands Together: Emergence and Outcome of Co-Creation. California Management Review, 55(3), 5-26. doi: $10.1525 / \mathrm{cmr} .2013 .55 .3 .5$

Ingram, O. C., Jr. (2003). The Conceptualization and Perception of Servant Leadership in Christian Higher Education. (Ed.D.), The Southern Baptist Theological Seminary, Ann Arbor, United States. Retrieved from https://search-proquestcom.neptune.ndu.edu.lb:9443/docview/305317739?accountid=28281 ProQuest Dissertations \& Theses Global database. (305317739)

International Religious Freedom Report 2010. (2010). United States: Burea of Democracy, Human Rights, and Labor.

International Religious Freedom Report 2017. (2017). United States: Burea of Democracy, Human Rights, and Labor.

Ioannou, I., \& Serafeim, G. (2012). What Drives Corporate Social Performance? The Role of Nation-level Institutions. Journal of International Business Studies, 43(9), 834-864.

Jackson, G., \& Apostolakou, A. (2010). Corporate Social Responsibility in Western Europe: An Institutional Mirror or Substitute? Jounal of Business Ethics, 94(3), 371-394. doi: $10.1007 / \mathrm{s} 10551-009-0269-8$

Jackson, T. (2001). Cultural Values and Management Ethics: A 10-Nation Study. Human Relations, 54(10), 1267-1302.

Jallat, F., \& Shultz, C. J. (2011). Lebanon: From Cataclysm to Opportunity-Crisis Management Lessons for MNCs in the Tourism Sector of the Middle East. Journal of World Business, 46, 476-486. doi: 10.1016/j.jwb.2010.10.008 
Jamali, D, \& Neville, B. (2011). Convergence Versus Divergence of CSR in Developing Countries: An Embedded Multi-Layered Institutional Lens. Jounal of Business Ethics, 102, 599-621. doi: 10.1007/s10551-011-0830-0

Jamali, D. (2007). The Case for Strategic Corporate Social Responsibility in Developing Countries. Business and Society Review, 112(1), 1-27.

Jamali, D. (2009). Constraints and Opportunities Facing Women Entrepreneurs in Developing Countries: A Relational Perspective. Gender in Management: An International Journal, 24(4), 232-251. doi: 10.1108/17542410910961532

Jamali, D. (2010). The CSR of MNC Subsidiaries in Developing Countries: Global, Local, Substantive or Diluted? Jounal of Business Ethics, 93, 181-200. doi: 10.1007/s10551010-0560-8

Jamali, D., Abdallah, H., \& Hmaidan, S. (2010). The Challenge of Moving Beyond Rhetoric: Paradoxes of Diversity Management in the Middle East. Equality, Diversity and Inclusion: An International Journal, 29(2), 167-185. doi:

$10.1108 / 02610151011024484$

Jamali, D., Hallal, M., \& Abdallah, H. (2010). Corporate Governance and Corporate Social Responsibility: Evidence from the Healthcare Sector. Corporate Governance, 10(5), 590-602. doi: 10.1108/14720701011085562

Jamali, D., Karam, C., Yin, J., \& Soundararajan, V. (2017). CSR Logics in Developing Countries: Translation, Adaptation and Stalled Development. Journal of World Business, 52, 343-359. 
Jamali, D., \& Keshishian, T. (2009). Uneasy Alliances: Lessons Learned from Partnerships Between Businesses and NGOs in the Context of CSR. Jounal of Business Ethics, 84, 277-295. doi: 10.1007/s10551-008-9708-1

Jamali, D., \& Mirshak, R. (2007). Corporate Social Responsibility (CSR): Theory and Practice in a Developing Country Context. Journal of Business Ethics, 72, 243-262. doi: $10.1007 / \mathrm{s} 10551-006-9168-4$

Jamali, D., \& Mirshak, R. (2010). Business-Conflict Linkages: Revisiting MNCs, CSR, and Conflict. Jounal of Business Ethics, 93(3), 443-464. doi: 10.1007^10551-009-0232-8

Jamali, D., Safieddine, A. M., \& Rabbath, M. (2008). Corporate Governance and Corporate Social Responsibility Synergies and Interrelationships. Corporate Governance: An International Review, 16(5), 443-459. doi: 10.1111/j.1467-8683.2008.00702.x

Jamali, D., \& Sdiani, Y. (2013). Does Religiosity Determine Affinities to CSR? Journal of Management, Spirituality \& Religion, 10(4), 309-323. doi:

$10.1080 / 14766086.2013 .802251$

Jamali, D., Sidani, Y., \& El-Asmar, K. (2009). A Three Country Comparative Analysis of Managerial CSR Perspectives: Insights From Lebanon, Syria and Jordan. Jounal of Business Ethics, 85(2), 173-192. doi: 10.1007/s10551-008-9755-7

Jamali, D., Zanhour, M., \& Keshishian, T. (2009). Peculiar Strengths and Relational Attributes of SMEs in the Context of CSR. Jounal of Business Ethics, 87(3), 355-377. doi: $10.1007 / \mathrm{s} 10551-008-9925-7$

Jaramillo, F., Mulki, J. P., \& Solomon, P. (2006). The Role of Ethical Climate on Salesperson's Role Stress, Job Attitudes, Turnover Intention, and Job Performance. The Journal of Personal Selling and Sales Management, 26(3), 271-282. 
Jarzabkowski, P., Matthiesen, J., \& Van de Ven, A. (2009). Doing Which Work? A Practice Approach to Institutional Pluralism. In A. T. Lawrence, R. Suddaby \& B. Leca (Eds.), Institutional Work: Actors and Agency in Institutional Studies of Organizations (pp. 284-316). Cambridge: Cambridge University Press.

Jawad, R. (2002). A Profile of Social Welfare in Lebanon: Assessing the Implications for Social Development Policy. Global Social Policy, 2(3), 319-342. doi: $10.1177 / 14680181020020030501$

Jawad, R. (2009). Social Welfare and Religion in the Middle East : A Lebanese Perspective. Great Britain: The Policy Press.

Jenkins, H. (2006). Small Business Champions for Corporate Social Responsibility. Jounal of Business Ethics, 67(3), 241-256. doi: 10.1007/s10551-006-9182-6

Jenkins, H. (2009). A Business Opportunity Model of Corporate Social Responsibility for Small- and Medium-Sized Enterprises. Business Ethics: A European Review, 18(1), 21-36. doi: 10.1111/j.1467-8608.2009.01546.x

Jeong, Y., \& Weiner, R. J. (2012). Who Bribes? Evidence from the United Nations' Oil-ForFood Program. Strategic Management Journal, 33(12), 1363-1383. doi: 10.1002/smj.1986

Jepperson, R. L., \& Meyer, J. W. (2011). Multiple Levels of Analysis and the Limitations of Methodological Individualisms. Sociological Theory, 29(1), 54-74.

Johnson, G., Scholes, K., \& Whittington, R. (2008). Exploring Corporate Strategy (8th ed.). Harlow, England: Financial Times Prentice Hall.

Johnson, G., Whittington, R., \& Scholes, K. (2011). Exploring Strategy: Text \& Cases (9th ed.). Harlow, England: Financial Times Prentice Hall. 
Johnston, H. J., I.,II. (2008). International Leadership in Cross-cultural Environments: The Relationship Between National Culture and Corporate Culture as It Pertains to Work Ethic and Corporations. (PhD), Capella University, Ann Arbor, United States. Retrieved from https://search-proquestcom.neptune.ndu.edu.lb:9443/docview/304816987?accountid=28281 ProQuest Central database. (3291970)

Jonck, P., Van, D. W. F., \& Sobayeni, N. C. (2017). A Generational Perspective on Work Values in A South African Sample. SA Journal of Industrial Psychology, 43. doi: 10.4102/sajip.v43i1.1393

Jones, C., Lee, J. Y., \& Lee, T. (2020). Institutionalizing Place: Materiality and Meaning in Boston's North End. In P. Haack, J. Sieweke \& L. Wessel (Eds.), Microfoundations of Institutions (pp. 211-240). Bingley: Emerald Publishing Limited.

Jones, G., \& George, J. (2011). Contemporary Management. New York: McGraw-Hill.

Jones, P., Comfort, D., \& Hillier, D. (2013). Playing the Game: Corporate Social Responsibility and the Games Industry. Journal of Public Affairs, 13(3), 335-344.

Jones, T.M. (1980). Corporate social responsibility revisited, redefined. California Management Review (Pre-1986), 22(000003), 59-67.

Joseph, C., Gunawan, J., Sawani, Y., Rahmat, M., Avelind Noyem, J., \& Darus, F. (2016). A Comparative Study of Anti-Corruption Practice Disclosure Among Malaysian and Indonesian Corporate Social Responsibility (CSR) Best Practice Companies. Journal of Cleaner Production, 112, 2896-2906.

Joseph, J. (2003). National Business Ethics Survey 2003: How Employees View Ethics in Their Organizations. Washington, DC: Ethics Resource Center. 
Joseph, S. (2011). Political Familism in Lebanon. The ANNALS of the American Academy of Political and Social Science, 636, 150-163. doi: 10.1177/0002716211398434

Joyce, M. C. (2014). Activism Success: A Concept Explication. (Master's), University of Washington, Ann Arbor, United States. Retrieved from https://search-proquestcom.neptune.ndu.edu.lb:9443/docview/1566477828?accountid=28281 ProQuest Dissertations \& Theses Global database. (1562969)

Joyner, B. E., \& Payne, D. (2002). Evolution and Implementation: A Study of Values, Business Ethics and Corporate Social Responsibility. Jounal of Business Ethics, 41(4), 297-311.

Judge, W. Q., Douglas, T. J., \& Kutan, A. M. (2008). Institutional Antecedents of Corporate Governance Legitimacy. Journal of Management, 34(4), 765-785. doi: $10.1177 / 0149206308318615$

Juholin, E. (2004). For Business or the Good of All? A Finnish Approach to Corporate Social Responsibility. Corporate Governance, 4(3), 20-31. doi: 10.1108/14720700410547477

Kakabadse, N., \& Kakabadse, K. (2010). Effecting change for sustainable lifestyles:

Governing for 4 Ps. Paper presented at the 5th Global Conference on Social Responsibility and Indo Portuguese Business Meeting, Hotel Radisson Blue, Lisbon, Portugal.

Kalantari, B. (2010). Herbert A. Simon on Making Decisions: Enduring Insights and Bounded Rationality. Journal of Management History, 16(4), 509-520. doi: $10.1108 / 17511341011073988$

Kang, E. (2008). Director Interlocks and Spillover Effects of Reputational Penalties From Financial Reporting Fraud. Academy of Management Journal, 51(3), 537-555. 
Kassar, K., Baraka, D., Musharbash-Tannous, D., \& Nour, S. (2017). The State of CSR in Lebanon: Trends and Observations of National Corporate Social Responsibility The Country Report. Lebanon: CSR Lebanon.

Katz, J. P., Swanson, D. L., \& Nelson, L. K. (2001). Culture-based Expectations of Corporate Citizenship: A Propositional Framework and Comparison of Four Cultures. International Journal of Organizational Analysis, 9(2), 149-171.

Kaufman, A. (2004). Reviving Phoenicia: In Search of Identity in Lebanon. London: I.B. Tauris.

Khalaf, S. (2002). Civil and Uncivil Violence in Lebanon: A History of the Internationalization of Communal Conflict. New York: Columbia University Press.

Khan, S. A., Al-Maimani, K. A., \& Al-Yafi, W. A. (2013). Exploring Corporate Social Responsibility in Saudi Arabia: The Challenges Ahead. Journal of Leadership, Accountability and Ethics, 10(3), 65-78.

Khanna, T., \& Palepu, K. (2010). Winning in the Emerging Economies: A Road Map for Strategy and Execution. Cambridge, MA: Harvard University Press.

Khishfe, R., \& BouJaoude, S. (2016). Lebanese Students' Conceptions of and Attitudes towards Science and Related Careers Based On Their Gender and Religious Affiliations. International Journal of Science and Mathematics Education, 14(1), 145167. doi: 10.1007/s10763-014-9587-0

Kilcullen, M., \& Judith, O. K. (1999). At least do no harm: sources on the changing role of business ethics and corporate social responsibility. Reference Services Review, 27(2), $158-178$. 
Kim, H. R., Lee, M., Lee, H. T., \& Kim, N. M. (2010). Corporate Social Responsibility and Employee-Company Identification. Journal of Business Ethics, 95(4), 557-569. doi: 10.1007A10551-010-0440-2

Kincaid, M. (2011). The Essence of Corporate Social Responsibility From A Servantleadership Perspective. (PhD), Gonzaga University, Ann Arbor, United States. Retrieved from https://search-proquestcom.neptune.ndu.edu.lb:9443/docview/920317947?accountid=28281 ProQuest Central database. (3492488)

King, A. A., \& Lenox, M. J. (2000). Industry Self-regulations Without Sanctions: The Chemical Industry's Responsible Care Program. The Academy of Management Journal, 43(4), 698-716.

King, A. A., \& Toffel, M. W. (2007). Self-regulatory Institutions for Solving Environmental Problems. Perspectives and Contributions from the Management Literature. Harvard Business School working papers, 07-089(1), 1-32.

Kirshner, S. (2007, Feb 15). Lebanon's Future Hangs in the Balance as Rivals Duel, Canadian Jewish News, p. 11.

Kleinrichert, D. (2007). Responsibility and Practice in Notions of Corporate Social Responsibility. (Doctor of Philosophy), University of South Florida. (3260072)

Knight, A., \& Ruddock, L. (2008). Advanced Research Methods in the Built Environment. Chichester, U.K.: Wiley-Blackwell.

Knight, G., \& Greenberg, J. (2002). Promotionalism and Subpolitics: Nike and Its Labor Critics. Management Communication Quarterly, 15(4), 541-570. doi: $10.1177 / 0893318902154002$ 
Knudsen, J. S. (2013). The Growth of Private Regulation of Labor Standards in Global Supply Chains: Mission Impossible for Western Small- and Medium-Sized Firms? Jounal of Business Ethics, 117(2), 387-398. doi: 10.1007/s10551-012-1527-8

Kolk, A., Hong, P., \& Van Dolen, W. (2010). Corporate Social Responsibility in China: An Analysis of Domestic and Foreign Retailers' Sustainability Dimensions. Business Strategy and the Environment, 19, 289-303.

Kolk, A., \& Lenfant, F. (2010). MNC Reporting on CSR and Conflict in Central Africa. Jounal of Business Ethics, 93(2), 241-255. doi: 10.1007/S10551-009-0271-1

Kolk, A., \& Van Tulder, R. (2006). Poverty Alleviation as Business Strategy? Evaluating Commitments of Frontrunner Multinational Corporations. World Development, 34(5), 789-801. doi: 10.1016/j.worlddev.2005.10.005

Konsa, K. (2013). Heritage as a Socio-Cultural Construct: Problems of Definition. Baltic Journal of Art History, 6, 125-151. doi: 10.12697/BJAH.2013.6.05

Koonmee, K., Singhapakdi, A., Virakul, B., \& Lee, D. J. (2010). Ethics Institutionalization, Quality of Work Life, and Employee Job-Related Outcomes: A Survey of Human Resource Managers in Thailand. Journal of Business Research, 63, 20-26. doi: 10.1016/j.jbusres.2009.01.006

Kostova, T., \& Roth, K. (2002). Adoption of Organizational Practice by Subsidiaries of Multinational Corporations: Institutional and Relational Effects. Academy of Management Journal, 45(1), 215-233.

Kotler, P., \& Lee, N. (2005). Corporate Social Responsibility: Doing the Most Good for Your Company and Your Cause. Hoboken, New Jersey: John Wiley \& Sons, Inc. 
Kowalski, K. M. (2015, Jan 2015). How the Industrial Revolution AFFECTS YOU. AppleSeeds, 17, 26-29.

Kraisornsuthasinee, S. (2012). CSR through the heart of the Bodhi tree. Social Responsibility Journal, 8(2), 186-198. doi: 10.1108/17471111211234824

Kraus, P., \& Brtitzelmaier, B. (2012). A Literature Review on Corporate Social Responsibility: Definitions, Theories and Recent Empirical Research. International Journal of Management Cases, 14(4), 282-296.

Kumar, T. (2017). The Impact of CSR on Transnational \& Multinational Corporations in Bangladesh: A Comparative Analysis on the Basis of Carrols's Pyramid Regarding Global Perspective. Review of Integrative Business and Economics Research, 6(4), 432-456.

Kusku, F., \& Zarkada-Fraser, A. (2004). An Empirical Investigation of Corporate Citizenship in Australia and Turkey. British Journal of Management, 15(1), 57-72.

Lacy, P., Cooper, T., Hayward, R., \& Neuberger, L. (2010). A New Era of Sustainability: UN Global Compact-Accenture CEO Study 2010.

Lacy, P., \& Hayward, R. (2013). The UN Global Compact-Accenture CEO Study on Sustainability 2013.

Lantos, G. P. (2001). The boundaries of strategic corporate social responsibility. Journal of Consumer Marketing, 18(7), 595-632.

Lantos, G. P. (2002). The ethicality of altruistic corporate social responsibility. Journal of Consumer Marketing, 19(3), 205-232. doi: 10.1108/07363760210426049

Larkin, C. (2010). Beyond The War? The Lebanese Postmemory Experience. International Journal of Middle East Studies, 42, 615-635. doi: 10.1017/S002074381000084X 
Lauesen, L. M. (2013). CSR in the Aftermath of the Financial Crisis. Social Responsibility Journal, 9(4), 641-663. doi: 10.1108/SRJ-11-2012-0140

Lawrence, T. (2010). Power, Institutions, and Organizations. In R. Greenwood, C. Oliver, K. Sahlin \& R. Suddaby (Eds.), The SAGE Handbook of Organizational Institutionalism. California: Thousand Oaks.

Lawrence, T. B., \& Suddaby, R. (2006). Institutions and Institutional Work. In S. R. Clegg, C. Hardy, T. B. Lawrence \& W. R. Nord (Eds.), The SAGE Handbook of Organization Studies (2nd ed., pp. 215-254). London: SAGE.

Lawrence, T. B., Suddaby, R., \& Leca, B. (2009). Institutional Work: Actors and Agency in Institutional Studies of Organizations. New York: Cambridge University Press.

Lawrence, T. B., Suddaby, R., \& Leca, B. (2011). Institutional Work: Refocusing Institutional Studies of Organization. Journal of Management Inquiry, 20(1), 52-58. doi: $10.1177 / 1056492610387222$

Lawrence, T. B., Winn, M., \& Jennings, P. D. (2001). The Temporal Dynamics of Institutionalization. The Academy of Management Review, 26(4), 624-644. doi: 10.5465/AMR.2001.5393901

Lebanon Banking \& Financial Services Report - Q2 2019. (2019). London: Fitch Solutions Group Limited.

Lebanon Information Technology Report - 2011. (2011). London: Business Monitor International.

Lebanon labour market risk report - Q1 2019. (2019). London: Fitch Solutions Group Limited. Lebanon Telecoms Report - 2018. (2018). London: Fitch Solutions Group Limited. 
Leca, B., Battilana, J., \& Boxenbaum, E. (2009). Agency and Institutions: A Review of Institutional Entrepreneurship. The Academy of Management Annals, Working Paper.

Lee, K., \& Carter, S. (2005). Global Marketing Management. New York: Oxford University Press.

Lee, M. P. (2008). A Review of The Theories of Corporate Social Responsibility: Its Evolutionary Path and The Road Ahead. International Journal of Management Reviews, 10(1), 53-73. doi: 10.1111/j.1468-2370.2007.00226.x

Leedy, P. D., \& Ormrod, J. E. (2001). Practical Research: Planning and Design (7th ed.). Upper Saddle River, NJ: Merrill/Prentice Hall.

Leedy, P. D., Ormrod, J. E., \& Johnson, L. R. (2019). Practical Research: Planning and Design (12th ed.). New York: Pearson.

Leichtman, M. A. (2010). Migration, War, and the Making of a Transnational Lebanese Shi-I Community in Senegal. International Journal of Middle East Studies, 42, 269-290. doi: $10.1017 / \mathrm{S} 002074381000005 \mathrm{X}$

Lenartowicz, T., \& Johnson, J. P. (2002). Comparing Managerial Values in Twelve Latin American Countries: An Exploratory Study. Management International Review, 42(3), $279-307$.

Levy, D. L., \& Kaplan, R. (2007). CSR and Theories of Global Governance: Strategic Contestation in Global Issue Arenas. In A. Crane, D. Matten, A. McWilliams, J. Moon \& D. S. Siegel (Eds.), The Oxford Handbook of Corporate Social Responsibility. Oxford: Oxford University Press. 
Li, S. , Fetscherin, M., Alon, I., Lattemann, C., \& Yeh, K. (2010). Corporate Social

Responsibility in Emerging Markets: The Importance of the Governance Environment.

Management International Review, 50(5), 635-654. doi: 10.1007/s11575-010-0049-9

Liao, W., \& Teng, M. (2010). The Relationship Between Ethics Training and Employee

Satisfaction: A Mediator of Corporate Responsibility Practices. The Journal of Human Resource and Adult Learning, 6(1), 9-18.

Lin-Hi, N., \& Blumberg, I. (2018). The Link Between (Not) Practicing CSR and Corporate Reputation: Psychological Foundations and Managerial Implications. Jounal of Business Ethics, 150, 185-198. doi: 10.1007/s10551-016-3164-0

Lindberg, O., \& Rantatalo, O. (2015). Competence in Professional Practice: A Practice Theory Analysis of Police and Doctors. Human Relations, 68(4), 561-582. doi:

$10.1177 / 0018726714532666$

Lindgreen, A., Kotler, P., Vanhamme, J., \& Maon, F. (2012). A Stakeholder Approach to Corporate Social Responsibility: Pressures, Conflicts, and Reconciliation. England: Gower Publishing Limited.

Lindgreen, A., Swaen, V., \& Campbell, T. T. (2010). Corporate Social Responsibility Practices in Developing and Transitional Countries: Botswana and Malawi. Jounal of Business Ethics, 90, 429-440. doi: 10.1007/s10551-010-0415-3

Lizardo, O., \& Limited. (2020). Specifying The "What" and Separating The "How": Doings, Sayings, Codes, and Artifacts As The Building Blocks of Institutions. In P. Haack, J. Sieweke \& L. Wessel (Eds.), Microfoundations of Institutions (pp. 217-234). Bingley: Emerald Publishing. 
Logsdon, J. M., \& Wood, D.J. (2002). Business Citizenship: From Domestic to Global Level of Analysis. Business Ethics Quarterly, 12(2), 155-187.

Longenecker, J.G., McKinney, J.A., \& Moore, C.W. (2004). Religious Intensity, Evangelical Christianity, and Business Ethics: An Empirical Study. Journal of Business Ethics, $55(4), 373-386$.

Lounsbury, M. (2001). Institutional Sources of Practice Variation: Staffing College and University Recycling Programs. Administrative Science Quarterly, 46(1), 29-56.

Lounsbury, M. (2002). Institutional Transformation and Status Mobility: The Professionalization of the Field of Finance. The Academy of Management Journal, $45(1), 255-266$.

Luo, Y., \& Wang, S. L. (2012). Foreign Direct Investment Strategies by Developing Country Multinationals: A Diagnostic Model for Home Country Effects. Global Strategy Journal, 2(3), 244-261. doi: 10.1111/j.2042-5805.2012.01036.x

Lynn, M. (2015, September 28). Corporate Social Responsibility Has Become A RacketAnd A Dangerous One, The Daily Telegraph.

Macintosh, J. C. C. (1999). The issues, effects and consequences of the Berle-Dodd debate, 1931-1932. Accounting, Organizations and Society, 24, 139-153.

Maclagan, P. W. (1998). Management and Morality: A Developmental Perspective. London: Sage publications

Maguire, S., Hardy, C., \& Lawrence, T. B. (2004). Institutional Entrepreneurship in Emerging Fields: HIV/AIDS Treatment Advocacy in Canada. Academy of Management journal, 47(5), 657-679. doi: 10.5465/20159610 
Maignan, I. (2001). Consumers' Perceptions of Corporate Social Responsibilities: A CrossCultural Comparison. Jounal of Business Ethics, 30(1), 57-72.

Maignan, I., \& Ferrell, O. C. (2004). Corporate Social Responsibility and Marketing: An Integrative Framework. Journal of the Academy of Marketing Science, 32(1), 3-19.

Maignan, I., \& Ferrell, O.C. (2003). Nature of Corporate Responsibilities: Perspectives from American, French and German consumers. Journal of Business Research, 56(1), 5567.

Maignan, I., \& Ralston, D. A. (2002). Corporate Social Responsibility in Europe and the U.S.: Insights from Businesses' Self-Presentations. Journal of International Business Studies, 33(3), 497-514.

Mainardes, E., Alves, H., \& Raposo, M. (2012). A Model for Stakeholder Classification and Stakeholder Relationships. Management Decision, 50(10), 1861-1879. doi: $10.1108 / 00251741211279648$

Mair, J., Robinson, J., \& Hockerts, K. (2006). Social Entrepreneurship. Basingstoke: Palgrave Macmillan.

Makdisi, S. (2004). The Lessons of Lebanon: The Economics of War and Development London: I. B. Tauris \& Co. Ltd.

Makdisi, S., \& El-Khalil, Y. (2013). Lebanon: The Legacy of Sectarian Consociationalism and the Transition to a Fully-fledged Democracy. Lebanon: Issam Fares Institute for Public Policy and International Affairs, American University of Beirut.

Makdisi, U. (2000). The Culture of Sectarianism: Community, History, and Violence in Nineteenth-century Ottoman Lebanon. Berkeley, California: University of California Press. 
Malina, M. A., Norreklit, H. S.O., \& Selto, F. H. (2011). Lessons Learned: Advantages and Disadvantages of Mixed Method Research. Qualitative Research in Accounting and Management, 8(1), 59-71. doi: 10.1108/11766091111124702

Mangan, J., Lalwani, C., \& Gardner, B. (2004). Combining Quantitative and Qualitative Methodologies in Logistics Research. International Journal of Physical Distribution \& Logistics Management, 34(7), 565-578. doi: 10.1108/09600030410552258

Marano, V., Tashman, P., \& Kostova, T. (2017). Escaping the Iron Cage: Liabilities of Origin and CSR Reporting of Emerging Market Multinational Enterprises. Journal of International Business Studies, 48, 386-408.

Marques-Mendes, A., \& Santos, M. J. (2016). Strategic CSR: An Integrative Model for Analysis. Social Responsibility Journal, 12(2), 363-381.

Marquis, C., Glynn, M. A., \& Davis, G. F. (2007). Community Isomorphism and Corporate Social Action. Academy of Management Review, 32(3), 925-940.

Marquis, C., \& Tilcsik, A. (2013). Imprinting: Toward a Multilevel Theory. The Academy of Management Annals, 7(1), 193-243.

Martincak, D., \& Polavka, M. (2012). Contribution of Corporate Social Responsibility to the Shareholder Value: Experimental Perspective. E+M Ekonomie a Management(3), 108124.

Mason, C., Kirkbride, J., \& Bryde, D. (2007). From Stakeholders to Institutions: The Changing Face of Social Enterprise Governance Theory. Management Decision, 45(2), 284-301. doi: 10.1108/00251740710727296 
Matten, D., \& Moon, J. (2008). "Implicit" and "Explicit" CSR: A Conceptual Framework for a Comparative Understanding of Corporate Social Responsibility. The Academy of Management Review, 33(2), 404-424.

Mayoux, L. (2001). Tackling the Down Side: Social Capital, Women's Empowerment and Micro-Finance in Cameroon. Development and Change, 32(3), 435-464. doi: $10.1111 / 1467-7660.00212$

Mazereeuw-van der Duijn Schouten, C., Graafland, J., \& Kaptein, M. (2014). Religiosity, CSR Attitudes, and CSR Behavior: An Empirical Study of Executives' Religiosity and CSR. Jounal of Business Ethics, 123(3), 437-459. doi: 10. 1007/s1055 1-013-1 847-3

McKinsey Global Institute. (2013). Urban World: The Shifting Global Business Landscape.

McWilliams, A., \& Siegel, D. (2000). Corporate Social Responsibility and Financial Performance: Correlation or Misspecification? Strategic Management Journal, 21(5), 603-609.

McWilliams, A., \& Siegel, D. (2001). Corporate Social Responsibility: A Theory of the Firm Perspective. Academy of Management Review, 26(1), 117-127. doi: 10.5465/AMR.2001.4011987

McWilliams, A., Van Fleet, D. D., \& Cory, K. D. (2002). Raising Rivals' Costs Through Political Strategy: An Extension of Resource-based Theory. Journal of Management Studies 39(5).

Mehrdost, H. (2012). Strategies to Promote Social Responsibility in Cultural Organizations. International Journal of Business and Social Science, 3(6).

Melki, J. (2014). The Interplay of Politics, Economics and Culture in News Framing of Middle East Wars. Media, War \& Conflict, 7(2), 165-186. doi: 10.1177/1750635214537405 
Mena, S. , \& Suddaby, R. (2016). Theorization as Institutional Work: The Dynamics of Roles and Practices. Human Relations, 69(8), 1669-1708. doi: 10.1177/0018726715622556

Merriam, S.B. (2002). Qualitative Research in Practice: Examples for Discussion and Analysis (1st ed.). San Francisco: Jossey-Bass.

Meyer, J. W., \& Jepperson, R. L. (2000). The "Actors" of Modern Society: The Cultural Construction of Social Agency. Sociological Theory, 18(1), 100-120.

Meyer, K. E. (2004). Perspectives on Multinational Enterprises in Emerging Economies. Journal of International Business Studies, 35(4), 259-276.

Mihalache, S. S. (2013). Aspects Regarding Corporate Social Responsibility Definition and Dimensions. Paper presented at the International Conference Marketing - from Information to Decision, Cluj-Napoca: Babes Bolyai University.

Mijatovic, I. S., \& Stokic, D. (2010). The Influence of Internal and External Codes on CSR Practice: The Case of Companies Operating in Serbia. Jounal of Business Ethics, 94(4), 533-552. doi: 10.1007/s10551-009-0280-0

Miles, M. B., \& Huberman, A. M. (1994). Qualitative Data Analysis: An Expanded Sourcebook (2nd ed.). Thousand Oaks, California: Sage Publications, Inc.

Miles, M. B., Huberman, A. M., \& Saldana, J. (2014). Qualitative Data Analysis: A Methods Sourcebook (3rd ed.). United States of America: SAGE Publications Inc.

Miller, J. (2008). The Ongoing Legitimacy Project: Corporate Philanthropy As Protective Strategy. European Management Review, 5, 151-164.

Ministry of Finance. (2010). Lebanon Country Profile 2010. Lebanon: Ministry of Finance. Ministry of Finance. (2012). Lebanon Country Profile 2012. Lebanon: Ministry of Finance. 
Misangyi, V. F., Weaver, G. R., \& Elms, H. (2008). Ending Corruption: The Interplay among Institutional Logics, Resources, and Institutional Entrepreneurs. The Academy of Management Review, 33(3), 750-770.

Mishra, S., \& Modi, S. B. (2016). Corporate Social Responsibility and Shareholder Wealth: The Role of Marketing Capability. Journal of Marketing, 80(1), 26-46. doi: $10.1509 / j m .15 .0013$

Moon, J. (2001). Business Social Responsibility: A source of Social Capital? Reason in Practice, 1(3), 35-45.

Moon, J. (2007). The Contribution of Corporate Social Responsibility to Sustainable Development. Sustainable Development, 15(5), 296-306. doi: 10.1002/sd.346

Moon, J., \& Vogel, D. (2008). Corporate Responsibility, Government and Civil Society. In A. Crane, D. Matten, A. McWilliams, J. Moon \& D. S. Siegel (Eds.), The Oxford Handbook of Corporate Social Responsibility. Oxford: Oxford University Press.

Mooney Cotter, A. M. (2011). Culture Clash: An International Legal Perspective on Ethnic Discrimination. London: Ashgate Publishing.

Morgeson, F. P., Aguinis, H., Waldman, D. A., \& Siegel, D. S. (2013). Extending Corporate Social Responsibility Research to the Human Resource Management and Organizational Behavior Domains: A Look to the Future. Personnel psychology, 66(4), 805-824. doi: 10.1111/peps.12055

Morrell, K., \& Anderson, M. (2006). Dialogue and scrutiny in organizational ethics. Business Ethics: A European Review, 15(2), 117-129.

Morrison, J. (2015). Business Ethics: New Challenges in a Globalised World. United Kingdom: Palgrave. 
Morsing, M., \& Perrini, F. (2009). CSR in SMEs: Do SMEs Matter for the CSR Agenda? Business Ethics: A European Review, 18(1), 1-6. doi: 10.1111/j.14678608.2009.01544.x

Mosley, D. C., Pietri, P. H., \& Megginson, L. C. (1996). Management : leadership in action. New York: HarperCollins.

Mueller, K., Hattrup, K., Spiess, S. O., \& Lin-Hi, N. (2012). The Effects of Corporate Social Responsibility on Employees’ Affective Commitment: A Cross-Cultural Investigation. Journal of Applied Psychology, 97(6), 1186-1200. doi: 10.1037/a0030204

Mulki, J. P., Jaramillo, J. F., \& Locander, W. B. (2009). Critical Role of Leadership on Ethical Climate and Salesperson Behaviors. Journal of Business Ethics, 86(2), 125-141. doi: $10.1007 / \mathrm{s} 10551-008-9839-4$

Muller, A., \& Kolk, A. (2010). Extrinsic and Intrinsic Drivers of Corporate Social Performance: Evidence from Foreign and Domestic Firms in Mexico. Journal of Management Studies, 47(1). doi: 10.1111/j.1467-6486.2009.00855.x

Muller, R., Spang, K., \& Ozcan, S. (2009). Cultural Differences in Decision Making in Project Teams. International Journal of Managing Projects in Business, 2(1), 70-93. doi: $10.1108 / 17538370910930527$

Munro, V. (2013). Stakeholder Understanding of Corporate Social Responsibility (CSR) in Emerging Markets with a Focus on Middle East, Africa (MEA) and Asia: A Study of Stakeholders to Assist Multinational Corporations in Understanding Regional Requirements for Operating in Emerging Markets. Journal of Global Policy and Governance, 2(1), 59-77. doi: 10.1007/s40320-013-0026-3 
Murillo, D., \& Lozano, J. M. (2006). SMEs and CSR: An Approach to CSR in their Own Words. Jounal of Business Ethics, 67(3), 227-240. doi: 10.1007/s10551-006-9181-7

Murphy, P. E. (2005). Developing, Communicating and Promoting Corporate Ethics Statements: A Longitudinal Analysis. Journal of Business Ethics, 62(2), 183-189. doi: 10.1007A10551-005-0189-1

Muthuri, J. N., Chapple, W., \& Moon, J. (2009). An Integrated Approach to Implementing 'Community Participation' in Corporate Community Involvement: Lessons from Magadi Soda Company in Kenya. Jounal of Business Ethics, 85, 431-444. doi: $10.1007 / \mathrm{s} 10551-008-9739-7$

Muthuri, J. N., \& Gilbert, V. (2011). An Institutional Analysis of Corporate Social Responsibility in Kenya. Jounal of Business Ethics, 98(3), 467-483. doi: $10.1007 / \mathrm{s} 10551-010-0588-9$

Mwaura, K. (2005). Reality and Prospects of the Proposed Constitutional Changes in Kenya. In M. Huniche \& E. R. Pedersen (Eds.), Corporate Citizenship in Developing Countries: New Partnership Perspectives. Denmark: Copenhagen Business School Press.

Myhill, J. (2006). Language, Religion and National Identity in Europe and the Middle East : A historical study. John Benjamins Publishing Company: Amsterdam.

Nasser, R., \& Abouchedid, K. (2003). Occupational Attainment through Lebanon's Higher Education: Using Individual, Societal, Structural and Gender Factors as Predictors. Career Development International, 8(7), 328-338. doi: 10.1108/13620430310505287

Nassif, N. (2014). Corruption in Sport: The Case of Lebanon. Middle East Law and Governance, 6, 123-140. doi: 10.1163/18763375-00602003 
Nelson, J. (2000). The Business of Peace. London: Prince of Wales Business Forum.

Nestle. (2005). The Nesde Commitment to Africa. Vevey.

Ng, T. W. H., Yam, K. C., \& Aguinis, H. (2019). Employee Perceptions of Corporate Social Responsibility: Effects on Pride, Embeddedness, and Turnover. Personnel Psychology, 72(1), 107-137. doi: 10.1111/peps.12294

Noorderhaven, N. G., \& Harzing, A. (2003). The "Country-of-origin Effect" in Multinational Corporations: Sources, Mechanisms and Moderating Conditions. Management International Review, 43(2), 47-66.

Nooteboom, B. (2000). Learning and Innovation in Organizations and Economies. Oxford: Oxford University Press.

O'Rourke, P. J. (2007a, Jul 16). Adam Smith's Holy Trinity; the Wealth of Nations is Our Most Important Economic Text. Yet Few Have Read It. This Week, P.J. O'rourke Discusses What The Classic Book Actually Says, National Post.

O'Rourke, P. J. (2007b, July 20). Adam Smith's 13 Golden Rules For Government; The Wealth of Nations is History's Most Important Economic Text. Yet Few Have Read the Dense Tome's Full 1,100 Pages. This Week, Satirist P.J. O'rourke Tells Post Readers What The Classic Book Actually Says, National Post.

Oliver, C. (1992). The Antecedents of Deinstitutionalization. Organization Studies, 13(2).

Oliver, C., \& Holzinger, I. (2008). The Effectiveness of Strategic Political Management: A Dynamic Capabilities Framework. The Academy of Management Review, 33(2), 496520. 
Olowokudejo, F., Aduloju, S. A., \& Oke, S. A. (2011). Corporate Social Responsibility and Organizational Effectiveness of Insurance Companies in Nigeria. The Journal of Risk Finance, 12(3), 156-167. doi: 10.1108/15265941111136914

Onwuegbuzie, A. J., \& Leech, N. L. (2005). Taking the “Q”' Out of Research: Teaching Research Methodology Courses Without the Divide Between Quantitative and Qualitative Paradigms. Quality \& Quantity, 39, 267-296. doi: 10.1007/s11135-004$1670-0$

Orlikowski, W. J., \& Barley, S. R. (2001). Technology and Institutions: What Can Research on Information Technology and Research on Organizations Learn from Each Other? MIS Quarterly, 25(2), 145-165.

Orlitzky, M., Schmidt, F. L., \& Rynes, S. L. (2003). Corporate Social and Financial Performance: A Meta-analysis. Organization Studies, 24(3), 403-441.

Palazzo, G., \& Richter, U. (2005). CSR Business as Usual? The Case of the Tobacco Industry. Jounal of Business Ethics, 61, 387-401. doi: 10.1007/s10551-005-7444-3

Paley, J. (2000). Paradigms and Presuppositions: The Difference Between Qualitative and Quantitative Research. Scholarly Inquiry for Nursing Practice, 14(2), 143-155.

Papasolomou-Doukakis, I., Krambia-Kapardis, M., \& Katsioloudes, M. (2005). Corporate Social Responsibility: The Way Forward? Maybe Not! A Preliminary Study in Cyprus. European Business Review, 17(3), 263-279.

Parboteeah, K. P, Paik, Y., \& Cullen, J. B. . (2009). Religious groups and Work Values: A Focus on Buddhism, Christianity, Hinduism, and Islam. International Journal of Cross Cultural Management, 9(1), 51. 
Park, D., \& Krishnan, H. A. (2001). Supplier Selection Practices Among Small Firms in the United States: Testing Three Models. Journal of Small Business Management, 39(3), 259-271.

Park, E., Kim, K. J., \& Kwon, S. J. (2017). Corporate Social Responsibility as A Determinant of Consumer Loyalty: An Examination of Ethical Standard, Satisfaction, and Trust. Journal of Business Research, 76, 8-13. doi: 10.1016/j.jbusres.2017.02.017

Parke, R. D. (2004). Development in the Family. Annual Review of Psychology, 55, 365-399.

Pedersen, M. B., \& Nygaard, I. (2018). System Building in the Kenyan Electrification Regime: The Case of Private Solar Mini-grid Development. Energy Research \& Social Science, 42, 211-223.

Pellegrino, C., \& Lodhia, S. (2012). Climate Change Accounting and the Australian Mining Industry: Exploring the Links Between Corporate Disclosure and the Generation of Legitimacy. Journal of Cleaner Production, 36, 68-82. doi:

10.1016/j.jclepro.2012.02.022

Peloza, J. (2009). The Challenge of Measuring Financial Impacts from Investments in Corporate Social Performance. Journal of Management, 35(6), 1518-1541. doi: $10.1177 / 0149206309335188$

Peloza, J., \& Shang, J. (2011). How Can Corporate Social Responsibility Activities Create Value for Stakeholders? A Systematic Review. Journal of the Academy of Marketing Science, 39(1), 117-135. doi: 10.1007/s11747-010-0213-6

PepsiCo. (2003). Growth \& Trust: PepsiCo 2003. Purchase, NY. 
Perez, A., \& Rodriguez Del Bosque, I. (2013). Measuring CSR Image: Three Studies to Develop and to Validate a Reliable Measurement Tool. Jounal of Business Ethics, 118, 265-286. doi: 10.1007/s10551-012-1588-8

Peters, N. J., Hofstetter, J. S., \& Hoffmann, V. H. (2011). Institutional Entrepreneurship Capabilities for Interorganizational Sustainable Supply Chain Strategies. The International Journal of Logistics Management, 22(1), 52-86. doi: $10.1108 / 09574091111127552$

Peters, S., Miller, M., \& Kusyk, S. (2011). How Relevant is Corporate Governance and Corporate Social Responsibility in Emerging Markets? Corporate Governance, 11(4), 429-445. doi: 10.1108/14720701111159262

Phillips, N., Lawrence, T. B., \& Hardy, C. (2004). Discourse and Institutions. The Academy of Management Review, 29(4), 635-652.

Phillips, N., \& Malhotra, N. (2008). Taking Social Construction Seriously: Extending the Discursive Approach in Institutional Theory. In R. Greenwood, C. Oliver, K. Sahlin \& R. Suddaby (Eds.), Handbook of Organizational Institutionalism (pp. 702-720). London: Sage.

Pisani, N., Kourula, A., Kolk, A., \& Meijer, R. (2017). How Global Is International CSR Research? Insights and Recommendations from a Systematic Review. Journal of World Business, 52, 591-614.

Porter, M. E., \& Kramer, M. R. (2006). Strategy \& Society: The Link Between Competitive Advantage and Corporate Social Responsibility. Harvard Business Review, 48(12).

Powell, T. C., Lovallo, D., \& Fox, R. (2011). Behavioral Strategy. Strategic Management Journal, 32(13), 1369-1386. doi: 10.1002/smj.968 
Powell, W. W. (2020). Institutions On The Ground. In P. Haack, J. Sieweke \& L. Wessel (Eds.), Microfoundations of Institutions (pp. 419-428). Bingley: Emerald Publishing Limited.

Powell, W. W., \& Colyvas, J. A. (2008). Microfoundations of Institutional Theory. In R. Greenwood, C. Oliver, K. Sahlin \& R. Suddaby (Eds.), Handbook of Organizational Institutionalism (pp. 276-298). London: Sage.

Powell, W. W., \& DiMaggio, P. J. (1991). The New Institutionalism in Organisational Analysis. Chicago: The University of Chicago Press.

Prasnikar, J., Pahor, M., \& Vidmar Svetlik, J. (2008). Are National Cultures Still Important in International Business? Russia, Serbia and Slovenia in Comparison. Management, $13(2), 1-26$.

Quazi, A. M., \& O'Brien, D. (2000). An Empirical Test of A Cross-national Model of Corporate Social Responsibility. Jounal of Business Ethics, 25(1), 33-51.

Quek, G. C., \& Ling, C. (2013). McDonald's Apology Over A Pig Toy: A Cultural Territorial Clash. Australasian Marketing Journal, 21(4), 228-233. doi:

10.1016/j.ausmj.2013.08.002

Rahaman, A. S., Lawrence, S., \& Roper, J. (2004). Social and Environmental Reporting at The VRA: Institutionalised Legitimacy or Legitimation Crisis? Critical perspectives on accounting, 15(1), 35-56. doi: 10.1016/S1045-2354(03)00005-4

Ramamurti, R., \& Singh, J. V. (2009). Emerging Multinationals in Emerging Markets. Cambridge: Cambridge University Press. 
Ramasamy, B., \& Yeung, M. C. (2009). Chinese Consumers' Perception of Corporate Social Responsibility (CSR). Jounal of Business Ethics, 88, 119-132. doi: 10.1007/s10551008-9825-X

Rassemblement Canadien pour le Liban. (2004). History of Lebanon: From prehistory to 2004. Quebec: Rassemblement Canadien pour le Liban.

Rawley, J. A., \& Behrendt, S.D. (2005). The Transatlantic Slave Trade: A History (Revised ed.). Lincoln, NE: University of Nebraska Press.

Rayton, B. A. (2006). Examining the Interconnection of Job Satisfaction and Organizational Commitment: An Application of the Bivariate Probit Model. International Journal of Human Resource Management, 17(1), 139-154. doi: 10.1080/09585190500366649

Reed, D. (2002). Employing Normative Stakeholder Theory in Developing Countries. Business \& Society, 41(2), 166-207. doi: 10.1177/0007650302041002003

Rego, A., Leal, S., Cunha, M. P., Faria, J., \& Pinho, C. (2010). How the Perceptions of Five Dimensions of Corporate Citizenship and their Inter-Inconsistencies Predict Affective Commitment. Journal of Business Ethics, 94(1), 107-127. doi: 10.1007/s10551-009$0252-4$

Renouard, C., \& Lado, H. (2012). CSR and Inequality in the Niger Delta (Nigeria). Corporate Governance: The International Journal of Business in Society, 12(4). doi: $10.1108 / 14720701211267810$

Rescher, N. (1969). Introduction to Value Theory New Jersey, U.S.A: Prentice-Hall.

Richbell, S. M., Watts, H. D., \& Wardle, P. (2006). Owner-managers and Business Planning in the Small Firm. International Small Business Journal, 24(5), 496-514. doi: $10.1177 / 0266242606067275$ 
Riege, A. M. (2003). Validity and Reliability Tests in Case Study Research: A Literature Review with “Hands-on” Applications for Each Research Phase. Qualitative Market Research: An International Journal, 6(2), 75-86. doi: 10.1108/13522750310470055

Robbins, S. P., \& Coulter, M. (2014). Management (12th ed.). Harlow, Essex, England: Pearson Education Limited.

Robbins, S. P., \& Coulter, M. (2016). Management (13th ed.). Harlow, Essex, England: Pearson Education Limited.

Robbins, S. P., \& Coulter, M. K. (2005). Management (8th ed.). Upper Saddle River, N.J.: Pearson/Prentice Hall.

Roberts, K., Dowell, A., \& Nie, J. B. . (2019). Attempting Rigour and Replicability in Thematic Analysis of Qualitative Research Data; A Case Study of Codebook Development. BMC Medical Research Methodology, 19(1). doi: 10.1186/s12874-0190707-y

Rodell, J. B., \& Lynch, J. (2016). Perceptions of Employee Volunteering: Is It “Credited” or “Stigmatized” by Colleagues? Academy of Management Journal, 59(2), 611-635. doi: 10.5465/amj.2013.0566

Rodriguex, P., Siegel, D. S., Hillman, A., \& Eden, L. (2006). Three Lenses on the Multinational Enterprise: Politics, Corruption, and Corporate Social Responsibility. Journal of International Business Studies, 37(6), 733-746.

Rokeach, M. (1973). The Nature of Human Values. New York: Free Press.

Rollinson, D. (2002). Organizational Behaviour: An Integrated Approach. Harlow: Pearson Education 
Rout, C. C., \& Aldous, C. (2016). How To Write A Research Protocol. Southern African Journal of Anaesthesia and Analgesia, 22(4), 101-107. doi:

$10.1080 / 22201181.2016 .1216664$

Rozuel, C., \& Kakabadse, N.D. (2011). Managerial ethics as a prerequisite to CSR: The person behind the role. In S. O. Idowu \& C. Louche (Eds.), Theory and Practice of Corporate Social Responsibility (pp. 3-22). New York: Springer Berlin Heidelberg.

Rubin, B. (2009). Lebanon: Liberation, Conflict, and Crisis. New York: Palgrave Macmillan.

Rupp, D. E. (2011). An Employee-centered Model of Organizational Justice and Social Responsibility. Organizational Psychology Review 1(1), 72-94. doi: $10.1177 / 2041386610376255$

Rupp, D. E., Williams, C. A., \& Aguilera, R. V. (2010). Increasing Corporate Social Responsibility Through Stakeholder Value Internalization (and the Catalyzing Effect of New Governance): An Application of Organizational Justice, Self-determination, and Social Influence Theories. In M. Schminke (Ed.), Managerial Ethics: Managing the Psychology of Morality (pp. 69-88). New York: Routledge.

Sakarya, S., Bodur, M., Yildirim-Oktem, O., \& Selekler-Goksen, N. (2012). Social Alliances: Business and Social Enterprise Collaboration for Social Transformation. Journal of Business Research, 65(12), 1710-1720. doi: 10.1016/j.jbusres.2012.02.012

Salamey, I. (2009). Failing Consociationalism in Lebanon and Integrative Options. International Journal of Peace Studies, 14(2).

Salamey, I. (2014). The Government and Politics of Lebanon (1st ed.). New York: Routledge.

Salloukh, B. F. (2017). The Syrian War: Spillover Effects on Lebanon. Middle East Policy, 24(1), 62-78. 
Sandhu, H. S., \& Kapoor, S. (2010). Corporate Social Responsibility Initiatives: An Analysis of Voluntary Corporate Disclosure. South Asian Journal of Management, 17(2), 47-80.

Sapovadia, V. K. (2006). Micro Finance: The Pillars of A Tool to Socio-economic Development. Development Gateway.

Sarita, P. (2017). Constructivism: A New Paradigm in Teaching and Learning. International Journal of Academic Research and Development, 2(4), 183-186.

Saunders, M., Lewis, P., \& Thornhill, A. (2003). Research Methods for Business Students (3rd ed.). Harlow, Essex, England: Prentice Hall.

Saunders, M., Lewis, P., \& Thornhill, A. (2009). Research Methods for Business Students (5th ed.). Harlow, Essex, England: Prentice Hall.

Saunders, M., Lewis, P., \& Thornhill, A. (2019). Research Methods for Business Students (8th ed.). Harlow, Essex, England: Prentice Hall.

Sauser, W. I., Jr. (2005). Ethics in Business: Answering the Call. Journal of Business Ethics, 58, 345-357. doi: 10.1007/s10551-004-5715-Z

Savage, G. T., Bunn, M. D., Gray, B., Xiao, Q., Wang, S., Wilson, E. J., \& Williams, E. S. (2010). Stakeholder Collaboration: Implications for Stakeholder Theory and Practice. Jounal of Business Ethics, 96(1), 21-26. doi: 10.1007/s 10551-011-0939-1

Scandelius, C., \& Cohen, G. (2016). Achieving Collaboration with Diverse Stakeholders-The Role of Strategic Ambiguity in CSR Communication. Jounal of Business Research, 69, $3487-3499$.

Schatzki, T. R. (2005). Peripheral Vision: The Sites of Organizations. Organization Studies, 26(3), 465-484. doi: 10.1177/0170840605050876 
Schaubroeck, J. M., Hannah, S. T., Avolio, B. J., Kozlowski, S. W. J., Lord, R. G., Trevino, L. K., ... Peng, A. C. (2012). Embedding Ethical Leadership Within and Across Organization Levels. The Academy of Management Journal, 55(5), 1053-1078.

Schermerhorn, J. R. (2005). Management (8th ed.). New York: Wiley.

Schultz, F., \& Wehmeier, S. (2010). Institutionalization of Corporate Social Responsibility within Corporate Communications: Combining Institutional, Sensemaking and Communication Perspectives. Corporate Communications: An International Journal, 15(1), 9-29.

Schwartz, M. (2001). The Nature of the Relationship between Corporate Codes of Ethics and Behaviour. Jounal of Business Ethics, 32(3), 247-262.

Schweitzer, M. E., Ordonez, L., \& Douma, B. (2004). Goal Setting As A Motivator of Unethical Behavior. Academy of Management Journal, 47(3), 422-432.

Scott, W. R. (2001). Institutions and Organizations. Thousand Oaks: Sage Publications.

Scott, W. R. (2008). Institutions and Organizations: Ideas and Interest. Thousand Oaks, CA: Sage.

Sekaran, U. (2003). Research Methods for Business: A Skill-building Approach (4th ed.). New York: John Wiley \& Sons.

Sekaran, U., \& Bougie, R. (2009). Research Methods for Business: A Skill-Building Approach (5th ed.). Chichester, West Sussex, United Kingdom: John Wiley \& Sons Ltd.

Sekaran, U., \& Bougie, R. (2016). Research Methods for Business: A Skill-Building Approach (7th ed.). Chichester, West Sussex, United Kingdom: John Wiley \& Sons Ltd. 
Selekler-Goksen, N. N., \& Oktem, O. Y. (2009). Countervailing Institutional Forces:

Corporate Governance in Turkish Family Business Groups. Journal of Management \& Governance, 13(3), 193-213. doi: 10.1007/s10997-009-9083-z

Selznick, P. (1949). TVA and The Grass Roots: A Study in the Sociology of Formal Organization Berkeley: University Of California Press.

Sen, S., Gurhan-Canli, Z., \& Morwitz, V. (2001). Withholding Consumption: A Social Dilemma Perspective on Consumer Boycotts. Journal of Consumer Research, 28(3), 399-417. doi: 10.1086/323729

Shah, S., \& Ramamoorthy, V. E. (2014). Soulful Corporations : A Values-Based Perspective on Corporate Social Responsibility. New Delhi: Springer.

Sharaiha, F., \& Ibrahim, B. L. (2008). The Republic of Lebanon. In B. L. Ibrahim \& D. H. Sherif (Eds.), From Charity to Social Change: Trends in Arab Philanthropy. Cairo: American University in Cairo Press.

Sharma, S. (2000). Managerial Interpretations and Organizational Context as Predictors of Corporate Choice of Environmental Strategy Academy of Management Journal, 43(4), $681-697$.

Sharma, S., \& Henriques, I. (2005). Stakeholder Influences on Sustainability Practices in the Canadian Forest Products Industry. Strategic Management Journal, 26(2), 159-180. doi: $10.1002 / \mathrm{smj} .439$

Shaw, J. A., Kontos, P., Martin, W. , \& Victor, C. (2017). The Institutional Logic of Integrated Care: An Ethnography of Patient Transitions. Journal of Health Organization and Management, 31(1), 82-95. doi: 10.1108/JHOM-06-2016-0123 
Sheldon, P. J., \& Park, S. Y. (2011). An Exploratory Study of Corporate Social Responsibility in the U.S. Travel Industry. Journal of Travel Research, 50(4), 392-407. doi: $10.1177 / 0047287510371230$

Sidani, Y. (2002). Management in Lebanon. In M. Warner (Ed.), International Encyclopedia of Business and Management (2nd ed., pp. 3797-3802). London: Thomson Learning.

Sidani, Y., Zbib, I., Rawwas, M., \& Moussawer, T. (2009). Gender, Age, and Ethical Sensitivity: The Case of Lebanese Workers. Gender in Management: An International Journal, 24(3), 211-227. doi: 10.1108/17542410910950886

Siegel, D. S. (2009). Green Management Matters Only If It Yields More Green: An Economic/Strategic Perspective. Academy of Management Perspectives, 23(3), 5-16.

Singhapakdi, A., Gopinath, M., Marta, J. K., \& Carter, L. L. (2008). Antecedents and Consequences of Perceived Importance of Ethics in Marketing Situations: A Study of Thai Businesspeople. Jounal of Business Ethics, 81(4), 887-904. doi: 10.1007A10551$007-9555-5$

Skivenes, M., \& Trygstad, S. C. (2010). When Whistle-Blowing Works: The Norwegian Case. Human Relations, 63(7), 1071-1097. doi: 10.1177/0018726709353954

SMEs and Startups Form Backbone of Lebanon's Growth. (2018, March 3). SyndiGate Media Inc.

Solomon, R. C. (2002). Business ethics and virtue. In R. E. Frederick (Ed.), A companion to business ethics (pp. 30-37). Malden, Massachusetts: Blackwell Publishers Inc.

Sonpar, K., Pazzaglia, F., \& Kornijenko, J. (2010). The Paradox and Constraints of Legitimacy. Jounal of Business Ethics, 95(1), 1-21. 
Soppe, A., Schauten, M., Soppe, J., \& Kaymak, U. (2011). Corporate Social Responsibility Reputation (CSRR): Do Companies Comply with Their Raised CSR Expectations ? Corporate Reputation Review, 14(4), 300-323.

Sorenson, C. (2011). Canada the Good? . Maclean's, 123, 43.

Spector, B. (2008). "Business Responsibilities in a Divided World": The Cold War Roots of the Corporate Social Responsibility Movement. Enterprise \& Society, 9(2), 314-336. doi: $10.1093 / \mathrm{es} / \mathrm{khn} 023$

Spence, L. J., \& Lozano, J. F. (2000). Communicating about Ethics with Small Firms: Experiences from the U.K. and Spain. Jounal of Business Ethics, 27(1/2), 43-53.

Srinivasan, V. (2009). CSR and Ethics in MSMEs in India. African Journal of Business Ethics, 4(2), 32-36.

Stackhouse, M. L. (1995a). Spirituality and the Corporation. In M. L. Stackhouse, D. P. McCann, S. J. Roels \& P. N. Williams (Eds.), On Moral Business (pp. 501-507). Grand Rapids, Michigan: Eerdmans.

Stackhouse, M. L. (1995b). What Then Shall We Do? On Using Scripture in Economic Ethics. In M. L. Stackhouse, D. P. McCann, S. J. Roels \& P. N. Williams (Eds.), On Moral Business (pp. 109-113). Grand Rapids, Michigan: Eerdmans.

Stanaland, A. J. S., Lwin, M. O., \& Murphy, P. E. (2011). Consumer Perceptions of the Antecedents and Consequences of Corporate Social Responsibility. Jounal of Business Ethics, 102(1), 47-55 doi: 10.1007/s10551-011-0904-z

Stevens, B. (2008). Corporate Ethical Codes: Effective Instruments For Influencing Behavior. Jounal of Business Ethics, 78(4), 601-609. doi: 10.1007/s10551-007-9370-z 
Stieb, J.A. (2009). Assessing Freeman's Stakeholder Theory. Journal of Business Ethics. Journal of Business Ethics, 87, 401-414.

Stites, J. P., \& Michael, J. H. (2011). Organizational Commitment in Manufacturing Employees: Relationships with Corporate Social Performance. Business and Society, $50(1), 50-70$.

Studer, S., Welford, R., \& Hills, P. (2006). Engaging Hong Kong Businesses in Environmental Change: Drivers and Barriers. Business Strategy and the Environment, 15(6), 416-431. doi: $10.1002 /$ bse.516

Suddaby, R. (2010). Challenges for Institutional Theory. Journal of Management Inquiry, 19(1), 14-20. doi: 10.1177/1056492609347564

Suddaby, R., \& Greenwood, R. (2005). Rhetorical Strategies of Legitimacy. Administrative Science Quarterly, 50(1), 35-67.

Sullivan, A., \& Sheffrin, S. M. (2003). Economics: Principles in Action. Upper Saddle River, NJ: Pearson Prentice Hall.

Sullivan, R. (2003). Business and Human Rights: Dilemmas and Solutions. United Kingdom: Greenleaf Publishing.

Syed, J., \& Murray, P. (2009). Combating the English Language Deficit: The Labour Market Experiences of Migrant Women in Australia. Human Resource Management Journal, 19(4), 413-432. doi: 10.1111/j.1748-8583.2009.00106.x

Tavani, H. T., \& Grodzinsky, F. S. (2014). Trust, Betrayal, and Whistle-blowing: Reflections on the Edward Snowden Case. SIGCAS Computers \& Society, 44(3).

Taylor, J. G., \& Scharlin, P. J. (2004). Smart Alliance : How a Global Corporation and Environmental Activists Transformed a Tarnished Brand J. C. Scott (Ed.) 
Teddlie, C., \& Johnson, R. B. (2009). Methodological thought since the 20th century. In C. Teddlie \& A. Tashakkori (Eds.), Foundations of Mixed Methods Research: Integrating Quantitative and Qualitative Techniques in the Social and Behavioral Sciences (pp. 62-82). Thousand Oaks, CA: SAGE.

Teo, H. H., Wei, K. K., \& Benbasat, I. (2003). Predicting Intention to Adopt Interorganizational Linkages: An Institutional Perspective. MIS Quarterly, 27(1), 1949.

Tetrault Sirsly, C. A. (2009). 75 Years of Lessons Learned: Chief Executive Officer Values and Corporate Social Responsibility. Journal of Management History, 15(1), 78-94. doi: $10.1108 / 17511340910921808$

The Economist Intelligence Unit. (2007). Country Profile 2007 - Lebanon, The Economist Intelligence Unit.

The Economist Intelligence Unit. (2019). Country Profile 2019 - Lebanon, The Economist Intelligence Unit.

Thorne, L., Mahoney, L., \& Bobek, D. (2010). A Comparison of the Association between Corporate Social Responsibility and Executive Compensation: United States versus Canada. Research on Professional Responsibility and Ethics in Accounting, 14, 37-56. doi: 10.1108/S1574-0765(2010)0000014006

Thorne, L., Mahoney, L. S., Gregory, K., \& Convery, S. (2017). A Comparison of Canadian and U.S. CSR Strategic Alliances, CSR Reporting, and CSR Performance: Insights into Implicit-Explicit CSR. Jounal of Business Ethics, 143, 85-98. doi:

$10.1007 / \mathrm{s} 10551-015-2799-6$ 
Thornton, P. H. (2004). Markets From Culture: Institutional Logics and Organizational Decisions in Higher Education Publishing. Stanford, CA: Stanford University Press.

Tihanyi, L., Griffith, D. A., \& Russell, C. J. (2005). The Effect of Cultural Distance on Entry Mode Choice, International Diversification, and MNE Performance: A Meta-Analysis. Journal of International Business Studies, 36(3), 270-283.

Tilley, F. (2000). Small Firm Environmental Ethics: How Deep Do They Go? . Business Ethics: A European Review, 9(1).

Timmermans, S., \& Tavory, I. . (2012). Theory Construction in Qualitative Research: From Grounded Theory to Abductive Analysis. Sociological Theory, 30(3), 167-186. doi: $10.1177 / 0735275112457914$

Tolbert, P., \& Zucker, L. G. . (2020). What Are Microfoundations? Why and How To Study Them? In P. Haack, J. Sieweke \& L. Wessel (Eds.), Microfoundations of Institutions (pp. 3-8). Bingley: Emerald Publishing Limited.

Tolk, A. (2013). Ontology, Epistemology, and Teleology for Modeling and Simulation: Philosophical Foundations for Intelligent M\&S Applications. Verlag: Springer.

Traboulsi, F. (2007). A History of Modern Lebanon. London: Pluto Press.

Trank, C., \& Washington, M. (2009). Maintaining an Institution in a Contested Organizational Field: The Work of the AACSB and Its Constituents. In A. T. Lawrence, R. Suddaby \& B. Leca (Eds.), Institutional Work: Actors and Agency in Institutional Studies of Organizations. Cambridge: Cambridge University Press.

Transparency international. (2017). Corruption Perceptions Index 2017.

Trevino, L. K., \& Brown, M. E. (2004). Managing to be ethical: debunking five business ethics myths. Academy of Management Executive, 18(2), 69-81. 
Trullen, J., \& Stevenson, W. B. (2006). Strategy and Legitimacy: Pharmaceutical Companies' Reaction to the HIV Crisis. Business \& Society, 45(2), 178-210.

Tsalikis, J., Seaton, B., \& Tomaras, P. (2002). A New Perspective on Cross-Cultural Ethical Evaluations: The Use of Conjoint Analysis. Jounal of Business Ethics, 35(4), 281-292. doi: 10.1023/A:1013855326809

Tsui, A. (2004). Contributing to Global Management Knowledge: A Case for High Quality Indigenous Research. Asia Pacific Journal of Management, 21, 491-513.

Turker, D. (2009). How Corporate Social Responsibility Influences Organizational Commitment. Journal of Business Ethics, 89(2), 189-204. doi: 10.1007/s10551-0089993-8

Tutelian, M., Khayyat, M., \& Abdel Monem, A. (2007). Lebanon Family Health Survey 2004: Principal Report. Cairo, Egypt: Pan Arab Project for Family Health.

Ullah, S., \& Jamali, D. (2010). Institutional investors and corporate social responsibility: the role of Islamic financial institutions. International Review of Business Research Papers, 6(1), 619-630.

UNCTAD. (2007). World Investment Report 2007: Transnational Corporations, Extractive Industries and Development. United Nations, New York and Geneva.

UNDP. (2003). Enhancing Business Community Relations.

Unerman, J., \& Bennett, M. (2004). Increased Stakeholder Dialogue and the Internet: Towards Greater Corporate Accountability or Reinforcing Capitalist Hegemony? Accounting, Organizations, and Society, 29(7), 685-707.

Unilever. (2003). Summary Social Review: 2003: Listening, Learning, Update on Progress. Rotterdam, Germany/London. 
Valentine, S., \& Barnett, T. (2002). Ethics Codes and Sales Professionals' Perceptions of Their Organizations' Ethical Values. Jounal of Business Ethics, 40(3), 191-200.

Valentine, S., Godkin, L., Fleischman, G. M., \& Kidwell, R. (2011). Corporate Ethical Values, Group Creativity, Job Satisfaction and Turnover Intention: The Impact of Work Context on Work Response. Journal of Business Ethics, 98(3), 353-372. doi: 10.1007/s10551-010-0554-6

Valentine, S., Nam, S., Hollingworth, D., \& Hall, C. (2014). Ethical Context and Ethical Decision Making: Examination of an Alternative Statistical Approach for Identifying Variable Relationships. Journal of Business Ethics, 124(3), 509-526. doi: $10.1007 / \mathrm{s} 10551-013-1879-8$

Van Der Vegt, G. S. , Essens, P., Wahlstrom, M., \& George, G. (2015). Managing Risk and Resilience. Academy of Management Journal, 58(4), 971-980. doi: 10.5465/amj.2015.4004

Van Marrewijk, M. (2003). Concepts and Definitions of CSR and Corporate Sustainability: Between Agency and Communion. Jounal of Business Ethics, 44(2), 95-105. doi: 10.1023/A:1023331212247

Van Ommering, E. (2011). Schooling in Conflict: An Ethnographic Study from Lebanon. International Journal of Sociology and Social Policy, 31(9/10), 543-554. doi: $10.1108 / 01443331111164133$

Van Oosterhout, J. (2010). he Role of Corporations in Shaping the Global Rules of the Game: In Search of New Foundations. Business Ethics Quarterly, 20(2), 253-264.

Victor, B., \& Cullen, J. B. (1988). The Organizational Bases of Ethical Work Climates. Administrative Science Quarterly, 33(1), 101-125. 
Videras, J., \& Alberini, A. (2000). The Appeal of Voluntary Environmental Programs: Which Firms Participate and Why? Contemporary Economic Policy, 18(4), 449-461.

Visser, W. (2006). Revisiting Carroll's CSR Pyramid - An African Perspective. In E. R. Pedersen \& M. Huniche (Eds.), Corporate Citizenship in Developing Countries : New Partnership Perspectives. Denmark: Copenhagen Business School Press.

Visser, W. (2008). Corporate Social Responsibility in Developing Countries. In A. Crane, D. Matten, A. McWilliams, J. Moon \& D. S. Siegel (Eds.), The Oxford Handbook of Corporate Social Responsibility (pp. 473-479). Oxford: Oxford University Press.

Visser, W. (2010). The Age of Responsibility: CSR 2.0 and the New DNA of Business. Journal of Business Systems, Governance and Ethics, 5(3), 7-22. doi: 10.15209/jbsge.v5i3.185

Vivar, C. G., McQueen, A., Whyte, D. A., \& A., Navidad C. (2007). Getting Started with Qualitative Research: Developing a Research Proposal. Nurse Researcher, 14(3), 6073.

Von Weltzien Heivik, H., \& Shankar, D. (2011). How Can SMEs in a Cluster Respond to Global Demands for Corporate Responsibility? Jounal of Business Ethics, 101(2), 175195. doi: 10.1007 /s10551-01 0-0708-6

Vorster, N. (2010). An Ethical Critique of Milton Friedman's Doctrine on Economics and Freedom. Journal for the Study of Religions and Ideologies, 9(26), 163-188.

Vurro, C., Russo, A., \& Perrini, F. (2009). Shaping Sustainable Value Chains: Network Determinants of Supply Chain Governance Models. Jounal of Business Ethics, 90(4), 607-621. doi: 10.1007A10551-010-0595-X 
Waddock, S. (2004). Parallel Universes: Companies, Academics, and the Progress of Corporate Citizenship. Business and Society Review, 109(1), 5-42.

Waddock, S. A. (2008). Building a New Institutional Infrastructure for Corporate Responsibility. Academy of Management Perspectives, 22(3), 87-108.

Waddock, S. A., Bodwell, C., \& Graves, S. B. (2002). Responsibility: The New Business Imperative. The Academy of Management Executive (1993-2005), 16(2), 132-148.

Wahid, F., \& Sein, M. K. (2013). Institutional Entrepreneurs: The Driving Force in Institutionalization of Public Systems in Developing Countries. Transforming Government: People, Process, and Policy, 7(1), 76-92. doi:

$10.1108 / 17506161311308179$

Wahito, M. (2012, November 12). GE to Invest in Kenyan Wind Power Sector, Capital Business.

Waldman, D. A., \& Siegel, D. (2008). Defining the Socially Responsible Leader. The Leadership Quarterly, 19(1), 117-131. doi: 10.1016/j.leaqua.2007.12.008

Waldman, D. A., Sully De Luque, M., Washburn, N., House, R. J., Adetoun, B., Barrasa, A., . . . Wilderom, C. P. M. (2006). Cultural and Leadership Predictors of Corporate Social Responsibility Values of Top Management: A GLOBE Study of 15 Countries. Journal of International Business Studies, 37(6), 823-837. doi: 10.1057/palgrave.jibs.8400230

Walsh, J., Meyer, A. D, \& Shoonhoven, C. B. (2006). A Future for Organization Theory: Living in and Living with Changing Organizations. Organization Science, 17(5), 657$671,673-675$. 
Wang, H., Tong, L., Takeuchi, R., \& George, G. (2016). Corporate Social Responsibility: An Overview and New Research Directions. Academy of Management Journal, 59(2), 534-544. doi: 10.5465/amj.2016.5001

Wang, J., \& Peyvandi, A. (2018). Objectivism Versus Constructivism in Global Business Education: An Empirical Study International Journal of Education Research, 13(1).

Wang, T., \& Bansal, P. (2012). Social Responsibility in Newventures: Profiting from A Longterm Orientation. Strategic Management Journal, 33, 1135-1153. doi: 10.1002/smj.1962

Ward, H., \& Smith, C. (2006). Corporate Social Responsibility at a Crossroads: Futures for CSR in the UK to 2015. London: Russell Press.

Watson, M. (2007). Trade Justice and Individual Consumption Choices: Adam Smith's Spectator Theory and the Moral Constitution of the Fair Trade Consumer. . European Journal of International Relations, 13(2), 263-288,291.

Weaver, G. R., \& Agle, B. R. (2002). Religiosity and Ethical Behavior in Organizations: A Symbolic Interactionist Perspective. The Academy of Management Review, 27(1), 77 97.

Weber, K. (2006). From Nuts and Bolts to Toolkits: Theorizing With Mechanisms. Journal of Management Inquiry, 15(2), 119-123.

Weber, K., \& Glynn, M. A. (2006). Making Sense with Institutions: Context, Thought and Action in Karl Weick’s Theory. Organization studies, 27(11), 1639-1660. doi: $10.1177 / 0170840606068343$ 
Weerakkody, V., Dwivedi, Y. K., \& Irani, Z. (2009). The Diffusion and Use of Institutional Theory: A Cross-Disciplinary Longitudinal Literature Survey. Journal of Information Technology, 24(4), 354-368. doi: 10.1057/jit.2009.16

Weir, D. (2012). Management teaching, the spiritual dimension and the acceptance of the Islamic other. Journal of Management, Spirituality \& Religion, 9(1), 67-81. doi: $10.1080 / 14766086.2012 .641098$

Welford, R. (2005). Corporate Social Responsibility in Europe, North America and Asia: 2004 Survey Results. The Journal of Corporate Citizenship(17), 33-52.

White, E. D. (2019). Christianity, Islam, and the UK Independence Party: Religion and British Identity in the Discourse of Right-Wing Populists. A Journal of Church and State, O(0), 1-22. doi: $10.1093 /$ jes/csy082

Williams, C. A. (2004). Civil Society Initiatives and "Soft Law" in the Oil and Gas Industry. New York University Journal of International Law \& Politics, 36(2-3), 457-502.

Williams, H. (2012). Lebanon: A History, 600 - 2011. New York: Oxford University Press.

Williamson, P. J., Ramamurti, R., Fleury, A., \& Fleury, M. T. L. (2013). The Competitive Advantage of Emerging Market Multinationals. Cambridge: Cambridge University Press.

Wood, D. J. (2010). Measuring Corporate Social Performance: A Review. International Journal of Management Reviews, 12(1), 50-84. doi: 10.1111/j.14682370.2009.00274.x

World Bank. (2016). Financial Sector Assessment: Lebanon

World Bank. (2019). Lebanon Economic Monitor. 
World Business Council for Sustainable Development. (1999). Corporate Social Responsibility: Meeting Changing Expectations. Geneva: WBCSD.

World Business Council for Sustainable Development. (2000). Corporate Social Responsibility: Making Good Business Sense. Geneva: WBCSD.

World Economic Forum. (2015). The Global Competitiveness Report 2015-2016.

World Economic Forum. (2017). The Global Competitiveness Report 2017-2018.

Worthington, I., Ram, M., \& Jones, T. (2006). Exploring Corporate Social Responsibility in the U.K. Asian Small Business Community. Jounal of Business Ethics, 67(2), 201-217. doi: $10.1007 /$ s10551-006-9024-6

Wuyts, S., Colombo, M. G., Dutta, S., \& Nooteboom, B. (2005). Empirical Tests of Optimal Cognitive Distance. Journal of Economic Behavior \& Organization, 58, 277-302. doi: 10.1016/j.jebo.2004.03.019

Yang, X., \& Rivers, C. (2009). Antecedents of CSR Practices in MNCs' Subsidiaries: A Stakeholder and Institutional Perspective. Jounal of Business Ethics, 86(2), 155-169. doi: 10.1007A10551-009-0191-0

Yelkikalan, N., \& Kose, C. (2012). The Effects of the Financial Crisis on Corporate Social Responsibility. International Journal of Business and Social Science 3(3).

Yin, J., \& Zhang, Y. (2012). Institutional Dynamics and Corporate Social Responsibility (CSR) in an Emerging Country Context: Evidence from China. Jounal of Business Ethics, 111(2), 301-316. doi: 10.1007/s 10551-012-1243-4

Yin, R. K. (1994). Case Study Research: Design and Methods (2nd ed.). Newbury Park, CA: Sage.

Yin, R. K. (2003). Case Study Research Design and Methods (3rd ed.). London: Sage. 
Yin, R. K. (2009). Case Study Research Design and Methods (4th ed.). London: Sage.

Zadek, S. (2004). The Path to Corporate Responsibility. Harvard Business Review, 82(6), $125-$ 132.

Zhai, Q., \& Su, J. (2019). A Perfect Couple? Institutional Theory and Entrepreneurship Research. Chinese Management Studies, 13(3), 616-644. doi: 10.1108/CMS-07-20170194

Zietsma, C., \& Lawrence, T. B. (2010). Institutional Work in the Transformation of an Organizational Field: The Interplay of Boundary Work and Practice Work. Administrative Science Quarterly, 55(2), 189-221.

Zietsma, C., \& McKnight, B. (2009). Building the Iron Cage: Institutional Creation Work in the Context of Competing Proto-institutions. In T. Lawrence, R. Suddaby \& B. Leca (Eds.), Institutional Work: Actors and Agency in Institutional Studies of Organizations (pp. 143-177). Cambridge: Cambridge University Press.

Zilber, T. (2009). Institutional Maintenance As Narrative Acts. In A. T. Lawrence, R. Suddaby \& B. Leca (Eds.), Institutional Work: Actors and Agency in Institutional Studies of Organizations (pp. 204-235). Cambridge: Cambridge University Press.

Zilber, T. B. (2002). Institutionalization as an Interplay Between Actions, Meanings, and Actors: The Case of a Rape Crisis Center in Israel. The Academy of Management Journal, 45(1), 234-254.

Zimmerman, M. A., \& Zeitz, G. J. (2002). Beyond Survival: Achieving New Venture Growth by Building Legitimacy. The Academy of Management Review, 27(3), 414-431.

Zinbarg, E. D. (2001). Faith, Morals, and Money: What the World's Great Religions Tell Us About Ethics in the Marketplace. New York: Continuum. 
Zucker, L. G. (1991). Postscript: Microfoundations of Institutional Thought. In P. DiMaggio \& W. W. Powell (Eds.), The New Institutionalism in Organizational Analysis (pp. 103107). Chicago: University of Chicago Press.

Zucker, L. G., \& Schilke, O. (2020). Towards A Theory of Micro-institutional Processes:

Forgotten Roots, Links to Social-psychological Research, and New Ideas In P. Haack, J. Sieweke \& L. Wessel (Eds.), Microfoundations of Institutions (pp. 371-390). Bingley: Emerald Publishing Limited. 


\section{Appendices}

\section{Appendix A - Interview Protocol}

Date of the interview:

Interviewee's name:

Interviewee's job position:

MNCs' name:

Time of interview:

Duration of the interview:

\begin{tabular}{|c|c|c|}
\hline Questions & $\begin{array}{l}\text { Researcher's personal notes. } \\
\text { What do we aim to find with } \\
\text { these questions? How does the } \\
\text { response to these questions } \\
\text { contribute to addressing the } \\
\text { research questions? }\end{array}$ & $\begin{array}{l}\text { Researcher's } \\
\text { personal notes } \\
\text { during the } \\
\text { interview. }\end{array}$ \\
\hline $\begin{array}{l}\text { Section A: } \\
\text { Personal/demographic/educationa } \\
\text { 1 questions: } \\
\text { 1- Age } \\
\text { 2- Gender } \\
\text { 3- Educational Level } \\
\text { 4- Religion } \\
\text { 5- Nationality } \\
\text { 6- Ethnic Background }\end{array}$ & $\begin{array}{l}\text { To identify/clarify } \\
\text { participants' background as a } \\
\text { context to help draw } \\
\text { inferences on relationship } \\
\text { between managers' } \\
\text { personal/demographic/educati } \\
\text { onal characteristics and their } \\
\text { CSR/Ethics. } \\
\text { Ethnic background questions: } \\
\text { Which group of people would } \\
\text { you identify yourself with? } \\
\text { How would you describe } \\
\text { yourself? }\end{array}$ & \\
\hline Section B: & $\begin{array}{l}\text { Similar to the aims of the } \\
\text { questions in section } \mathrm{A} \text {, the aim } \\
\text { of the questions in section } \mathrm{B} \text { is }\end{array}$ & \\
\hline
\end{tabular}




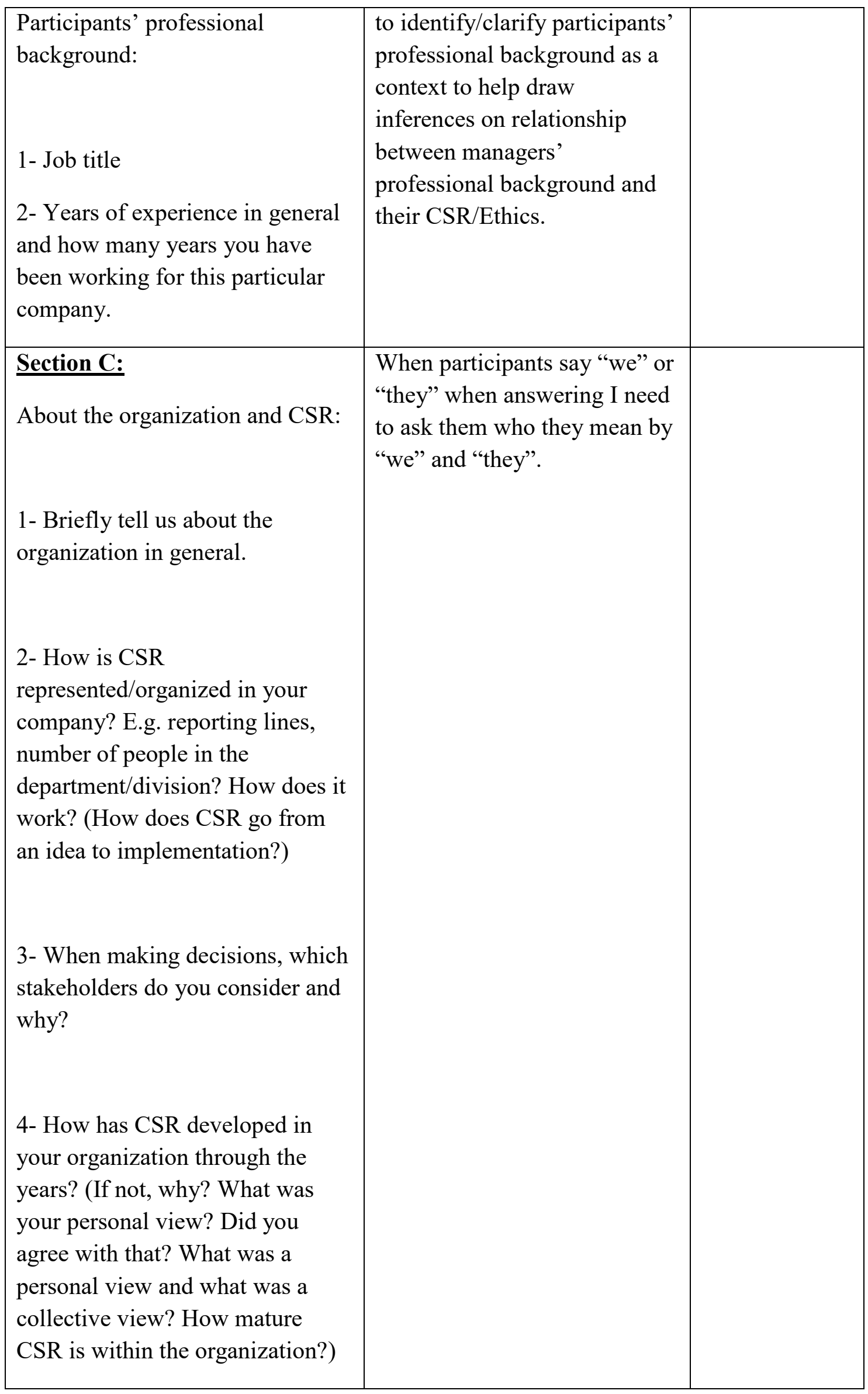


5- Is and how is CSR 'codified' e.g. code of ethics, value statements? If not, why? If yes, can I have it? (Things we can see i.e. documents, written statements, etc.) (What do you think ethics mean to your organization? Can you describe the organization's business ethics? How does business ethics play a role in the organization's CSR?)

6-What do you think CSR mean to your organization?

\section{Section D:}

CSR and you:

The questions in Section D may be addressed as part of the participants' response to questions in Section C.

1- What does CSR mean to you personally? (define, understand, perceive, operationalize it) (In case the answer to this question is different from the answer to the question of what CSR means to the organization, how do you feel about it?)

2- How long have you been practicing CSR and why do you engage in it? (Interviewee and organization)

\section{Section E:}

In case not elaborated upon in Section $C$ and in case I have time during the interview I 


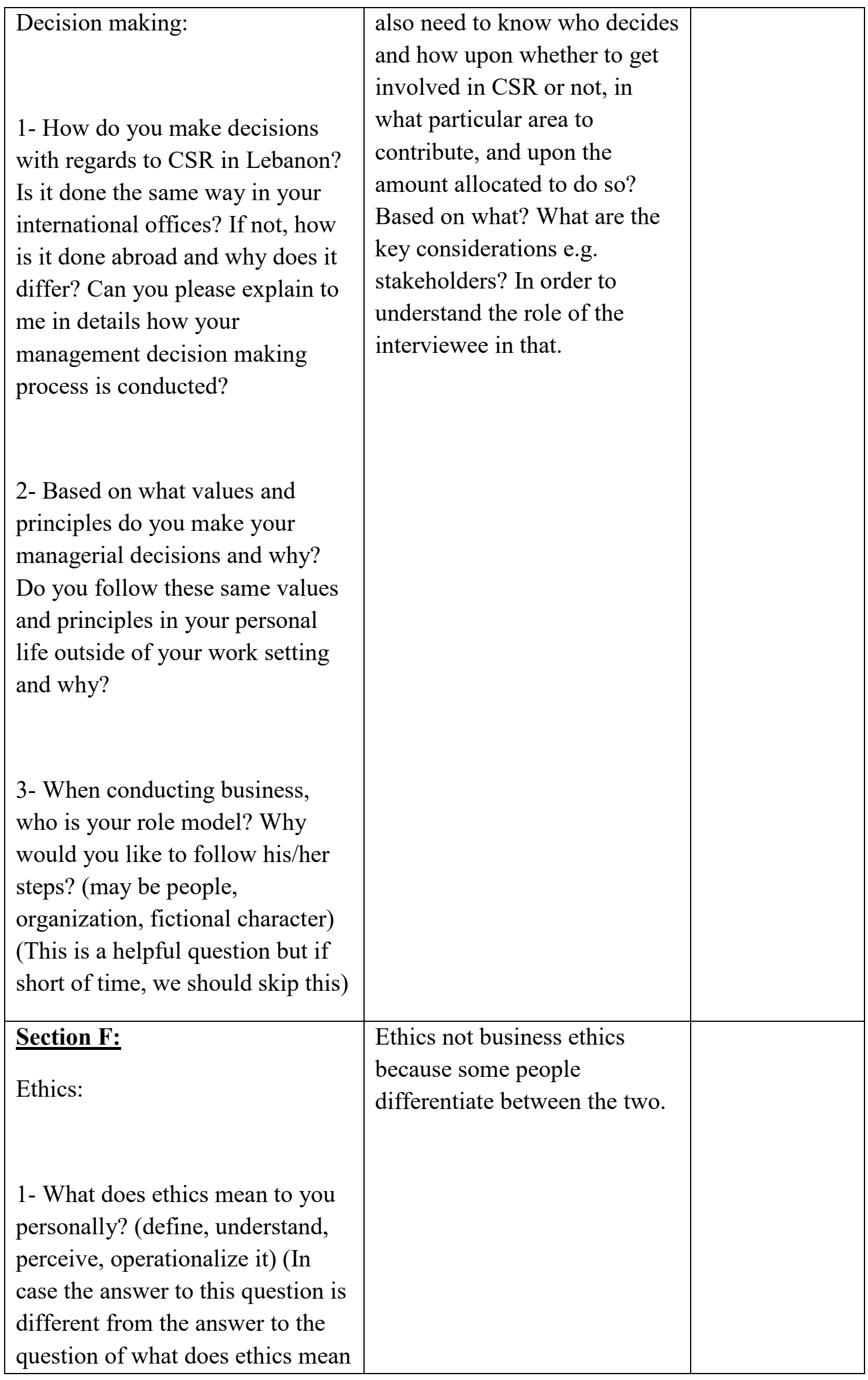




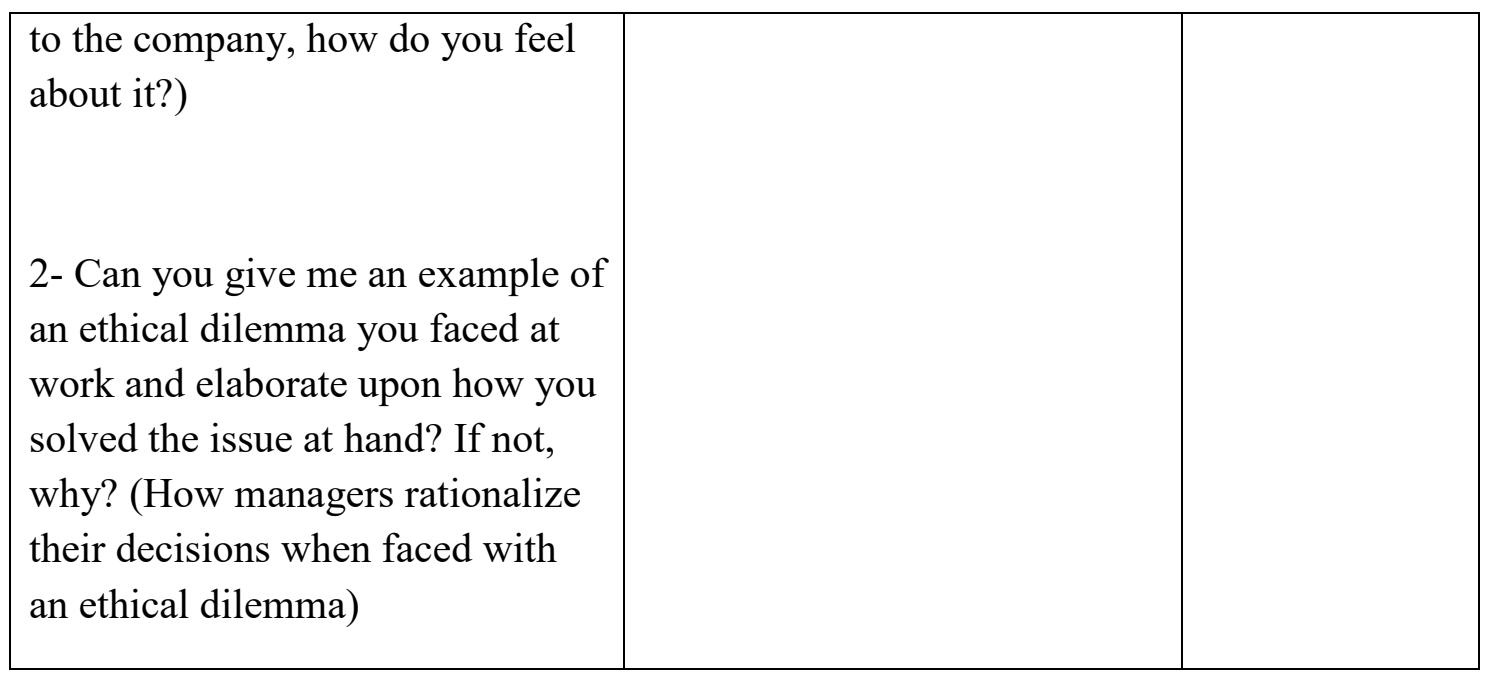


Project Supervisor

Dr Mark Loon

Worcester Business School

University of Worcester

Phone: +44 (0) 1905855471

Email:m.loon@worc.ac.uk

Date:

NAME:

POSITION:

ORGANIZATION:

Subject: Invitation to participate in a research project entitled "Corporate Social

Responsibility in Multinational Companies Based in Lebanon: Exploring the Role of Managers' Individual and Situational Factors in Institutionalizing CSR".

Dear Sir/Madam,

You are invited to participate in the research project identified above which is being conducted by Marguerite Eid, who is a PhD student from the Business School at the University of Gloucestershire, United Kingdom. This project is part of a Doctor of Philosophy study at the University of Gloucestershire and is being supervised by Dr Mark Loon from the Worcester Business School, University of Worcester, United Kingdom.

Why is the research being done?

The aim of the study is to explore how managers make corporate social responsibility (CSR) decisions in multinational companies based in Lebanon.

\section{Who can participate in the research?}

Any CSR manager, top manager, CEO, or owner of a multinational company operating in Lebanon. 


\section{UNIVERSITY OF GLOUCESTERSHIRE}

at Cheltenham and Gloucester

\section{What choice do you have?}

Participation in this research project is entirely voluntary and you may withdraw consent at any time without giving a reason. Your decision to participate or not to participate in this project will not affect you in any way. Additionally, not participating in this study will not affect your relationship with the University of Gloucestershire.

\section{What will you be asked to do?}

If you are willing to participate, you will partake in an anonymous semi-structured interview with the student researcher at a location of your choice within Lebanon.

\section{How much time will it take?}

The interview is expected to take no more than one hour.

\section{How will your privacy be protected?}

Only the researchers will have access to the collected data. All responses will be treated with the strictest confidence and none of the responses will be divulged to any other party. Respondents or their organisations will not be identified in any report or publication.

\section{How will the information collected be used?}

The information obtained from this interview will primarily be used to produce the $\mathrm{PhD}$ disertation by Marguerite Eid.

\section{Further information}

If you would like further information about this study, then please contact the project supervisor, Dr Mark Loon by email or telephone.

Thank you for considering this invitation. We encourage you to retain this information sheet for your record.

Yours sincerely,

Marguerite Eid 
UNIVERSITY OF GLOUCESTERSHIRE

at Cheltenham and Gloucester

\author{
Consent Form for Participation in the Research Project \\ "Corporate Social Responsibility in Multinational Companies Based in Lebanon: \\ Exploring the Role of Managers' Individual and Situational Factors in Institutionalizing \\ CSR".
}

Dear Sir/Madam,

I, project "Corporate Social Responsibility in Multinational Companies Based in Lebanon: Exploring the Role of Managers' Individual and Situational Factors in Institutionalizing CSR", which is to be conducted by Marguerite Eid and Dr Mark Loon from the University of Gloucestershire, and all of my queries have been answered satisfactorily.

I hereby voluntarily participate in the study. I agree to participate in a confidential semistructured interview and respond to a follow-up summary of this interview. I understand that the project will be conducted in accordance with the Information letter, a copy of which I have retained.

I understand I can withdraw my approval at any time, without penalty, and do not have to give any reason for withdrawing.

I understand that all of the information about participants that is collected will remain confidential to the researchers and that all of the information gathered from the survey will be stored securely and once the information has been analysed the questionnaires will be destroyed. I also understand that my identity and the identity of my organisation will not be revealed without consent to anyone other than the investigators conducting the project.

Signature:

Name:

Position:

Organization:

Date: 


\section{Appendix D - History of CSR}

Literature suggests that CSR existed in many societies around the world and in the corporate world for a long period of time even though the activities related to CSR were not called as such (Idowu, 2011). Griseri and Seppala (2010) noted that several books about ancient times explained that traders showed some moral responsibilities. Moreover, concerns about the ethical behaviour of people who engaged in commerce can be traced back to 1750 before Christ $(\mathrm{BC})$ in writings of the ancient Babylonian Code of Hammurabi that were derived from even earlier sets of laws (Carroll, Lipartito, Post, \& Werhane, 2012). Researchers frequently claim that official writings of CSR started in the 1950s (Idowu, 2011). However, scholars such as Du Bois (1896, as cited in Idowu, 2011), Cook (2003), Rawley and Behrendt (2005), and Idowu (2009) argue that this may not be the case because many acts of social responsibility existed even before the 1950s. Kraus and Brtitzelmaier (2012) stated that in the 1930s, Edwin Merrick Dodd, a professor at Harvard Law School (Macintosh, 1999), argued that managers have social responsibilities towards societies.

Historically, many important ideas and events developed the preliminary perceptions of moral responsibility and shaped the concept of CSR which is known and practiced nowadays. Carroll, Lipartito, Post, and Werhane (2012) posited that the recognition of the human rights, the Industrial Revolution, the free enterprise system, and the expansion of the modern corporation are some events and ideas that had the most influence on the emergence of CSR.

The first idea that triggered CSR was the recognition of the human rights by John Locke (1632-1704) and its further development by Thomas Jefferson (1743-1826) (Carroll et al., 2012). Human rights comprise the right to live, to be free, to survive, to possess property, 
to choose where he or she wants to work and to get paid for this work, and to have a freedom of speech and vote (Carroll et al., 2012).

The industrial revolution first started in Great Britain between 1750 and 1830 and then spread to other European countries and to North America (Idowu, 2011). People shifted from living in rural areas and working in farms to living in cities and working in factories (Kowalski, 2015). This change in individuals' lifestyles had a positive influence on people but also lead to many social, economic, and environmental problems (Idowu, 2011). During that time, the only concern was to produce goods and services to meet customers' demand (Idowu, 2011). No one cared about the negative impacts that this mass production had on the lives of people and on the environment (Idowu, 2011). During this period, in the eighteenth century, most businessmen's main concern was making profit, but some of them were known for their social responsibility (Idowu, 2011).

Farmer (1997) explained that at the end of the seventeenth century, the industrial revolution lead to the free enterprise system and free trade. Adam Smith published a book in 1776, The Wealth of Nations, which had a major influence on the economics field and in which he discussed the economic benefits that companies and society would earn from the division of labor (O'Rourke, 2007a; Robbins \& Coulter, 2016). Smith (1723-1790) posited that economic and wealth growth in a society were driven by labour (Jones \& George, 2011). He added that if the work of labor is organized, divided, and mechanized the productivity of a nation will increase (O'Rourke, 2007a, 2007b). According to O'Rourke (2007a, 2007b), Smith stressed on the importance of human capital, so it can be inferred that the tribute that Smith gave to labor and the value that the workforce generates were a key contributor to CSR. Furthermore, Smith developed the concept of free enterprise which is based on the idea that economic value is created when firms practice free trade and fair competition in their relevant 
industries, and when individuals exchange products and services freely in an open market without stringent and direct governmental controls (Farmer, 1997).

Watson (2007) described free trade as fair trade where there is corporate acts of justice. In line with Watson's (2007) description of free trade, it can be deduced that firms will practice a limited self-interest; companies should be fair when conducting business and abide by the laws and regulations of the societies where they operate. This notion was an important contributor to the emergence of other ideas that formed CSR and corporate behaviour (Carroll et al., 2012). It can be concluded from the writings of Jones and George (2011) about the evolution of management practices that the Industrial Revolution and the expansion of the free enterprise system resulted in a substantial growth of trade in the nineteenth century which drove firms to form their corporations differently using more efficient and flexible legal forms. Nations started developing their own incorporation laws that allowed the establishment of corporations which are known today and that have limited liabilities and unlimited life (Elliott, 2007).

Griseri and Seppala (2010) argued that although the first publications on the role of businesses in societies were in the early 1930s, the actual trend of CSR surfaced in companies in the 1960s. Crane, Matten, and Spence (2008) pinpointed six major common characteristics that exist in most definitions and studies of CSR: first, CSR is mainly voluntary; second, CSR concentrates on managing the implications of the products or services offered; third it focuses on the idea that stakeholders other than the company are important; fourth, day-to-day activities and decision-making should consider environmental, economic, and social concerns; fifth, CSR must be rooted in business practices and values; and sixth, CSR is going beyond philanthropic actions and focuses on operational concerns. 
The concepts of sustainability and social responsibility started over a century ago when businessman like Sir Titus Salt offered his employees in Saltaire, West Yorkshire social benefits (Hack et al., 2014). During the 1950s and 1960s, companies were practicing “enlightened self-interest" through CSR actions and their main concern was to benefit the population (Hack et al., 2014, p. 47). CSR activities were mainly philanthropic including "community service and employee welfare" and responsibility was considered a managerial role (Hack et al., 2014, p. 47).

The emergence of CSR increased the pressures on firms to take socially responsible actions, for instance, eliminate discrimination in the workplace and correct the negative impacts of their operations on society by becoming more environmentally friendly (Griseri \& Seppala, 2010). During the 1950s, academic literature with regards to the responsibilities of corporations gained popularity when writers like Bowen claimed that when corporations grow and do business worldwide, their consumption and influence on planet's resources grow as well (Hack et al., 2014).

During the 1970s, CSR was considered as a company's responsibility towards its stakeholders; mainly its employees, customers, community, and the environment (Hack et al., 2014). Bowen (1953, as cited in Blindheim \& Langhelle, 2010) claimed that CSR should be the responsibility of all employees because individual charitable actions could not be felt alone. Friedman (1970, as cited in Hack et al., 2014) explained that CSR was not strictly applied to individuals to support, but it was a suggestion for firms to practice it if they wanted (Alcaniz, Caceres, \& Perez, 2010). So it is unfair to assume that all companies will practice CSR (Hack et al., 2014).

CSR was strongly debated during the 1970s which increased its popularity in the business and academic fields (Hack et al., 2014). The issues that stimulated CSR in the 1960s 
formed a process that developed throughout the years to finally induce the establishment of governmental rules and regulations in the 1980s (Griseri \& Seppala, 2010). It appears that whenever the general public and the government want to implement and enforce something, the government takes action by formulating laws and regulations to make it legal. The impetus of government actions with regards to CSR in the 1980s are perhaps a reflection of society's demand for corporations to behave in a responsible way. During 1980s and 1990s, corporations had the power of making decisions and debates with regards to causes that they considered socially responsible for their companies (Hack et al., 2014).

In 1980, Jones argued that companies were considered to have influence over solving social problems. During the 1990s, the tendency of writers was to create opportunities through combining business and society (Hack et al., 2014). Companies were encouraged to concentrate on what is personally the most important to them while emphasizing the fact that some fields of CSR depended on place and time (Hack et al., 2014).

Horrigan (2010) claimed that CSR became a global issue in the twenty-first century. CSR is considered an ethical and responsible course to conduct business (Hack et al., 2014). Bondy, Moon, and Matten (2012) posited that "CSR is becoming institutionalized within society" (p. 282). CSR institutionalization is also reflected in the eruption of trainings, workshops, and seminars with regards to CSR (Bondy et al., 2012). In addition to the emergence of special Master and PhD programs devoted to CSR (Bondy et al., 2012). This globalization of CSR is mainly caused by the idea that CSR is part of the response to many problems facing today's world and also perhaps due to the growth and expansion of MNCs and global companies practicing CSR (Horrigan, 2010).

Ward and Smith (2006) posited that the United Kingdom (UK) is the world leader of CSR for several reasons: its universal positioning and its colonial past, major companies 
which started CSR actions were headquartered in the UK, its superior journalistic class, the influence of the eighteenth century's Industrial Revolution and its involvements in some of the earliest privatization procedures, its environmental NGOs' leading commitment with corporations, and the insurance industry which was a major trigger of change. UK has a CSR comparative advantage which allows it to impact other leaders around the world to seriously take into consideration CSR matters (Idowu, 2011). Today, more and more countries are codifying CSR into law (Bondy et al., 2012). Many business reports, stockholder resolutions, and investment activities are focusing on CSR (Bondy et al., 2012). With time CSR will become a firm's competitive advantage (Hack et al., 2014). 


\section{Selected key definitions of CSR by several scholars throughout time}

\begin{tabular}{|c|c|c|}
\hline Definition & Author & Key focus \\
\hline $\begin{array}{l}\text { Social responsibility is } \\
\text { businessmen's duties to make } \\
\text { decisions and follow the rules and } \\
\text { guidelines which coincide with } \\
\text { society's values and objectives. }\end{array}$ & Bowen (1953) & $\begin{array}{l}\text { CSR in line with society's } \\
\text { values and objectives. }\end{array}$ \\
\hline $\begin{array}{l}\text { CSR is the activities and decisions } \\
\text { that businesspeople engage in for } \\
\text { causes beyond the company's "direct } \\
\text { economic and technical interest". }\end{array}$ & Davis (1960) & $\begin{array}{l}\text { CSR goes beyond the } \\
\text { company's "direct } \\
\text { economic and technical } \\
\text { interest". }\end{array}$ \\
\hline $\begin{array}{l}\text { CSR is the economic, legal, ethical, } \\
\text { and philanthropic responsibilities } \\
\text { that society expects from businesses } \\
\text { at a specific point in time. }\end{array}$ & Carroll (1979) & $\begin{array}{l}\text { Economic, legal, ethical, } \\
\text { and philanthropic } \\
\text { responsibilities. }\end{array}$ \\
\hline $\begin{array}{l}\text { CSR is managers' duties to establish } \\
\text { rules, make decisions, and act in } \\
\text { ways that go beyond legal } \\
\text { requirements and are appropriate in } \\
\text { terms of goals and values of society. }\end{array}$ & $\begin{array}{l}\text { Mosley, Pietri, } \\
\text { and Megginson } \\
\text { (1996) }\end{array}$ & $\begin{array}{l}\text { Making decisions beyond } \\
\text { legal requirements and } \\
\text { appropriate in terms of } \\
\text { goals and values of } \\
\text { society. }\end{array}$ \\
\hline $\begin{array}{l}\text { CSR is the ethical conduct of } \\
\text { businesses towards society; } \\
\text { managers working responsibly with } \\
\text { stakeholders who have a legal } \\
\text { interest in the company; and it is the } \\
\text { obligation of a firm to work ethically } \\
\text { and positively impact the economic } \\
\text { development of the society and the } \\
\text { welfare of its employees and their } \\
\text { families, and the general public. }\end{array}$ & $\begin{array}{l}\text { World Business } \\
\text { Council for } \\
\text { Sustainable } \\
\text { Development } \\
\text { (1999) }\end{array}$ & Ethical responsibilities. \\
\hline $\begin{array}{l}\text { CSR is a requirement for businesses } \\
\text { to recognize that they should be } \\
\text { publicly responsible for their } \\
\text { economic performance as well as for } \\
\text { their environmental and social }\end{array}$ & $\begin{array}{l}\text { Confederation } \\
\text { of British } \\
\text { Industry (2001) }\end{array}$ & $\begin{array}{l}\text { Economic, social, and } \\
\text { environmental } \\
\text { responsibilities. In } \\
\text { addition to supporting } \\
\text { human rights, }\end{array}$ \\
\hline
\end{tabular}




\begin{tabular}{|c|c|c|}
\hline $\begin{array}{l}\text { actions. Generally, CSR comprises } \\
\text { the degree to which corporations } \\
\text { should support human rights, } \\
\text { egalitarianism, social advancement, } \\
\text { and sustainable development goals } \\
\text { worldwide. }\end{array}$ & & $\begin{array}{l}\text { egalitarianism, social } \\
\text { advancement, and } \\
\text { sustainable development } \\
\text { goals worldwide. }\end{array}$ \\
\hline $\begin{array}{l}\text { CSR is a notion whereby } \\
\text { corporations voluntarily incorporate } \\
\text { environmental and social issues in } \\
\text { their business operations and in their } \\
\text { relationships with their stakeholders. }\end{array}$ & $\begin{array}{l}\text { European } \\
\text { Commission } \\
(2002)\end{array}$ & $\begin{array}{l}\text { Philanthropic, } \\
\text { environmental, and social } \\
\text { responsibilities. }\end{array}$ \\
\hline $\begin{array}{l}\text { CSR is a notion where firms } \\
\text { voluntarily take into consideration } \\
\text { social and environmental issues } \\
\text { while conducting business and while } \\
\text { interacting with their stakeholders. }\end{array}$ & $\begin{array}{l}\text { European Union } \\
\text { (2004) }\end{array}$ & $\begin{array}{l}\text { Philanthropic, social, and } \\
\text { environmental } \\
\text { responsibilities. }\end{array}$ \\
\hline $\begin{array}{l}\text { CSR is the obligation to enhance } \\
\text { society's welfare throughout } \\
\text { charitable contributions of business } \\
\text { wealth and corporate practices. }\end{array}$ & $\begin{array}{l}\text { Kotler and Lee } \\
(2005)\end{array}$ & Philanthropy. \\
\hline $\begin{array}{l}\text { CSR is the ethical or responsible } \\
\text { treatment of the internal and external } \\
\text { stakeholders of a company which is } \\
\text { considered acceptable in } \\
\text { civilizations. Social encompasses } \\
\text { environmental and economic } \\
\text { obligations. The broader purpose of } \\
\text { social responsibility is to } \\
\text { continuously improve the standard of } \\
\text { living while maintaining the } \\
\text { company's profitability. }\end{array}$ & Hopkins (2007) & $\begin{array}{l}\text { Ethical responsibilities } \\
\text { considered acceptable in } \\
\text { civilizations. }\end{array}$ \\
\hline $\begin{array}{l}\text { CSR is a predetermined procedure to } \\
\text { delineate stakeholders' relations, to } \\
\text { manage decision-making, to } \\
\text { establish expectancies, and to decide } \\
\text { on obligations between society and } \\
\text { the corporate world. This is a } \\
\text { continuing procedure as commitment } \\
\text { and beliefs change with time. }\end{array}$ & $\begin{array}{l}\text { Baddache and } \\
\text { Nicolai (2013) }\end{array}$ & $\begin{array}{l}\text { CSR as a predetermined } \\
\text { procedure to manage } \\
\text { decision-making. }\end{array}$ \\
\hline
\end{tabular}


Evolving phases of CSR according to Frederick (Source: Lawrence \& Weber (2011, as cited in Kraus \& Brtitzelmaier, 2012, p. 286))

\begin{tabular}{|c|c|c|c|}
\hline & Phases of CSR & CSR Drivers & $\begin{array}{l}\text { CSR Policy } \\
\text { Instruments }\end{array}$ \\
\hline $\begin{array}{l}\text { CSR1 } \\
\text { 1950s-1960s }\end{array}$ & $\begin{array}{l}\text { Corporate Social } \\
\text { Stewardship } \\
\text { Corporate } \\
\text { philanthropy - acts } \\
\text { of charity, managers } \\
\text { as public trustee- } \\
\text { stewards, balancing } \\
\text { social pressures }\end{array}$ & $\begin{array}{l}\text { Executive } \\
\text { conscience, company } \\
\text { image/reputation }\end{array}$ & $\begin{array}{l}\text { Philanthropic funding, } \\
\text { public relations }\end{array}$ \\
\hline $\begin{array}{l}\text { CSR2 } \\
1960 \mathrm{~s}-1970 \mathrm{~s}\end{array}$ & $\begin{array}{l}\text { Corporate Social } \\
\text { Responsiveness } \\
\text { Social impact } \\
\text { analysis, } \\
\text { strategic priority for } \\
\text { social response, } \\
\text { organizational } \\
\text { redesign and training } \\
\text { for responsiveness, } \\
\text { stakeholder mapping } \\
\text { and implementation }\end{array}$ & $\begin{array}{l}\text { Social unrest/protest, } \\
\text { repeated corporate } \\
\text { misbehaviour, public } \\
\text { policy/government } \\
\text { regulation, } \\
\text { stakeholder } \\
\text { pressures, think tank } \\
\text { policy papers }\end{array}$ & $\begin{array}{l}\text { Stakeholder strategy, } \\
\text { Regulatory } \\
\text { compliance, social } \\
\text { audits, public affairs } \\
\text { function, governance } \\
\text { reform, } \\
\text { political lobbying }\end{array}$ \\
\hline $\begin{array}{l}\text { CSR3 } \\
1980 \mathrm{~s}-1990 \mathrm{~s}\end{array}$ & $\begin{array}{l}\text { Corporate/Business } \\
\text { Ethics Foster an } \\
\text { ethical corporate } \\
\text { culture, establish an } \\
\text { ethical organizational } \\
\text { climate, recognize } \\
\text { common ethical } \\
\text { principles }\end{array}$ & $\begin{array}{l}\text { Religious /ethnic } \\
\text { beliefs, technology- } \\
\text { driven value } \\
\text { changes, } \\
\text { human rights } \\
\text { pressures, code of } \\
\text { ethics, ethics } \\
\text { committee/officer } \\
\text { audits, ethics } \\
\text { training, stakeholder } \\
\text { negotiations }\end{array}$ & $\begin{array}{l}\text { Mission/vision/values, } \\
\text { statements, CEO } \\
\text { leadership ethics }\end{array}$ \\
\hline
\end{tabular}




\begin{tabular}{|l|l|l|l|}
\hline CSR4 & $\begin{array}{l}\text { Corporate / Global } \\
\text { 1990s-2000s }\end{array}$ & $\begin{array}{l}\text { Global economic } \\
\text { trade/ investment, } \\
\text { Cigh-tech } \\
\text { stakeholder } \\
\text { partnerships, } \\
\text { integrate financial, } \\
\text { social, and } \\
\text { environmental } \\
\text { performance, } \\
\text { identify }\end{array}$ & $\begin{array}{l}\text { Intergovernmental } \\
\text { compacts, global audit } \\
\text { geopolitical } \\
\text { shifts/competition, } \\
\text { ecological } \\
\text { dialogue, } \\
\text { sustainability }\end{array}$ \\
& $\begin{array}{l}\text { awareness/concern, } \\
\text { NGO pressures } \\
\text { impacts, } \\
\text { sustainability of } \\
\text { company and } \\
\text { environment }\end{array}$ & audits/reports \\
& & \\
\end{tabular}




\section{Appendix G - Lebanon's History, Geography, and Competitiveness}

\section{Lebanon's History:}

Writers of history books, all types of literature, research, and government publications confirm that Lebanon has a history of six thousand years that began with the Phoenicians in pre-Biblical times (Kaufman, 2004). Lebanon's history progressed into other eras: “Persian, Greek, Roman, Byzantine, Arab, Crusader, Turkish, and French", ending up as an independent country in modern times (Kaufman, 2004, p. 1). Lebanon was part of Ottoman Syria but France declared Greater Lebanon as a separate country in 1920 (Hirst, 2010). On November 22, 1943 Lebanon gained its independence and this date is still celebrated every year as the Independence Day (Rassemblement Canadien pour le Liban, 2004).

Since its independence from the French mandate in 1943, Lebanon follows a parliamentarian democratic regime with a centralized government (Jamali, 2007). The system is based on a sectarian distribution of power among the eighteen religious sects distributed across the country (Van Ommering, 2011). Based on the National Pact, which is the treaty that was made at independence, Lebanon should always have a Maronite Christian President, a Sunni prime minister, a Shi'i speaker of the parliament, and his representative should be a Greek Orthodox (Joseph, 2011). Senates from every religion meet to create public policy (Gunderson, 1997). Unfortunately, the political and economic goals of every sect transcend the national purpose of the society (Gunderson, 1997).

Since 1943, Lebanon was known in the region for its great public freedom where individuals with multiple cultures, religions, ideas, trends, and currents coexisted peacefully and democratically (Jamali, 2007). Unfortunately, this peaceful coexistence was distorted and a civil war destroyed the country from 1975 to 1990 (Larkin, 2010). Underprivileged religious sects were ready to use violence to earn a bigger stake of the political control and economic 
wealth (Gunderson, 1997). The sects who were in control were also willing to use violence because they were afraid to lose their political and economic power (Gunderson, 1997). So, this tension between sects exploded in a civil war of fifteen years in which all parties were willing to defend their religious sects through violent actions and try to gain control over the country. During this civil war, two Lebanese Presidents were assassinated; President Bashir Gemayel on September 14, 1982 and President Rene Moawad on November 22, 1988 (Rassemblement Canadien pour le Liban, 2004). Saudi Arabia, Syria, and the USA with the implicit approval of Israel, created the Ta'if agreement to end this civil war and prevent the conflict from spreading to the region by leaving Lebanon under the control of thirty thousand Syrian troops (Gunderson, 1997). The war ended with approximately one hundred and fifty thousand dead, one hundred thousand people with injuries for life, seventeen thousand individuals who disappeared, and one million persons emigrated (Van Ommering, 2011).

The civil war rigorously deteriorated Lebanon's political, social, and economic structures (Sidani, Zbib, Rawwas, \& Moussawer, 2009). The country is still in the reconstruction stage of its social, economic, and political structures and organizations (Jamali, 2007). As a primary step, the physical infrastructure was restored and rebuilt and the public sector is operating normally (Jamali \& Mirshak, 2007). But the difficulty lies in the economic rehabilitation of Lebanon (Jamali, 2007). It can be inferred from Jamali's (2007) work that Lebanon is always facing continuous clashes which may be one of the causes that prevent the country from operating normally and flourishing.

On February 14, 2005 the Lebanese Prime Minister Rafik Hariri, who was the most famous postwar Lebanese reconstruction millionaire, and twenty-two individuals were assassinated (Borell, 2008). Hariri's assassination through a huge bomb explosion in downtown Beirut gave rise to the Cedar Revolution which caused a major change in Lebanon and whose creators wanted political violence and division to stop and Syria to withdraw from 
Lebanon (Burgis-Kasthala, 2013). Supporters of Syria formed a political alliance and conducted a big protest on March 8, 2005 thanking Syria for its presence in Lebanon and for backing up the country against Israel (Abboud \& Muller, 2013). In response to this protest, supporters of the Cedar Revolution, who are also the opponents of Syria, conducted a huge protest on March 14, 2005 calling for the Syrian troops to withdraw from Lebanon and an international body to investigate Hariri's murder (Abboud \& Muller, 2013). The Cedar Revolution's goals were achieved after approximately two months from these protests when Syria withdrew from Lebanon in April 2005 (Kirshner, 2007). Since that time and until today, the Lebanese society became divided among two political parties, called March 8 and March 14 according to the dates of the protests, who are in a continuous conflict (Burgis-Kasthala, 2013).

In July 2006, a war between Hezbollah, a Lebanese party, and the military of Israel erupted for thirty-four days (Melki, 2014). The war started after Hezbollah kidnapped two Israeli militaries on the borders of Lebanon and Israel which gave rise again to the never ending conflict between Hezbollah and Israel (Benziman, 2013). The war ended with one thousand and one hundred Lebanese and one hundred and fifty-nine Israelis dead, thousands of people injured, approximately one million Lebanese and five hundred thousand Israelis relocated, tens of thousands of houses, plants, and bridges demolished, and a massive economic and environmental loss of billions of dollars (Melki, 2014).

Assassinations of key figures in Lebanon including politicians, journalists, and intellectuals, wars, sectarian divisions, and random violence through car bombs continue till today scaring the Lebanese citizens, tourists, and habitants of the Middle East. Some of the assassinations include the murders of "Samir Qasir, a journalist and an anti-Syrian political activist; George Hawi, an ex-Lebanese Communist Party leader... and Gebran Tueni, a prominent anti-Syrian MP and editor-in-chief of An-Nahar, a leading daily newspaper in 
Lebanon", and an attempt to assassinate May Chidiac, a famous television news journalist (Borell, 2008, p. 56). In addition to the assassination of the cabinet minister Pierre Gemayel in November 2006, who was a Christian Leader against Syria (Leichtman, 2010).

Despite its small size, Lebanon has long attracted an international attention. Countries of the Middle East and the West significantly influenced Lebanon's internal politics for their self-interest (Joseph, 2011). From the beginning of its formation, Lebanon faced many downturns, wars, and internal and external conflicts. Some writers view this continuous struggle as the result of a weak Lebanese government, foreign control, regional interventions, opposing patriotisms and sociopolitical conflicts, economic inequalities and class fights, or ethnic and association devotions (Larkin, 2010). Jamali (2007) explains that grouping citizens by religion greatly affects Lebanon's political and social character and is the main cause of the country's most hostile and continuous conflicts. Religion is the main identity of the Lebanese and every religious group belongs to a certain city or geographical area (Gunderson, 1997). The continuous tension between the numerous religious sects has always been a burden on Lebanon as it often turns into violence between sects and even between families of the same sect (Gunderson, 1997).

A country's history sets the ground for and underpins its political, legal, economic, technological, and socio-cultural environments. Thus, this section provided the preceding information regarding Lebanon's history to explain the background and the reasons behind Lebanon's current environment. This will clarify and facilitate the understanding of the different institutions that play a role in the Lebanese society and that subsequently influence business practices and conduct.

\section{Lebanon's Geography:}

Lebanon is a Middle Eastern country of approximately ten thousand four hundred and fifty-two square kilometers located in Western Asia and the East coast of the Mediterranean 
Sea (Tutelian, Khayyat, \& Abdel Monem, 2007). It is surrounded by Syria from the north and east, by Israel from the south, and by the Mediterranean Sea from the west (Hirst, 2010).

Lebanon's capital is Beirut which is the central hub of the country where most businesses operate and where the majority of the population lives (Traboulsi, 2007). Lebanon's name initially came from the Aramaic language and means "white" which refers to the name of its mountain (Rassemblement Canadien pour le Liban, 2004, p. 7). Mount Lebanon has distinctive climate, characteristics, rain-fall, flora, and three thousand meter peaks that are covered with snow all year long which make it different than other Middle Eastern countries (Rassemblement Canadien pour le Liban, 2004).

\section{Lebanon's location in the Middle East (Source: (Rassemblement Canadien pour le Liban, 2004, p. 7))}

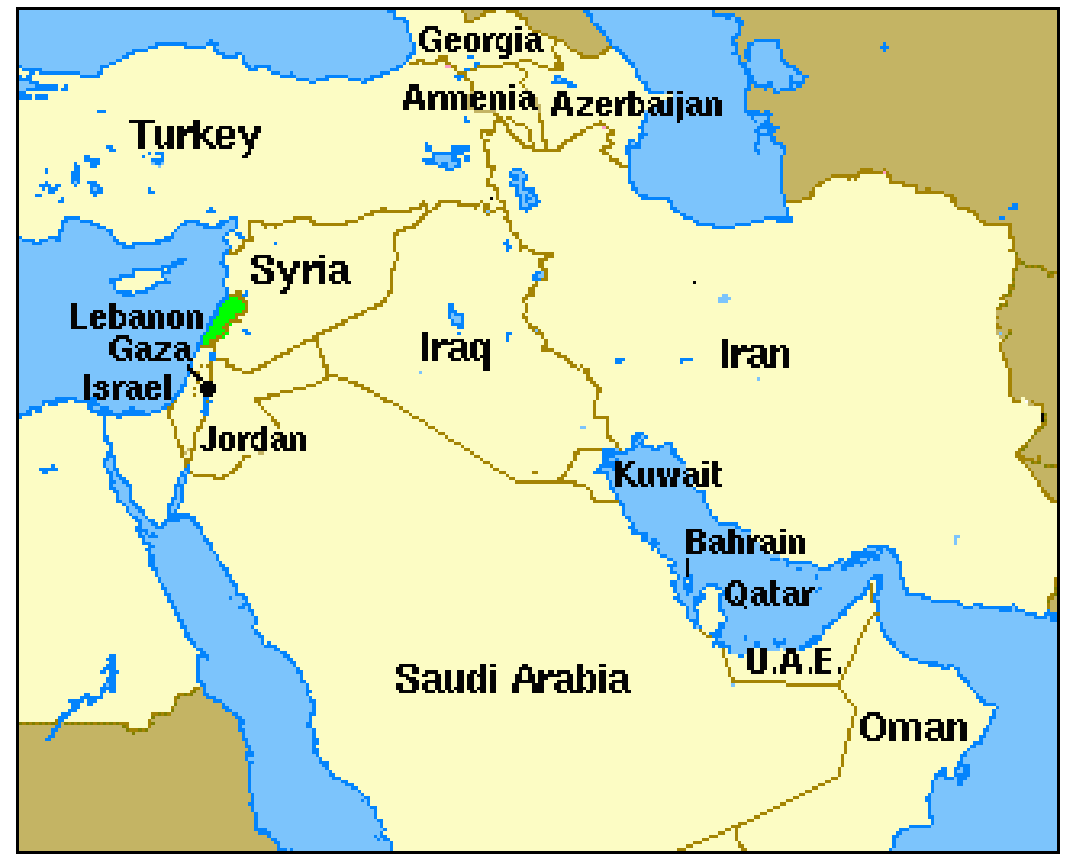

Lebanon is characterized by a Mediterranean climate and significant water wealth which contribute to the welfare of the citizens and the country's touristic position (Tutelian et al., 2007). It can be inferred from the work of Tutelian, Khayyat, and Abdel Monem (2007) that Lebanon's four seasons: autumn, winter, spring, and summer may be a major asset that 
attracts tourists from all countries around the world. Rubin (2009) explained that Lebanon is a small country with a distinctive geography that made it an attractive touristic location. Rubin (2009) intimates that tourists may perhaps be attracted to visit Lebanon because of its mountains, rivers, waterfalls, the sea, and many touristic locations that can be reached in a very small period of time and without taking a plane or a train to do so. For example, a tourist may take a thirty minutes' drive only to get from the mountains to the sea which is perhaps very rare to find in other countries.

Map of Lebanon (Source: (Rassemblement Canadien pour le Liban, 2004, p. 8))

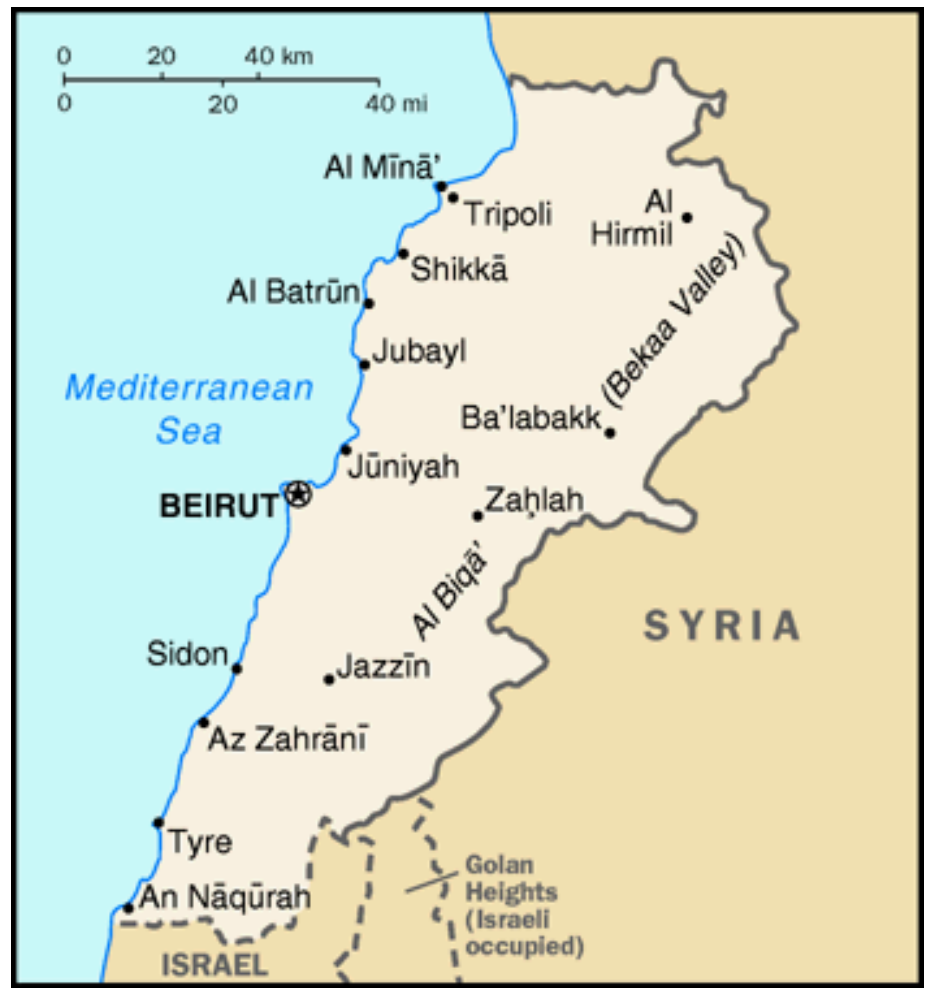

\section{Lebanon's Competitiveness:}

The global competitiveness index is a measure of national competitiveness which is defined as a group of institutions, rules, and features that define the productivity level of a country (World Economic Forum, 2015). Lebanon ranked 105 out of 137 countries covered in the rankings of the Global Competitiveness Index for 2017-2018 (World Economic Forum, 2017). Lebanon's performance is comparatively stable, with the nation pressing above its 
capacity with regards to business complexity, technological readiness, and innovation, but is still hampered by a bad macroeconomic environment, and unproductive organizations and labor market (World Economic Forum, 2017). Syria's circumstances and the huge inflow of refugees has additionally worn out economic resources and formed a burden on the state's health and education system, with intensification in the number of infectious diseases (Blanchet, Fouad, \& Pherali, 2016; Salloukh, 2017). Information and communications technology use was enhanced due to increased universal internet bandwidth and mobile broadband subscriptions (Lebanon Telecoms Report - 2018, 2018). Deflation improved underwriting Lebanon's macroeconomic context (World Economic Forum, 2017). The following figure provides an overview of Lebanon's performance as depicted by the Global Competitiveness index. 
Lebanon's performance overview (Source: (World Economic Forum, 2017))

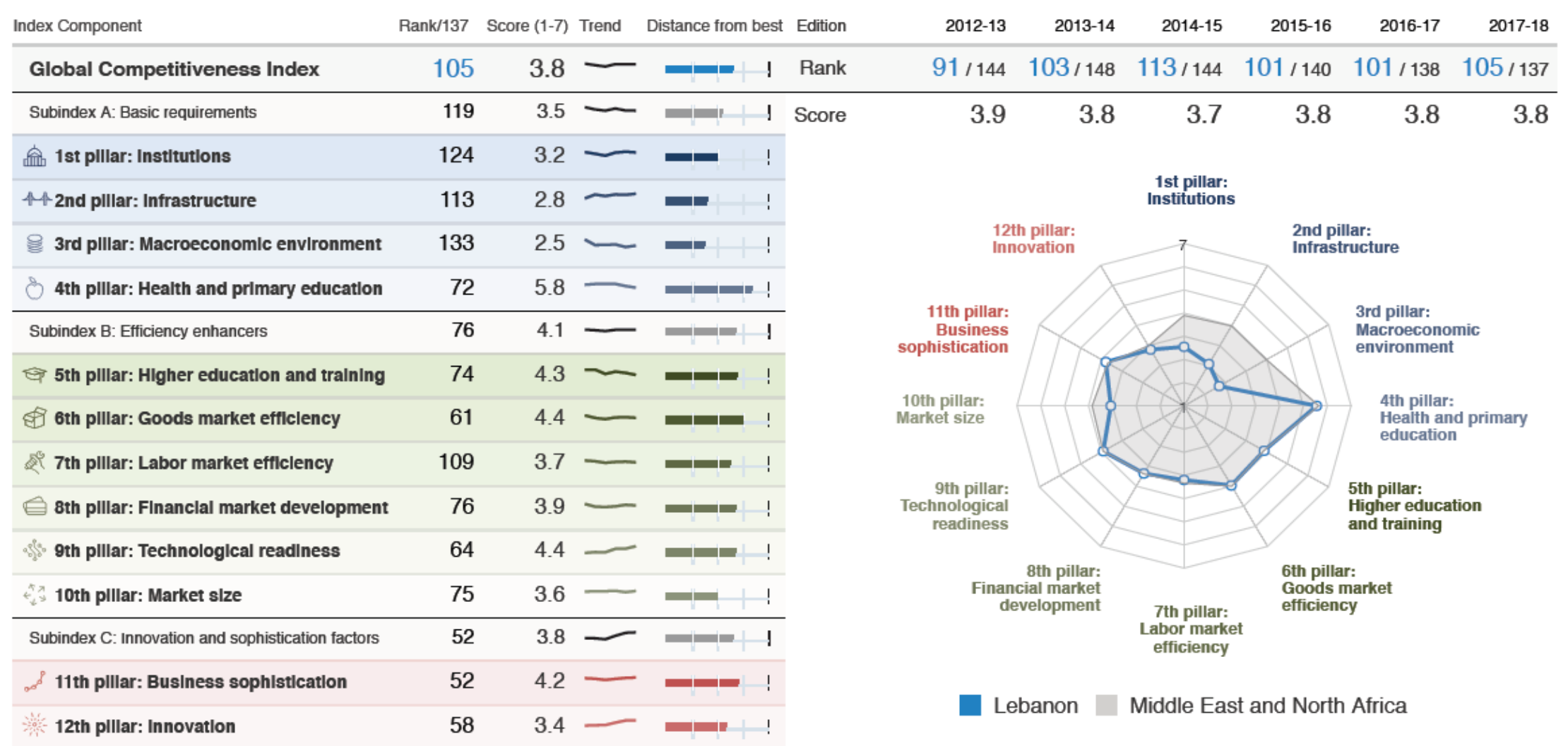


For the past fifty years, the economy in the Middle East had been greatly unstable which caused ongoing economic, political, and social uncertainties (Dirani, 2007). Needed labor reorganization, particularly in the Lebanese public sector, had been greatly noticed in the economic and political chaos (Dirani, 2007). The role that Lebanon played before the war had been taken by other countries such as Amman, United Arab Emirates, Bahrain, and Cairo (Dirani, 2007). Ironically, the Lebanese themselves have been of assistance to make this conceivable, by shifting the service industry abroad (Nasser \& Abouchedid, 2003).

The workforce in Lebanon is generally considered overeducated for the requirements of the domestic market and this fact along with the economic recession, has caused a brain drain of approximately 20,000 Lebanese per year (Galey, 2009). This also created a huge diaspora of more than 820,000 Lebanese in 2017 and an unemployment rate of 6.7 percent because educated Lebanese are seeking employment in countries that have a demand for highly skilled workers (Lebanon labour market risk report - Q1 2019, 2019). The brain drain is a transitory solution for the unemployment problem, is lessening the skills in the country, and provoking a lack of competitiveness of the workforce (Dirani, 2007).

Moreover, compared to other Arab nations, Lebanon does not have a lot of natural resources apart from its modest agricultural capability and water supplies and its location in the region (Dirani, 2007). It does not have a comparative advantage in the agricultural and industrial industries (Dirani, 2007). The Lebanese citizens generally earn money by providing services to foreigners (Dirani, 2007). Besides, Lebanon's information technology market is established to benefit from a considerable investment in telecommunication infrastructure, intended for considerably topping up the country's poor broadband facilities (Lebanon Information Technology Report - 2011, 2011). There are possible opportunities for information technology (IT) sellers in segments like banking, telecommunications, 
government, utilities, and real estate, however, a lot will depend on the political stabilization essential to apply economic changes (Lebanon Information Technology Report - 2011, 2011). SMEs are also an opportunity for the IT market because they make up a bulk of Lebanon's 700,000 businesses, even though they lack access to financing (Lebanon Information Technology Report - 2011, 2011). 